\title{
PREDICTING OUTDOOR THERMAL COMFORT IN URBAN AREAS
}

BY

VICTORIA JO LOUISE TONER

A thesis

submitted to the Victoria University of Wellington

in fulfilment of the requirements for the degree of

Master of Building Science

Victoria University of Wellington 



\section{ABSTRACT}

Outdoor thermal comfort is key to creating vibrant outdoor urban spaces. The built form is able to modify solar radiation and wind. However, there is currently no way of considering the effect of the built form on thermal comfort when designing a new development based on the environmental factors - wind, solar radiation, and ambient temperature. Current practice for designing outdoor thermal comfort is based on simple design guidelines, and knowledge of local wind and sun patterns.

A Process for Predicting Outdoor Thermal Comfort has been developed. This predicts thermal comfort based on solar radiation, wind, and ambient temperature using The Wellington Comfort Index. The process is able to predict comfort at a single point within a proposed urban development using specialised computer programs. Through predicting how the combination of solar radiation, wind, and ambient temperature will affect comfort, improvements can be made to comfort during the design phase.

The aim of this thesis project is to develop the Process for Predicting Outdoor Thermal Comfort into a Comfort Tool for use at the preliminary design stage of a development. The intended users of the tool are professionals working in urban planning and architecture, such as designers and consultants who have experience with three-dimensional modelling and simulation programs.

A case study research approach was used to test The Comfort Tool's ability to inform design changes through communicating thermal comfort across a proposed development. A range of case studies were selected with different built forms. This was to test if The Comfort Tool can predict comfort in case studies with different levels of solar radiation and wind at pedestrian level due to the variations in the built forms.

This research confirmed that a tool can be developed for predicting comfort across a proposed development, which can also test proposed design changes for their success during the design phase. However, further investigation is needed to determine whether The Wellington Comfort Index can be used in other cities. 



\section{ACKNOWLEDGEMENTS}

I would like to firstly acknowledge my supervisor, Michael Donn. I greatly appreciate the support, challenging of ideas, and enthusiasm for outdoor thermal comfort you have offered me over the past two years.

I am thankful for the assistance of the staff at Victoria University. This includes the librarians and technical staff at the School of Architecture and Design who have assisted me on numerous occasions, as well as Jonathan Flutey and Andre Geldenhuis from Victoria University's ITS department. Dennis Dawson also deserves a special acknowledgement for assisting with statistics, and Kirsten Reid for providing academic writing assistance.

I appreciate the financial support from Victoria University of Wellington for the Masters by Thesis Scholarship, as well as Building Research Association New Zealand (BRANZ) for the BRANZ Scholarship.

I would like to acknowledge Darren Walton and Paul Carpenter for your discussions throughout my thesis. As well as Denise Linnell from Re:Start Mall.

I am grateful for my friends, colleagues and fellow students, and the academics at the School of Architecture. I have appreciated the discussions, feedback, and banter we have shared over the duration of this thesis.

I would like to thank Michael Donn, Julia Thompson, James Sullivan, Linda Erikson, Carol Toner, Ethan Duff, Joseph Sturm, and Terrie Berthold for providing constructive feedback on this thesis. This is greatly appreciated.

I would also like to thank my parents, Carol and Patrick Toner for your continuous support, love, and care throughout my studies.

Finally, I would like to thank my partner Ben Threadwell for your ongoing encouragement and optimism, as well as keeping my spirits high a throughout this thesis.

This thesis is dedicated to Christchurch, may you rise from the ashes with your beauty and heritage intact.

Victoria Toner, 30th April 2015 



\section{Author:}

Victoria Toner

School of Architecture

Victoria University of Wellington

E-mail: tonervictoria@gmail.com

\section{Primary Supervisor:}

Michael Donn

Senior Lecturer, Building Environmental Science

School of Architecture

Victoria University of Wellington

E-mail:michael.donn@vuw.ac.nz 



\section{CONTENTS}

1. OUTDOOR THERMAL COMFORT - CONTEXT AND SCOPE OF THE STUDY ...........................................10

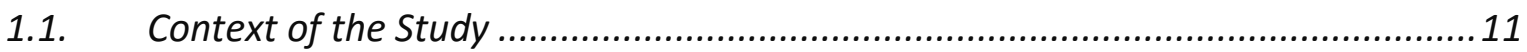

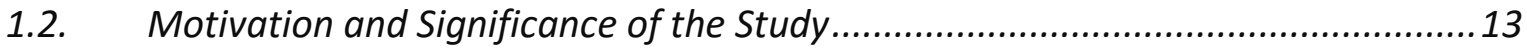

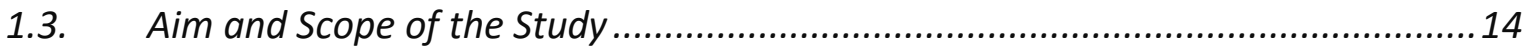

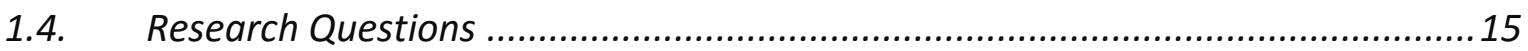

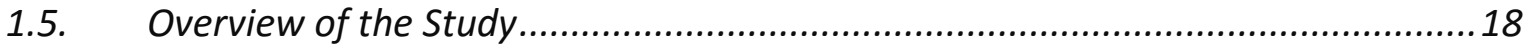

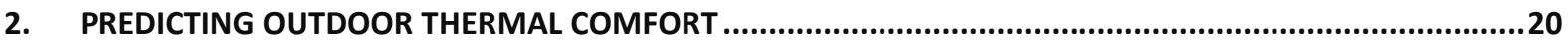

2.1. Definition and Perception of Thermal Comfort .........................................21

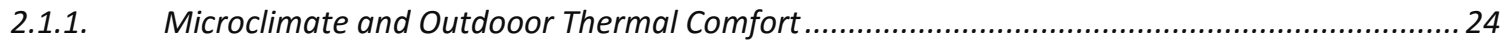

2.2. Quantifying Thermal Comfort using Comfort Indices....................................26

2.3. Urban Planning and Thermal Comfort ....................................................30

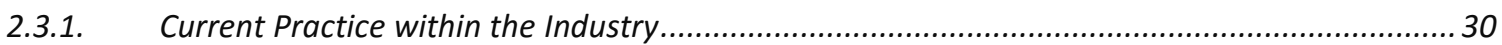

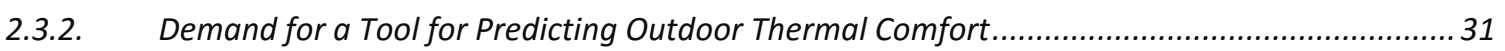

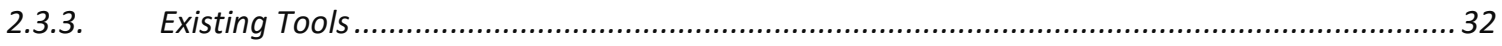

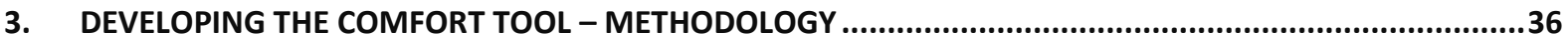

3.1. Selection of Case Studies for Testing The Comfort Tool .....................................38

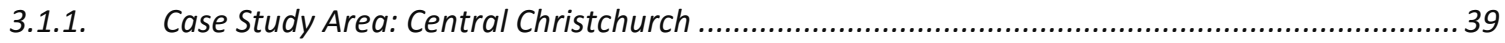

3.2. Can the Process for Predicting Outdoor Thermal Comfort be developed into a tool

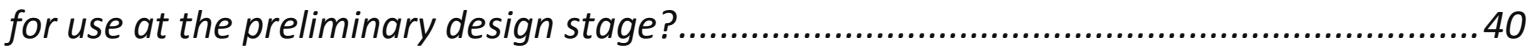

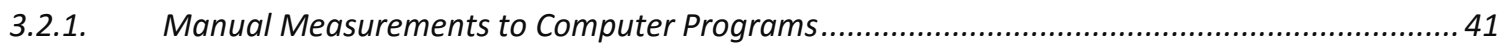

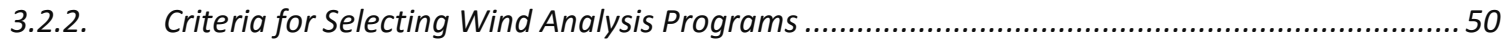

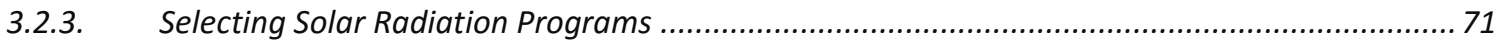

3.3. Can thermal comfort be automatically communicated across a development? .. 72

3.4. What is the applicability of The Wellington Comfort Index to cities outside of

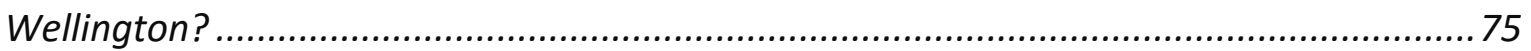

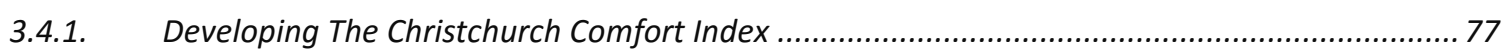

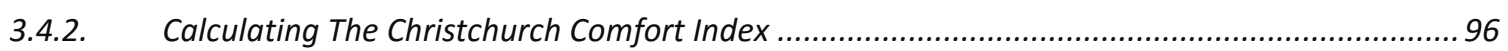

4. ARE THE RESULTS FROM A COMFORT TOOL ABLE TO INFORM DESIGN CHANGES?...........................108

4.1. Mapping Thermal Comfort - Discussion .............................................. 109 
4.2. Evaluating The Comfort Tool for Different Urban Design Scenarios ...................111

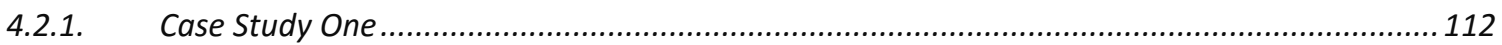

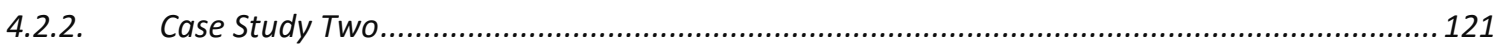

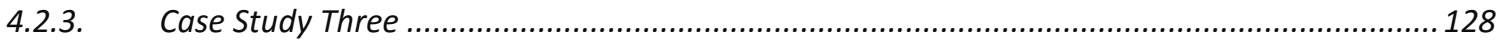

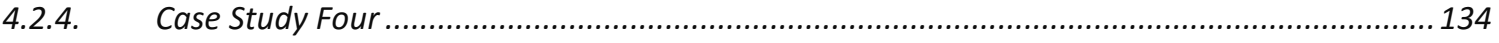

4.3. Assumptions and Considerations of The Comfort Tool.....................................141

4.3.1. Modelling Assumptions and Considerations........................................................................... 141

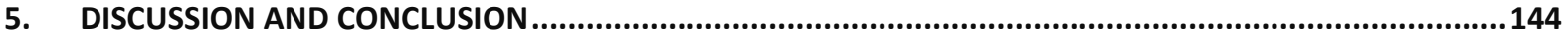

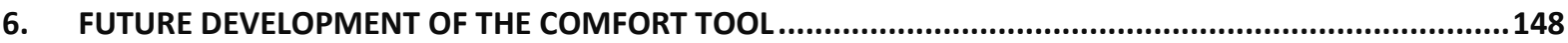

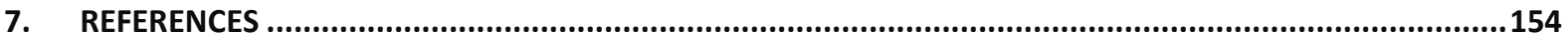

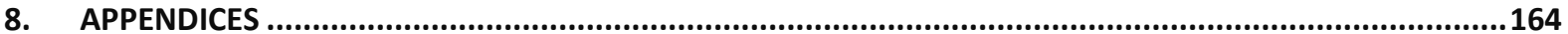

8.1. Appendix One: The Development of The Comfort Tool .....................................165

8.1.1. Simple City Test Results for Assessing Wind Analysis Programs for their Accuracy .................. 165

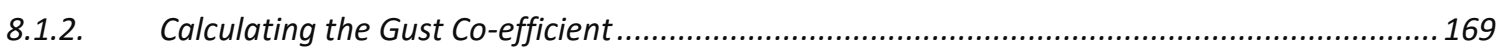

8.2. Appendix Two: Development of The Christchurch Comfort Index......................170

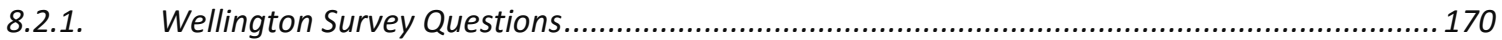

8.2.2. Demographic Questions Included in the Christchurch Survey ................................................ 177

8.2.3. Temperatures During the Survey Period .......................................................................... 178

8.2.4. List of Equipment, Accuracy, and Specifications................................................................ 179

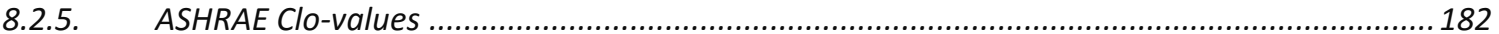

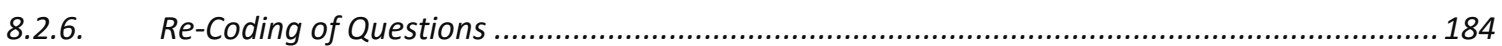

8.2.7. Survey Results: Raw Data of The Christchurch Comfort Index............................................... 187

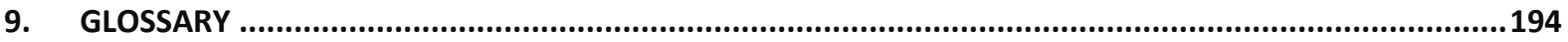


Outdoor thermal comfort is often an accidental outcome of other design decisions. Without comfort assessments in the preliminary design stage of a project, thermal comfort issues may only become evident after a building has been constructed. Comfort in this context is defined as not feeling any thermal discomfort, otherwise interpreted as feeling thermally neutral (Givoni et al., 2003, p. 78). Since the 1970 s it has been acknowledged that outdoor thermal comfort is the combined effect of solar radiation, wind, and ambient temperature (Isyumov \& Davenport, 1977, p. 407). Urban planners and designers currently use a number of techniques for assessing wind and solar radiation across an urban area. These include wind tunnel testing and computerised assessments of solar radiation at pedestrian level. Techniques generally focus on one environmental factor, rather than the combined effect of solar radiation, wind, and ambient temperature on outdoor thermal comfort. Common practice is to assess wind or solar radiation for a single point in time, or selected days which represent the hottest or coolest days of the year.

Some urban plans include information to encourage designers to consider the effect that a new building may have on solar radiation and wind at pedestrian level. These vary from general guidelines or objectives, to specific by-laws or requirements which need to be met. Guidelines or objectives may include zoning within a city to restrict building heights. An example of this is the Central City Development Unit's plan for Central Christchurch ('Planning and Consents', 2013). Cities such as Wellington and Boston have specific wind requirements for buildings over a specified height. Wind tunnel tests can determine whether a proposed building meets the requirements such as wind gusts being below a specified speed at pedestrian level (Boston Development Authority, 2006, p. 45; Wellington City Council, 2007, p. 14).

A tool which facilitates the analysis of outdoor thermal comfort during the design stage of a development would represent a significant advance in urban planning and impact the quality of outdoor spaces. As wind, ambient temperature, and solar radiation are the three environmental factors which influence people's comfort it is important that a thermal 
comfort tool is based on a comfort index which assesses comfort based on the combined effect of these environmental factors on outdoor thermal comfort, as one can offset the others (Gaitani, Mihalakakou, \& Santamouris, 2007, p. 318; Givoni et al., 2003, p. 77; Marialena Nikolopoulou \& Steemers, 2003, p. 95)..

\subsection{CONTEXT OF THE STUDY}

A comfort index, referred to in this thesis project as The Wellington Comfort Index was developed from 569 survey results collected in parks and urban malls in Central Wellington. The Wellington Comfort Index combines solar radiation, wind, and ambient temperature to predict the degree people would need to change their behaviour to maintain their comfort levels (Walton, Dravitzki, \& Donn, 2007, p. 3173). These behavioural changes may include changing their clothing level, moving in or out of the wind or sun, or changing their activity level. This was then developed into a Process for Predicting Outdoor Thermal Comfort.

This Process for Predicting Outdoor Thermal Comfort is able to predict how comfortable a single point within a proposed development will be for each hour of the year. The Process uses computer programs to calculate wind and solar radiation in the surrounding areas of a proposed urban development, with ambient temperature measured at a regional weather station. When design changes are made to a built form, the impact of these design changes on thermal comfort can be compared to the original design for the same point (Figure 1.1).

Difference in Thermal Comfort for two Built Form Options

$$
\text { Windy } \square \text { Cold } \square \text { Cool } \square \text { Neutral } \square \text { Warm } \square \text { Hot }
$$

Proposed Built Form

Alternative Built Form

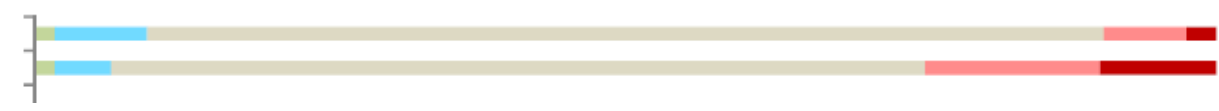

Percentage of Summer time hours

Figure 1.1 shows that the proposed built form has more hours where it is considered thermally neutral. Whereas, the alternative built form has more hours of the year where it is considered warm (pink) and hot (red).

This Process was tested by calculating thermal comfort at a single point within a proposed development. The buildings in the North and South of the development were then 
switched to determine if the Process for Predicting Outdoor Thermal Comfort could capture the change in thermal comfort from switching of the buildings (Figure 1.2).

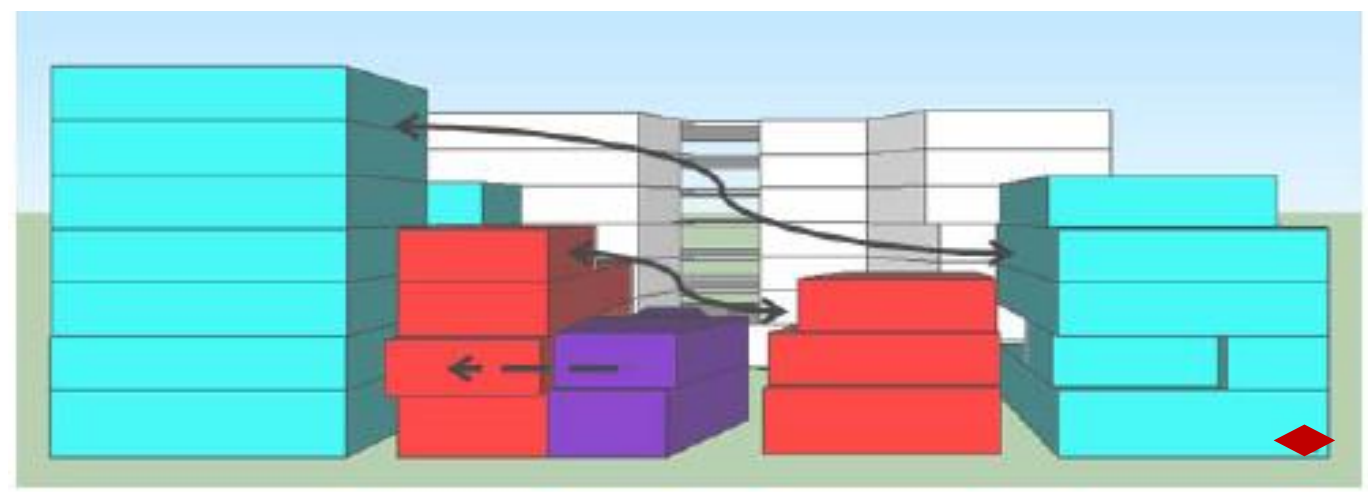

Figure 1.2 shows the urban form of the proposed development, with arrows indicating how the buildings were switched to test the Process for Predicting Outdoor Thermal Comfort. Thermal comfort was calculated at a single point in this test (red diamond).

This thesis project develops the Process for Predicting Outdoor Thermal Comfort into a tool for predicting thermal comfort. The development of a tool for predicting outdoor thermal comfort includes creating criteria which assist consultants and designers in selecting their own computer programs for calculating wind; developing a way of automatically communicating thermal comfort levels across a development, rather than at a single point; and testing whether The Wellington Comfort Index on which the Process for Predicting Outdoor Thermal Comfort is based is applicable to cities outside of Wellington.

The Process for Predicting Outdoor Thermal Comfort cannot be used for urban planning and architecture without these improvements. This is because the computer program used in the Process for Predicting Outdoor Thermal Comfort for calculating wind has not been tested for its accuracy independently (U.S. Department of Energy, 2011). This means that the thermal comfort results from the Process for Predicting Outdoor Thermal Comfort may be misleading. 


\subsection{MOTIVATION AND SIGNIFICANCE OF THE STUDY}

The 2010 and 2011 Canterbury Earthquakes caused significant damage within Central Christchurch. This had a large impact on New Zealand, with more than eighty-percent of the buildings in the central business district being demolished (Clark, 2012). This provides a unique opportunity to plan the new city centre in a way which will improve outdoor thermal comfort through its urban planning.

Even before the Canterbury Earthquakes, Christchurch City Council had plans for the existing city to become more resilient and lively through the Christchurch Revitalisation Strategy and Project Central City (Christchurch City Council, 2006b, p. 1). The core goals were to create "A vibrant, fun, exciting, safe and sustainable heart of Christchurch. A heart whose economy, environment, culture and society are healthy and strong" (Christchurch City Council, 2006a, p. 3). The plans included increasing the population living within Central Christchurch from 6,000 to 30,000 by 2026 (Christchurch City Council, 2006a, p. 10, 2006b, p. 1). The Lanes Design Guide was issued by the Christchurch City Council which focused on creating lanes through the city to improve pedestrian-ways (Christchurch City Council, 2006b, p. 14).

After the earthquakes, the Christchurch Central Recovery Plan was developed through the Central City Development Unit (CCDU). Its core goals are similar to the Project Central City core goals stated above. However, there is additional emphasis on creating a compact core with a stronger built identity. Providing a tool that reliably reports the impact of building design on outdoor thermal comfort would contribute to these plans and support their core goals of improving vitality and liveability (Canterbury Earthquake Recovery Authority, 2012). 


\subsection{AIM AND SCOPE OF THE STUDY}

The aim of this thesis project is to develop the Process for Predicting Outdoor Thermal Comfort into a tool for use at the preliminary design stage of a development. The intended use is for designers and consultants who have experience with three-dimensional modelling and computer programs for calculating wind and solar radiation.

The purpose of a comfort tool is assessing thermal comfort in urban areas where people are likely to spend time outdoors. Typical examples include lanes with cafés or bars opening onto them, or urban seating areas such as city malls.

A comfort tool's use is aimed at the preliminary design phase of a project. This allows for design decisions such as the size and location of buildings within a site to be tested for their effect on outdoor thermal comfort. Other preliminary design decisions which will impact thermal comfort levels include the orientation of lanes, building footprints, and the height of buildings. Focus on preliminary design is important because once a building is under construction or is complete, there are fewer options for improving outdoor thermal comfort through the built form (Donn, Selkowitz, \& Bordass, 2012, p. 188). 


\subsection{RESEARCH QUESTIONS}

Research questions have been defined to frame the development of the Process for Predicting Outdoor Thermal Comfort into a tool. These questions combined test the hypothesis that a tool for predicting thermal comfort can be developed which can inform design changes through communicating thermal comfort across a proposed development.

The purpose of this thesis project is to test whether it is possible to develop the Process for Predicting Outdoor Thermal Comfort into a tool which can inform and test design changes. A secondary objective is to test the applicability of The Wellington Comfort Index to cities outside of Wellington.

The research approach is guided by four research questions:

\section{Are the results from a comfort tool able to inform design changes?}

It is important that the tool developed is able to communicate the information needed to inform design decisions. This will be tested by examining whether the tool can communicate thermal comfort levels across a development, and can highlight areas of thermal discomfort. It should allow designers and consultants to test design solutions for mitigating issues with discomfort and compare their performance to the original design.

Four case studies will be used to understand if a comfort tool can inform design decisions. The results of these case studies are presented in Section 4.2 'Are the results from a Comfort Tool able to Inform Design Changes?'

2. Can the Process for Predicting Outdoor Thermal Comfort be developed into a tool for use at the preliminary design stage?

The Process for Predicting Outdoor Thermal Comfort needs to be improved before it can be used as a tool for predicting thermal comfort in the preliminary design stage. Currently the Process for Predicting Outdoor Thermal Comfort uses a computer program for calculating wind which has not been tested for its accuracy, and it is unknown if there are other wind analysis programs which are able to also be used as well.

To assist consultants and designers in selecting wind analysis programs, criteria will be developed which allows for wind analysis programs to be tested for their accuracy and 
ability to calculate wind speeds in a format which can be used in The Process for Predicting Outdoor Thermal Comfort.

The techniques used to develop the criteria for selecting wind analysis programs are presented in Section 3.2 'Can the Process for Predicting Outdoor Thermal Comfort be developed into a tool for use at the preliminary design stage'.

\section{Can thermal comfort be automatically communicated across a development?}

Currently the Process for Predicting Outdoor Thermal Comfort needs to be repeated for each point where comfort is being tested within a development. This means that calculating thermal comfort across a whole development would be time consuming as the Process for Predicting Outdoor Thermal Comfort needs to be repeated hundreds of times on a grid across the development. Without an automated process it would be difficult for designers and consultants to understand the relative level of thermal comfort in different areas of a development.

A way for the Process for Predicting Outdoor Thermal Comfort to calculate thermal comfort for a number of points across a case study simultaneously will be developed. It is important that the application selected for calculating thermal comfort across a case study can also be applied to other case studies. The Process for Predicting Outdoor Thermal Comfort will also be automated, allowing for consultants to simply enter the required data, then for the tool to calculate and display the outdoor thermal comfort results.

The techniques used to develop a way of automating of the Process for Predicting Outdoor Thermal Comfort are in Section 3.2 'Can the Process for Predicting Outdoor Thermal Comfort be developed into a tool for use at the preliminary design stage'. The success of the tool at automatically calculating thermal comfort across a development are displayed in Section 4 'Are the Results from a Comfort Tool able to Inform Design Changes?' 
4. What is the applicability of The Wellington Comfort Index to cities outside of Wellington? Before The Wellington Comfort Index can be used in cities outside of Wellington, it needs to be tested to see whether it is applicable to other cities. The Wellington Comfort Index is the basis of the Process for Predicting Outdoor Thermal Comfort. It includes four environmental factors, mean and maximum wind, ambient temperature, and mean radiant temperature. Each has a different degree of importance in predicting thermal comfort. However, it is unknown if these four environmental factors have the same degree of importance in cities outside of Wellington.

The techniques used for calculating The Wellington Comfort Index for Christchurch, and the results are discussed in Section 3.4 'What is the Applicability of The Wellington Comfort Index to Cities Outside of Wellington?' 


\subsection{OVERVIEW OF THE STUDY}

This thesis consists of five further chapters within three main parts. Chapter Two situates the current study within related literature. The theoretical underpinnings of outdoor thermal comfort are discussed. This includes a critical review of the relevant literature. This review provides context, and understanding of current practice for quantifying outdoor thermal comfort within urban planning and architecture.

Chapter Three defines and justifies the techniques which are used for developing the Process for Predicting Outdoor Thermal Comfort. This includes discussing the considerations for the criteria for selecting wind analysis programs, and techniques for communicating thermal comfort across a development. Techniques used to test the application of The Wellington Comfort Index to cities outside of Wellington are also discussed. The results of testing The Wellington Comfort Index on cities outside of Wellington are included in this chapter.

Chapters four and five are the concluding chapters. In Chapter Four the results of the developed tool are presented. Chapter Five concludes this thesis project with a summary of conclusions for each of the research questions, including how thermal comfort can be communicated across a whole development, and whether the results of the tool are able to inform design changes. Chapter Six is the future development chapter which identifies ways the developed tool could be improved, but are outside the scope of this thesis project. 
pg. 19 


\section{PREDICTING OUTDOOR THERMAL COMFORT}

Cities with thermally comfortable outdoor spaces can attract people to spend more time outdoors, as well as increase vitality and resilience (Lian Chen, Edward Ng, 2011, p. 120). However, designing thermally comfortable outdoor spaces is complex as there are no set rules to follow. It is the combination of solar radiation, wind, and ambient temperature which determines thermal comfort. Therefore, understanding this dynamic relationship is key before a tool can be developed to assist designers and consultants with creating thermally comfortable outdoor spaces.

This chapter introduces thermal comfort broadly, as well as specifically for the outdoors. This is followed by a brief historical overview of assessing and quantifying thermal comfort, and current techniques for predicting outdoor thermal. This provides context for understanding the importance of the development of a tool for predicting thermal comfort, for use within urban planning and architecture. 


\subsection{DEFINITION AND PERCEPTION OF THERMAL COMFORT}

Thermal comfort for indoor and outdoor environments can be described as when people feel thermally neutral or the point where people feel satisfied with their thermal conditions. Indoor comfort is defined as a "condition of mind in which satisfaction is expressed with the environment" (American Society of Heating, Refrigerating and Air-Conditioning Engineers, 1985). Air quality, humidity, radiation exchange with the environment, and convective heat exchange affect people's thermal comfort in the indoors and outdoors. Indoors these can be controlled using mechanical heating, ventilation, and air-conditioning more easily to ensure people feel satisfied with their thermal conditions. However, in the outdoors, solar radiation and wind also affect thermal comfort (Gaitani et al., 2007, p. 318; Givoni et al., 2003, p. 77; Marialena Nikolopoulou \& Steemers, 2003, p. 95).

In the outdoors, thermal comfort is also described as an absence of any thermal discomfort, or when people feel neither hot or cold (Givoni et al., 2003, p. 81; Marialena Nikolopoulou \& Steemers, 2003, p. 98). This definition has expanded to include environmental stimulation through variations in wind, solar radiation, and shade (Givoni et al., 2003, p. 78; Marialena Nikolopoulou \& Steemers, 2003, p. 98). It is these variations in the climate which attract people to spend time outdoors (Marialena Nikolopoulou \& Steemers, 2003, p. 98). 
Although wind, solar radiation, and ambient temperature determine if a microclimate is thermally comfortable, the perception of what is thermally comfortable varies between individuals. Microclimate for this thesis project is defined as the climate within or surrounding a city block or development. It can be designed through changing the form of buildings, landscaping, and shading to allow or block wind or solar radiation at pedestrian level. Thermal Comfort in a microclimate is measured using the same parameters as the general climate: solar radiation, wind, and ambient temperature. It is these parameters which a tool for predicting comfort should be calculating thermal comfort upon.

An individual's perception of thermal comfort can be influenced by an individual's thermal history or experience, time spent outdoors, perceived control of their thermal comfort, or their sense of place. Individuals may find different levels of gust and mean wind speed, solar radiation, and ambient temperature thermally comfortable based on their personal perception of thermal comfort (Marialena Nikolopoulou \& Steemers, 2003, p. 101; Thorsson, Lindqvist, \& Lindqvist, 2004, p. 149). If people feel they have control of their thermal comfort, they are likely to feel more comfortable than if they do not have control (Marialena Nikolopoulou \& Steemers, 2003, p. 97).

People's perception and adaption to the microclimate can be defined through understanding how people's bodies regulate changes in microclimate, or understanding what influences people's perception of thermal comfort (Eliasson, Knez, Westerberg, Thorsson, \& Lindberg, 2007, p. 73; Höppe, 2002, p. 661; Marialena Nikolopoulou \& Steemers, 2003, p. 95). People generally adapt to a climate physically in the short term, and psychologically over a period of time (Marialena Nikolopoulou \& Steemers, 2003, p. 97).

Physical adaption may include a person increasing or decreasing their exposure to the wind or solar radiation, changing their level of clothing, or increasing or decreasing their level of activity to improve their thermal comfort. This allows individuals to change their behaviour to maintain their personal thermal comfort levels in the microclimate. This is based on their perception of thermal comfort for a point in time. This is the theory that The Wellington Comfort Index was developed around. It quantifies the degree people will need to change their behaviour to maintain their thermal comfort (Walton et al., 2007, p. 3166). 
Psychological adaption directly influences an individual's perception of thermal comfort. It is influenced by experience, time of exposure, perceived control, and expectations (Marialena Nikolopoulou \& Steemers, 2003, p. 95). An example of psychological adaption is acclimatisation when an individual moves to a new country or city with a different climate. When wind patterns, ambient temperature, and solar radiation levels are different than an individual is used to, the new conditions may feel less thermally comfortable until they adapt to the new climate. This may be as little as two weeks, but tends to take longer when adapting to cold climates. Age, body mass, and metabolic rate may also affect the time it takes to acclimatise (Folk, 2015).

Psychological adaption also includes experience. An example of this is when the perception of thermal comfort is based on their expectations of a season. This may change between seasons based on the previous season. For example, spring is generally perceived as warmer than autumn, as people have just experienced winter. Whereas, in autumn, people have been in summer so perceive autumn as cooler than spring (Marialena Nikolopoulou \& Steemers, 2003, p. 97). This experience and the associated expectations mean that people's perception of thermal comfort varies between seasons, making it challenging to design an outdoor urban area that is perceived as thermally comfortable for all seasons. However, through basing a tool for predicting thermal comfort on an index which surveyed people over a range of seasons these experiences which affect people's perceived thermal comfort are captured in the index (Lykoudis \& Nikolopoulou, 2006, p. 1456).

A person's sense of place or familiarity may also influence their perception of thermal comfort, through increased positive thoughts or feelings towards a particular location (Knez, 2005, p. 208; Knez \& Thorsson, 2006, p. 259). This is interconnected with how people perceive outdoor thermal comfort, so is difficult to assess individually. 
2.1.1. MICROCLIMATE AND OUTDOOOR THERMAL COMFORT

Wind has a large influence of whether an outdoor space is perceived as thermally comfortable due to its cooling effect, known as wind chill. Wind chill is the perceived decrease in ambient temperature due to the flow of air on exposed skin (Parsons, 1997, p. 145). However, depending on the climate, it may be the cause of thermal comfort or discomfort. In cooler climates or seasons, wind may increase the feeling of thermal discomfort. Whereas, in a warm climates or seasons, wind causes air movement and may have a cooling effect on people, making them feel more thermally comfortable. The temperature of the wind can also influence thermal comfort. In a warm season or climate, when the wind travels over a mountain range and across the countryside, it may become a hot and dry wind. This could either increase the perceived temperature of the wind to a thermally comfortable level, or beyond to a thermally uncomfortable level. Lack of air movement may also cause thermal discomfort when ambient temperature is high or when someone is in direct solar radiation.

The larger the ratio between the gust and mean wind speeds, the more noticeable the wind (John Zacharias, Ted Stathopoulos, Hanging Wu, 2001, p. 213). Whereas, when this ratio is lower, the wind is less noticeable (Lykoudis \& Nikolopoulou, 2006, p. 1468; Walton et al., 2007, p. 3174). This may be a cause of thermal discomfort either due to the annoyance of the wind, or the cooling effect of the wind (Givoni et al., 2003, p. 78; Lykoudis \& Nikolopoulou, 2006, p. 1468).

It is often the solar radiation or ambient temperature which attracts people to use an outdoor space, or encourages people to spend more time in an outdoor area than they anticipated (Marialena Nikolopoulou \& Lykoudis, 2007, p. 3706). Solar radiation and ambient temperature within an urban area have a close relationship with the sun's annual patterns. Closer to the summer-solstice, the solar radiation levels are higher, increasing the feeling of warmth than in winter time. Cloud cover is also a factor as it may diffuse the solar radiation, making its warming effect less noticeable.

However, ambient temperature is not as predictable as solar radiation. This is demonstrated through comparing the typical ambient temperatures recorded over a year for three cities (Figure 2.1). These cities, Bangkok, Vancouver, and Christchurch, were selected as they have different climates, and are located in different areas of the world. In 
Bangkok the temperature varies by a few degrees each day as shown by the blue line, whereas in Christchurch as Vancouver there can be large variations between ambient temperatures each day as shown by the grey and orange lines.

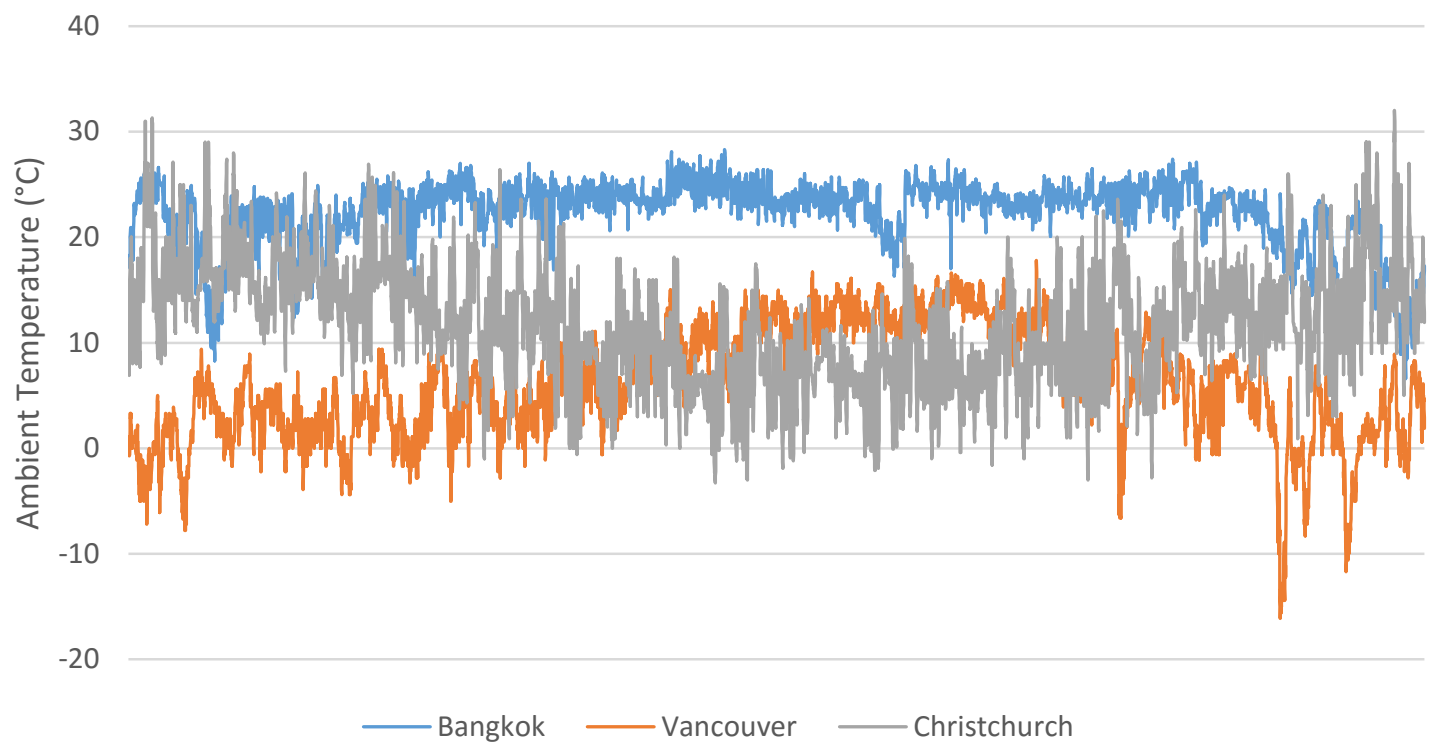

Figure 2.1 shows that some climates have large variations in ambient temperature between neighbouring days (orange and grey line). Whereas, other climates have fairly consistent temperatures between days (blue line) ('TMY Weather Data', 2013).

This is often determined by the topography and amount of rainfall which affects air movement and the cooling or warming of the earth's surface. Ambient temperature may also be higher in urban areas than open areas, such as the countryside, known as the heat island effect. This is due to cities having more traffic and air conditioning systems in a condensed areas which release their warm 'exhaust air' into the streets. Another reason is that buildings and roads are able to absorb heat, and slowly release it over time due to their thermal mass (2005 ASHRAE Handbook Fundamentals, 2005, p. 449).

Humidity levels may also be a factor in people's outdoor thermal comfort. When humidity levels are too high or too low, people are likely to feel thermally uncomfortable, especially when temperature levels are also high (Lykoudis \& Nikolopoulou, 2006, p. 1459). Unlike solar radiation, wind, and ambient temperature, humidity is not always included in indices for quantifying thermal comfort. This is due to studies which develop comfort indices often focusing on temperate climates where humidity is not a factor affecting thermal comfort (Sangkertadi, Reny Syafriny, 2012, p. 59) 


\subsection{QUANTIFYING THERMAL COMFORT USING COMFORT INDICES}

Thermal comfort indices were initially developed for the assessment of indoor environments where the conditions are controlled, often known as steady-state comfort indices. They are called steady-state as they make assumptions about people's metabolic rate and clothing level being consistent. When used to assess thermal comfort levels in a proposed building they assume all people are wearing the same level of clothing and have the same level of activity.

Until the 1980s, indoor thermal comfort was typically quantified using a formula based on an energy budget. The energy budget calculates energy exchanged between a person and their surrounding environment (Brown \& Gillespie, 1995, p. 65). The most established thermal comfort index based upon this theory is Fanger's Predicted Mean Vote (PMV), which gives a rating scale between thermally comfortable and thermally uncomfortable $(J$ Hoof, 2008, p. 182). Other thermal comfort indices based on the energy budget are the New Effective Temperature (ET*), developed by Gagge et al. in the early 1970s, and the Standard Effective Temperature (SET*), which also included clothing level (clo-value), and level of activity (Honjo, 2009, p. 43). As these indices are based on energy balance, they assume that people are able to reach thermal equilibrium through being exposed to an ambient climatic environment (Lian Chen, Edward Ng, 2011, p. 119).

Traditional thermal comfort theories such as Fanger's PMV studies, and ASHRAE's Fundamentals Handbook suggest that these thermal comfort indices can be applied to outdoor environments without modification (Jacket, Walton, \& Cleland, n.d., p. 1). Although, Honjo has acknowledged that the outdoor environment is much more complex than the indoor environment, their study still states that the PMV, SET and PET steadystate comfort indices for the indoors have also proven suitable for outdoors (Honjo, 2009, p. 43). However, Spanolo and de Dear have highlighted that this assumption cannot be made without further testing as it is likely that the thermally neutral point, and the temperature band considered thermally comfortable changes for the outdoors compared with the indoors (Spagnolo \& de Dear, 2003, p. 721).

Steady-state comfort indices have been further developed into adaptive thermal comfort models as naturally ventilated buildings have become more common. Adaptive models 
assume that people play an active role in maintaining their thermal comfort (de Dear \& Schiller Brager, 2001, p. 101). This is due to naturally ventilated buildings, or buildings with a combination of mechanical and natural ventilation having a larger variations in temperature. However, the temperature range in which people feel thermally comfortable is larger. Adaptive models exclude assumptions about clothing level, and a wider range of metabolic rates are assumed (de Dear \& Schiller Brager, 2001, p. 107).

However, there is much debate surrounding the approach of using thermal comfort indices, which were initially developed for the indoors, for quantifying thermal comfort outdoors. Theories range from indoor thermal comfort indices being able to be applied directly to the outdoors, to steady-state comfort indices not being applicable to the outdoors, even with modification (Honjo, 2009, p. 43).

The idea that indoor thermal comfort indices can be applied to the outdoors has been tested. The Actual Sensation Vote (ASV) and Predicted Mean Vote (PMV) were both created for the indoors, and have had their applicability to the outdoors tested. This concludes that the ASV and PMV cannot be applied outdoors, as they suggested people would feel thermally uncomfortable even when the participants in the tests felt thermally comfortable (Marialena Nikolopoulou \& Steemers, 2003; Marialna Nikolopoulou, Baker, \& Steemers, 2001, p. 231). This is because the thermal comfort indices created for the indoors, do not include solar radiation and wind which are key factors influencing thermal comfort in the outdoors (Marialena Nikolopoulou, Baker, \& Steemers, 2001, p. 231). Indoor environments have fewer changes, such as temperature and air movement, so occupants can dress in a similar way each day. However, in the outdoors these assumptions cannot be made.

When assessing thermal comfort outdoors Hoppe has determined that, a thermal comfort index needs to consider how people's behaviour may change, in order to maintain their thermal comfort when there are changes in their microclimate (2002, p. 661). A universal thermal comfort index, known as the Universal Thermal Comfort Index (UTCI) has been developed for use in the indoors and outdoors for all climates. However, it has been concluded for a better assessment of outdoor thermal comfort there needs to be more detailed measurements and considerations than the UTCI includes. Although the aim of 
this UTCI is to be applied globally, more work is also required before this can happen (Honjo, 2009, p. 47; Spagnolo \& de Dear, 2003, p. 738).

A number of attempts have been made to generate an index which is able to quantify outdoor thermal comfort. These often take into account both environmental factors such as solar radiation, wind, ambient temperature, and the 'human dimension' of how people perceive the combined effect of the environmental factors on thermal comfort. The index is then able to measure the relationship between each environmental factor to understand the degree of thermal comfort. The rationale behind such attempt is to understand and quantify the relationship between each environmental factor and the degree of thermal comfort, as well as how people may change their behaviour to maintain their thermal comfort (Givoni et al., 2003; John Zacharias, Ted Stathopoulos, Hanging WU, 2001; Wu \& Kriksic, 2012). Therefore, these indices cannot be validated within controlled conditions such as a laboratory. This is because the indices require the unpredictability of outdoor conditions where people's responses cause them to change their behaviour to maintain thermal comfort.

When assessing outdoor thermal comfort, the level of activity, seating location, clothing level, and the length of time people spend outdoors should be considered (Gaitani et al., 2007, p. 318; Walton et al., 2007, p. 3167). Wind, solar radiation, and temperature may change within hours or even minutes, so people need to be able to readily change their behaviour to maintain their thermal comfort level (Thorsson et al., 2004, p. 155). People can change their clothing level to control their personal thermal comfort. It allows people to feel the same degree of thermal comfort in all seasons if they are dressed appropriately (Walton et al., 2007, p. 3167). As people perceive thermal comfort differently, people's level of clothing is different, and may change throughout the day. People also have the ability to move in and out of the solar radiation or wind to maintain their thermal comfort relative to the seating available, and their purpose for staying outdoors.

Further work has been recently completed to develop thermal comfort indices specifically for the outdoors which consider people's behavioural changes to maintain their thermal comfort (Givoni et al., 2003, p. 79; Walton et al., 2007, p. 3171). Field surveys are used for understanding and quantifying these behavioural changes. These match a participant's 
survey responses with wind, solar radiation, and temperature for the geographic location a participant completed a survey (Fiala, Lomas, \& Stohrer, 2001, p. 143; Jendritzky, Maarouf, \& Staiger, 2001; Shimazaki et al., 2011, p. 1716; Tokunaga \& Shukuya, 2011, p. 2220). Questions to determine variables such as how people perceive thermal comfort, their clothing levels, and the length of time they are outside are measured through a survey. This provides insight into how people perceive outdoor thermal comfort, as well as how they change their behaviour to adjust to changes in the microclimate. It is unknown whether these thermal comfort indices are applicable to climates other than those they were developed for because it is unknown how people perceive wind, solar radiation, and ambient temperature differently in different climates (Walton et al., 2007, p. 3173).

Currently there are two thermal comfort indices which could be used as the basis of a tool for predicting comfort. Each predicts thermal comfort in a different way. Givoni et al.'s formula (Equation 1) calculates thermal sensation which is the perception of heat or cold (Givoni et al., 2003, p. 78). It includes ambient temperature, wind, and solar radiation (Givoni et al., 2003, p. 80). Walton et al.'s approach (Equation 2) attempts to quantify behavioural changes to maintain thermal comfort. Walton's formula includes mean and maximum wind, ambient temperature, and mean radiant temperature. These are both multiple-linear regression formulas which were developed through surveying people about their perception of wind, solar radiation, and temperature while they were outdoors, rather than in a laboratory.

Equation 1 is Givoni et al.'s formula (Givoni et al., 2003, p. 80):

$$
\begin{gathered}
\text { Thermal Sensation }=1.2 \\
+0.1115 \times \text { Ambient Temperature } \\
+0.0019 \times \text { Solar Radiation }-0.3185 \times \text { Wind Speed }
\end{gathered}
$$

Equation 2 is Walton et al.'s formula (Walton et al., 2007, p. 3171):

Behavioural changes to maintain thermal comfort $=25.52$

+10.65 x Mean Wind - 5.77 x Maximum Wind

$+0.85 \times$ Mean Radiant Temperature $($ exposed)

$+0.53 \times$ Ambient Temperature 


\subsection{URBAN PLANNING AND THERMAL COMFORT}

Current practice in the urban planning and architecture for assessing thermal comfort in outdoor areas is typically based on simple guidelines. Tools have been developed for predicting outdoor thermal comfort which encourage urban planning to move from simple guidelines to considering solar radiation and wind. However, these tool have their limitations. These tools are often based on steady-state comfort indices, or do not consider the combined effect of solar radiation, wind and ambient temperature to predict the thermal comfort. However, with advances in thermal comfort indices which predict people's response to the microclimate, it is now possible to develop a tool for predicting thermal comfort for use within urban planning and architecture.

\subsubsection{CURRENT PRACTICE WITHIN THE INDUSTRY}

Some city plans do include basic design guidelines which consider wind or solar radiation. However, improving thermal comfort is often excluded from urban design. In a temperate climate, basic design guidelines include orientating roads to maximise solar radiation at pedestrian level, or defining a proportion of open area around a proposed building where there must be direct solar radiation at pedestrian level (Christchurch City Council, 2011; John Zacharias, Ted Stathopoulos, Hanging Wu, 2001, p. 299). These design guidelines are often blanket rules for the Northern or Southern Hemisphere (Brown, 2011, p. 373). However, the success of these guidelines is unknown. Simulation programs can be used to assess solar radiation, although, are often only used to test the worst case scenarios, typically the summer and winter solstice (Brown \& Gillespie, 1995, p. 373).

Wind is often neglected by urban planners, even though it is often the largest cause of thermal discomfort (Reiter, 2010, p. 857). This leaves major issues to be mitigated once a project is complete, or in the final design phase when it is often too late to make changes (Bottema, 1999, p. 4009). If these assessments were carried out earlier in a design project, then the urban form itself could be used to mitigate local wind speeds, or to increase solar radiation at pedestrian level (Reiter, 2010, p. 857). This would allow outdoor thermal comfort to be designed rather than being mitigated once a development is complete, and the issues with thermal comfort have been revealed. This is key in creating thermally 
comfortable urban areas as the urban form can alter wind patterns drastically, changing the microclimate within as little as a few metres (2007, p. 318; 2001, p. 298).

2.3.2. DEMAND FOR A TOOL FOR PREDICTING OUTDOOR THERMAL COMFORT Over the last twenty years studies have been conducted which analyse the relationship between outdoor thermal comfort and activities within an outdoor area (Lian Chen, Edward $\mathrm{Ng}, 2011$, p. 120). Areas where outdoor thermal discomfort has been mitigated and the microclimatic conditions have been improved have attracted more business, residents, and revenue (Marialena Nikolopoulou et al., 2001, p. 227). Additional benefits also include the increased use of active and public means of transport, as well as benefitting the overallimage of a city (Marialena Nikolopoulou et al., 2001, p. 227).

With the advances in technology, combined with the creation of indices for predicting people's response to the microclimate, it is now possible to develop a tool for predicting thermal comfort (Givoni et al., 2003, p. 80; Walton et al., 2007, p. 3171). This means that urban design can be informed by the predicted thermal comfort levels within a space, rather than basic design guidelines. It is important that an in-depth thermal comfort assessment specific to a development is carried out for different times of the day and year (Cheng \& Ng, 2006, p. 421).

Until recently the technologies have not existed to predict people's response to thermal comfort levels within an urban area. However, with the advances in technology such as Computational Fluid Dynamics (CFD) wind analysis programs (which can predict wind around a proposed development using a three-dimensional model) it is now possible to develop a tool for predicting thermal comfort (Houda, Zemmouri, Hasseine, Athmani, \& Bensalem, 2012, p. 1).

This has the ability to bridge the gap between urban design and the creation of microclimates (Brown, 2011, p. 373). For architects, planners, and urban designers design possibilities are also enriched through a greater understanding of how thermally comfortable a space is once it is constructed (Marialena Nikolopoulou \& Steemers, 2003, p. 
95). This allows designers to test how a change in design detail will change people's thermal comfort (Givoni et al., 2003, p. 77).

It is important that this tool is used in the preliminary design phase of a project when it is possible to modify the built form. This varies from current practice of assessing wind levels around proposed buildings using wind tunnels. As wind tunnel testing is expensive, assessments of wind are often conducted in the final design stage of a project. However, by this point it is generally too late to modify the built form to improve wind levels at pedestrian level (Bottema, 1999, p. 4009).

\subsubsection{EXISTING TOOLS}

There are a number of tools marketed for assessing outdoor thermal comfort. However, these are often based on a steady-state comfort index, such as the Predicted Mean Vote. They are also often time consuming and costly to use (Goshayeshi, Shahidan, Khafi, \& Ehtesham, 2013, p. 518). These are outlined below, as well as their intended purpose (Table 2.1).

Table 2.1 shows the current tools marketed for predicting thermal comfort. It shows that although they model environmental factors, they do not necessarily produce results which can inform design changes.

\begin{tabular}{l|l}
\hline Tools for Predicting Outdoor Thermal Comfort & \multicolumn{1}{c}{ What does it model? } \\
\hline TownScope & Thermal comfort using solar radiation as a predictor. \\
(Teller \& Azar, 2001) & \\
\hline Rayman Model - Predicted Mean Vote & $\begin{array}{l}\text { Models radiation fluxes and mean radiant } \\
\text { temperature. }\end{array}$ \\
(Matzarakis, 2007) & $\begin{array}{l}\text { Flow around and between buildings, exchange } \\
\text { processes at the ground surface and at building }\end{array}$ \\
Equivalent Temperature, or Universal Thermal & walls, building physics, impact of vegetation of the \\
Climate Index & $\begin{array}{l}\text { local microclimate, bioclimatology, and pollutant } \\
\text { dispersion using ambient temperature, wind, and } \\
\text { (Bruse, 2010; Bruse \& Fleer, 1998) }\end{array}$ \\
& $\begin{array}{l}\text { humidity. } \\
\text { Spatial variations of three-dimensional radiation } \\
\text { fluxes and mean radiant temperature }\end{array}$ \\
\hline
\end{tabular}


It is important that a tool for assessing the microclimate includes wind, solar radiation and ambient temperature through the use of a thermal comfort index. This is because wind, solar radiation, and ambient temperature have been identified as the key factors affecting outdoor thermal comfort in a temperate climate. Therefore, if one of these is not included, then the complexities of quantifying how thermally comfortable a space will be will not be captured. It is also important that a tool for predicting outdoor thermal comfort gives an understanding of people's responses to the microclimate. This human dimension will allow for changes to be made based on how people may feel thermally, allowing for design changes to be made in response to areas of thermal discomfort within a proposed development. 
This chapter has identified that there is currently no tool for quantifying outdoor thermal comfort based on a comfort index which can predict the degree people will need to change their behaviour to maintain their thermal comfort. As introduced in the Section '1.1 Context of the Study', although requiring further development, a Process for Predicting Outdoor Thermal Comfort does exist. It is based on a comfort index which predicts thermal comfort based on the degree people will need to change their behaviour to maintain thermal comfort. This process allows for proposed urban areas to be assessed for thermal comfort at the design stage.

This chapter has also established the complexities of quantifying outdoor thermal comfort, in terms of wind, solar radiation, ambient temperature, and the psychological aspect of thermal comfort. It is important that a tool for measuring outdoor thermal comfort includes these factors, allowing for the results to be informative, and reflective of the people within a city where a proposed development is located.

The next chapter outlines the methodology used to develop the Process for Predicting Outdoor Thermal Comfort into a comfort tool and introduces the case studies which will be used to test whether a comfort tool can be developed to inform design changes. 
pg. 35 


\section{DEVELOPING THE COMFORT TOOL - METHODOLOGY}

This chapter creates a methodology for developing the Process for Predicting Outdoor Thermal Comfort into a tool, known as The Comfort Tool. This Process for Predicting Outdoor Thermal Comfort is based on an index for predicting how people will change their behaviour to maintain their thermal comfort levels, known as The Wellington Comfort Index.

As discussed in Section 2.2. 'Quantifying Thermal Comfort Using Comfort Indices' there were two comfort indices which could have been used to calculate comfort in The Comfort Tool. Walton et al.'s formula (The Wellington Comfort Index) was selected as it was already the basis of the Process for Predicting Outdoor Thermal Comfort. It was also selected as it included maximum wind speed, along with mean wind speed, ambient temperature, and mean radiant temperature. However, Givoni et al.'s formula only included mean wind speed. It is important when predicting thermal comfort that both the maximum and mean wind speeds are included as the larger the ratio between the mean and maximum wind speeds, the more thermal discomfort the wind may cause (John Zacharias, Ted Stathopoulos, Hanging Wu, 2001, p. 213). The Wellington Comfort Index was also selected as it is based on the survey results of 649 participants. Whereas, Givoni et al.'s formula was based on the survey responses of six participants (Givoni et al., 2003, p. 78).

As discussed in the introduction, the Process for Predicting Outdoor Thermal Comfort exists that is able to predict thermal comfort for a single point in a development, calculating wind and solar radiation in computer programs around a three-dimensional model of a proposed development. These solar radiation and wind results for a single point within an area are then used to calculate the thermal comfort levels for a single point in a proposed development. The thermal comfort levels are based on The Wellington Comfort Index. The aim of this thesis project is to develop the Process for Predicting Outdoor Thermal Comfort into a tool for use at the preliminary design stage of a development.

The hypothesis is that a tool for predicting outdoor thermal comfort can be developed which can predict thermal comfort across a proposed urban development allowing for design changes to be informed. 
The primary research approach is a case study research approach. The process for The Comfort Tool's development is framed by the four key research questions outlined in the introduction:

1. Are the results from a comfort tool able to inform design changes?

2. Can the Process for Predicting Outdoor Thermal Comfort be developed into a tool for use at the preliminary design stage?

3. Can thermal comfort be automatically communicated across a development?

4. What is the applicability of The Wellington Comfort Index to cities outside of Wellington?

This chapter is in three sections. The first section introduces the case study area where case studies were selected for testing The Comfort Tool. The second part of this chapter develops the Process for Predicting Outdoor Thermal Comfort into The Comfort Tool. The final section of this chapter tests the applicability of The Wellington Comfort Index The Comfort Tool is based on for cities outside of Wellington, using Central Christchurch as a case study. 


\subsection{SELECTION OF CASE STUDIES FOR TESTING THE COMFORT TOOL}

A case study research approach has been selected for testing the hypothesis that a tool for predicting outdoor thermal comfort can be developed which can inform design changes. Four case studies were selected based on the differences in their built form.

The first case study was selected to test The Comfort Tool's ability to calculate thermal comfort across a case study. This case study also tested if the comfort results communicated the variations in thermal comfort, and if these variations could be used to inform design decisions. This case study was a large development of $8500 \mathrm{~m}^{2}$, which covered half a city block. It had a large internal courtyard surrounded by tiered buildings, designed to allow for solar radiation at pedestrian level. It also had lanes linking the internal courtyard to footpaths to the North, South, and West of the case study.

The three other case studies were selected based on the differences in their built form. These case studies helped to understand if the results from the first case study was a specific coincidence, or whether The Comfort Tool has the same degree of success for other case studies. The case studies were selected based on variations in their design from one another and how this may affect the wind and solar radiation at pedestrian level. These variations include:

- Site size

- Area of central courtyards

- Orientation

- Building layout within the boundaries of the development site

- Heights of buildings 
3.1.1. CASE STUDY AREA: CENTRAL CHRISTCHURCH

Central Christchurch was selected as a case study area to develop and test The Comfort

Tool. It has been selected as Central Christchurch is currently in the process of being redesigned and constructed as eighty-percent of their central city has been demolished after the 2010 and 2011 Canterbury Earthquakes. This provided a unique opportunity to test The Comfort Tool on numerous developments which were in the design phase.

The case study survey area is located within Central Christchurch (Figure 3.1). This is where a case study weather station was located for testing the applicability of The Wellington Comfort Index to cities outside of Wellington, using Central Christchurch as the case study area. This case study weather station was also used to calculate the gust co-efficient which is required as part of The Comfort Tool for calculating the gust co-efficient from the mean wind speed in the Typical Meteorological Year (TMY) weather file.

The location and a brief overview of each case study development is below (Figure 3.1). Design details of each case study, and the effects these design details may have on solar radiation and wind levels are outlined in Section 4.2 'Testing The Comfort Tool'.

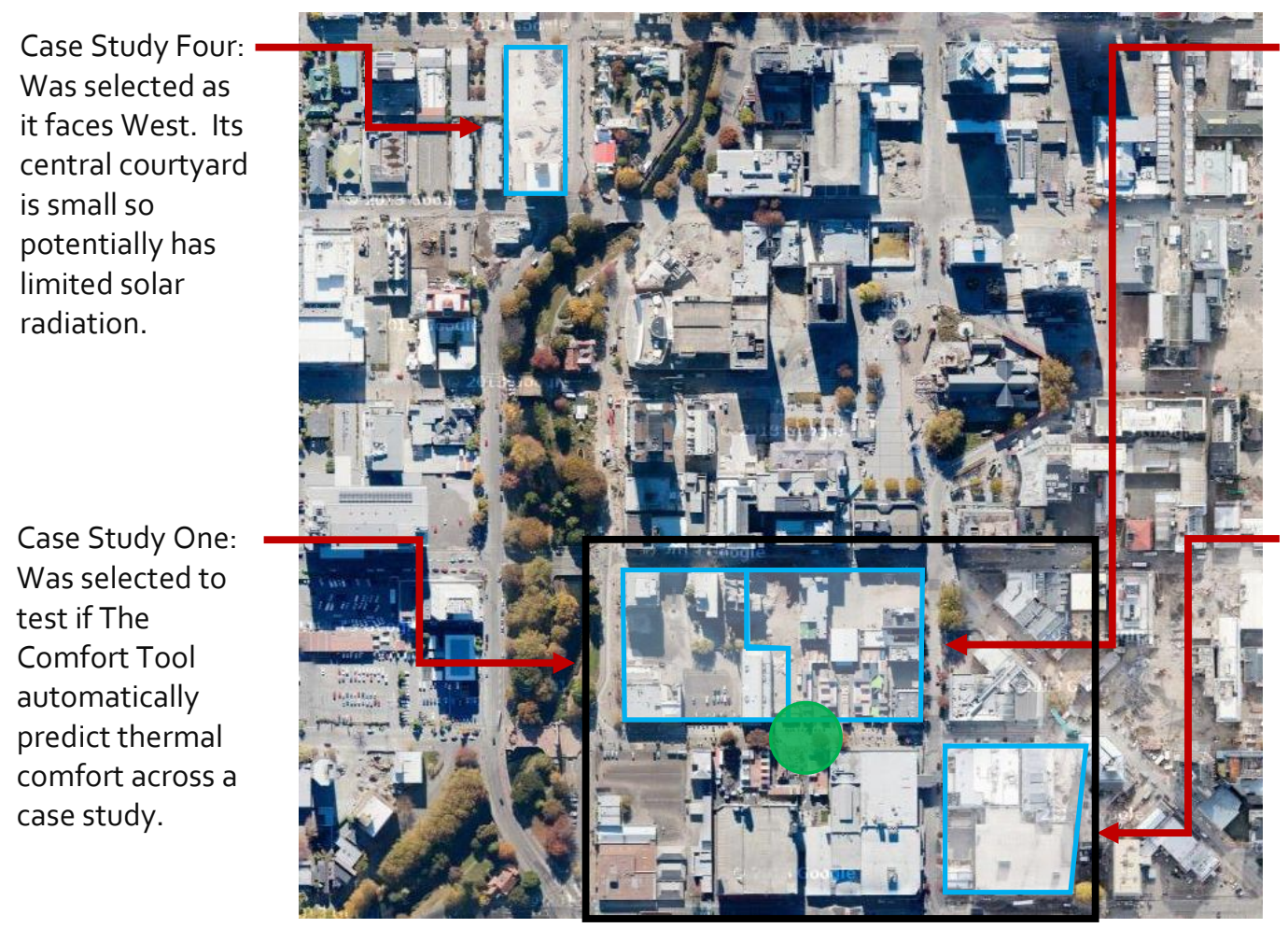

Case Study Two: Was selected as it faces the predominant wind, and all buildings are of similar height which may contribute to increased wind levels.

\section{Case Study Three:} Was selected as its primary use is in the evenings when only wind and ambient temperature influence comfort.

Figure 3.1 shows the location of the four case studies outlined in blue, within the case study area Central Christchurch. The case study weather station is indicated (green circle). The case study survey area is outlined (black). The case study survey area had to be selected within Central Christchurch as the weather data measured at the case study weather station was required. 


\subsection{CAN THE PROCESS FOR PREDICTING OUTDOOR THERMAL COMFORT BE}

\section{DEVELOPED INTO A TOOL FOR USE AT THE PRELIMINARY DESIGN STAGE?}

This section develops the Process for Predicting Outdoor Thermal Comfort into The Comfort Tool for use in urban planning and architecture. The Process for Predicting Outdoor Thermal Comfort is currently able to quantify thermal comfort based on microclimate conditions (mean and maximum wind, ambient air temperature, and mean radiant temperature) for each hour of the year. It is able to predict thermal comfort through solar radiation and wind being calculated in areas surrounding a three-dimensional computer model of a proposed development. These surrounding areas include courtyards, lanes, and neighbouring streets.

This section develops criteria to assist consultants in selecting a wind analysis program, automates the Process for Predicting Outdoor Thermal Comfort for a single point in a development to hundreds of points across a proposed development, and develops a way of communicating variations in thermal comfort across a development. The success of The Comfort Tool is tested in Section 4.2 'Evaluating The Comfort Tool for Different Urban Design Scenarios'. 
3.2.1. MANUAL MEASUREMENTS TO COMPUTER PROGRAMS

There are four environmental factors in The Comfort Tool: mean radiant temperature $\left({ }^{\circ} \mathrm{C}\right)$, ambient temperature $\left({ }^{\circ} \mathrm{C}\right)$, mean wind speed $(\mathrm{m} / \mathrm{s})$, and maximum wind speed $(\mathrm{m} / \mathrm{s})$. When The Wellington Comfort Index was developed these environmental factors were measured manually. However, for The Comfort Tool to predict thermal comfort in areas surrounding a proposed building which is not yet constructed, computer programs were used to calculate wind and solar radiation around a three-dimensional model of a proposed development. Ambient temperature was used from a weather file for Christchurch (Figure 3.2).

Weather Data

Ambient temperature

(TMY weather file)

Solar radiation and ambient temperautre

(TMY weather file)

\section{Wind speed measured at regional weather station (TMY weather file)}

Mean wind speed at

$1.2 \mathrm{~m}$ high within a proposed development
Transitional

Calculations

$\mathrm{n} / \mathrm{a}$

Black Globe Temperature

(Equations 3 \& 4)

Wind reduction factor calculated in wind analysis programe

Gust co-efficient

(Equation 7)
Inputs for The

Comfort Tool

Ambient temperature

Mean Radiant

Temperature

(Equation 5)

Mean wind speed at

$1.2 \mathrm{~m}$ high within a proposed development

Maximum wind gust

Figure 3.2 shows the summary table for the process of calculating the inputs for The Comfort Tool from the typical meteorological year weather file.

The height of $1.2 \mathrm{~m}$ represents the average height of someone seated (Walton et al., 2007, p. 3168). Therefore, the environmental factors included in The Comfort Tool are converted to $1.2 \mathrm{~m}$. This is also the same height used as the participant height for the development of The Wellington Comfort Index, which is the basis of The Comfort Tool (Walton et al., 2007, p. 3168). 


\section{Ambient Temperature}

The ambient temperature is the air temperature measured with a thermometer or thermocouple (Walton et al., 2007, p. 3168). It does not take into account humidity or the wind chill factor. The ambient temperature is based on historical weather data from a Typical Meteorological Year (TMY) weather file. This weather file is based on thirty years of data measured at a regional weather station (Gates, Liley, \& Donn, 2011, p. 1600). A statistical algorithm is used to select the most typical weather months from thirty years of weather data (Parsons, 1997, p. 523).

These TMY weather files are available for eighteen locations within New Zealand, and more than two-thousand internationally. For each location, it contains meteorological information such as ambient temperature, wind speed and patterns, and solar radiation. The height that this weather data is measured varies between regional weather stations. However, for Christchurch it is measured at a height of thirty seven metres. This type of weather file was selected as it represents the weather of a typical year, rather than weather data for a specific year which may contain unseasonable weather extremes.

As Central Christchurch is the case study area for The Comfort Tool, the ambient temperature for The Comfort Tool is directly from the TMY weather file measured at the Christchurch International Airport. The ambient temperature does not need adjusting from the TMY weather file measured at the Christchurch International Airport (37m) for use in The Comfort Tool as temperature only changes slightly with a decrease in height. This temperature change is approximately $0.03^{\circ} \mathrm{C}$ for each ten metre change in height (Stoffel, 2005 , p. 8). Therefore, there would only be a change in temperature of $0.1^{\circ} \mathrm{C}$ when converting the ambient temperature from a height of thirty-seven metres to pedestrian height (1.2m).

\section{Mean Radiant Temperature}

Mean radiant temperature is described as the influence of the temperature of a surface radiating on to an individual (Parsons, 1997, p. 134). This was measured using a thermocouple in a 150 $\mathrm{mm}$ globe thermometer placed in direct sunlight during the survey used to develop The Wellington Comfort Index (Walton et al., 2007, p. 3168). However, the 
mean radiant temperature cannot be calculated using a computer program and is not included in a TMY weather file. For this reason, it was calculated from the black globe temperature. The black globe temperature was calculated from the solar radiation and ambient temperature recorded in the TMY weather file for Christchurch.

To convert the solar radiation and ambient temperature to the black globe temperature, two formulae were used (Equation 3 and Equation 4). This measured the ambient temperature, humidity, and wind at a central weather station. These measurements were then used to generate models for estimating black globe temperature. The variables which contribute to the black globe temperature were then identified using simple correlation models (Turco et al., 2008, p. 2). This developed two models for calculating black globe temperature, one for the day, and one for the night time. Day and night periods are defined by the level of solar radiation.

Equation 3 is used for calculating black globe temperature during the day (Turco et al., 2008, p. 5):

$$
B G T_{d}=\left(1.360 T_{\text {air } d}-2.358\right) \times(0.075 \ln (R s)-0.562)
$$

Equation 4 is used for calculating black globe temperature at night (Turco et al., 2008, p. 5):

$$
B G T_{n}=\left(0.942 T_{\text {air } n}\right)
$$

Where:

$B G T_{d}=$ day-time black globe temperature $\left({ }^{\circ} \mathrm{C}\right)$

$T_{\text {air } d}=$ day-time air temperature $\left({ }^{\circ} \mathrm{C}\right)$

$B G T_{n}=$ night black globe temperature $\left({ }^{\circ} \mathrm{C}\right)$

$T_{\text {air } n}=$ night-time air temperature $\left({ }^{\circ} \mathrm{C}\right)$

$R s=$ solar radiation $\left(\mathrm{W} / \mathrm{m}^{2}\right)$

This black globe temperature was then converted to the mean radiant temperature for use in The Comfort Tool (Walton et al., 2007, p. 3169). It was converted using the following equation (Equation 5). 
Equation 5 is used for calculating the mean radiant temperature from the black globe temperature (Walton et al., 2007, p. 1369):

$$
{ }^{t} m r=\sqrt[4]{\frac{1.10 \times 10^{8} v_{a}^{0.6}}{\varepsilon D^{0.4}}}\left(t_{g}-t_{a}\right)+\left(t_{g}+273\right)^{4}-273
$$

Where:

${ }^{t} m r=$ mean radiant temperature $\left({ }^{\circ} \mathrm{C}\right)$

$\varepsilon=$ emissivity of the globe (0.95)

$D=$ diameter $(0.15 \mathrm{~m})$

$t_{g}=$ globe thermometer temperature $\left({ }^{\circ} \mathrm{C}\right)$

$t_{a}=$ ambient temperature $\left({ }^{\circ} \mathrm{C}\right)$

$v_{a}=$ air velocity $(\mathrm{m} / \mathrm{s})$

\section{Mean Wind Speed}

For The Comfort Tool, the mean wind speed at pedestrian height $(1.2 \mathrm{~m})$ was calculated by applying a wind reduction factor to the mean wind speed in the TMY weather file for Christchurch. The wind reduction factor was calculated using a wind analysis program for each individual case study. It takes into account how the wind speed reduces with height (Figure 3.3) as well as how the buildings and terrain reduce the wind speeds using the power law (Hussin, 2002, p. 468; Spera \& Richards, 1979, p. 1). The power law includes the mean wind speed and the terrain-roughness co-efficient which is a function of the type of terrain the wind is travelling across (Equation 6).

Equation 6 is the power law for calculating wind at different heights and different terrains (Gandemer \& Guyot, 1976, p. 20):

$$
\frac{\bar{U}_{z}}{\bar{U}_{G}}=\left(\frac{z}{z_{G}}\right)^{\alpha}
$$

\section{Where:}

$\bar{U}_{\mathrm{z}}=$ Mean wind speed at site $(\mathrm{m} / \mathrm{s})$

$\bar{U}_{G}=$ Mean wind speed at gradient boundary layer $(\mathrm{m} / \mathrm{s})$

$\mathrm{z}=$ Measurement height at case study area $(4 \mathrm{~m})$

$\mathrm{z}_{\mathrm{G}}=$ Height of local regional weather station located $2 \mathrm{~km}$ from case study area

$\alpha=$ Terrain-roughness co-efficient ( 0.35 for small density city) 


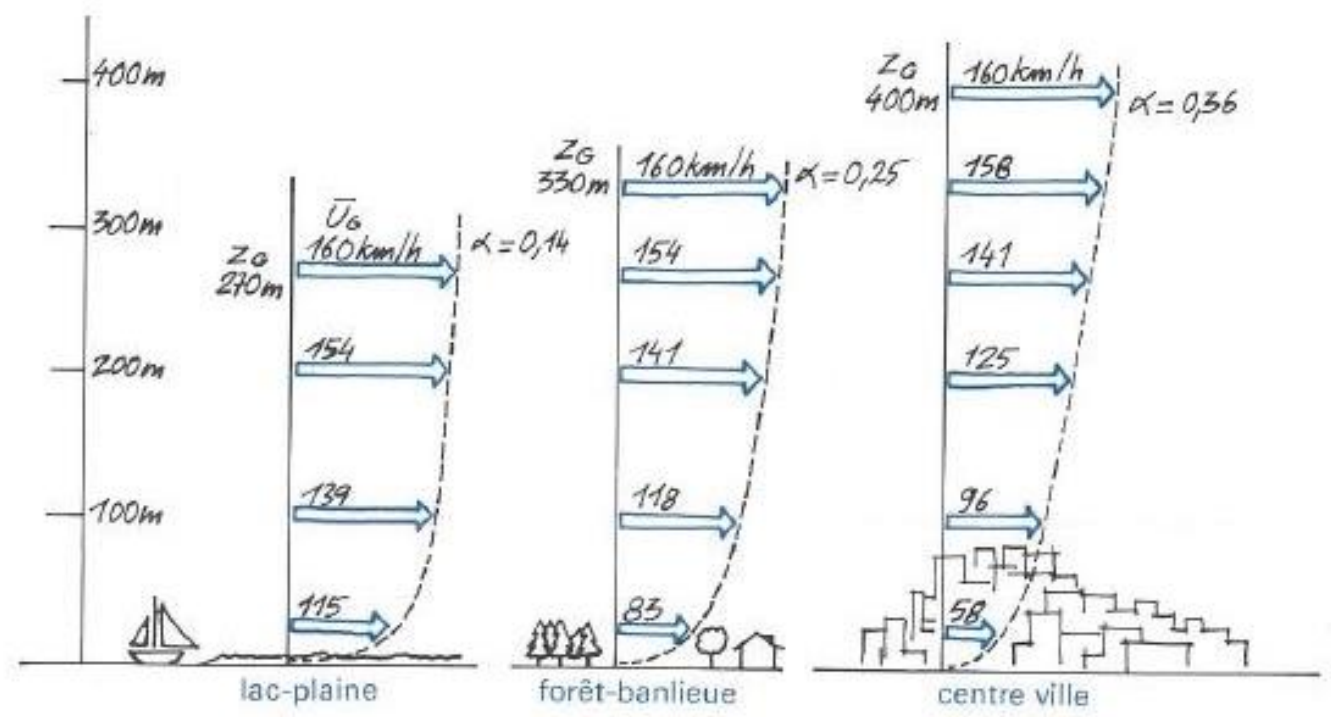

Figure 3.3 shows the terrain-roughness co-efficient $(\alpha)$ for different terrains. 'Lac-plaine' is terrain between a lake and a plain, 'forêt-banlieve' is terrain between a forest and a suburb, and 'centreville' is the centre of a town (Gandemer \& Guyot, 1976, p. 20).

The wind analysis programs also takes into account how the wind speed is reduced or accelerated based on the built form of the individual case study. This built form includes the size, orientation, and widths of lanes (Figure 3.4). The wind reduction factor was calculated for eight wind directions: North, North-east, East, South-east, South, Southwest, West, and North-west, for 121 measurement points across each case study. 


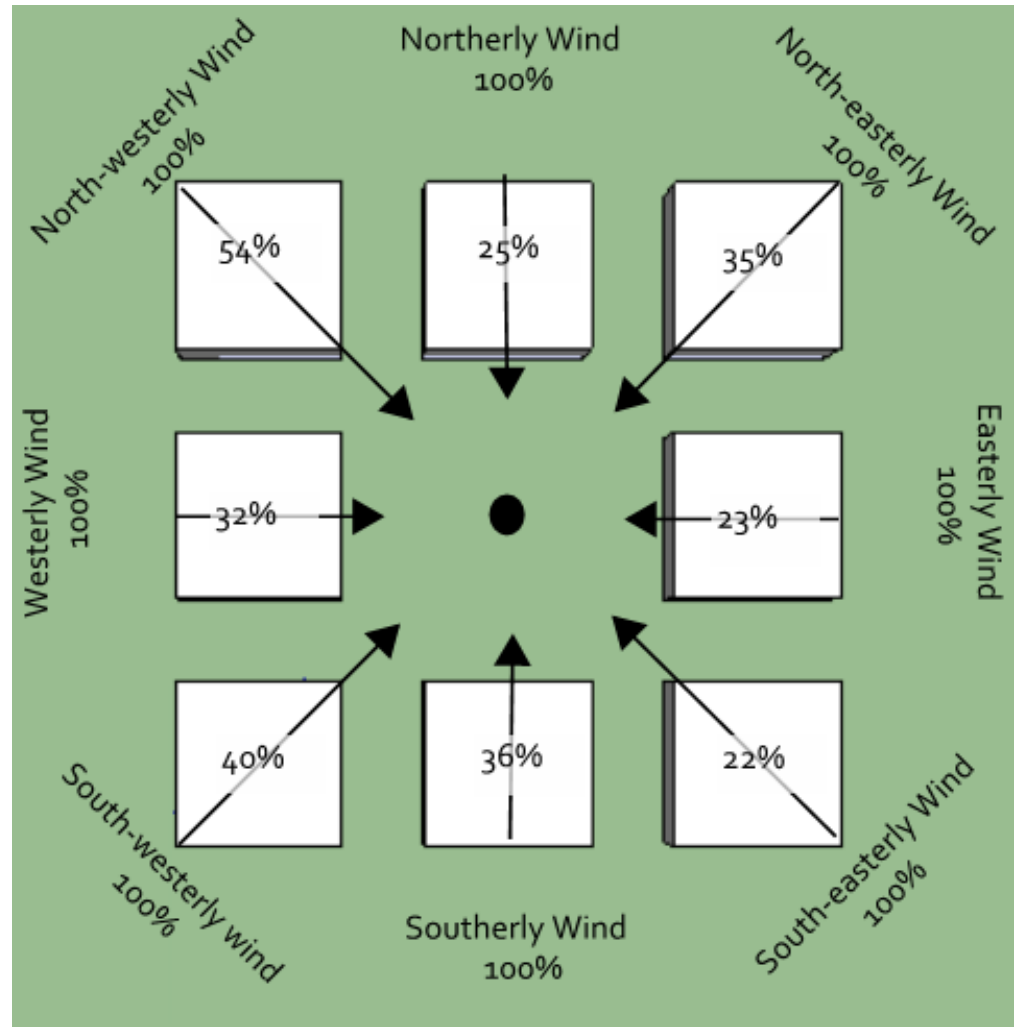

Figure 3.4 shows a plan view of eight city blocks with a central open area. This is an example of how wind speeds in an exposed area (one-hundred-percent of prevailing wind speed) would reduce through the eight city blocks into the central open area for each wind direction.

These wind reduction factors (eight wind directions, at 121 measurement points across each case study) were applied to the mean wind speed in the TMY weather file for Christchurch. The mean wind speed in the TMY weather file was converted from the measurement height of thirty-seven metres to a height of one-hundred and twenty metres. This is because the wind reduction factors calculated in the wind analysis programs calculate the wind reduction factor based on wind at a height of one-hundred and twenty metres above ground level. 


\section{Maximum Wind Speed}

The maximum wind speed, otherwise known as gustiness, cannot be calculated in a wind analysis program and is not included in the TMY weather file. However, a gust co-efficient can be used to calculate the maximum wind speed based on the mean wind speed. The gust co-efficient is represented as a percentage of the relative size of standard deviation to the mean wind speed (Rofail, 2007, p. 4). The gust co-efficient is different in each city, as it is governed by the terrain-roughness within the city (Blocken \& Carmeliet, 2004, p. 111; Walton et al., 2007, p. 3174).

Although some wind analysis programs state that they can calculate the maximum wind speed or gustiness, the definition of maximum wind speed or gustiness may be different. However, it can be calculated from the mean and maximum wind speeds measured within a case study area.

For the case study the gust co-efficient was calculated from the mean and maximum wind speed measured at the case study weather station. Three-second wind data is typically used to calculate the gust co-efficient specific for a location (Groen \& Wever, 2009, p. 20). However, the case study weather station was only able to measure the mean and maximum wind speed for each sixteen-second period. For this reason, the gust co-efficient was calculated based on the hourly data measured at the case study weather station (Jamieson, Carpenter., \& Cenek, 1992, p. 2303; Rofail, 2007, p. 1). The justification of the gust coefficient being calculated using hourly data is that the gust co-efficient was applied to the hourly data in the TMY weather file for Christchurch which reports the data hourly.

Equation 7 is the equation used to calculate the gust co-efficient (Rofail, 2007, p. 4):

$$
g=\frac{\left(U_{\max }\right)-\bar{U}}{\sigma_{u}}
$$

Where:

$g=$ gust co-efficient

$U_{\max }=$ maximum wind gust $(\mathrm{m} / \mathrm{s})$

$\bar{U}=$ average wind speed $(\mathrm{m} / \mathrm{s})$

$\sigma_{u}=$ the standard deviation of a $3 \mathrm{~s}$ average wind speed $(\mathrm{m} / \mathrm{s})$ 
The gust co-efficient was calculated using a linear regression analysis to quantify the relationship between the mean and maximum wind speeds in the case study area. For the case study area, the gust speed can be calculated from the mean wind speed in the TMY weather file using the formula:

$$
\text { Gust }=2.1 \times \bar{U}+0.94 \text {. }
$$

However, before the gust co-efficient was applied to the mean wind speed in the TMY weather file, it was converted to pedestrian height (1.2m) using the power law (Equation 6). The gust co-efficient was then applied to the mean wind speed at pedestrian height. See Appendix 8.1.2. 'Calculating the Gust Co-Efficient' for the linear regression analysis.

\section{Maximum Wind Speed for Outdoor Thermal Comfort}

At an unknown wind speed, no matter what the ambient temperature and solar radiation levels, people will no longer be able to change their behaviour to maintain their thermal comfort. Considerations for this threshold include the length of time people are stationary and their level of activity before they sat down. It also depends on the frequency of wind gusts, the magnitude of the gusts, and the length of time the gust is experienced (Blocken \& Gualtieri, 2012; Bottema, 2000, p. 1; He \& Song, 1999, p. 299; Mochida \& Lun, 2008; Tominaga et al., 2008; Yoshie et al., 2007). It is important that this point where people can no longer change their behaviour to maintain their thermal comfort, is communicated in The Comfort Tool.

A threshold of $5 \mathrm{~m} / \mathrm{s}$ has been set for Christchurch. This is defined on the Extended Land Beaufort Scale as a moderate breeze (Met Office U.K., n.d.). This value is based on previous studies which attempted to understand the maximum comfortable wind speeds for different activities (Table 3.1). In these studies, the threshold generally changed based on the level of activity. For example, for people sitting for a long period, a threshold of 2.4 m/s was set (Willemsen \& Wissse, 2007, p. 1541). Whereas, the general threshold for all activities the threshold is set to $5 \mathrm{~m} / \mathrm{s}$ (Bottema, 2000, p. 6; He \& Song, 1999, p. 299; Willemsen $\&$ Wissse, 2007, p. 1545). The reason $5 \mathrm{~m} / \mathrm{s}$ was selected was because this is the maximum threshold in which people can change their behaviour to maintain their thermal comfort which is applied to all seasons. If this threshold was set lower, then The Comfort 
Tool may identify areas of a case study as too windy for people to maintain their thermal comfort, even when thermal comfort levels can be maintained.

Table 3.1 shows the maximum wind speeds which are thermally comfortable for different activities defined by different studies

\begin{tabular}{|c|c|c|c|}
\hline Author/Study & Activity & $\begin{array}{l}\text { Wind Speeds } \\
\text { (Threshold of } \\
\text { Thermal Comfort) }\end{array}$ & $\begin{array}{l}\text { Extended Land } \\
\text { Beaufort Scale } \\
\text { Description }\end{array}$ \\
\hline $\begin{array}{l}\text { A method for optimisation of wind } \\
\text { discomfort criteria (Bottema, 2000, p. } \\
\text { 2) }\end{array}$ & $\begin{array}{l}\text { Pedestrian } \\
\text { thermal } \\
\text { discomfort }\end{array}$ & $6 \mathrm{~m} / \mathrm{s}$ & Moderate breeze \\
\hline $\begin{array}{l}\text { A method for optimisation of wind } \\
\text { discomfort criteria (Bottema, 2000, p. } \\
\text { 6) }\end{array}$ & All activities & $5 \mathrm{~m} / \mathrm{s}$ & Gentle Breeze \\
\hline $\begin{array}{l}\text { Design for wind comfort in The } \\
\text { Netherlands Procedures, criteria and } \\
\text { open research issues - code NEN 8100 } \\
\text { (Willemsen \& Wissse, 2007, p. 1545) }\end{array}$ & $\begin{array}{l}\text { All activities } \\
\text { (including sitting) }\end{array}$ & $5 \mathrm{~m} / \mathrm{s}$ & Gentle Breeze \\
\hline $\begin{array}{l}\text { Design for wind comfort in The } \\
\text { Netherlands Procedures, criteria and } \\
\text { open research issues (Willemsen \& } \\
\text { Wissse, 2007, p. 1541) }\end{array}$ & $\begin{array}{l}\text { Sitting for a long } \\
\text { period }\end{array}$ & $2.4 \mathrm{~m} / \mathrm{s}$ & Light Breeze \\
\hline $\begin{array}{l}\text { Design for wind comfort in The } \\
\text { Netherlands Procedures, criteria and } \\
\text { open research issues (Willemsen \& } \\
\text { Wissse, 2007, p. 1541) }\end{array}$ & $\begin{array}{l}\text { Sitting for a short } \\
\text { period of time }\end{array}$ & $3.9 \mathrm{~m} / \mathrm{s}$ & Gentle Breeze \\
\hline $\begin{array}{l}\text { Evaluation of pedestrian winds in } \\
\text { urban area by numerical approach } \\
\text { (He \& Song, 1999, p. 299) }\end{array}$ & All activities & $5 \mathrm{~m} / \mathrm{s}$ & Gentle Breeze \\
\hline $\begin{array}{l}\text { Building Research Translation } \\
\text { Discomfort Due to Wind Near } \\
\text { Buildings Aerodynamic Concepts } \\
\text { (Gandemer, 1978, p. 10) }\end{array}$ & All activities & $\overline{\mathrm{U}}+\sigma \leq 6 \mathrm{~m} / \mathrm{s}^{*}$ & $\begin{array}{l}\text { Depending on } \\
\text { activity }\end{array}$ \\
\hline
\end{tabular}


3.2.2. CRITERIA FOR SELECTING WIND ANALYSIS PROGRAMS

In the Process for Predicting Outdoor Thermal Comfort the local wind speeds were calculated at a single point in the development. The local wind speeds were calculated by applying a wind reduction factor for each wind direction to the mean wind speed in the TMY weather file. The wind reduction factors were calculated next to a three-dimensional computer model of a case study using a wind analysis program. However, as part of the development of the Process for Predicting Outdoor Thermal Comfort into The Comfort Tool there needs to be a greater understanding of wind analysis programs, their accuracy, and their ability to calculate wind reduction factors which can easily be used in The Comfort Tool. To achieve this, criteria were developed. These criteria aim to assist consultants and designers in selecting wind analysis programs through the creation of criterion which identify considerations when selecting a wind analysis program.

The criteria was developed through using a number of wind analysis programs to calculate wind in areas surrounding a standard test for testing the accuracy of wind analysis programs and calibrating wind tunnels, known as The Simple City. This process identified where a user of the wind analysis program would be required to make a decision or change a setting. This was then added to the criteria. The criteria includes:

a. Can the three-dimensional model of a proposed development be imported or constructed in the wind analysis program?

b. Is it able to work on Microsoft operating systems?

c. Is it a text based wind analysis program?

d. Can the wind be calculated locally, or is it required to be simulated in the cloud?

e. Can the terrain-roughness be specified?

f. Can the size of the computational domain be changed?

g. Can a numerical solution be selected which is suitable for calculating wind in urban areas?

h. Is the mesh automatically adjusted?

i. Is the convergence calculated to allow for accurate results?

j. Can the wind reduction factor be calculated by the wind analysis program?

k. Can the results be accessed for a specific point? Can they be exported or is this a manual process? 
Each criterion is discussed in detail in the next section.

This criteria is important as the use of wind analysis programs is currently not standard practice within urban planning and architecture. The skills and understanding required for wind analysis programs is not widely taught within universities, and on the occasions when wind analysis programs are used within urban planning and architecture, the skills are often self-taught.

The criteria considers both the ease of operation of a wind analysis program for use within The Comfort Tool, and how easily the wind reduction factors can be copied into The Comfort Tool.

\section{The Standard Test - The Simple City}

The Simple City Test is a standard wind pattern test (Figure 3.5) used for both wind tunnels and wind analysis programs (Jamieson et al., 1992, p. 2302; Yoshie et al., 2007, p. 1562). For this project, the wind tunnel results for The Simple City Test were used to benchmark the results of wind analysis programs. This is because wind tunnel tests are considered the most accurate way of simulating wind patterns (Yoshie et al., 2007, p. 1571). The development and understanding of wind tunnels is also further advanced than wind analysis programs. Although datasets also exist for calibrating wind tunnels which could be used to validate the wind analysis programs, wind analysis programs are more commonly calibrated and validated against wind tunnel data.

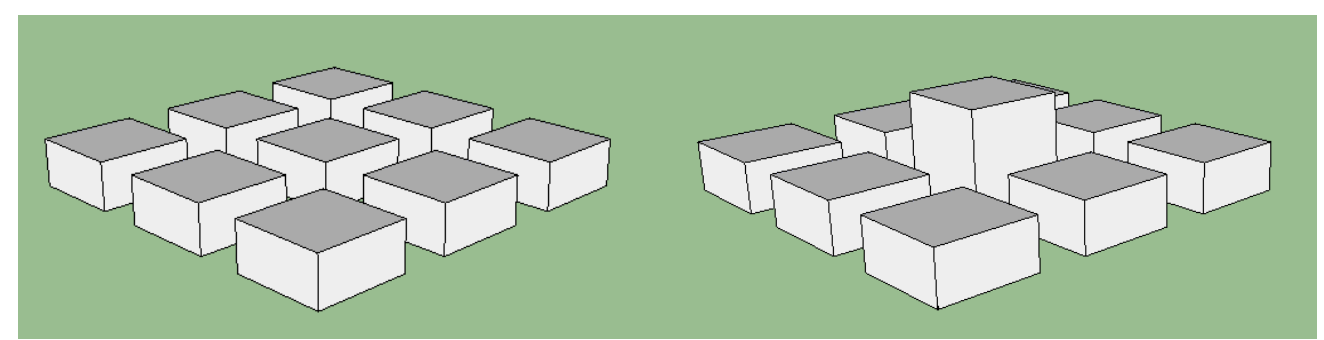

Figure 3.5 shows The Simple City. Left: Uniform Simple City (all city blocks thirty metres in height). Right: Non-uniform Simple City (Central City Block sixty metres in height) 


\section{The Criteria}

A prerequisite of a wind analysis program being tested against the criteria was whether it could calculate the wind reduction factor for a single point within a The Simple City for each wind direction. As discussed earlier, the wind reduction factor determines how a single point within an urban development is sheltered from wind in each direction (Figure 3.4). It is the percentage of the wind at an exposed location, experienced in an urban area.

The criteria is separated into three key parts; Ease of Accessibility of the computer programs, Wind Analysis Program Settings, and the Outputs from the wind analysis program. The criteria is in three parts to assist with the understanding of what considerations are important for each phase of the process for analysing wind.

\section{Criteria Part One: Ease of accessibility}

a) Can the three-dimensional model of a proposed development be imported or constructed in the wind analysis program?

Depending on the wind analysis program, a three-dimensional model of a proposed urban development may be able to be modelled in the wind analysis program or can be imported from a three-dimensional modelling program. One obstacle of this may be the file types. The wind analysis program may only accept particular file types, and a three-dimensional modelling program may only be able to export particular file types - are these compatible?

b) Is it able to work on Microsoft operating systems?

Microsoft Windows is the most commonly used operating system in urban planning and architecture, followed by Macintosh. This is important as some wind analysis programs (for example OpenFOAM) only work on Linux, a less common operating system. 
c) Is it a text based wind analysis program?

Some wind analysis programs are text based, meaning specialist coding skills are required to operate them. This makes them inaccessible to people without these skills, limiting the consultants or designers who can use them.

d) Can the wind be calculated locally, or is it required to be simulated in the cloud? Wind modelling programs can require a large amount of computational resources. The size of the urban area modelled, as well as the number of data points where the wind reduction factor is being calculated determine how long the calculations take. If there is an option for completing the wind analysis in the cloud, then results may be completed in less time, or in more detail.

\section{Criteria Part Two: Wind Analysis Program Settings}

These are the settings for calculating the wind flow (turbulent flow) within urban areas.

e) Can the terrain-roughness be specified?

The terrain-roughness defines the terrain the wind has travelled across from where the wind was measured (TMY weather file) to the location of the case study, and how this reduces wind speed. The terrain-roughness depends on many factors such as the topography and density of a city or if the wind flows across lakes or rivers (Blocken, Janssen, \& Hooff, 2012, p. 16).

For this criterion, it is recommended that the terrain-roughness used in the wind analysis program is the same as the type of topography the wind travels across from the regional weather station where the TMY weather data is collected as the area where a proposed development is located. 
Table 3.2 shows the terrain-roughness which determines the terrain the wind has travelled over between the regional weather station and the site where a case study is located.

\begin{tabular}{l|l}
\hline \multicolumn{1}{c|}{ Terrain Category } & \multicolumn{1}{c}{ Terrain-roughness ( $\alpha$ ) } \\
\hline Terrain between a lake and a plain (Gandemer \& & $\alpha=0.14$ \\
Guyot, 1976, p. 20). & \\
\hline Terrain between a forest and a suburb (Gandemer \& & $\alpha=0.25$ \\
Guyot, 1976, p. 20). & \\
\hline Low density city - buildings and trees are small and & $\alpha=0.35-0.5$ \\
widely spaced (Grimmond \& Oke, n.d., p. 1283). & \\
\hline Medium density city - Buildings are between two & $\alpha=0.55-0.7$ \\
and four storeys, there are mature trees (Grimmond & \\
\& Oke, n.d., p. 1283). & \\
\hline High density city - Buildings and trees are close & $\alpha=0.6-0.85$ \\
together and are of similar heights (Grimmond \& \\
Oke, n.d., p. 1283).
\end{tabular}

f) Can the size of the computational domain be changed?

The computational domain contains a building or proposed development for the wind reduction factors to be calculated around (Figure 3.6). It should be large to avoid artificial accelerations of the wind flow (Blocken et al., 2012, p. 18). The height of the computational domain should be at least five times the height of the tallest building, and ten times the height in front and behind the site or building where the wind is being assessed (Tominaga et al., 2008, p. 1751). In some wind analysis programs this computational domain is automatic. However, it is important that the automatic computational domain is adjusted to be the recommended size (five times the height of the tallest building, and ten times the height in front and behind). 


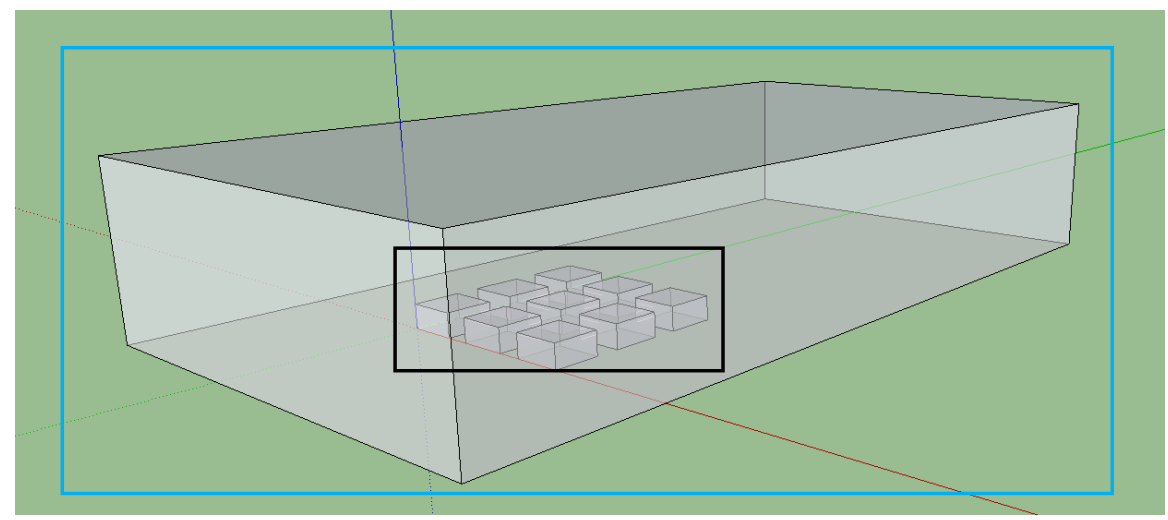

Figure 3.6 shows the computational domain (blue) around The Simple City (black)

g) Can a numerical solution be selected which is suitable for calculating wind in urban areas?

The fundamental equations for fluid motion have been known since the 19th century which can be solved using a number of numerical solutions (Blocken \& Gualtieri, 2012, p. 1). These numerical solutions attempt to solve the fundamental equation. However, numerical solutions can be suited to different applications and involve different levels of computer intensity. For example, calculating wind around a building would use a different numerical solution than calculating air or fluid flow through a heating, ventilation, and air conditioning system. The numerical solutions required for calculating wind patterns in an urban area are classed as part of Environmental Fluid Mechanics (EFM). In EFM, the numerical solutions are attempting to solve turbulence flows, meaning that the flows (the wind) have irregular fluctuations with their magnitude and direction. There are three main numerical solutions for solving these turbulent flows, Direct Numerical Simulation (DNS), Large Eddy Simulation (LES), and Reynolds-Averaged Navier Stokes (RANS) (Blocken \& Gualtieri, 2012, p. 3).

Direct Numerical Simulation (DNS) solves the exact Navier-Stokes equation in detail. However, due to the level of detail it is computationally demanding. Therefore, less detailed Navier-Stokes equations are more suitable for the application of simulating wind in urban areas. 
Large Eddy Simulation (LES) resolves only the large turbulence flows to reduce the computational intensity. However, the smaller turbulent flows are still estimated. This reduces the computational intensity, although can still be computationally intensive (Yoshie et al., 2007, p. 1577). Therefore, is only suited when the computational power is available (Mochida \& Lun, 2008, p. 1520).

Reynolds-Averaged Navier Stokes (RANS) only calculates the average flow of wind at the different levels of turbulence. This is less computationally intensive as it still includes the smaller turbulent flows. RANS models, such as the $k$-epsilon $(k-\varepsilon)$ model are commonly used for solving turbulent flows in urban areas (Blocken et al., 2012, p. 17; Fadl \& Karadelis, n.d., p. 367; Tominaga et al., 2008, p. 1750). There are a number of variations of this model, including the standard $k$-epsilon $(k-\varepsilon)$ model, modified $k$-epsilon (modified $k$ - $\varepsilon$ ) model or the Differential SecondMoment (Reynolds-stress) turbulence model. The modified $k$ - $\varepsilon$ model gives more accurate results when higher wind speeds are calculated. However, the accuracy is less in areas with lower wind speeds. It is the most commonly used numerical solution for calculating wind in urban areas (Blocken \& Gualtieri, 2012; Fadl \& Karadelis, n.d., p. 367; Franke et al., 2004).

For this criterion, it is recommend that a RANS model is used, such as the $k-$ epsilon model, as it requires less computational power than the other numerical solutions, while still producing accurate results. 
h) Is the mesh automatically adjusted?

The accuracy of the results across an urban development depends on the detail of the analysis (Franke et al., 2004, p. 7). This can be referred to as the mesh resolution (Figure 3.7). The mesh is a series of shapes over the surface of a building, which the numerical solution is calculated across. There needs to be a balance with mesh resolution, as the finer the mesh the more detailed the results, however, this increases the computational period. Some wind analysis programs allow for a combination of mesh size. For example, where wind patterns are more complex around corners, a more detailed mesh may be applied.
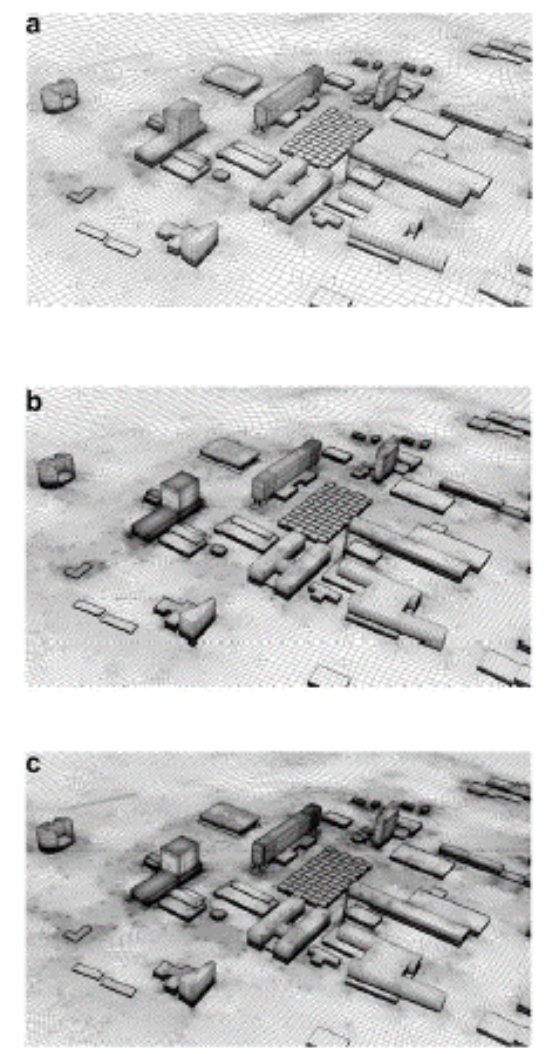

Figure 3.7 show a demonstration of mesh or mesh resolution. Top: Coarse mesh. Middle: Medium mesh. Bottom: Fine mesh (Blocken et al., 2012, p. 27) .

The mesh resolution recommend for resolving the numerical solution for wind in urban areas varies between studies. However, the mesh is generally recommended to be between a coarse and medium mesh for urban applications (Blocken et al., 2012, p. 27; Franke et al., 2004, p. 4).

For this criterion, it is recommended that the sensitivity of the mesh is tested. Each wind analysis program may apply mesh differently, so a mesh size cannot be defined. However, testing the sensitivities of the mesh can define the detail of the mesh (Tominaga et al., 2008, p. 1753). Once a reduction in mesh size only results in a slight change in wind reduction factors (less than $1 \%$ ), then the mesh is the correct coarseness for the application. 
i) Is the convergence calculated to allow for accurate results?

The convergence of a wind analysis program tells the user if the numerical solution has been resolved. Wind modelling programs repeat a numerical solution until further iterations do not improve the wind reduction factors. Depending on the wind analysis program, the number of iterations may be automatically set to infinite; whereas, in others the number of iterations has to be set. It is important that the number of iterations is high so that the numerical solution can be resolved before the wind analysis program stops running any further iterations.

\section{Criteria Part Three: Outputs}

j) Can the wind reduction factor be calculated by the wind analysis program? The wind reduction factor can either be an automatic output from a wind analysis program, or it may be calculated manually based on the reference wind speed. The reference wind speed is the wind entering the computational domain based on the terrain-roughness co-efficient. The wind speed measured at specified points within a proposed urban development is then divided by the reference wind speed. For example, if the wind speed calculated by the wind analysis program is $2 \mathrm{~m} / \mathrm{s}$, and the reference wind speed is $10 \mathrm{~m} / \mathrm{s}$, then the wind reduction factor is twentypercent.

k) Can the results be accessed for a specific point?

It is important that the wind reduction factor for a single point within a proposed development can be generated as a numerical value, rather than only an image (Blocken \& Carmeliet, 2004, p. 122). As wind reduction factors may be calculated for a series of points across a proposed urban development, it is important that these results can be accessed or even exported in a file to make the process of putting the wind reduction factors for each measurement point into The Comfort Tool less time consuming. 
Identifying the Usefulness and Accuracy of Wind Analysis Programs

Once the criteria was complete, three wind modelling programs were tested against it, using a three-dimensional model of The Simple City as the urban form the wind reduction factors were calculated around. This had three purposes. These were to use the criteria to select a wind analysis program for calculating wind reduction factors in an urban application; to identify if the wind modelling programs were able to produce results that could be used in The Comfort Tool; and to test the accuracy of these wind modelling programs.

Initial exploration identified six wind analysis programs which could be tested against the criteria. However, three of the programs did not meet the prerequisites of being able to calculate the wind reduction factors for each wind direction at a specified point. Two of the programs were not able to calculate the wind reduction factor for each wind direction at a single point within the areas surrounding The Simple City, and one of the programs could not be installed. For these reasons, these three programs were excluded from this thesis project.

The results of testing the three remaining wind analysis programs against the criteria are below. The results of the accuracy based on The Simple City Test are in Section 3.2.2 'Criteria for Selecting Wind Analysis Programs'. 


\section{Wind Analysis Program One: UrbaWind}

\section{UbaWind is a wind analysis program developed by Meteodyn specifically for modelling}

flows in an urban environment. It is able to calculate the wind reduction factor for each

wind direction. It has been validated against wind tunnel testing and on-site

measurements (U.S. Department of Energy, 2011).

\begin{tabular}{|c|c|}
\hline \multicolumn{2}{|c|}{ a) Can the geometry of a proposed urban development be imported or constructed? } \\
\hline Yes & $\begin{array}{l}\text { The geometry can be imported as an STL file, which can be created in a three-dimensional } \\
\text { modelling program such as SketchUp. }\end{array}$ \\
\hline \multicolumn{2}{|c|}{ b) Is it able to operate on Microsoft Windows operating system? } \\
\hline Yes & Microsoft only. \\
\hline \multicolumn{2}{|c|}{ c) Is it a text based program? } \\
\hline No & It has a dashboard interface. \\
\hline \multicolumn{2}{|c|}{ d) Can the wind be calculated locally, or is it required to be simulated in the cloud? } \\
\hline Yes, both & Locally or in the cloud. \\
\hline \multicolumn{2}{|c|}{ e) Can the terrain-roughness be specified? } \\
\hline Yes & $\begin{array}{l}\text { The terrain-roughness can be set for a high density city, small density city, water, or the open } \\
\text { country. A file can also be imported which allows for different terrain-roughness' in each } \\
\text { direction of a case study. }\end{array}$ \\
\hline \multicolumn{2}{|c|}{ f) Can the size of the computational domain be changed? } \\
\hline Yes & $\begin{array}{l}\text { The automatic computational domain is } 120 \mathrm{~m} \text { in height, and has approximately } 90 \mathrm{~m} \text { in each } \\
\text { direction between the site of the proposed urban development being assessed and where } \\
\text { wind enters the computational domain. }\end{array}$ \\
\hline \multicolumn{2}{|c|}{ g) Can a numerical solution be selected which is suitable for calculating wind in urban area? } \\
\hline No & $\begin{array}{l}\text { The numerical solution considers the relationship between wind changes and the mean wind } \\
\text { speed gradients, similar to the k- } \varepsilon \text { model ('Meteodyn } \mathrm{FAO}^{\prime}, 2010 \text { ). Although it is not an } \\
\text { exact specified numerical model, it is trusted due to the results of The Simple City Test for } \\
\text { UrbaWind and the wind tunnel tests being similar. }\end{array}$ \\
\hline \multicolumn{2}{|c|}{ h) Is the mesh automatically adjusted? } \\
\hline Yes & $\begin{array}{l}\text { The mesh is generated with refinement near ground level and around buildings } \\
\text { automatically. The number of mesh cells is directly proportional to the amount of memory } \\
\text { space on the computer available. As the mesh is calculated for the whole computational } \\
\text { domain, it is important that the computational domain is not too large as the detail of the } \\
\text { mesh may be reduced to adapt to the memory on the computer. This may lead to the results } \\
\text { not being as detailed as they could have been. }\end{array}$ \\
\hline \multicolumn{2}{|c|}{ i) Is convergence calculated to allow for accurate results? } \\
\hline Yes & $\begin{array}{l}\text { The iterations continue until convergence is met. Where there are some uncertainties, in } \\
\text { covergence UrbaWind highlights the wind directions which did not reach } 100 \% \text { convergence. } \\
\text { This allows for these wind directions to be calculated again. }\end{array}$ \\
\hline \multicolumn{2}{|c|}{ j) Can the wind reduction factor be calculated by the wind analysis program? } \\
\hline Yes & The wind reduction factor is the direct output for UrbaWind. \\
\hline \multicolumn{2}{|c|}{ k) Can the results be accessed for a specific point? } \\
\hline Yes & $\begin{array}{l}\text { The results can be accessed for a specific point, and exported as a comma-separated values } \\
\text { (CSV) file. This allows for the wind reduction factors for each wind direction to be easily } \\
\text { copied into The Comfort Tool. }\end{array}$ \\
\hline
\end{tabular}




\section{Wind Analysis Program Two: Simulation CFD - By Autodesk}

Simulation CFD is a multiple-use general application fluid and air analysis program

(Autodesk, 2015). It has not been designed specifically for calculating wind in urban areas.

The mean wind speed is able to be measured at specified points throughout an urban area,

which can then be used to calculate the wind reduction factor. At the time wind analysis

programs were assessed against the criteria, Simulation CFD had not been validated.

a) Can the geometry of a proposed urban development be imported or constructed?

\begin{tabular}{l|l} 
Yes & Geometry can be constructed in Revit or through Autodesk Inventor and opened directly into
\end{tabular} Simulation CFD.

b) Is it able to operate on Microsoft Windows operating system?

\begin{tabular}{l|l}
\hline Yes & It is also able to operate on a Macintosh operating system. \\
\hline
\end{tabular}

c) Is it a text based program?

\begin{tabular}{l|l} 
No & It has a dashboard interface.
\end{tabular}

d) Can the wind be calculated locally, or is it required to be simulated in the cloud?

\begin{tabular}{l|l}
\hline Yes & Simulations can either be completed locally or in the cloud.
\end{tabular}

e) Can the terrain-roughness be specified?

\begin{tabular}{l|l}
\hline No & This is not a setting in Simulation CFD.
\end{tabular}

f) Can the size of the computational domain be changed?

Yes $\quad$ The computational domain is not automatic in Simulation CFD. However, the computational domain can be created manually. The computational domain is known as an 'exterior volume' in Simulation CFD. One end of the exterior volume has to be set as the boundary inlet, and the opposite end needs to be set as a pressure outlet (set as zero pressure to act as the boundary outlet).

g) Can a numerical solution be selected which is suitable for calculating wind in urban areas?

\begin{tabular}{l|l} 
Yes & The $k-\varepsilon$ numerical solution is included.
\end{tabular}

h) Is the mesh automatically adjusted?

\begin{tabular}{l|l} 
Yes & Mesh generation is automatic. The user is also able to manually refine the mesh in areas
\end{tabular} where the wind patterns may be more complex, such as the corners of buildings.

i) Is convergence calculated to allow for accurate results?

\begin{tabular}{l|l}
\hline Yes & The number of iterations is set manually. This means that the number of iterations is set too
\end{tabular} low, then the wind flows in areas surrounding a proposed development might not be fully calculated before the wind analysis program stops.

\begin{tabular}{l|l}
\hline j) Can the wind reduction factor be calculated by the wind analysis program? \\
\hline Yes & $\begin{array}{l}\text { The wind reduction factor is not a direct output. However, when assessing Simulation CFD } \\
\text { against the criteria the wind speed was set to } 10 \mathrm{~m} / \mathrm{s} \text { at a height of } 120 \mathrm{~m} \text { as this is the same } \\
\text { wind scenario which was used in the wind tunnel tests. The wind speeds (m/s) calculated by } \\
\text { Simulation CFD were then divided by } 10 \mathrm{~m} / \mathrm{s} \text { to calculate the wind reduction factor. }\end{array}$ \\
\hline k) Can the wind reduction factors be accessed for a specific point? \\
\hline Yes & $\begin{array}{l}\text { The results can be accessed through manually selecting a point for the wind speeds to be } \\
\text { displayed. }\end{array}$ \\
\hline
\end{tabular}




\section{Flow Design by Autodesk - Plugin for Revit}

Flow design is a virtual wind tunnel which is able to simulate wind flows around buildings. It is designed as a user-friendly wind analysis program for people who do not have experience with wind analysis programs. There are two versions, a plugin for Revit, and a standalone version. However, only the plugin for Revit is able to calculate the wind reduction factor for a specified point for each wind direction. It works through Revit, a three-dimensional CAD program used within urban planning and architecture. At the time the wind analysis programs were assessed against the criteria, validation for Flow Design had only been completed through a comparison with another wind analysis program. This concluded that Flow Design is able to simulate wind patterns in a similar way to Fluent ('Flow Design Preliminary Validation Brief', 2014, p. 6).

a) Can the geometry of a proposed urban development be imported or constructed?

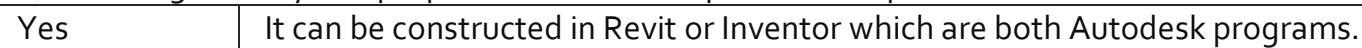

b) Is it able to operate on a Windows operating system?

\begin{tabular}{l|l}
\hline Yes & Yes, as well as Macintosh. \\
\hline
\end{tabular}

c) Is it text based?

\begin{tabular}{l|l} 
No & It has a dashboard interface.
\end{tabular}

d) Can the wind be calculated locally, or is it required to be simulated in the cloud?

\begin{tabular}{l|l} 
Yes, both & Simulations can be either completed locally or in the cloud
\end{tabular}

e) Can the terrain-roughness be specified?

No $\quad$ The terrain-roughness cannot be set. However, the boundary conditions can manually be set. The automatic boundary conditions are uniform and do not take into account the wind travelling across terrain before it reaches The Simple City at a height of $120 \mathrm{~m}$ before it enters the computational domain. However, these can be manually calculated using the power law. f) Can the size of the computational domain be changed?

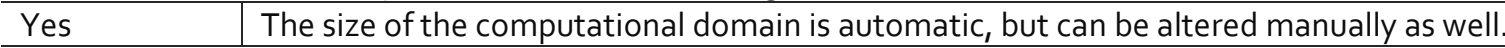

g) Can a numerical solution be selected which is suitable for calculating wind in urban environments?

\begin{tabular}{l|l} 
Yes & The numerical solution used is a simplified version of Smagorinsky Large Eddy Simulation
\end{tabular} (LES). It has been adapted to be more tolerable to geometry to increase the ease of using the program and simulating wind fast. However, it is unknown in which way the numerical solution was simplified.

h) Is the mesh automatically adjusted?

\begin{tabular}{l|l}
\hline No & The mesh can be applied and adjusted manually to be as coarse or fine as required. \\
\hline j) Is convergence calculated to allow for accurate results? \\
\hline Yes & $\begin{array}{l}\text { The user is notified once the model has stabilised. However, it is unknown how Flow Design } \\
\text { determines that the results have stabilised. }\end{array}$
\end{tabular}

k) Can the wind reduction factor be calculated by the wind analysis program?

\begin{tabular}{l|l} 
Yes & Although the wind reduction factor is not directly calculated by Flow Design, it can be
\end{tabular} calculated by setting the wind speed to $10 \mathrm{~m} / \mathrm{s}$ (to align with the wind tunnel test results for The Simple City), the dividing the calculated wind speed by $10 \mathrm{~m} / \mathrm{s}$ to calculate the wind shelter factor.

l) Can the results be accessed for a specific point?

\begin{tabular}{l|l} 
Yes & They can be accessed for a specified point by manually selecting the point. These results
\end{tabular} cannot be exported. 
Through testing these three wind analysis programs it was found that criteria could be developed for selecting a wind analysis program. It was able to highlight the strengths and weaknesses of each program. Out of the three wind analysis programs tested, UrbaWind was able to meet most of the requirements of a wind analysis program set by the criteria. As the angle of the wind in Simulation CFD is a manual process through the threedimensional modelling program, it would be time consuming to use this for calculating the wind reduction factors for eight wind directions. Therefore, UrbaWind and Flow Design have the most potential for calculating the wind reduction factors for The Comfort Tool, depending on their accuracy. The next section compares these programs for their accuracy against wind tunnel test results. 


\section{Testing the Accuracy of the Wind Modelling Programs}

The Simple City Test was used to test the accuracy of these three wind analysis programs. It was selected as it was a standard test which could be conducted in each of the programs. The results were compared to The Simple City results for the wind tunnel tests as they are considered the most accurate way of calculating wind in urban areas (Fadl \& Karadelis, n.d., p. 363; Reiter, 2010, p. 858; Tominaga et al., 2008, p. 1756). The Simple City Test was also selected as the wind tunnel results for The Simple City are available to compare the wind analysis program results.

The Simple City has two variations. The Uniform Simple City has nine city blocks, each sixty-by-sixty metres, which are thirty metres in height (Figure 3.5). There are thirty metre wide roads between each city block. Whereas, the Non-uniform Simple City's central block is sixty metres in height (Jamieson et al., 1992, p. 2302; Kepa, 2010, p. 49; Yoshie et al., 2007, p. 1553).

To allow for the results of the wind modelling programs to be compared against the wind tunnel results, the height where the wind entered the computational domain; the wind speed and angles; and the terrain-roughness had to align between the wind analysis programs and wind tunnel tests for The Simple City. This was so that the wind reduction factors generated by each program were based on the same assumptions as the wind tunnel test, allowing for the wind reduction factors to be comparable (Table 3.3).

Table 3.3 shows how the wind tunnel and wind analysis program settings were aligned so the results are comparable

\begin{tabular}{l|c|c|c|c}
\hline & Wind Tunnel & UrbaWind & Flow Design - Revit & Simulation CFD \\
\hline Wind Speed & $10 \mathrm{~m} / \mathrm{s}$ & $\mathrm{n} / \mathrm{a}$ & $10 \mathrm{~m} / \mathrm{s}$ & $120 \mathrm{~m} / \mathrm{s}$ \\
\hline $\begin{array}{l}\text { Inlet Boundary } \\
\text { Conditions Height }\end{array}$ & $120 \mathrm{~m}$ & $120 \mathrm{~m}$ & $120 \mathrm{~m}$ \\
\hline $\begin{array}{l}\text { Wind Angles } \\
\text { Tested }\end{array}$ & $\begin{array}{c}360^{\circ} \text { (North) } \\
45^{\circ} \text { (North-east) }\end{array}$ & $\begin{array}{c}360^{\circ} \text { (North) } \\
45^{\circ} \text { (North-east) }\end{array}$ & $\begin{array}{c}360^{\circ} \text { (North) } \\
45^{\circ} \text { (North-east) }\end{array}$ & $360^{\circ}$ (North) \\
\hline $\begin{array}{l}\text { Height wind } \\
\text { reduction factor } \\
\text { was measured from } \\
\text { street level }\end{array}$ & Two metres & Two metres & Two metres & Two metres \\
\hline $\begin{array}{l}\text { Terrain-roughness } \\
\text { (small density } \\
\text { city) }\end{array}$ & $\begin{array}{c}\text { (small density city) } \\
\text { (s) }\end{array}$ & $\begin{array}{c}\text { Power law (using } \\
\text { terrain-roughness) } \\
\text { the boundary } \\
\text { conditions }\end{array}$ & $\begin{array}{c}\text { Not a setting in } \\
\text { Simulation CFD }\end{array}$ \\
\hline
\end{tabular}




\section{Results of Simple City Tests}

The wind reduction factors were calculated in sixteen locations within The Simple City for each wind modelling program. There was a total of sixteen measurement points, eight were one metre from the Central City Block, and eight were in the centre of the roads between the Central City Block, and the Outer City Blocks (Figure 3.8).

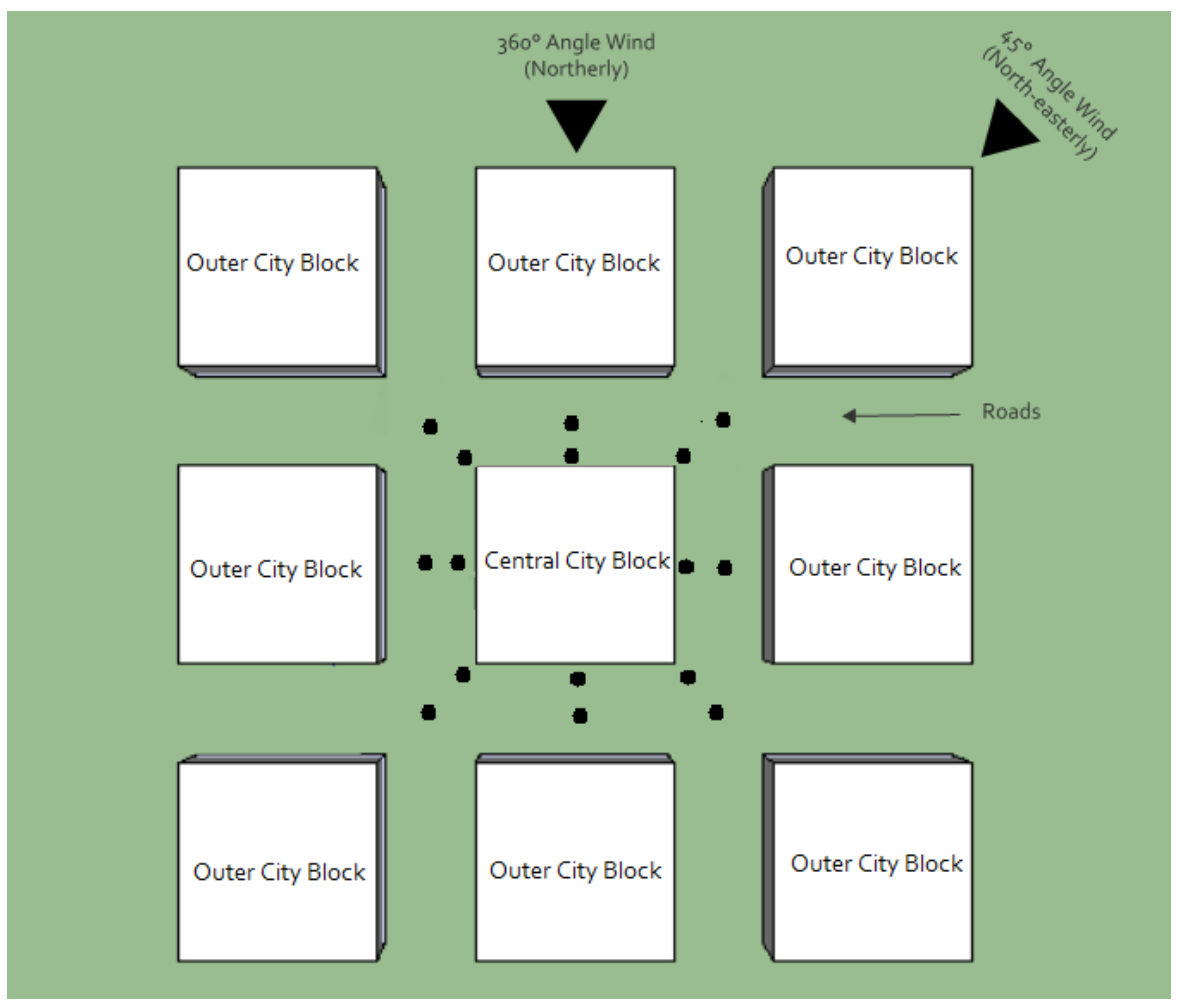

Figure 3.8 shows the sixteen measurement points. The eight were one metre from the base of the Central City Block. The other eight were fifteen metres from the Central City Block.

Once a wind analysis programs had been compared against the criteria, it was then used to calculate the wind reduction factors for each of the sixteen points around the Central City Block in The Simple City. These wind reduction factors were then compared to the results of the wind tunnel tests for the same sixteen points in The Simple City (Figure 3.8). This allowed for the accuracy of the wind analysis programs to be tested. 


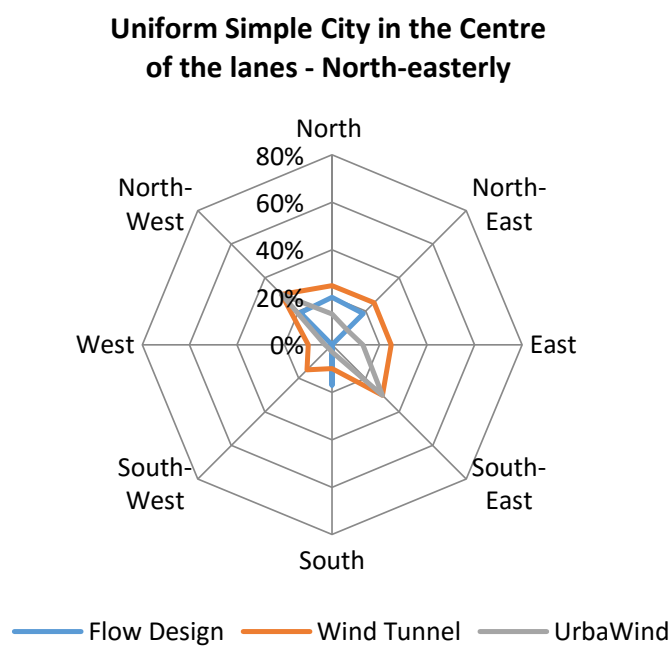

Figure 3.9 shows that Flow Design (blue) pattern is symmetrical. However, does not align with the wind tunnel test results (orange). UrbaWind (grey) follows the wind tunnel test results the most closely. However, there is a still ten percent difference in their wind reduction factors.
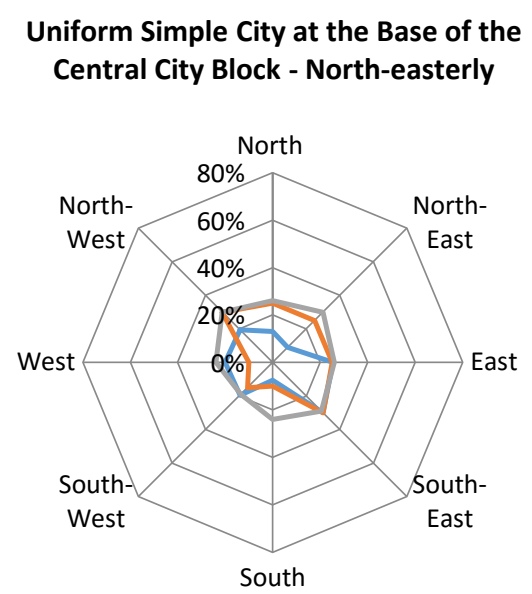

Flow Design —Wind Tunnel UrbaWind

Figure 3.10 shows the wind tunnel test results (orange) and the UrbaWind (grey) results follow a similar pattern between the Northwest to the South-east directions when the wind is from a North-easterly direction.

For the wind reduction factors measured centrally in the lanes (Figure 3.9) from a Northeasterly direction Flow Design (blue) and UrbaWind (grey) did not follow a similar pattern. The wind tunnel (orange) results were similar in all wind directions (between twentypercent and thirty-percent), with a slightly lower wind reduction factor calculated in the West and South directions. Urbawind followed the wind tunnel tests the most closely.

Figure 3.10 shows the wind tunnel test results (orange) for the eight points around the Central City Block, and the UrbaWind results (grey). Between the North-west and Southeast direction, the shelter factors for UrbaWind and the wind tunnel tests were similar, calculating the wind reduction factors as thirty-percent of the wind speed at an exposed location at the height of 120 metres. However, for points in the West and South, the wind tunnel calculated smaller wind reduction factors than UrbaWind. Flow Design (blue) did not follow a similar pattern to UrbaWind or the Wind Tunnel Tests. Simulation CFD was unable to calculate the shelter factors for a North-easterly direction ( $45^{\circ}$ degree angle) without manually changing the angle in the geometry modelling program. 
Results for Uniform Simple City- Northerly

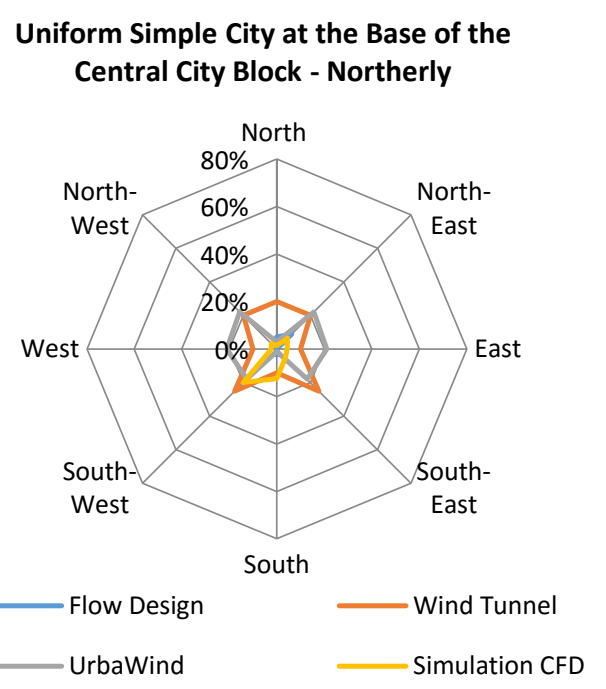

Figure 3.11 shows that the wind tunnel test results (orange) and UrbaWind (grey) do not follow a similar pattern in a Northerly wind. Simulation CFD (yellow) and Flow Design (blue) patterns are not symmetrical, which suggests that they are not taking into account the built form's effect on the wind.

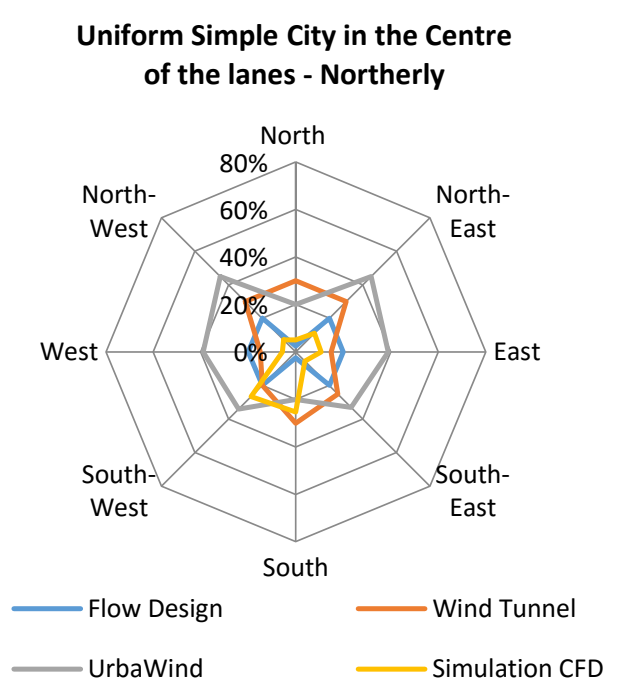

Figure 3.12 shows that none of the wind analysis programs followed a similar pattern as the wind analysis program. UrbaWind (grey) and Flow Design follow a similar pattern.

When the wind was at a Northerly $\left(360^{\circ}\right.$ angle), none of the wind analysis programs followed the same patterns as the wind tunnel tests for the measurement points taken at the base of the Central City Block (Figure 3.11). The wind tunnel tests (orange) had a twenty-percent wind reduction factor for the points in the North-West, North, and NorthEast directions, and a ten-percent wind reduction factor at the points in the East, South and West directions. However, the UrbaWind (grey) results were indicating a twenty-percent wind reduction at the points in all directions except for the North and South which had wind reduction factors of zero. Despite the results being different between the UrbaWind and wind tunnel tests, the results were still symmetrical this indicates that the city blocks were taken into account in the calculation of the wind reduction factors. Simulation CFD (yellow) and Flow Design (blue) did not follow any similar patterns with the wind tunnel tests. UrbaWind was more familiar to the user in these tests than the other wind analysis programs as it had been used in the development of the Process for Predicting Outdoor Thermal Comfort. 


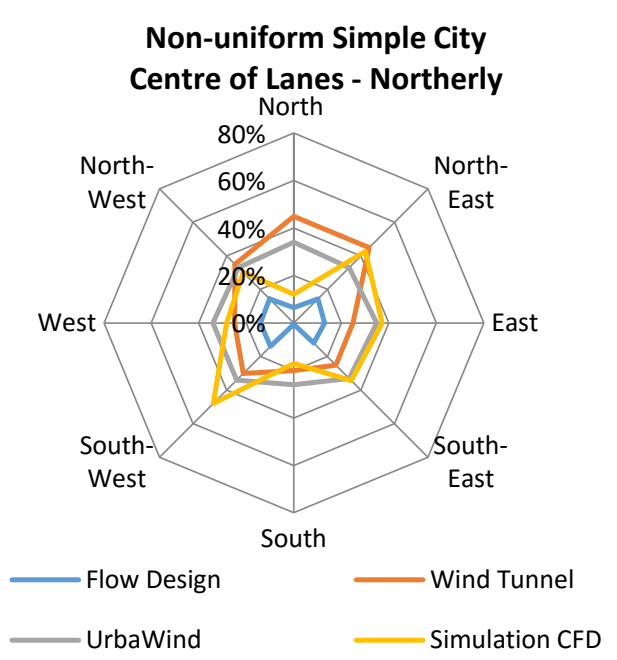

Figure 3.13 shows the wind reduction factors for the Non-uniform Simple City. None of the wind analysis programs follow the same pattern as the wind tunnel tests. However, there is only a twenty-percent difference in wind reduction factors.

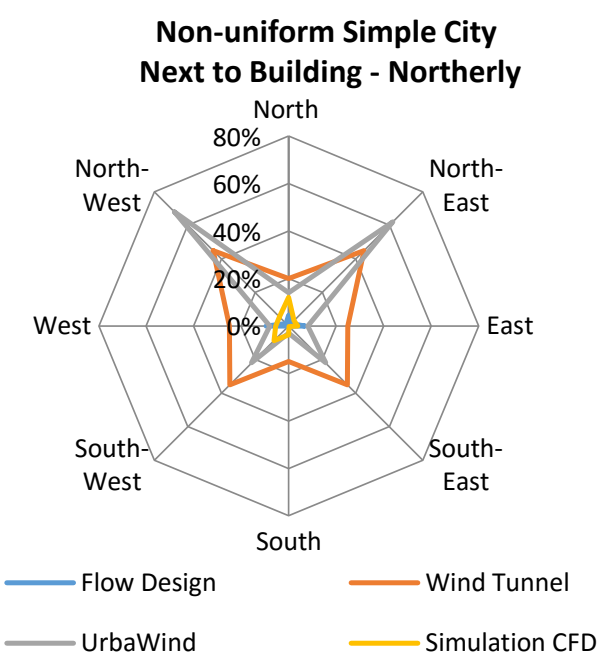

Figure 3.14 shows the wind reduction factors for the Non- uniform Simple City. Although UrbaWind (grey) and the wind tunnel tests (orange) follow a similar pattern, there is still a forty-percent difference in the wind reduction factors.

For the Non-uniform Simple City Flow Design (blue) and UrbaWind (grey) had symmetrical results in the centre of the laneways for a Northerly wind when the Central City Block was twice the height of the surrounding blocks (Figure 3.13). For these wind tunnel test results, they were not symmetrical (orange). Simulation CFD's results (yellow) were more similar than The Simple City when all city blocks were the same height. However, did not follow the same pattern as the wind tunnel results. The UrbaWind (grey), Simulation CFD (yellow) and the wind tunnel results (orange) calculated different wind reduction factors. However, the difference between these wind reduction factors was less than twenty-percent for the majority of the measurement points.

When the measurement points were at the base of the Central City Block for a Northerly wind $\left(360^{\circ}\right)$ UrbaWind (grey) and the wind tunnel tests (orange) had the most similar shelter factors (Figure 3.14). However, there was a large difference in the wind reduction factors for some wind directions. In the North-westerly direction, and the North-easterly direction the shelter factors for UrbaWind were seventy-percent of the wind measured at an exposed location. Whereas, the wind tunnel results were only thirty percent of the wind. 


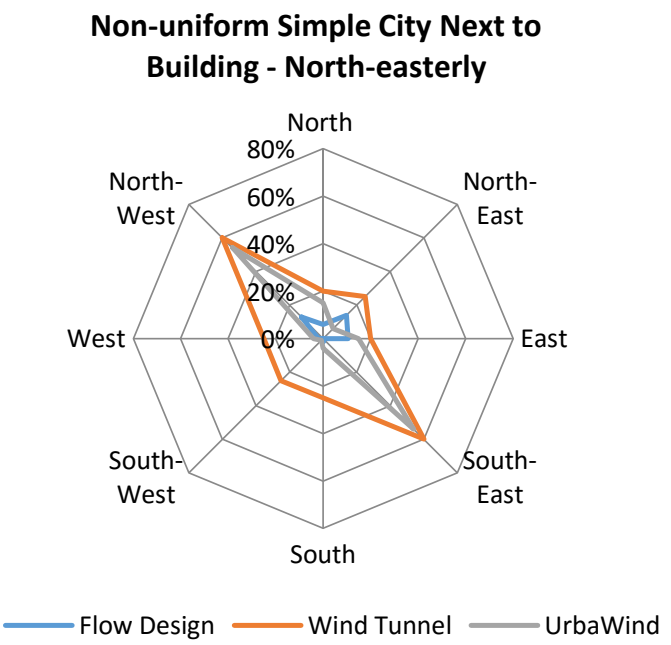

Figure 3.15 shows UrbaWind and the wind tunnel test results followed a similar pattern with the greatest difference in wind reduction factors of twenty-percent in the South-east and North-west directions.

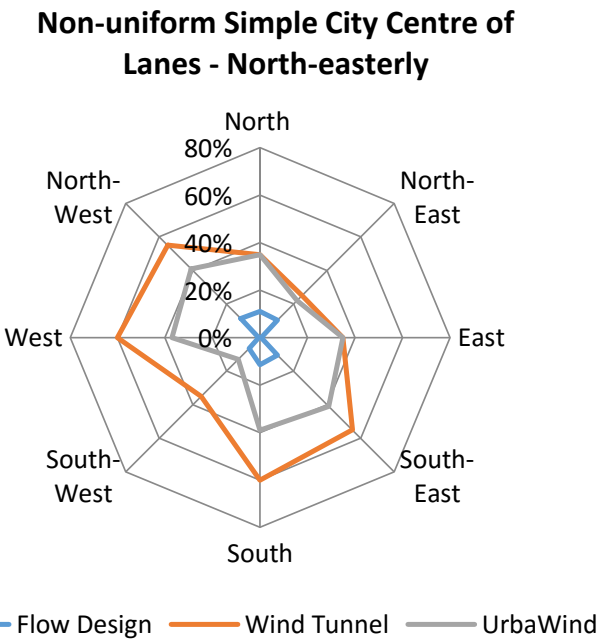

Figure 3.16 shows that UrbaWind and the wind tunnel tests follow a similar pattern. There is a difference of twenty-percent in wind reduction factors in the West and South directions.

When the wind reduction factors were calculated for a North-easterly wind at the base of the Central City Block the wind tunnel results (orange) and UrbaWind (grey) followed a similar pattern (Figure 3.15). The greatest difference between the wind reduction factors was a twenty-percent difference. Flow Design (blue) did not follow the pattern of the wind tunnel results.

When the wind reduction factors were calculated for the Non-uniform Simple City in the centre of the lanes the wind reduction factors for Urabwind (grey) and the wind tunnel results (orange) followed a similar pattern (Figure 3.16). At the most there was a twentypercent difference in wind reduction factors in the West and the South directions. 
This concluded that the wind reduction factors measured in UrbaWind followed the wind reduction factors from the wind tunnel results the most closely. Flow Design's results were symmetrical when the measurement points were located centrally in the lanes. However, when the wind reduction factors were calculated at the base of the Central City Block, the wind reduction factors did not follow a pattern, and were not symmetrical. The wind direction was not able to be changed in Simulation CFD to a $45^{\circ}$ angle (Northerly), so it was only tested for calculating the wind reduction factors for a Northerly wind $\left(360^{\circ}\right)$.

This exercise also identified that although there are a number of wind assessment programs available to people within urban planning and architecture, it is important that their accuracy is tested using a standard test.

The wind analysis program selected is independent of The Comfort Tool. However, a wind analysis program is still part of the process for using The Comfort Tool. For this reason, the wind tunnel test results are included in Appendix 8.1.1. 'Simple City Test Results for Assessing Wind Analysis Programs for their Accuracy'. This allows for consultants and designers to select a wind analysis program that is available to them, and test it for its accuracy. 
3.2.3. SELECTING SOLAR RADIATION PROGRAMS

EnergyPlus was used to demonstrate how a computer program for calculating solar radiation would be used as part of The Comfort Tool. It has been selected as it is able to calculate the solar radiation $\left(\mathrm{W} / \mathrm{m}^{2}\right)$ for selected measurement points across a case study, and export the solar radiation levels for each hour of the year to a comma separated values (CSV) file. This CSV file allows the results to easily be copied into The Comfort Tool using excel.

EnergyPlus has been validated against the International Energy Agency's Building Energy Simulation Test (BESTEST). This is a standard test developed between the International Energy Agency Solar Cooling and Heating Programme Implementing Agreement (IEA SHC) and the American Society of Heating, Refrigerating and Air-Conditioning Engineers to test building simulation programs for their accuracy ('DOE Sponsored Tools - Building Energy Simulation Test (BESTEST)', 2011).

Only one program for calculating solar radiation was used as the calculations are less complex than wind analysis programs as they are simply calculating where a threedimensional model of a building will cast a shadow based on the TMY weather file, and the longitude and latitude which determines when the sun will rise and set for each day of the year.

Although there are not many programs available for calculating solar radiation, the practice is more common within urban planning and architecture than wind analysis programs. However, when selecting a computer program for calculating solar radiation it must be acknowledged that many CAD programs are only able to illustrate the time that an area may be in the direct sunlight, rather than the actual solar radiation.

When selecting a program for calculating solar radiation, it is important that it is able to calculate the solar radiation at a selected point within a development for each hour of the year. It is also important that the solar radiation calculated can be exported, or easily copied into The Comfort Tool. This is because there may be solar radiation calculations for each hour of the year for hundreds of measurement points across a case study. 


\subsection{CAN THERMAL COMFORT BE AUTOMATICALLY COMMUNICATED ACROSS A DEVELOPMENT?}

This section develops a way of automating the Process for Predicting Outdoor Thermal Comfort for a single point in a development to calculate thermal comfort across a proposed development. This will allow for the thermal comfort results to be calculated and communicated automatically.

For thermal comfort to be calculated for a number of points across a development, solar radiation and wind also had to be calculated at each of these points. The closer together these points were located, the more detailed the analysis. However, due to the limitations of the computer programs, the measurement points could not be closer than ten metres together.

UrbaWind was selected as the wind analysis program used as a demonstration of a wind analysis program being used in conjunction with The Comfort Tool. It was selected as the shelter factors calculated in UrbaWind using The Simple City test were the closest to the wind tunnel results for The Simple City Test.

Although UrbaWind could calculate the wind reduction factors at more than 121 measurement points, it took between two and three hours to calculate the wind reduction factors for each of the eight wind directions, depending on the size and detail of the threedimensional model of the case study. This meant that the calculation of the wind reduction factors were taking up to a day to complete for this thesis project. However, in the future, it is likely that this time will reduce due to the advances in technology.

EnergyPlus, the computer program used for calculating solar radiation was able to measure the solar radiation at 121 measurement points within the case study developments. However, it aborted if any more than 121 measurement points were selected for calculating solar radiation.

For calculating thermal comfort across the four case studies, a ten-by-ten metre grid was laid out evenly across the case studies in the solar radiation and wind analysis programs. This allowed for solar radiation and wind to be calculated at a sufficient number of points to provide detail in the thermal comfort results without it taking days for the wind to be 
calculated, or the computer program aborting due to there being too many measurement points.

When the case studies were put into the computer programs, the lanes and courtyards within each case study did not often align with the ten-by-ten metre grid. This meant that the rows of measurement points for solar radiation and wind had to be moved manually by one or two metres to align with the lanes and courtyards (Figure 3.17).
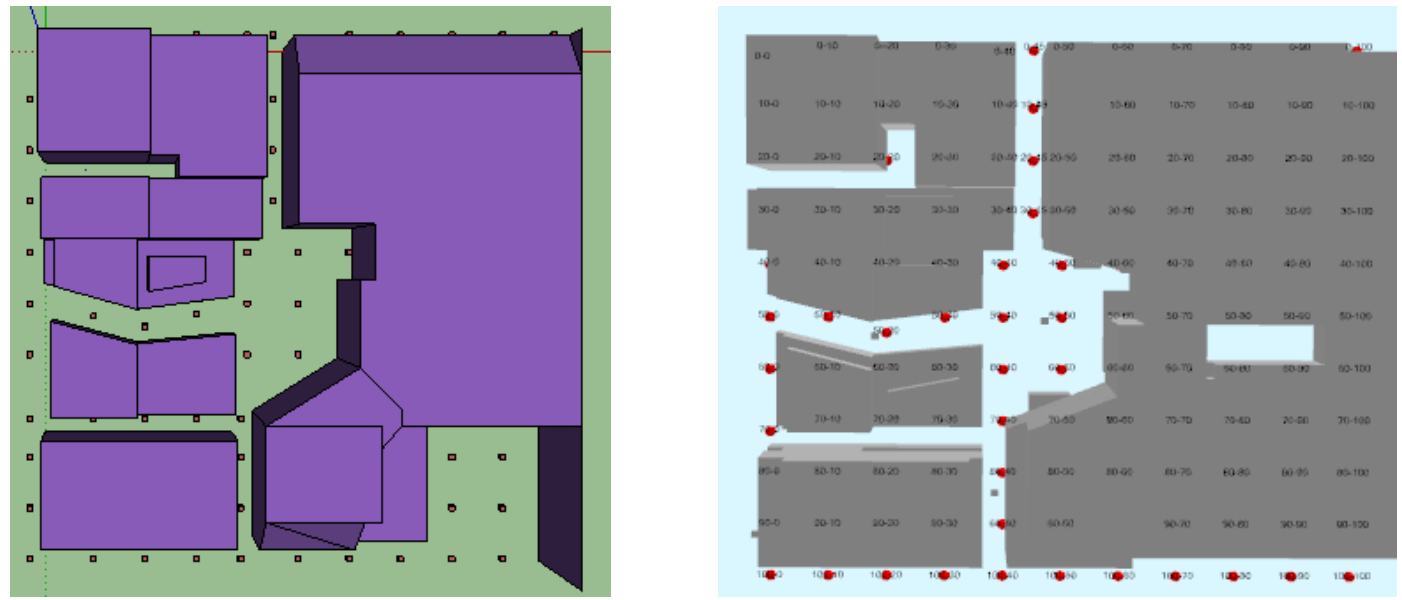

Figure 3.17 show the measurements points for solar radiation (Left) and wind reduction factors (right) for Case Study One.

Once the wind and solar radiation had been calculated for each of these measurement points, these were copied into The Comfort Tool. The Comfort Tool then used a macroinstruction, also known as a macro to automatically copy the solar radiation and wind reduction factor into the correct cells in The Comfort Tool, for each hour of the year. This process was repeated 121 times until thermal comfort was calculated across the whole case study. This was then displayed across a plan view of the case study as shown in Figure 3.18 diagram (1). 
1)

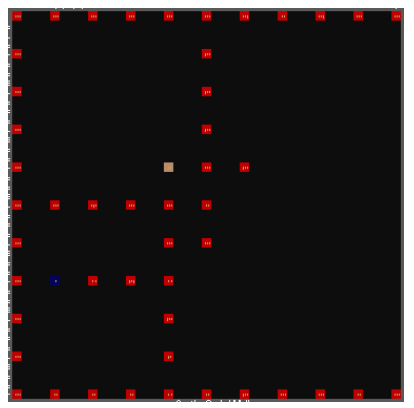

4)

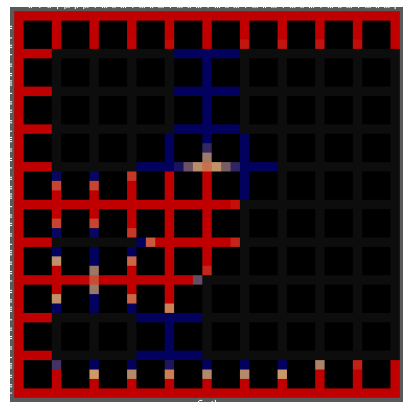

2)

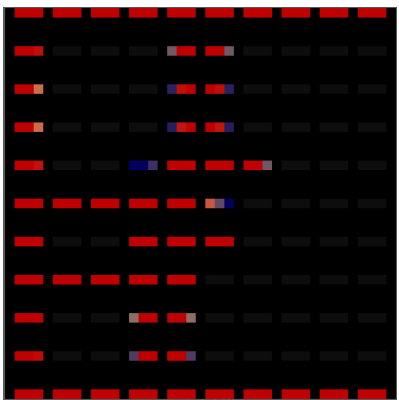

5)

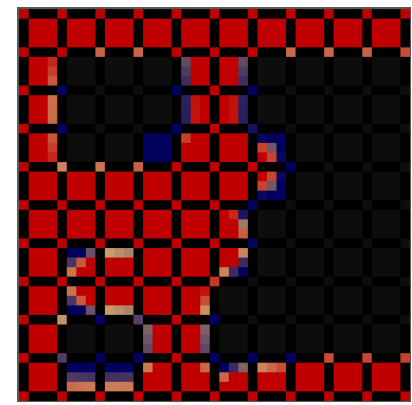

3)

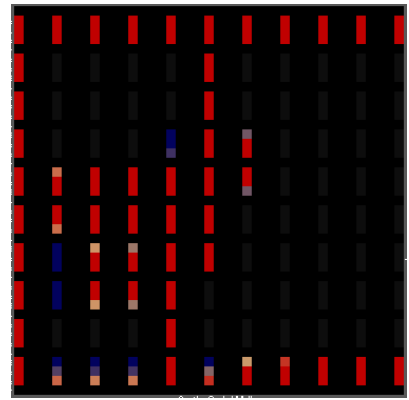

6)

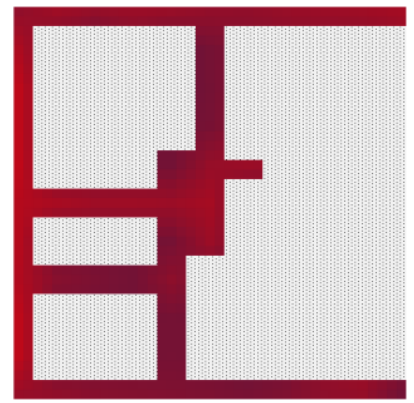

Figure 3.18 shows the interpolation technique used which takes the 121 measurement points where solar radiation and wind reduction factors were measured. The Comfort Tool then automatically averaged the surrounding cells for each point systematically (rows, columns, between rows and columns) until the whole area was shaded communicating the thermal comfort.

A linear interpolation technique was then used to interpolate the thermal comfort results for the 121 measurement points out to show thermal comfort across the whole case study. This interpolation technique averaged the thermal comfort results between two points in rows (2), columns (3), between the rows and columns (4), in all directions (5). This then displayed the thermal comfort across a development, rather than just for the 121 measurement points where thermal comfort was calculated (Figure 3.18).

Although the measurement points had to be moved manually one or two metres to align the lanes and courtyards, this interpolation technique averaged the thermal comfort results across more than ten metres. This allowed for the measurement points in the solar radiation and wind analysis programs to be moved one or two metres, and for the comfort results to still be communicated. 


\section{OUTSIDE OF WELLINGTON?}

This section develops a methodology for testing whether The Wellington Comfort Index can be applied to cities outside of Wellington, using Christchurch as a case study. The applicability of The Wellington Comfort Index to other cities is unknown (Walton et al., 2007, p. 3173). However, the methodology used to develop The Wellington Comfort Index was proven to be accurate (Walton et al., 2007, p. 3173). This was tested through separating the sample used to create The Wellington Comfort Index into two groups, and conducting a regression analysis on each group to test the strength of the relationships between the variables (Field, 2013, p. 882). This concluded that there were similar relationships within the two groups between the variables (Walton et al., 2007, p. 3170).

In Section 3.2 'Can the Process for Predicting Outdoor Thermal Comfort be developed into a tool for use at the preliminary design stage?' the Process for Predicting Outdoor Thermal Comfort was developed into The Comfort Tool through creating criteria to assist developers and consultants in selecting wind analysis programs. The Process for Predicting Outdoor Thermal Comfort was automated from calculating thermal comfort for a single point in a development to calculating thermal comfort at a number of points across a case study. These results were automatically displayed on a plan view of the case study.

However, The Wellington Comfort Index (a multiple-factor regression formula) behind The Comfort Tool has not been tested to determine if it is able to predict thermal comfort for cities outside of Wellington.

This process for testing The Wellington Comfort Index's applicability to cities outside of Wellington has three keys steps: conducting the same survey that was used to develop The Wellington Comfort Index in Central Christchurch, the case study area; calculating the comfort index for Christchurch, known as The Christchurch Comfort Index from the survey responses for Christchurch; and analysing the two thermal comfort indices to determine if the predictors of thermal comfort (mean wind, solar radiation, mean radiant temperature, and maximum wind) in Christchurch are the same as in Wellington.

The Wellington Comfort Index was developed from surveys and observations recorded in the three urban parks and malls. It measures people's ability to change their behaviour to 
maintain thermal comfort in outdoor urban areas (Walton et al., 2007, p. 3166). The survey period was over a nine month period to capture variances in the climate between seasons. 649 people were surveyed, while simultaneously measuring the gust and mean wind speed $(\mathrm{m} / \mathrm{s})$, and the mean radiant temperature in the shade and in the direct sun $\left({ }^{\circ} \mathrm{C}\right)$ (Walton et al., 2007). The survey results of participants were matched with the mean wind speed; mean radiant temperature (exposed and shaded); and the ambient temperature measured at a temporary weather station in the survey area at a height of 1.96 metres. The mean wind speed was also measured next to each participant. This was to understand the wind speeds and temperatures each participant was experiencing while taking part in the survey. The final Wellington Comfort Index includes mean wind speed, maximum gust speed, mean radiant temperature, and ambient temperature as the predictors of thermal comfort.

Equation 8 shows The Wellington Comfort Index

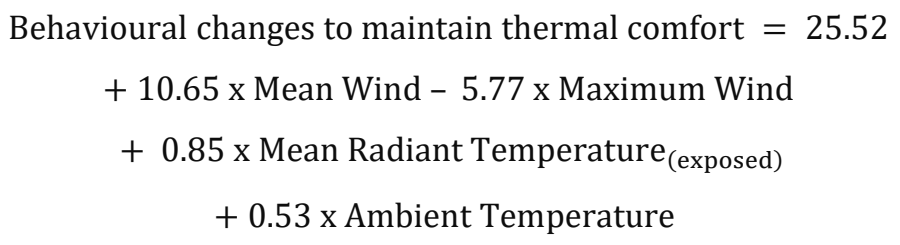

The results of The Wellington Comfort Index are able to predict thermal comfort through calculating the degree people will need to change their behaviour to maintain their thermal comfort. The results of The Wellington Comfort Index is a number for each hour of the year between one and one hundred, known as a thermal comfort score. These fall along a continuum, with fifty as the mid-point. It is stated in the study used to calculate The Wellington Comfort Index "Thus above and below the comfort index mean score of 50 there are values one would appropriately describe as 'uncomfortable'"' (Walton et al., 2007, p. 3173). Therefore, the number is fifty means that it is thermally comfortable. Whereas, the closer the number is to one or one-hundred, the more people will need to change their behaviour to maintain their thermal comfort (Figure 3.19). 


\begin{tabular}{cllr}
\hline $\begin{array}{c}\text { Thermal Comfort } \\
\text { Scores }\end{array}$ & $\begin{array}{l}\text { One } \\
\text { More change is required }\end{array}$ & Fifty & $\begin{array}{r}\text { One-hundred } \\
\text { Thermally Neutral }\end{array}$ \\
\hline
\end{tabular}

Figure 3.19 shows the interpretation of The Wellington Comfort Index. Red indicates that people will need to change their behaviour to maintain their comfort. Whereas, the neutral colour shows that people will feel thermally neutral.

Central Christchurch has been selected as the case study for testing The Wellington Comfort Index's applicable to cities outside of Wellington. This decision was based on the climate being different than in Wellington. In the TMY weather file for Christchurch the temperature typically range is larger than Wellington's temperature range. In Christchurch temperatures reach as low as $-5^{\circ} \mathrm{C}$ in winter, and as high as $31^{\circ} \mathrm{C}$ in summer. Whereas, in Wellington the temperature reaches as low as $2^{\circ} \mathrm{C}$ in winter, and as high as $26^{\circ} \mathrm{C}$ in summer. As discussed in Section 3.2.1 'Manual Measurements to Computer Programs' TMY weather files are representative of the typical weather for each month based on thirty years of data; rather than containing the weather data for a specific year (Gates et al., 2011, p. 1599).

3.4.1. DEVELOPING THE CHRISTCHURCH COMFORT INDEX

The methodology used to develop The Wellington Comfort Index was deconstructed to determine how it would need to be adapted when the same survey was conducted in Christchurch to calculate The Christchurch Comfort Index. A key difference between the development of The Wellington Comfort Index and The Christchurch Comfort Index included using smartphones or tablets to collect the data in Christchurch, rather than manual surveys.

\section{Survey Area and Accessibility of the Online Mobile Survey}

In Wellington, the survey area included three urban parks and malls (Walton et al., 2007, p. 3168). However, in Central Christchurch only one urban area was used as the survey collection area. This area was selected as it is the only outdoor area of Central Christchurch which currently has a group of shops and cafés to attract people. There are often performances, street markets, and buskers in this area as well. Locals and visitors to Christchurch and New Zealand spend time in this area. It was assumed that these responses would be representative of people undertaking similar activities to people surveyed in Wellington's parks and urban malls. 
For Christchurch, the survey could be accessed anywhere due to it being an online mobile survey accessible on tablets and smartphones. However, only the survey results from participants within this case study survey area were used to calculate The Christchurch Comfort Index, as the case study weather station was located centrally in the case study survey area (Figure 3.1).

Controls were put in place to prevent people taking part in the survey who were not outdoors. If a participant attempted to open the survey on their desktop or laptop computer a message popped-up which prevented them from taking part in the survey. This message explained that the participant would need to use a smartphone or tablet, and be situated outdoors.

If a smartphone or tablet was unable to access a participant's Global Positioning System (GPS) location, the participant was notified. This is because the participant's GPS location was required so that the metrological data measured at the case study weather station could be matched to their survey responses. Permission to gain participant's GPS location was required before they could take part in the survey.

This was to ensure that participant's GPS location was from their smartphone or tablet. If it could not be found, it would be estimated from the mobile-data or Wi-Fi network signals. This may have been inaccurate, and it would have been difficult to separate actual GPS data from an approximate location based on mobile-data or Wi-Fi network signals. 


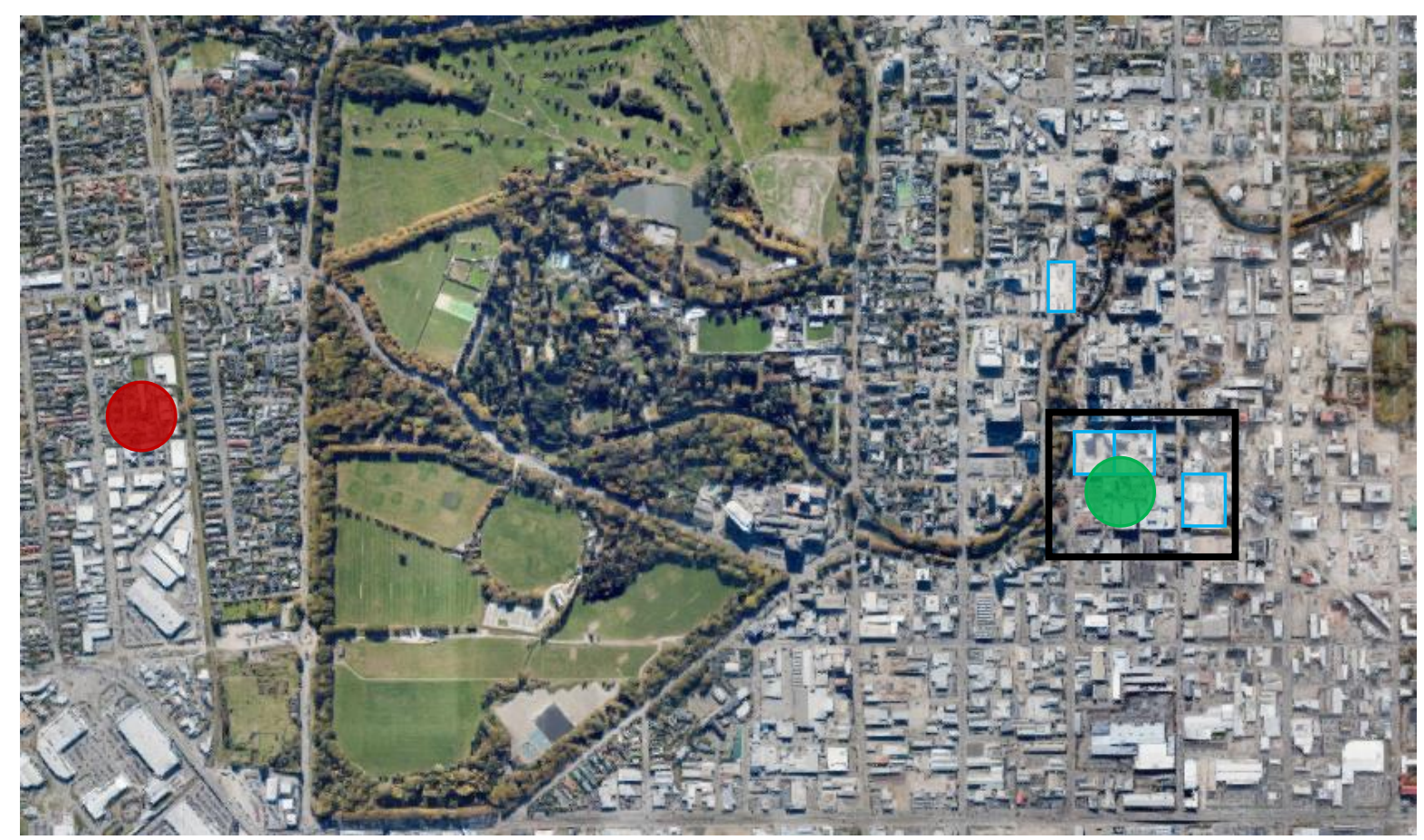

Figure 3.20 shows the local regional weather station (red circle), and the case study weather station (green circle) located centrally in the case study survey area (black). The location of the case studies in relation to the case study survey area are indicated (white and blue).

\section{'Automating' the Survey Conducted in Wellington}

The survey used to develop The Wellington Comfort Index was a manual survey. Surveyors approached potential participants in set areas of Wellington city, and asked if they would like to take part in the survey. The survey responses for each participant were matched with the mean wind speed; mean radiant temperature (exposed and shaded); and ambient temperature measured at a local weather station located centrally in the survey area at a height of 1.96 metres. This was to understand the microclimate conditions the participant was experiencing while taking part in the survey.

For Christchurch, an online mobile version of the original survey accessible on tablets and smartphones was developed. This online mobile survey was selected as it allows for the Wellington survey to be conducted in Christchurch, without the need for surveyors being present. The online mobile survey also allowed for people to complete the survey on any day within the survey period. Whereas, for the Wellington survey people could only take part in the survey when a surveyor was present. This would have not affected the comparison of the predictors of comfort in The Wellington Comfort Index and The Christchurch Comfort Index. 
As sixty-four percent of New Zealanders between the ages of fifteen and sixty-five owned a smartphone as of December 2013, it is unlikely that this data collection technique biased the survey results (Frost \& Sullivan, 2013). It was unknown if this data collection technique biased the results between people from different socio-economic groups, but it is unlikely that it biased the final results. This assumption is based on it being unlikely that people of different socioeconomic groups would perceive thermal comfort differently than one another.

\section{Survey Period}

For Wellington, the survey period was thirteen days over a nine month period to include a range of microclimatic conditions (Walton et al., 2007, p. 3168). For Christchurch, The survey period was between October 2014 and January 2015. This period included a range of microclimatic conditions (Figure 3.21). The temperatures ranged from less than $0^{\circ} \mathrm{C}$ to more than $30^{\circ} \mathrm{C}$. This covered the range of temperatures typically experienced in Christchurch. However, as shown in Figure 3.21, participants took part in the survey when temperatures were between $13^{\circ} \mathrm{C}$ and $24^{\circ} \mathrm{C}$. The mean wind speeds ranged from o m/s to $6.5 \mathrm{~m} / \mathrm{s}$. This range of climatic conditions is important as if the participants all took part in the survey when the climatic conditions were similar, then this would have biased The Christchurch Comfort Index. For the complete range of ambient temperatures of the survey period, See Appendix 8.2.3 'Temperatures During the Survey Period'. 


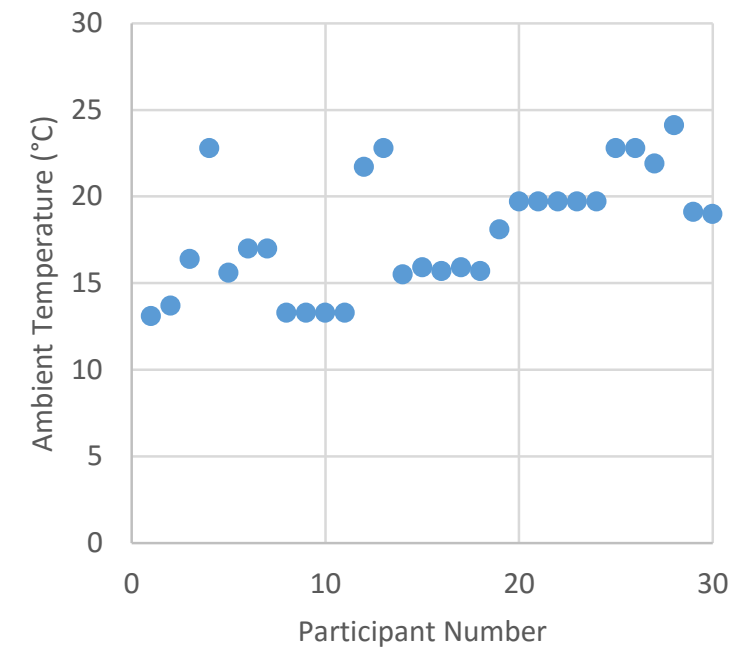

Ambient Temperature $\left({ }^{\circ} \mathrm{C}\right)$

Figure 3.21 shows the ambient temperature measured at the case study weather station (blue) when participants were taking part in the survey. Temperature ranged from $13^{\circ} \mathrm{C}$ and $24^{\circ} \mathrm{C}$.

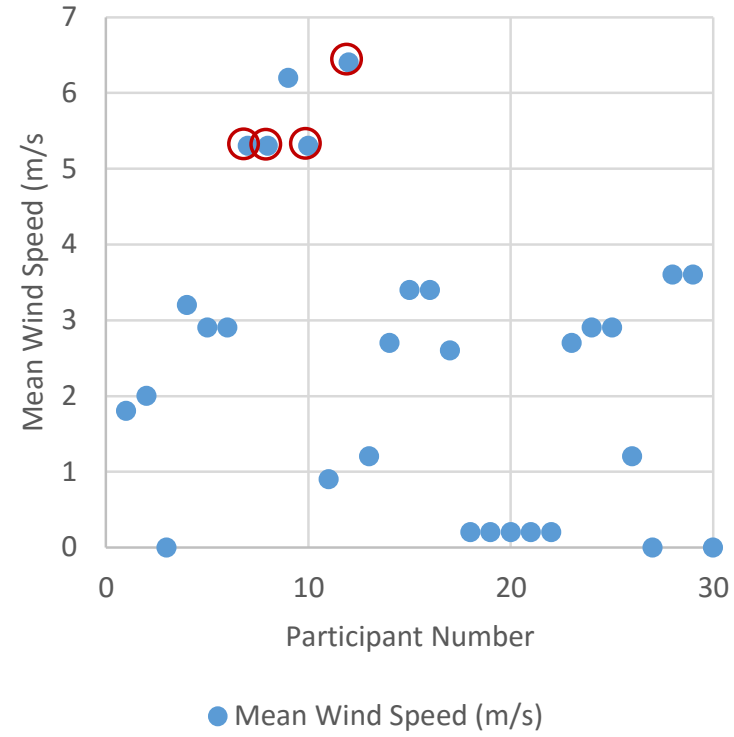

Figure 3.22 shows the mean wind speed while participants took part in the survey (blue). Four

of these measurements (blue and red) were taken from the local regional weather station $2 \mathrm{~km}$ from the case study area as the case study weather station had missing data. Wind speeds were between o $\mathrm{m} / \mathrm{s}$ and $6.3 \mathrm{~m} / \mathrm{s}$.

In Wellington, surveyors handed out the surveys between 11am and 3pm (Walton et al., 2007, p. 3168). As the online mobile survey could be accessed at any point in time in Christchurch, this could not be controlled. However, twenty-four of the survey results in Christchurch were between 11am and 3pm, with six between $3 \mathrm{pm}$ and $4 \mathrm{pm}$. These survey responses were included in The Christchurch Comfort Index. This would have not biased the survey results as the response of these participant's to the Modified Bedford Scale question "rate how warm or could you feel" were similar to the participants who completed the survey between 11am and 3pm. See Appendix '8.2.7 Survey Results: Raw Data of The Christchurch Comfort Index'.

\section{Meteorological Data Collection}

For the development of The Wellington Comfort Index a temporary weather station was located centrally in the survey area. For the development of The Christchurch Comfort Index a case study weather station was located centrally in the case study area. It was mounted to the roof of a single storey temporary structure which was located in the case study survey area. The weather station was high above the temporary building's roof to 
limit the effect of wind passing over the roof, as this would have changed the wind patterns and resulted in inaccurate wind measurements. This weather station measured the meteorological data over the survey period. This meteorological data included solar radiation $\left(\mathrm{W} / \mathrm{m}^{2}\right)$, mean and maximum wind speed $(\mathrm{m} / \mathrm{s})$, and ambient temperature $\left({ }^{\circ} \mathrm{C}\right)$. The data was measured for every ten minute period, which allowed the survey results of each participant to be paired with the meteorological data for the closest ten minute period. In the Wellington Survey, this data was measured at a temporary weather station at the height of 1.96 metres. However, for the development of The Christchurch Comfort Index, it was measured at the height of four metres due to the risk of vandalism. This is because the case study weather station was located in the survey period overnight when surveyors were not present.

The black globe temperature was measured in the study for developing The Wellington Comfort Index then converted to the mean radiant temperature. However, the black globe temperature could not be measured by the case study weather station in Central Christchurch. For this reason, the ambient temperature and solar radiation from the case study weather station were used to calculate the mean radiant temperature, which was then converted to the black globe temperature (Equation 3 and Equation 4).

The mean wind speed, ambient air temperature, and solar radiation were being used to calculate The Christchurch Comfort Index, were measured at the case study weather station. This was then compared to the data measured at the local regional weather station, located approximately $2 \mathrm{~km}$ from the case study survey area (Figure 3.20 ). This was to test if the case study weather station's data was accurate, based on the local regional weather station maintained by the National Institute of Water and Atmospheric Research.

Before the wind speeds could be compared, the wind speeds measured at the local regional weather station had to be converted from six metres to four metres. This was because the wind in the local regional weather station was measured at a height of six metres. Whereas the case study weather station was measured at a height of four metres.

To convert the wind speeds at the local regional weather station from six metres to four metres, the power law was used (Equation 6). The terrain-roughness co-efficient for a low density urban area of 0.35 was used for this calculation (Grimmond \& Oke, n.d., p. 1283). 
This comparison shows that the wind speeds are generally lower in the case study survey area than at the local regional weather station (Figure 3.23). The wind at the local regional weather station has a more distinctive pattern which suggests that it is sheltered from some of the primary wind directions. The wind speeds measured from the case study weather station were generally lower. This may be because the weather station is more sheltered as it is located in a higher density area of the city.

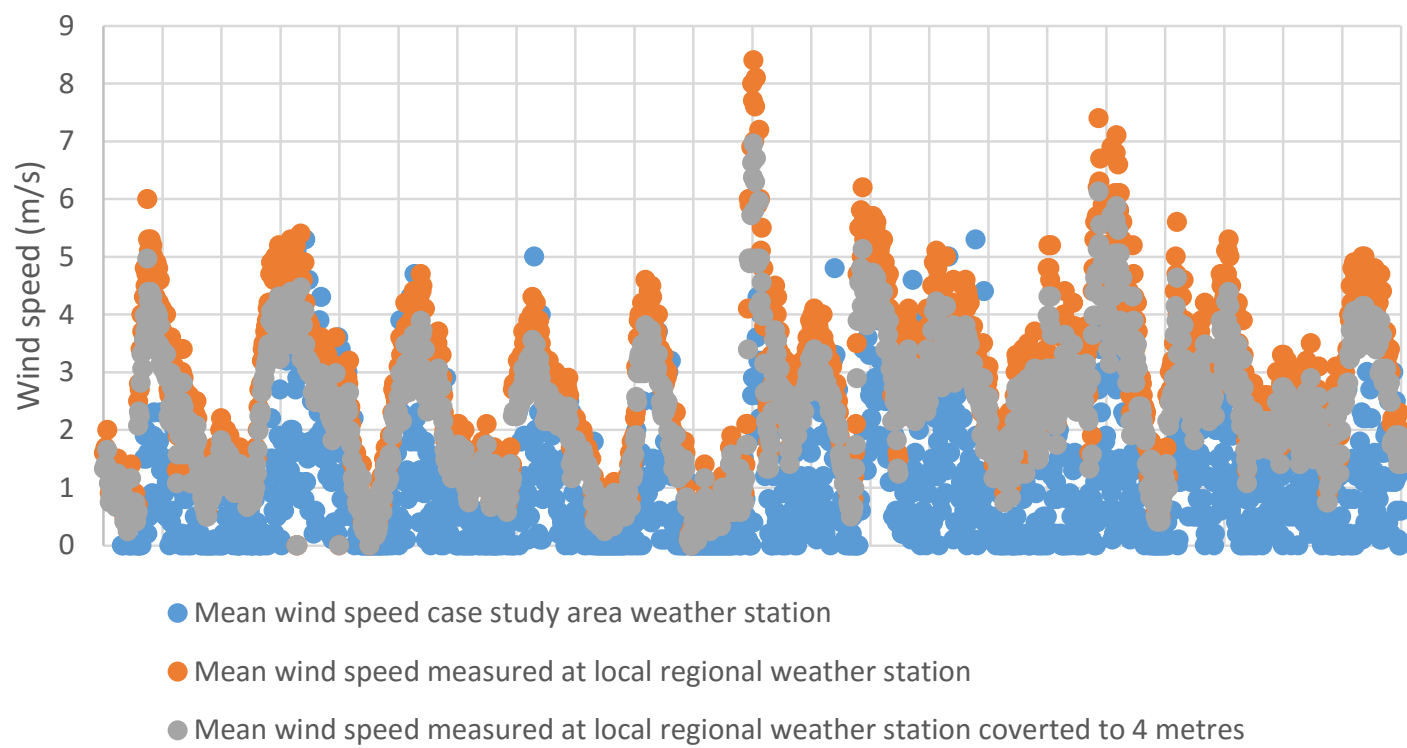

Figure 3.23 shows a comparison of the mean wind speeds at the case study weather station, and the wind speeds measured at a local regional weather station located $2 \mathrm{~km}$ from the case study survey area. This comparison of wind speeds is over a ten day period. 
Solar radiation and ambient temperature measured at the local regional weather station and the case study weather station were not converted due to the differences in height between the two weather stations. This is because it is unlikely that the two metres difference in height would affect the solar radiation and ambient air temperatures measured.

However, the solar radiation measured at the local regional weather station was converted from $\mathrm{MJ} / \mathrm{m}^{2}$ to $\mathrm{W} / \mathrm{m}^{2}$ allowing it to be comparable with the case study weather station (Equation 9).

Equation 9 is used for calculating solar radiation $\left(\mathrm{W} / \mathrm{m}^{2}\right)$ from $\mathrm{MJ} / \mathrm{m}^{2}$ (NIWA, 2015a):

$$
W / m^{2}=M J / m^{2} x \frac{1,000,000}{600}
$$

Where:

$1,000,000=$ Joules to Watts

$600=$ number of seconds in a ten minute period

The solar radiation measured at the two weather stations follows a similar pattern with less than $100 \mathrm{~W} / \mathrm{m}^{2}$ between the solar radiation measured at each of the weather stations (Figure 3.24). As this variation is not consistently occurring, it is likely not due to the weather stations being calibrated differently. It may be due to atmospheric conditions such as differences in cloud cover between the two weather stations ('Chapter 3: What influences the amount of solar radiation?', 2014). 


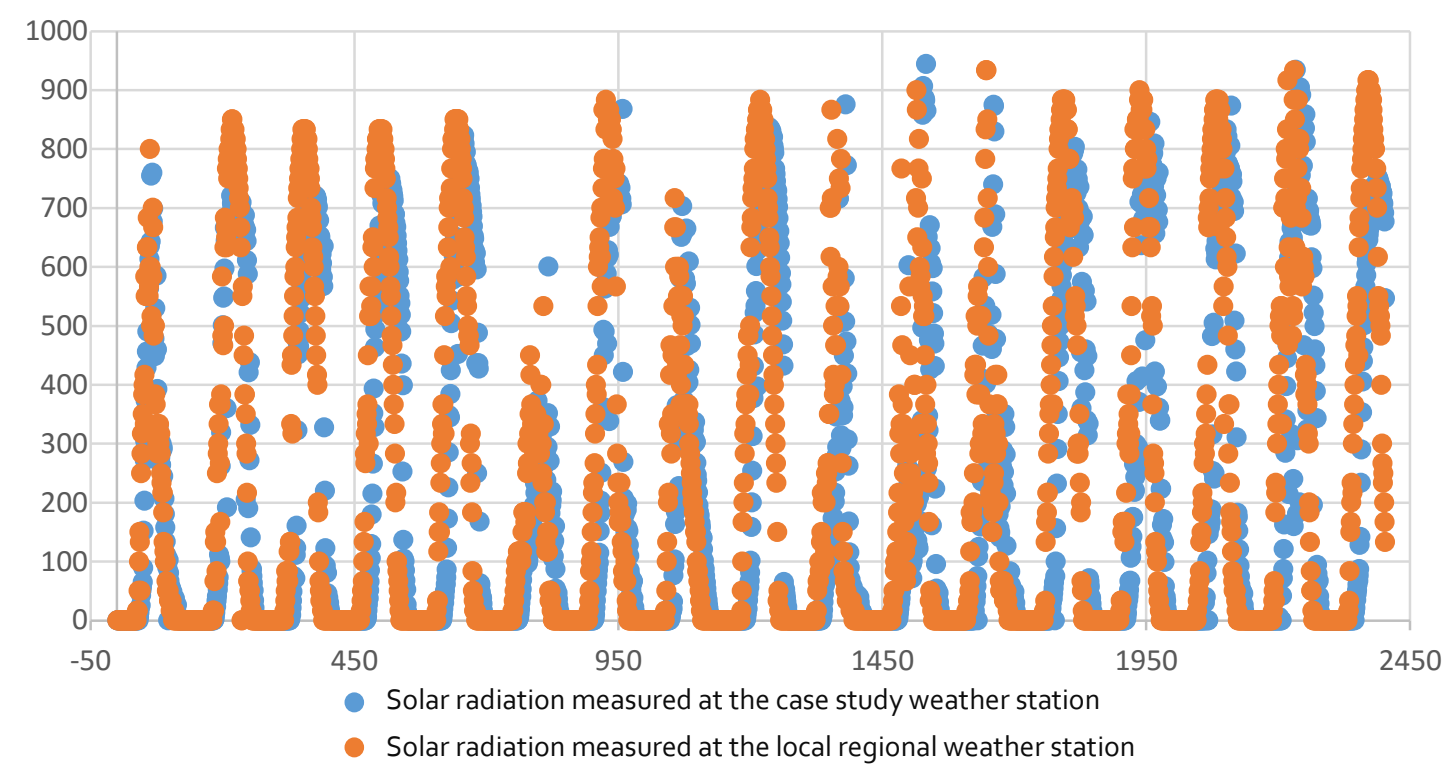

Figure 3.24 shows a comparison of the solar radiation measured at the case study weather station (blue) and the solar radiation measured at the local regional weather station (orange). These followed a close pattern with less than $100 \mathrm{~W} / \mathrm{m}^{2}$ between the measurements.

Ambient temperature was directly comparable between the local regional weather station and the case study weather station as they both measure the ambient temperature in degrees Celsius. The ambient temperature at the two weather stations followed a similar pattern. However, there was more than $3^{\circ} \mathrm{C}$ variation between the two weather stations approximately twenty-percent of the time (Figure 3.25). It is unknown what was causing this difference in temperature. It may have been due to the weather stations not being calibrated. Another reason may be the urban heat island effect, or the case study weather station being located two metres closer to street level than the local regional weather station. In the case study survey area the ambient temperature may have been slightly higher due to the thermal mass of the surrounding buildings, footpaths, and roads as these hold the heat from solar radiation. This is in comparison to the local regional weather station which is in a suburban area with mostly timber houses, and is located next to a large park. Therefore, there is less thermal mass surrounding this weather station to absorb and release the heat. 


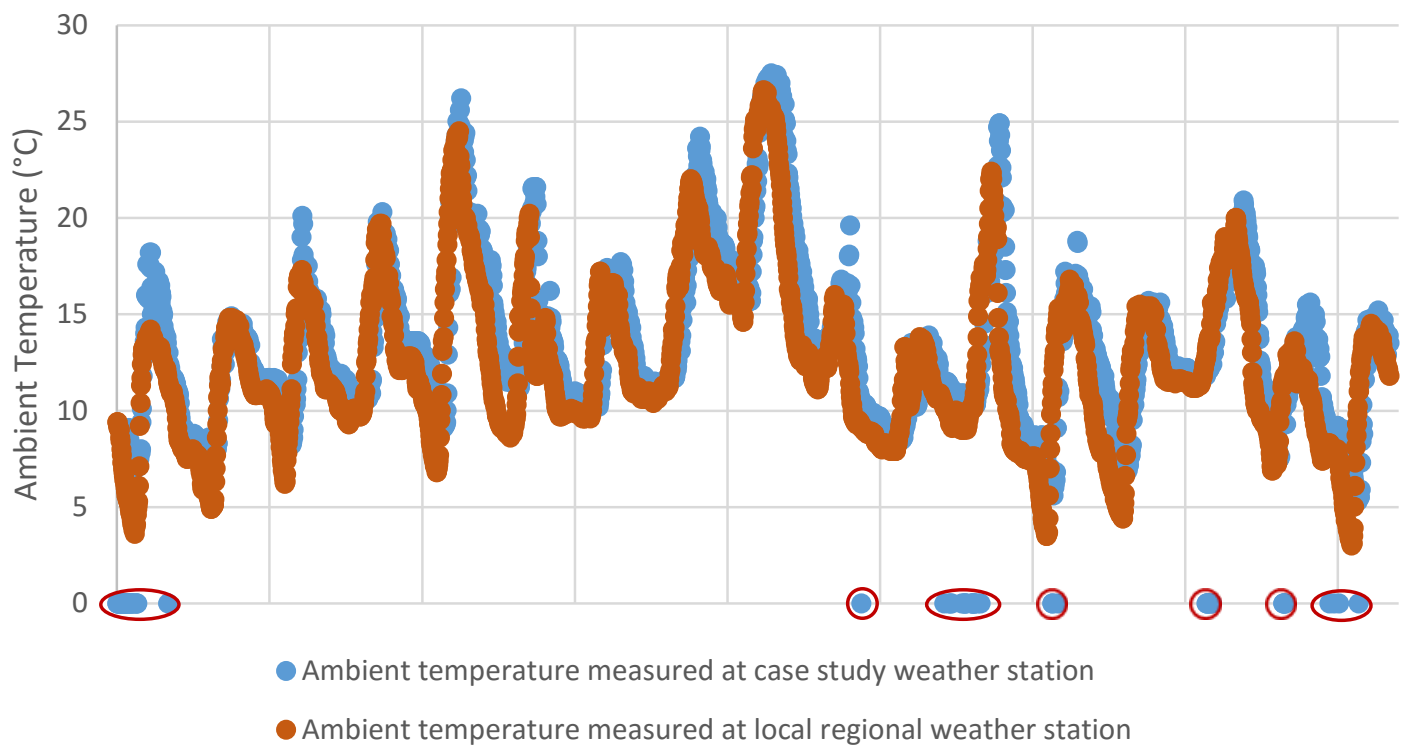

Figure 3.25 shows the ambient temperature measured by the case study weather station (blue) and measured at the local regional weather station (orange). The temperature was higher at the case study weather station. As the differences in temperature are not the same for each point in time, this suggests that it is not due to the calibration of the weather stations, but is due to a local factor. This may be the case study weather station being surrounded by more thermal mass. Whereas, the local regional weather station is in an open area.

In total, four-hundred and twenty measurements were compared between the case study weather station and the local regional weather station, over nine days. This focused on a reduced number of measurements covering more than a week, rather than comparing four months of ten minute data. This was to focus on the relationships between the case study weather station and the local regional weather station. If four months of ten minute data was compared it would be more difficult to identify the relationships due to the large amount of data.

As commonly experienced with experimental data, the case study weather station malfunctioned. It intermittently did not measure the weather data in the case study survey area. It is unknown what caused this on occasions. These points where data was not measured are indicated (Figure 3.25). See Appendix 8.2.4 'List of Equipment, Accuracy, and Specifications' for the specifications and accuracy of the case study and local regional weather stations. 
In the study that developed The Wellington Comfort Index, the surveyor also measured the wind speed next to each participant at a height of 1.2 metres (Walton et al., 2007, p. 3168). To calculate the wind speed at each participant for the Christchurch survey, the location within the survey area where the participant completed the survey was measured as part of the survey using GPS.

The GPS allowed for the wind reduction factor to be calculated using UrbaWind for each participant. UrbaWind has been tested for its accuracy as discussed in Section '3.2.2. Criteria for Selecting Wind Analysis Programs'. This concluded that the wind reduction factors calculated by UrbaWind followed the most similar pattern as the wind tunnel test than the other wind analysis programs. For the North-easterly wind ( $45^{\circ}$ angle) the wind reduction factors followed the wind tunnel results closely on the windward side of the Central City Block, with approximately a ten percent difference in wind speeds for the leeward side of the Central City Block. However, for the Northerly wind ( $360^{\circ}$ angle) there a ten percent difference in the wind reduction factors, and the relationship between UrbaWind and the wind tunnel tests did not mirror one another.

The wind reduction factors for each participant were calculated in UrbaWind within a threedimensional model of the case study survey area. These wind reduction factors were then applied to the wind measured at the case study weather station for the same ten minute period a participant started the survey. However, before this could be done, the mean wind measured at the case study weather station had to be converted to a height of onehundred and twenty metres. This is because the wind reduction factors calculated in UrbaWind are calculated for the wind speed at this height.

The wind speed measured at the case study weather station may have been fairly accurate in representing the wind speed each participant was experiencing while taking the survey. However, an item in The Wellington Comfort Index is the difference in wind speed between a participant, and the wind speed in an exposed location (measured at the case study weather station). Therefore, the wind speed at the participant was calculated based on a wind reduction factors calculated in UrbaWind for each participant. If this had not been done, there would be no difference in wind speeds between the participant and the wind speeds measured in the exposed location. The wind speeds measured at the case study 
weather station were converted to the height of one-hundred and twenty metres before the wind reduction factors were applied.

For quality assurance, the survey also recorded the accuracy of the GPS location recorded in metres. This allowed for survey results with more than a ten metre accuracy to be excluded from the study. This was because participants' location could not be determined accurately. Therefore, the wind speeds they were experiencing as they were taking the survey could not be determined. This excluded fifteen participants in total.

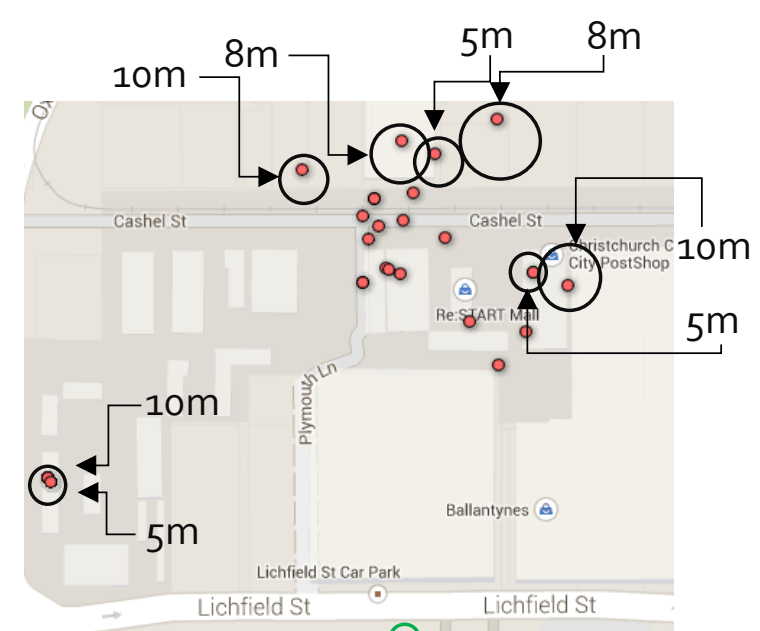

()

Figure 3.26 shows the locations where participants took part in the survey based on their GPS location.

Where the GPS location indicated that a participant was within a construction site, or was on top of a building, their position was moved into the case study survey area (Figure 3.26). The distance they were moved was by the GPS accuracy their GPS indicated (black). However, some of the participants were shown as being on top of buildings (green) in Google Maps. Often this was because a building had been demolished since Google Maps had been updated. Therefore, the participant was in the case study survey area, not inside a building.

In the development of The Wellington Comfort Index, surveyors recorded the time they handed out the survey so that the survey responses could be matched with the meteorological data. For The Christchurch Comfort Index the meteorological data was matched with the time the participant started the survey. As the survey period was usually below ten minutes, this meant that the participant completed the survey before the wind, ambient temperature, and solar radiation measurements at the case study weather station changed. However, on occasion the survey completion time was twenty minutes. On these occasions the weather data for the starting time was also used as it was likely that they had completed the survey as all the survey results were answered, but had not closed the survey. 
Wind, ambient temperature, or solar radiation was occasional missing from the data measured at the case study weather station. It is unknown why the case study weather station did not record data for every ten minute period. This may be due to the weather station having a wireless connection to the computer where the weather data was stored. Therefore, there may have been interference between the weather station and the computer. Another reason may have been the computer being turned off for periods of time.

As commonly experienced with experimental data, at times the equipment malfunctions. Rather than lose the responses from these times, processes have been developed for filling in the gaps. These have been tested to ensure they do not add further error through comparing the solar radiation, ambient temperature, and wind measured at local regional weather station and the case study weather station.

When there was missing data for a period that a participant took part in the survey, the data from the local regional weather station was used. Although the comparison of the solar radiation and ambient temperature show similar patterns, the wind patterns did not show a pattern. The wind data was used from the local regional weather station for four of the thirty survey results used to calculate The Christchurch Comfort Index after being converted to four metres to align with the case study weather station. Therefore, it is unlikely this biased the results as this converted wind data only represented twelve percent of the survey responses.

\section{Sample Size}

For the development of The Wellington Comfort Index, 649 participants took part in the survey. For development of The Christchurch Comfort Index, a total of total fifty-two people completed the survey. Of these, the results of thirty participants were used. This is because twenty-two participants had missing GPS data, or some of their survey results were missing.

Where there were missing survey results for a participant, their survey results were excluded from the study. It is unknown if this was the same technique used for developing The Wellington Comfort Index. However, as the statistics program (IBM SPSS Statistics) 
used to calculate The Wellington Comfort Index automatically exclude participants who have missing data (Field, 2013, p. 108). This decision was made to keep the methodology the same between the development of The Wellington Comfort Index and The Christchurch Comfort Index to maintain the reliability of the process.

Once the participants with missing GPS or survey responses were excluded, there was a total of thirty participants. Of these sixteen males took part, and fourteen females. Based on the central limit theorem this is a large sample size (Field, 2013, p. 54). Therefore, the sampling distribution is considered normal (Field, 2013, p. 54).

\section{Survey Questions for the Christchurch Survey}

Although thirty-three questions were included in the survey conducted in Wellington, The Wellington Comfort Index was only based on the responses to thirteen of the questions. Out of the thirty-three questions: the majority were about the environment (warmth, sunlight, wind, wetness, noise, air humidity, air quality); three were about the location the participant had chosen to sit; three were regarding the participants preference to warmth; and two were about the participants use of the location/reasoning for selecting the location. There were also two distractor questions included.

For The Wellington Comfort Index, a principal component analysis was conducted on the thirty-three questions to identify the components with a linear relationship to reduce the variables to be included in The Wellington Comfort Index, while maintaining as much information as possible (Field, 2013, p. 882). Any item which had a regressed value of less than $\mathrm{r} 0.30$ was removed as this suggests that the inclusion of this survey question does not add any more depth to The Wellington Comfort Index (Walton et al., 2007, p. 3170).

The calculation of The Christchurch Comfort Index was only based on these thirteen questions which were classed as important in the component analysis for Wellington. If the Christchurch survey included the full thirty-three questions this would been validating The Wellington Comfort Index. This would not be testing if the same predictors of thermal comfort which were important in The Wellington Comfort Index were also important in The Christchurch Comfort Index as more factors would be introduced. 
Fifteen items in total were included in The Wellington Comfort Index. Thirteen of these were direct responses to the survey questions. The other two items included whether the participant was wearing sunglasses or not (part of the clo-value question) and the difference in wind speed at the participant in relation to the wind speed at the case study weather station. This determined how sheltered the participant was in comparison to the case study weather station.

For the development of The Christchurch Comfort Index the thirteen questions which were included in The Wellington Comfort Index were included in the Christchurch survey. Although including the complete thirty-three questions may have given more insight to quantifying thermal comfort in Christchurch, this would have discouraged people taking part in the survey, known as respondent burden (Bradburn, 1978, p. 1). This would have also not met the aim of determining if the predictors of comfort in Christchurch were the same as in Wellington. A survey with the full thirty-three questions would have been validating The Wellington Comfort Index only including the fifteen items, based on thirteen questions are the predictors of comfort.

Table 3.4 shows the questions included in the Christchurch survey used to calculate The Christchurch Comfort Index.

\begin{tabular}{|c|c|}
\hline Question & Purpose for inclusion in survey \\
\hline $\begin{array}{l}\text { 1) Rate how warm or cold you } \\
\text { feel (Much too Warm, Too } \\
\text { Warm, Comfortably Warm, } \\
\text { Neutral, Comfortably Cool, Too } \\
\text { Cool, Much too Cool }\end{array}$ & $\begin{array}{l}\text { Modified Bedford Scale } \\
\text { This determined, on the Modified Bedford Scale how the } \\
\text { participant is feeling thermally }\end{array}$ \\
\hline $\begin{array}{l}\text { 2) "Rate your impression of the } \\
\text { wind level" (Much too windy, } \\
\text { Too windy, Comfortably windy, } \\
\text { Neutral, Slightly too cool, Too } \\
\text { still, Much too still) }\end{array}$ & $\begin{array}{l}\text { Subjective effect of wind force } \\
\text { This determined whether a participant perceives that the wind is } \\
\text { strong. }\end{array}$ \\
\hline $\begin{array}{l}\text { 3) "Rate how warm or cold your } \\
\text { surroundings are" (Hot, Warm, } \\
\text { Slightly too warm, Neutral, } \\
\text { Slightly too cool, Cool, Cold) }\end{array}$ & $\begin{array}{l}\text { Subjective effect of heat of surroundings } \\
\text { This determined whether a participant feels there is heat radiating } \\
\text { from materials surrounding them, such as concrete, a park bench, } \\
\text { or grass. }\end{array}$ \\
\hline $\begin{array}{l}\text { 4) "Rate your impression of the } \\
\text { cool effect of the wind" (Far too } \\
\text { chilly, Too chilly, A little too } \\
\text { chilly, Tolerable, Not } \\
\text { noticeable) }\end{array}$ & $\begin{array}{l}\text { Subjective effect of wind chill } \\
\text { This determined whether a participant feels it is cold due to the } \\
\text { wind. }\end{array}$ \\
\hline $\begin{array}{l}\text { 5) "In exposed places, the wind } \\
\text { is ............?" (Far too strong, } \\
\text { Too strong, A little too strong, } \\
\text { Tolerable, Not noticeable) }\end{array}$ & $\begin{array}{l}\text { Subjective effect of wind strength } \\
\text { This determined whether a participant feels it is a windy day. The } \\
\text { participant's perceived thermal comfort could be at any point on } \\
\text { the modified Bedford scale, even if they feel it is a windy day }\end{array}$ \\
\hline 6) "Today the wind is annoying" & Subjective effect of annoyance of the wind \\
\hline
\end{tabular}




\begin{tabular}{|c|c|}
\hline $\begin{array}{l}\text { (Strongly agree, Agree, Neither } \\
\text { agree nor disagree, Disagree, } \\
\text { Strongly disagree) }\end{array}$ & $\begin{array}{l}\text { This determined whether a participant feels that the wind is } \\
\text { annoying. However, even if the wind is annoying, they may still } \\
\text { feel 'warm' based on the modified Bedford scale. }\end{array}$ \\
\hline $\begin{array}{l}\text { 7) "Today is a really good day to } \\
\text { be outside in this sort of } \\
\text { location" }\end{array}$ & $\begin{array}{l}\text { Agreement whether it is a great day to be outside. This } \\
\text { determined whether a participant feels that the current } \\
\text { conditions are good to be in or not. }\end{array}$ \\
\hline $\begin{array}{l}\text { 8) This was not a question, but } \\
\text { the difference in wind speed } \\
\text { from where the participant was } \\
\text { sitting and the wind speed at } \\
\text { the case study weather station } \\
\text { when they were completing the } \\
\text { survey }\end{array}$ & $\begin{array}{l}\text { Wind speed (relative to central location) to determine if they were } \\
\text { sitting in an exposed location or a sheltered location while } \\
\text { completing the survey. Exposure is based on the comparison with } \\
\text { the case study weather station located in an exposed area of the } \\
\text { case study survey area. }\end{array}$ \\
\hline $\begin{array}{l}\text { 9) Your "Clo" Value: the value } \\
\text { of your clothing's insulation } \\
\text { (please tick next to items you } \\
\text { are current wearing) }\end{array}$ & $\begin{array}{l}\text { Estimated clo-value (clothing value) } \\
\text { As the clo-value determined how the participant is dressed. The } \\
\text { higher their clo-value the more clothing they are wearing. }\end{array}$ \\
\hline $\begin{array}{l}\text { 10) "Seating position: How } \\
\text { exposed are you in relation to } \\
\text { the wind?" (Facing, Turned } \\
\text { against, Side on, Partially } \\
\text { sheltered, Fully sheltered, No } \\
\text { wind/cannot tell) }\end{array}$ & $\begin{array}{l}\text { This question determined if they allowed themselves to be } \\
\text { exposed to the wind, or whether they were trying to limit the } \\
\text { effect of the wind on their thermal comfort. }\end{array}$ \\
\hline $\begin{array}{l}\text { 11)"Seating position: How } \\
\text { exposed are you in relation to } \\
\text { the sun?" (Facing, Turned } \\
\text { against, Side on, Partially } \\
\text { shaded, Fully shaded, No } \\
\text { wind/cannot tell) }\end{array}$ & $\begin{array}{l}\text { This question determined if they allowed themselves to be } \\
\text { exposed to the sun, or whether they were trying to limit the effect } \\
\text { of the sun on their thermal comfort. }\end{array}$ \\
\hline $\begin{array}{l}\text { 12) Are you wearing } \\
\text { sunglasses? (Yes, No) }\end{array}$ & This was part of the level of clothing (clo) question. \\
\hline $\begin{array}{l}\text { 13) Approximately how long } \\
\text { have you been here? (0-5, 6-15, } \\
15-30,30-60,60)\end{array}$ & $\begin{array}{l}\text { Time exposed } \\
\text { This determined whether a participant feels it is thermally } \\
\text { comfortable or not (more exposure = more thermal comfort?) }\end{array}$ \\
\hline $\begin{array}{l}\text { 14) How much longer do you } \\
\text { intend to stay here? }(0-5,6-15 \text {, } \\
15-30,30-60,60)\end{array}$ & $\begin{array}{l}\text { Exposure time preferred could determine their thermal comfort } \\
\text { levels (more time = more thermal comfort?) }\end{array}$ \\
\hline $\begin{array}{l}\text { 15) Before you sat down, how } \\
\text { long did you expect to stay } \\
\text { here? (0-5, 6-15, 15-30, 30-60, } \\
60)\end{array}$ & $\begin{array}{l}\text { Exposure time anticipated could determine their thermal comfort } \\
\text { levels (more time }=\text { more thermal comfort?) }\end{array}$ \\
\hline $\begin{array}{l}\text { 16) "Are you a visitor to New } \\
\text { Zealand?" }\end{array}$ & $\begin{array}{l}\text { This question was asked to allow flexibility in the survey data } \\
\text { analysis. If there was a large sample size, it could be separated } \\
\text { into two groups: visitors and locals to provide more detail in The } \\
\text { Wellington Comfort Index's applicability to cities outside of } \\
\text { Wellington. }\end{array}$ \\
\hline $\begin{array}{l}\text { 17) "Are you a visitor to } \\
\text { Canterbury?" }\end{array}$ & $\begin{array}{l}\text { This question was asked to allow flexibility in the survey data } \\
\text { analysis. If there was a large sample size, it could be separated } \\
\text { into two groups: visitors and locals to provide more detail in The } \\
\text { Wellington Comfort Index's applicability to cities outside of } \\
\text { Wellington. }\end{array}$ \\
\hline 18) Please indicate your gender & $\begin{array}{l}\text { This question was asked to allow flexibility in the survey data } \\
\text { analysis. If there was a large sample size, it could be separated } \\
\text { into two groups: males and females to understand the variations } \\
\text { between each sex and how they may perceive thermal comfort. }\end{array}$ \\
\hline
\end{tabular}


19) Please indicate your age

This question was asked to allow flexibility in the survey data analysis. If there was a large sample size, it could be separated into age groups to understand how at different ages people perceive thermal comfort differently.

See Appendix 8.2.1 'Wellington Survey Questions' for the full Wellington Survey. The demographic questions included in the survey in Christchurch are in Appendix 8.2.2 'Demographic Questions Included in the Christchurch Survey'. Human ethics was gained through Victoria Universities Ethics Committee before the survey period began.

Factors which may have influenced the Results of the Survey

A list of clothing items and their corresponding insulation value, known as a clo-value was included in the survey. The participant was asked to select all items of clothing they were wearing at the time they completed the survey. However, the actual clo-value of the items of clothing they were wearing may differ from the items of clothing they selected from the list provided.

An example of this is a short-sleeve knit sport shirt and a short-sleeved dress shirt. A participant may be wearing a short-sleeve knit shirt (clo-vlaue of 0.17), but indicate in their survey response that they are wearing a short-sleeved dress shirt (clo-value of 0.19).

Therefore, once their total clo-value was calculated, it may have been slightly different than the actual clo-value they were wearing.

In the study which developed The Wellington Comfort Index, the clo-value for winter coats and rain coats were not included. For these two items the clo-values from in ASHRAE 552012 were used (ASHRAE, 2013, p. 3). See Appendix 8.2.5 'ASHRAE Clo-values' for the ASHRAE clo-values.

There are some aspects of the survey conducted in Christchurch which could not be understood or controlled as easily due to a surveyor not being present in the case study survey area when a participant was taking the survey.

In the study for developing The Wellington Comfort Index, the surveyors noted down the surface each participant was sitting on. However, there was no surveyor present for the survey used to develop The Christchurch Comfort Index. For this reason a question was included in the survey which asked about the heat or cold radiating from the surfaces 
around the participants. This will have no effect on The Christchurch Comfort Index, as the surveyors observations of the surface a participant was sitting on was not included in in The Wellington Comfort Index.

In the study which developed The Wellington Comfort Index, the surveyor noted the participant's exposure to the wind. However, there was no surveyor present for the survey used to develop The Christchurch Comfort Index. For this reason this was included as a question in the Christchurch survey. The participant could select their exposure to the wind as Facing, Turned Against, Side On, Partially Sheltered, Fully Sheltered, No Wind/Can't Tell. As this question is perception based, this would have had the same degree of impact on The Wellington Comfort Index and The Christchurch Comfort Index whether it was the surveyor or the participant was selecting the exposure of the participant to the wind.

Similar as the exposure to the wind, the surveyor in Wellington also noted the participant's exposure to the sun. However, as there was not a surveyor present for the survey used to develop The Christchurch Comfort Index, this was included as a question in the Christchurch survey. The participant could select their exposure to the sun as Facing, Turned Against, Side On, Partially Shaded, Fully Shaded, No Sun. This would have had the same degree of impact on The Wellington Comfort Index and The Christchurch Comfort Index whether it was the surveyor or the participant selecting the exposure participant's to the sun.

In the study to develop The Wellington Comfort Index, it was assumed that the participant's activity level was constant due to them needing to be stationary to complete the survey. This assumption was also made for the development of The Christchurch Comfort Index as the participant was completing the survey on a smartphone or tablet which would be difficult to do if they were moving around. This would have no effect on The Christchurch Comfort Index as this is not a factor in either the Wellington or Christchurch Comfort Index.

In the Wellington study, no surveys were completed on days when it was raining. There was less control over this in the Christchurch study, as a surveyor was not present while a participant was completing the survey. However, the case study weather station measured precipitation, so could identify the days where it was raining. This had no impact on The 
Christchurch Comfort Index as no one completed the survey on days when the case study weather station indicated it was raining.

Factors which may have Influenced the Participant's Response

A number of variables may have affected the survey responses, but were not of primary interest in the study use to develop The Christchurch Comfort Index (Field, 2013, p. 15). Some of these could have been clarified through addressing them in the survey questions. However, as these questions were not included in the study conducted in Wellington, they were not included for the study in Christchurch.

It was unknown how recently the participant had eaten. If a participant had eaten, this have increased their digestive system activity and make them feel warmer. This had no impact when comparing the predictors of comfort in The Wellington Comfort Index and The Christchurch Comfort Index as this was unknown for both studies.

It was unknown whether the participant understood the questions. The way the questions are understood may vary between participants. This may be due to some participants not having English as their first language. This had no effect when comparing the predictors in The Wellington Comfort Index and The Christchurch Comfort Index as this was unknown for both studies.

It was unknown if the participant could read the survey. Participants may of also had impaired eyesight, or an issue with their eye sight which is not known. This could affect their responses through them randomly selecting the answers, or accidently selecting a different answer than they were intending. This had a limited effect when comparing The Wellington Comfort Index and The Christchurch Comfort Index as this would have influenced both surveys to the same degree. 
3.4.2. CALCULATING THE CHRISTCHURCH COMFORT INDEX

The methodology used to calculate The Christchurch Comfort Index was the same as was used to calculate The Wellington Comfort Index. However, when part of the methodology was unknown, assumptions were made based on common statistical practice for calculating a multiple-linear regression formula (Field, 2013).

As outlined above, there were fifteen items included in The Wellington Comfort Index, based on thirteen questions:

1. "Rate how warm or cold you feel" (7 point scale)

2. "Rate your impression of the wind level" (7 point scale)

3. "Rate how warm or cold your surroundings are" (7 point scale)

4. "Rate your impression of the cool effect of the wind" (5 point scale)

5. "In exposed places, the wind is ...?" (5 point scale)

6. "Today the wind is annoying" (5 point scale)

7. "Today is a really good day to be outside in this sort of location" (5 point scale)

8. Wind speed relative to a central location (difference in wind speed between participant and case study weather station)

9. "Your "Clo" Value: the value of your clothing's insulation" (answer in 'Clo')

10. "Seating position: exposure to the sun" (5 point scale?)

11. "Seating position: exposure to the wind" (5 point scale?)

12. Wearing of sunglasses (yes or no)

13. Time exposed (in minutes)

14. Exposure time preferred (in minutes)

15. Exposure time anticipated (in minutes) 


\section{Re-coding of Multiple-choice Questions}

In the survey for calculating The Christchurch Comfort Index, some of the multiple-choice questions were changed to simplify the re-coding of the questions for calculating The Christchurch Comfort Index. In Wellington, for items asking the participants how long they had been sitting in a location, or how long they intended to stay in that location, the response was a continuous value. This meant a participant could write down how many minutes they had been there as a number. However, in Christchurch, this was replaced with class intervals (for example, 0-5 minutes, 6-10 minutes etc.). This decision was made to simplify the re-coding of the data before the regression analysis was completed. This would not have made a difference to the conclusions reached by this analysis at this process followed common statistical practice for converting the continuous values to class intervals (Field, 2013, p. 10).

\section{Re-coding of Survey Responses}

It is unknown how the data was re-coded before the calculation of The Wellington Comfort Index. Although the authors of the original paper noted that the data was re-coded, they were unable to remember how they had re-coded the survey responses. However, it was stated that "Thus above and below the comfort index mean score of 50 there are values one would appropriately describe as 'uncomfortable'" (Walton et al., 2007, p. 3173). This definition of the interpretation of the results of The Wellington Comfort Index can be displayed on a continuum (Figure 3.27).

\footnotetext{
Thermal comfort Scores One Fifty One-hundred More change is required Thermally Neutral More change is required

Figure 3.27 shows how The Wellington Comfort Index is interpreted. The red indicates people would need to change their behaviour to maintain their comfort. Whereas, the neutral colour indicated where people would not need to change their behaviour to maintain their comfort.

The Wellington Comfort Index's results predict the degree people would need to change their behaviour to maintain their comfort on a scale between one and one-hundred. The midpoint, fifty represents thermally comfortable, and a number closer to one or one-hundred represents thermally uncomfortable. Therefore, the survey responses in Wellington would have been arranged to mirror this index.
} 
As an example the question "rate how warm or could you feel" is on a seven point scale, with four as the thermally neutral point, and one and seven representing thermally uncomfortable. Whereas, the question "in exposed places the wind is....?" the scale is a five point scale from "far too strong" representing thermally uncomfortable to "wind not noticeable" representing thermally comfortable. Therefore, the thermally comfortable and thermally uncomfortable scales of these two questions were arranged differently than one another (Figure 3.28).

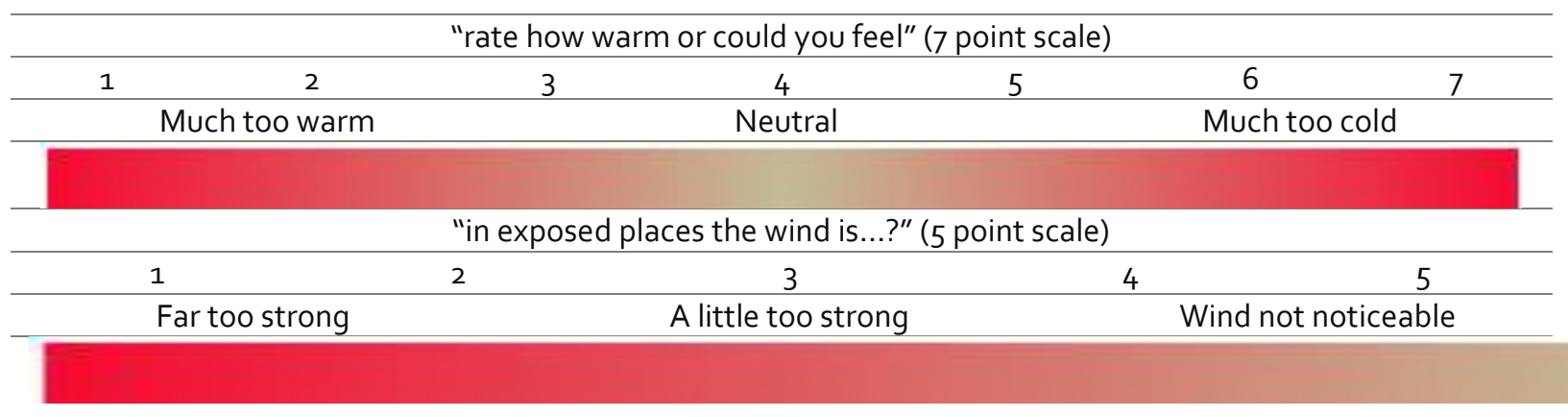

Figure 3.28 shows two of the questions from the survey, each with different scales.

For the calculation of The Christchurch Comfort Index the scales for each question were aligned with one as thermally comfortable midpoint of the scale, and a three, four, or five representing thermally uncomfortable at either end of the scale.

As an example two questions are displayed below to show how they were re-coded to align with the scale of The Wellington Comfort Index:

\begin{tabular}{|c|c|c|c|c|c|c|c|}
\hline \multirow{3}{*}{$\begin{array}{c}\text { Survey } \\
\text { Response }\end{array}$} & \multicolumn{7}{|c|}{ "rate how warm or could you feel" (7 point scale) } \\
\hline & 1 & 2 & 3 & 4 & 5 & 6 & 7 \\
\hline & \multicolumn{3}{|c|}{ Much too warm } & \multicolumn{2}{|c|}{ Neutral } & \multicolumn{2}{|c|}{ Much too cold } \\
\hline & \multicolumn{7}{|c|}{ "rate how warm or could you feel" (7 point scale) } \\
\hline \multirow[t]{2}{*}{ Re-coded } & 4 & 3 & 2 & 1 & 2 & 3 & \\
\hline & \multicolumn{3}{|c|}{ Much too warm } & Neutr & & Muc & \\
\hline
\end{tabular}

\begin{tabular}{|c|c|c|c|c|c|}
\hline \multirow{3}{*}{$\begin{array}{c}\text { Survey } \\
\text { Response }\end{array}$} & \multicolumn{5}{|c|}{ "in exposed places the wind is...?" (5 point scale) } \\
\hline & 1 & 2 & 3 & 4 & 5 \\
\hline & \multicolumn{2}{|c|}{ Far too strong } & A little too strong & \multicolumn{2}{|c|}{ Wind not noticeable } \\
\hline \multicolumn{6}{|c|}{ "in exposed places the wind is...?" (5 point scale) } \\
\hline Re-coded & 5 & 4 & 4 & 2 & 1 \\
\hline \multicolumn{3}{|c|}{ Far too strong } & A little too strong & \multicolumn{2}{|c|}{ Wind not noticeable } \\
\hline
\end{tabular}


All survey responses on a Likert Scale were re-coded with thermally comfortable as a one and a number closer to three, four, or five representing thermally uncomfortable. Questions which were not on a Likert Scale were not re-coded. The questions not re-coded include included the clo-value of the clothing a participant was wearing, whether they were wearing sunglasses, and the wind speed relative to the case study weather station. See Appendix 8.2.6 'Re-Coding of Questions' for the list of re-coded survey responses. The raw dataset for the Christchurch survey is included in Appendix 8.2.7 'Survey Results: Raw Data of The Christchurch Comfort Index'.

\section{Standardisation of the Survey Responses}

As with the development of The Wellington Comfort Index, the survey responses for each participant were standardised to achieve scale uniformity (Equation 10). This is because some responses were on a 1-5 scale, and some were on a 1-7 scale. Questions not on a Likert Scale were also standardised. This is standard practice in a generalised linear model to have survey responses on different scales and in different units (Field, 2013, p. 916).

Equation 10 is the equation used to standardised the survey responses (Field, 2013, p. 31):

$$
Z=\frac{(X-\mu)}{\sigma}
$$

Where:

$$
\begin{aligned}
& \mu=\text { mean } \\
& \sigma=\text { standard deviation of the survey responses for each question } \\
& X=\text { score (survey response) } \\
& Z=\text { standardised score (standardised survey response) }
\end{aligned}
$$

Kaiser-Meyer-Olkin Score - Relationships between Variables

For the Wellington study, a Kaiser-Meyer-Olkin score was calculated to understand if the correlations between the variables were sufficient to create The Wellington Comfort Index (Walton et al., 2007, p. 3170). This results in a number between zero and one. A value closer to one indicates that there are significant correlations between the variables. Therefore, The Wellington Comfort Index could be created from these variables. However, a number closer to zero indicates that there is a limited relationship between the variables. Therefore The Wellington Comfort Index would not be able to predict thermal comfort 
(Field, 2013, p. 877). For Wellington, the Kaiser-Meyer-Olkin score was .807. This suggests that there is a good relationship between the variables (the 15 items) to create The Wellington Comfort Index.

This step was excluded for Christchurch as it was likely that the fifteen items used to create The Christchurch Comfort Index would have an equally as strong relationship as in The Wellington Comfort Index. This is because the same fifteen items were included in The Christchurch Comfort Index.

\section{Principal Component Analysis - Identifying Patterns in a Dataset}

To understand if the variables which were included in The Wellington Comfort Index had the same importance in Christchurch, a principal component factor analysis was conducted for the Christchurch dataset.

Although the study for developing The Wellington Comfort Index reported that there were fifteen items included in The Wellington Comfort Index, when the dataset for the Wellington study was examined closely, there were only thirteen items in the raw dataset. Seating position relative to the sun, and seating position relative to the wind were not in the dataset for Wellington.

For this reason, the principal component factor analysis for Wellington and Christchurch only included the thirteen items which were available in both Wellington and Christchurch datasets. This excludes the two questions about the participant's relationship to the sun and the wind.

In the study used to develop The Wellington Comfort Index, the principal component analysis showed that Component One represented $25.4 \%$ of the variation of the fifteen items used to create The Wellington Comfort Index (Walton et al., 2007, p. 3170). However, as the dataset for Wellington was available, the principal component analysis was conducted again, using only the thirteen items which were included in the dataset. 
The variance in the items which made up Component One were compared for Wellington and Christchurch (Table 3.5). In Wellington, 31.112\% of the variance was represented by Component One. For Christchurch, 31.018\% of the variance was represented by Component One.

Table 3.5 shows the comparison of the variance in the survey responses represented by Component One between Wellington and Christchurch. It is this component which determines the weightings which represent the importance of each item on predicting comfort.

\begin{tabular}{|c|c|c|c|c|c|c|}
\hline \multirow{3}{*}{ Component } & \multicolumn{3}{|c|}{ Wellington: Total Variance Explained } & \multicolumn{3}{|c|}{ Christchurch: Total Variance Explained } \\
\hline & \multicolumn{3}{|c|}{ Extraction Sums of Squared Loadings } & \multicolumn{3}{|c|}{ Extraction Sums of Squared Loadings } \\
\hline & Total & $\begin{array}{l}\% \text { of } \\
\text { Variance }\end{array}$ & $\begin{array}{l}\text { Cumulative } \\
\%\end{array}$ & Total & $\begin{array}{l}\% \text { of } \\
\text { Variance }\end{array}$ & $\begin{array}{l}\text { Cumulative } \\
\%\end{array}$ \\
\hline 1 & 4.045 & 31.112 & 31.112 & 4.032 & 31.018 & 31.018 \\
\hline 2 & 1.891 & 14.550 & 45.662 & 1.994 & $15 \cdot 340$ & 46.357 \\
\hline 3 & 1.125 & 8.654 & $54 \cdot 315$ & 1.716 & 13.199 & $59 \cdot 557$ \\
\hline 4 & & & & 1.231 & 9.469 & 69.025 \\
\hline
\end{tabular}

Different items have different weightings of importance within Component One when predicting thermal comfort. Therefore these weightings need to be applied to the survey responses when calculating a single thermal comfort scale. The thermal comfort score represents a participant's responses to the survey questions, represented as a single number. It is the sum of a participant's response to a survey question which has been standardised to achieve scale uniformity, and multiplied by the weighting for each question which makes up Component One (Table 3.6). These weightings are automatically generated in the principal component analysis. This process is completed for each participant's survey responses, resulting in one number which represents each participant's survey results. In Christchurch there were a total of thirty thermal comfort scores, one for each participant.

Table 3.6 shows the weightings which represent the importance of each question for quantifying how people will adapt to maintain their thermal comfort levels in Christchurch and Wellington.

\begin{tabular}{l|l|l}
\hline \multicolumn{1}{c|}{ Question/ltem } & $\begin{array}{c}\text { Weighting from } \\
\text { Component One: } \\
\text { Christchurch } \\
\text { dataset }\end{array}$ & $\begin{array}{c}\text { Weighting from } \\
\text { Component One: } \\
\text { Wellington dataset }\end{array}$ \\
\hline Q1 Rate how warm or cold you feel & .260 & .591 \\
\hline Q2 Rate your impression of the wind level. & .845 & -.408 \\
\hline Q3 Rate how warm or cold your surroundings & -.009 & -.653 \\
\hline Q4 Rate your impression of the cooling effect of the wind & .694 & -.399 \\
\hline
\end{tabular}




\begin{tabular}{l|l|l}
\hline Q5 In exposed places, the wind is... & .694 & .332 \\
\hline Q6 Today the wind is annoying & .787 & -.509 \\
\hline $\begin{array}{l}\text { Q7 Today is a really good day to be outdoors in this sort of } \\
\text { area }\end{array}$ & .208 & -.695 \\
\hline Q8 Wind relative to the central location (exposed)? & -.375 & .321 \\
\hline Q9 Your "Clo" Value: the value of your clothing's insulation & .654 & .383 \\
\hline Q12 Sunglasses & -.201 & .749 \\
\hline Q13 Approximately how long have you been here? & -.081 & .530 \\
\hline Q14 How much longer would you like to stay here? & .762 & .470 \\
\hline $\begin{array}{l}\text { Q15 Before you sat down, how long did you expect to stay } \\
\text { here? }\end{array}$ & .655 & .523 \\
\hline
\end{tabular}




\section{Calculating The Christchurch Comfort Index}

To follow the process for creating The Wellington Comfort Index, the weighted and standardised thermal comfort scores for the Christchurch survey were also adjusted to have a minimum value of one, and a maximum value of one-hundred. This is so The Christchurch Comfort Index aligned with The Wellington Comfort Index.

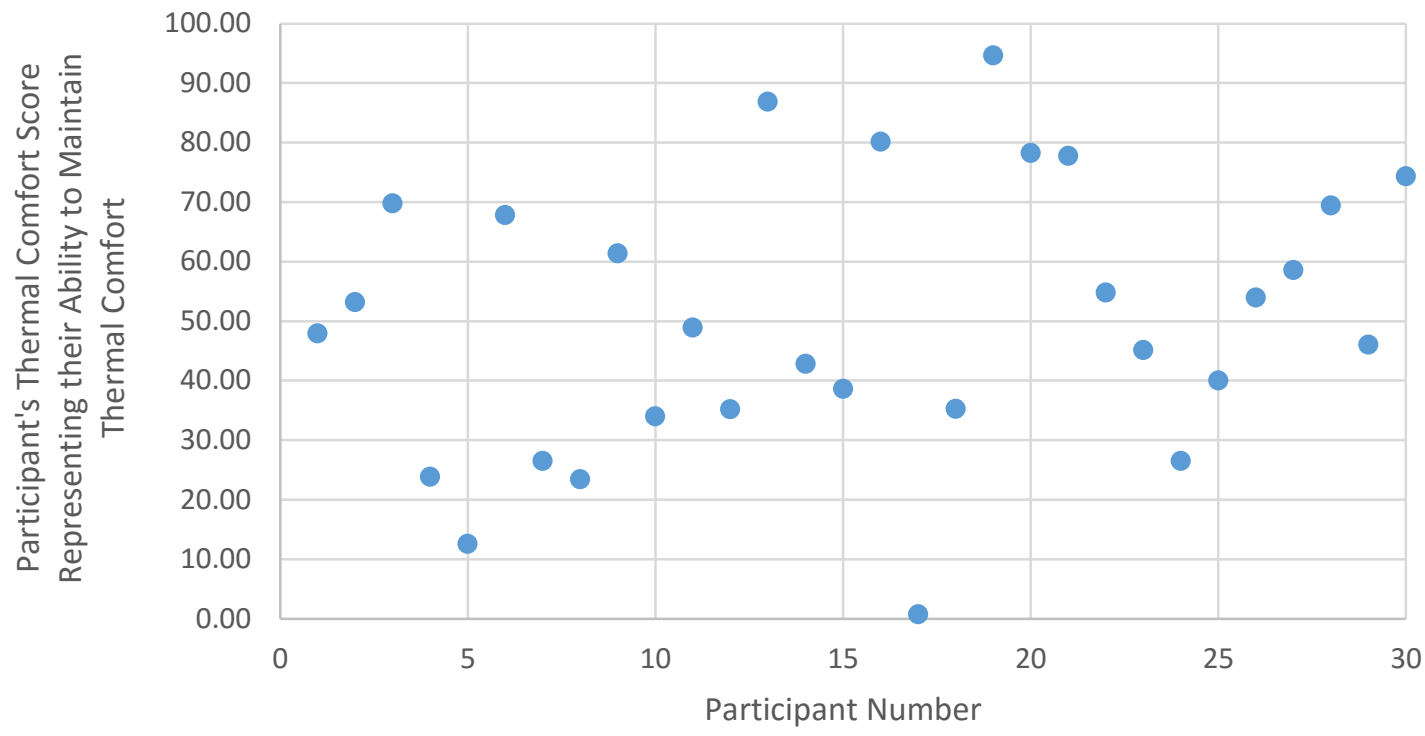

Figure 3.29 shows the sum of the weighted and standardised thermal comfort scores from the Christchurch survey for each participant. Each point on the graph represents a participant's response to the survey questions, as a single number.

For the development of The Christchurch Comfort Index, a regression analysis was conducted. The thermal comfort scores for each participant were the dependent variable (Figure 3.29). The independent variables were the mean wind speed, maximum wind speed, mean radiant temperature, and ambient temperature measured at the case study weather station. The regression analysis was to determine which environmental factors (mean wind speed, maximum wind speed, ambient temperature, and mean radiant temperature) were as statistically significant as when predicting outdoor thermal comfort in Christchurch. Therefore, whether they should be included in The Christchurch Comfort Index or not.

For the development of The Christchurch Comfort Index, any independent variable with a significance of $p<0.1$ was included in The Christchurch Comfort Index. This suggests that there may be up to a ten percent chance that this sample is not representative of the greater population (Field, 2013, p. 69). However, for The Wellington Comfort Index, there 
were 649 participants who took part in the survey. Therefore, The Wellington Comfort Index was based on independent variables which had a significance of $p<0.05$. This is due to there being more certainty in the results due to the larger sample (Field, 2013, p. 69).

Table 3.7 shows the significance of each independent variable is shown below. Due to the small sample size, any variables with a significance of more than $p<0.1$ were included in The Christchurch Comfort Index.

\begin{tabular}{l|l|l}
\hline \multicolumn{1}{c|}{ Independent Variables } & \multicolumn{1}{|c|}{ Significance $(p)$} & Regression Co-efficient $(B)$ \\
\hline Constant & 54.924 & 183.921 \\
\hline Maximum wind & .004 & 21.609 \\
\hline Mean wind & .237 & -8.393 \\
\hline Mean radiant temperature & .239 & 5.321 \\
\hline Ambient temperature & .053 & -19.098 \\
\hline
\end{tabular}

\section{Analysis For the use of The Wellington Comfort Index in other Cities}

Further investigation was required on whether The Wellington Comfort Index is applicable to other cities. If the sample used to develop The Christchurch Comfort Index was larger, it would be possible that The Christchurch Comfort Index would have included the mean wind speed and mean radiant temperature (Field, 2013, p. 72). This is because The Wellington Comfort Index is based on the responses of 649 participants. Whereas, The Christchurch Comfort Index is only based on the responses of thirty participants. If The Christchurch Comfort Index was based on a sample size similar to Wellington's then the greater the ability to find the effect that mean wind speed, maximum wind speed, mean radiant temperature, and ambient temperature have on predicting how people would change their behaviour to become comfortable (Field, 2013, p. 72). This would create more certainty in the results of the regression analysis and increase the possibility that their significant value ( $p$ ) would be below $p<0.1$. Therefore, would be included in The Christchurch Comfort Index as well. 
Equation 11 is The Christchurch Comfort Index:

Behavioural changes to maintain thermal comfort $=183.92$

+ 21.61 x Maximum Wind - $19.10 \times$ Ambient Temperature

Equation 12 is The Wellington Comfort Index (Walton et al., 2007, p. 3171):

Behavioural changes to maintain thermal comfort $=25.52$

$+10.65 \times$ Mean Wind - 5.77 x Maximum Wind

+ 0.85 x Mean Radiant Temperature ${ }_{(\text {exposed) }}$

$+0.53 \times$ Ambient Temperature

Maximum wind speed and ambient temperature were included in The Christchurch Comfort Index as they had a significance value of $p<0.1$ (Equation 10). However, mean wind speed and mean radiant temperature had high significance values of almost $p>0.25$ which suggests there is a seventy-five-percent chance that these variables were only representative of this specific sample used to calculate The Christchurch Comfort Index. 
This chapter has identified the methodology for developing the Process for Predicting Outdoor Thermal Comfort into The Comfort Tool. This included the reasoning behind the case study research approach and case studies selected. As discussed in Section 3.1 'Selection of Case Studies for Testing the Comfort Tool', the case studies were selected based on their variations in built form, orientation, and size. Section 3.2 'Can the Process for Predicting Outdoor Thermal Comfort be developed into a tool for use at the preliminary design stage?' developed criteria for selecting wind analysis programs and solar radiation programs which allow for consultants and designers to select their own software to use as part of The Comfort Tool. Section 3.3 'Can thermal comfort be automatically communicated across a development?' established how to display thermal comfort levels across a proposed development.

This chapter also established in Section 3.4 'What is the applicability of The Wellington Comfort Index to cities outside of Wellington?' that The Wellington Comfort Index may be applicable to cities outside of Wellington due to the ambient temperature and maximum wind speed being included in The Christchurch Comfort Index.

The next chapter evaluates the success of The Comfort Tool at predicting thermal comfort through using The Comfort Tool to calculate the comfort across four case studies. 
pg. 107 


\section{ARE THE RESULTS FROM A COMFORT TOOL ABLE TO INFORM DESIGN CHANGES?}

A case study research approach has been selected for The Comfort Tool's development. The purpose of this chapter is to evaluate the success of The Comfort Tool at predicting thermal comfort. This evaluation is based on two of the research questions: "Can thermal comfort be automatically communicated across a development?" and "Are the results from a comfort tool able to inform design changes?" These research questions are the criteria which are used to test the success of The Comfort Tool. If The Comfort Tool is able to do this, then these results prove that The Comfort Tool meets the aim of this thesis project which is to develop the Process for Predicting Outdoor Thermal Comfort into a tool for use at the preliminary design stage of a development. Three additional case studies were selected to evaluate whether The Comfort Tool can predict thermal comfort for a broad range of building types or whether the success of the first case study was a singular occurrence. This will determine if the success of the first case study was a specific coincidence, or whether The Comfort Tool has the same degree of success for other developments which have varying levels of wind and solar radiation at pedestrian level due to their variations in built form.

The two research questions have a different purpose in testing The Comfort Tool's ability to predict thermal comfort for use within urban planning and architecture. The first question: "Are the results from a comfort tool able to inform design changes?" is to investigate if the results communicated by The Comfort Tool provide information which can inform design changes. A design change may be moving a lane or changing the height of a building.

The second research question: "Can comfort be automatically communicated across a development?" determines if The Comfort Tool can automatically calculate and communicate thermal comfort levels across a case study. This is contrary to the Process for Predicting Outdoor Thermal Comfort where thermal comfort could only be calculated at a single point within the case study at a time. Therefore, to calculate thermal comfort across a whole development would be time consuming as the Process for Predicting Outdoor Thermal Comfort may need to be repeated hundreds of times. Without this assessment of 
comfort across a development, it would be difficult for designers and consultants to understand the level of thermal comfort in different areas of a development.

As well as this, it gains an understanding of how thermal comfort is displayed for differences in urban forms. For example, different angled and sized lanes and different sized courtyards may be displayed differently in The Comfort Tool than on the plans. To test this, it was asked if the results displayed on the plan view resembled the plan view of the development.

\subsection{MAPPING THERMAL COMFORT - DISCUSSION}

Before The Comfort Tool can be used to test the case studies against the criteria for testing the tool, a broader understanding of The Comfort Tool is required. As discussed in Section 3.3 'Can thermal comfort be automatically communicated across a development?' this equates to the thermal comfort being calculated for every ten metre point on a grid across a development. The Comfort Tool is an excel based tool. The solar radiation and the wind reduction factor for each of the 121 measurement points within a proposed development are all placed into a spreadsheet which allows for a macro to automatically go through the solar radiation measurement and wind reduction factor for each data point and calculate the thermal comfort using The Wellington Comfort Index for each hour of the year.

The solar radiation and wind reduction computer programs cannot be linked automatically as the selection of these computer programs is decided on by the consultant or designer based on the criteria developed in Section 3.2.2 'Criteria for Selecting Wind Analysis Programs'. This is to allow designers and consultants to select the wind analysis and solar radiation programs which are accessible to them. See Section 3.2.3 'Selecting Solar Radiation Programs' for discussion on solar radiation programs.

Once The Comfort Tool has calculated thermal comfort for each point within the proposed development, there are numerous ways the thermal comfort data can be averaged. In this thesis project, the data displayed is the average thermal comfort for approximately threehundred hours rather than for all 8760 hours of the year. This is separated into four hour periods of the day, for each season separately. However, the results of The Comfort Tool 
can be adapted for each development, allowing for The Comfort Tool to focus on key times of the day for each development.

If the thermal comfort results were displayed for the average of all hours of the year, the results could be misleading, and periods of thermal discomfort may be lost when averaged with a period where the thermal comfort levels may be considered comfortable. Another approach could have been to assess the thermal comfort for a typical day in summer and winter. However, if only these two days were selected, this would not give an adequate insight into the thermal comfort levels for a development which will be used all year around.

The scale used to interpolate the results of The Comfort Tool is displayed under each set of outdoor thermal comfort results. An in-depth explanation of each scale is contained following the glossary. 


\subsection{EVALUATING THE COMFORT TOOL FOR DIFFERENT URBAN DESIGN SCENARIOS}

Case Study One was selected to test The Comfort Tool's ability at informing design changes for improving outdoor thermal comfort. The characteristics of this case study are that it is a large development of $8500 \mathrm{~m}^{2}$ with a central courtyard. The buildings surrounding this courtyard are tiered to allow for more solar radiation at pedestrian level. There are lanes linking the central courtyard to the West, North, and South, which may cause issues with wind funnelling into this central area.

Case Study One was also selected as a case study as it was used in a previous study for developing the Process for Predicting Outdoor Thermal Comfort to test the success of The Process. This decision was made as it allowed the improvements in The Comfort Tool to be compared with the Process for Predicting Outdoor Thermal Comfort. An example of this is the time it takes to calculate the wind reduction factors across a proposed development. It was taking less than half an hour when wind was only being measured at one point within a proposed development. However, when wind is calculated at 121 measurement points, it took a day or more to calculate the wind reduction factors. This will make a difference in The Comfort Tool's use within urban planning and architecture. If using The Comfort Tool is costly (due to a lengthy process), then this may discourage developers from requesting an assessment of outdoor thermal comfort.

Case Study Two tests if The Comfort Tool can predict thermal comfort across a development with high levels of wind. Due to a large open courtyard which is surrounded by buildings of similar heights and lanes facing the East (the predominant wind direction) there may be issues with wind. This is in contrast to Case Study One which faces away from the predominant wind, and has the buildings tiered around the central courtyard which directs the wind away from pedestrian level.

Case Study Three tests if The Comfort Tool can show variations in thermal comfort for evening periods where there is no solar radiation. Therefore, wind is the only influence on thermal comfort which can be mitigated to improve outdoor thermal comfort levels. This case study also has narrow lanes. 
Case Study Four tests if The Comfort Tool can predict outdoor thermal comfort levels on a small case study constructed around a small courtyard. This may limit solar radiation in this courtyard due to the courtyard facing a neighbouring four storey building to the West of the case study site.

\subsubsection{CASE STUDY ONE}

Case Study One (Figure 4.1) was selected because it tests whether The Comfort Tool can predict outdoor thermal comfort results to help inform design changes for a large development. The development is $8500 \mathrm{~m}^{2}$, and covers half a city block. It consists of six buildings, and has lanes in the North, South, East, and West directions. The buildings around the central courtyard are tiered (blue rectangle) to allow for more solar radiation at pedestrian level.
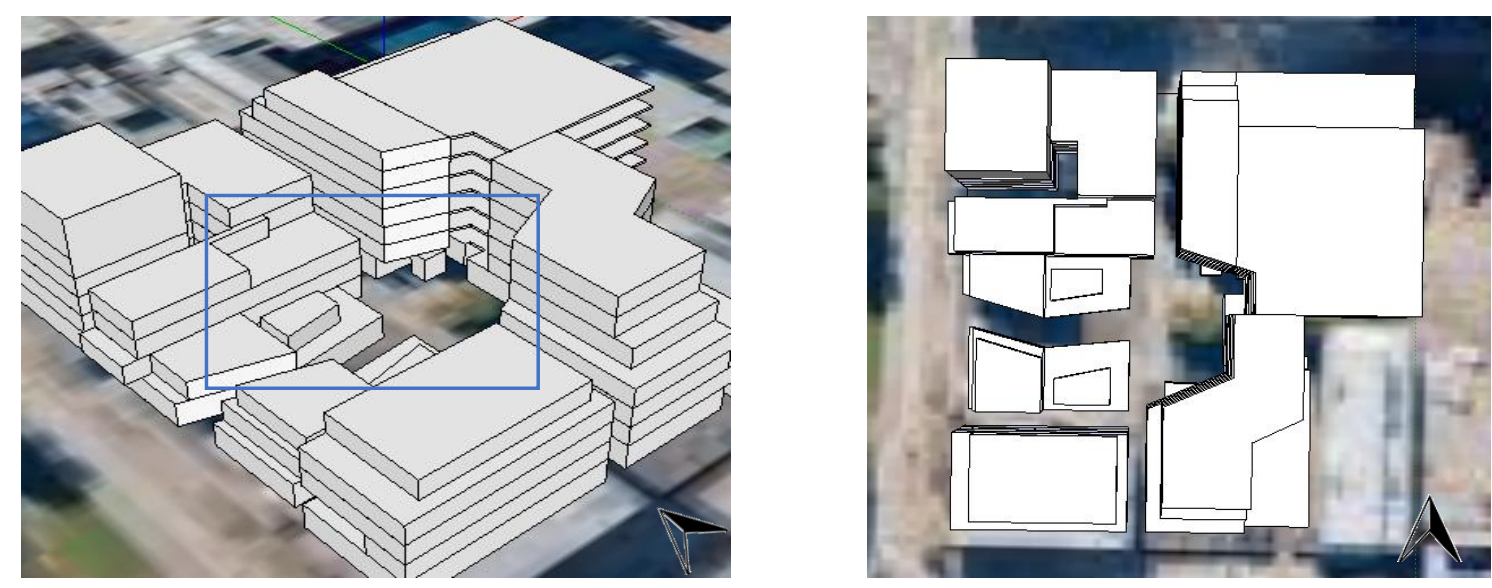

Figure 4.1 shows Case Study One. A perspective view is shown on the left. The blue rectangle shows the large central courtyard with the buildings tiered around it to allow for solar radiation at pedestrian level. A plan view is shown on the right.

\section{Can thermal comfort be automatically}

communicated across a development?

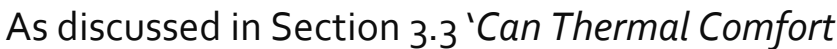
be Automatically Communicated Across a

Development?' the ten by ten metre grid had to be adjusted specifically for Case Study One so that the points where the solar radiation and wind reduction factors were calculated aligned with the lanes, courtyards, and surrounding

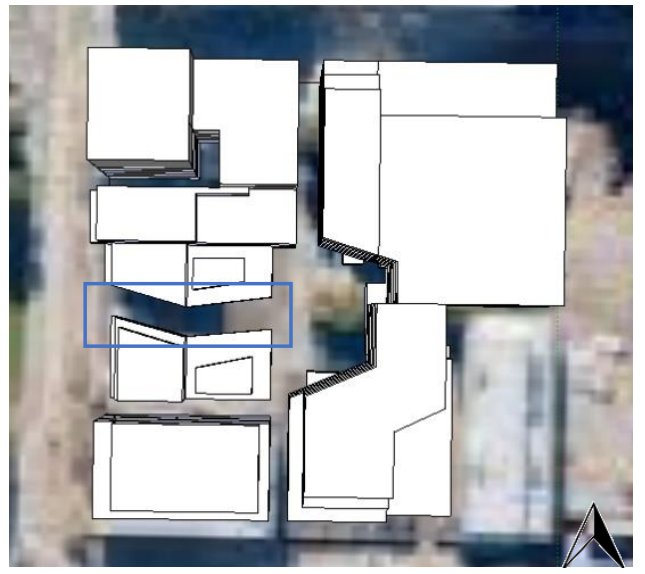

Figure 4.2 shows the lane which The Comfort Tool showed as a straight lane. 
footpaths. However, once this data was in The Comfort Tool itself, thermal comfort was calculated automatically using a macro. This meant that once the wind reduction factors and solar radiation measurements were in The Comfort Tool, there did not need to be any changes by the user.

The Comfort Tool is able to display variations in thermal comfort across a development. This is shown in Figure 4.3 by some areas of the case study being shaded red and some areas being shaded a neutral colour. The variations indicate areas which are thermally comfortable and areas where it is less comfortable. However, The Comfort Tool was not able to show the angled lane (blue rectangle, Figure 4.2), as it displayed it as a straight lane (Figure 4.3).

Thermal Comfort for Case Study One

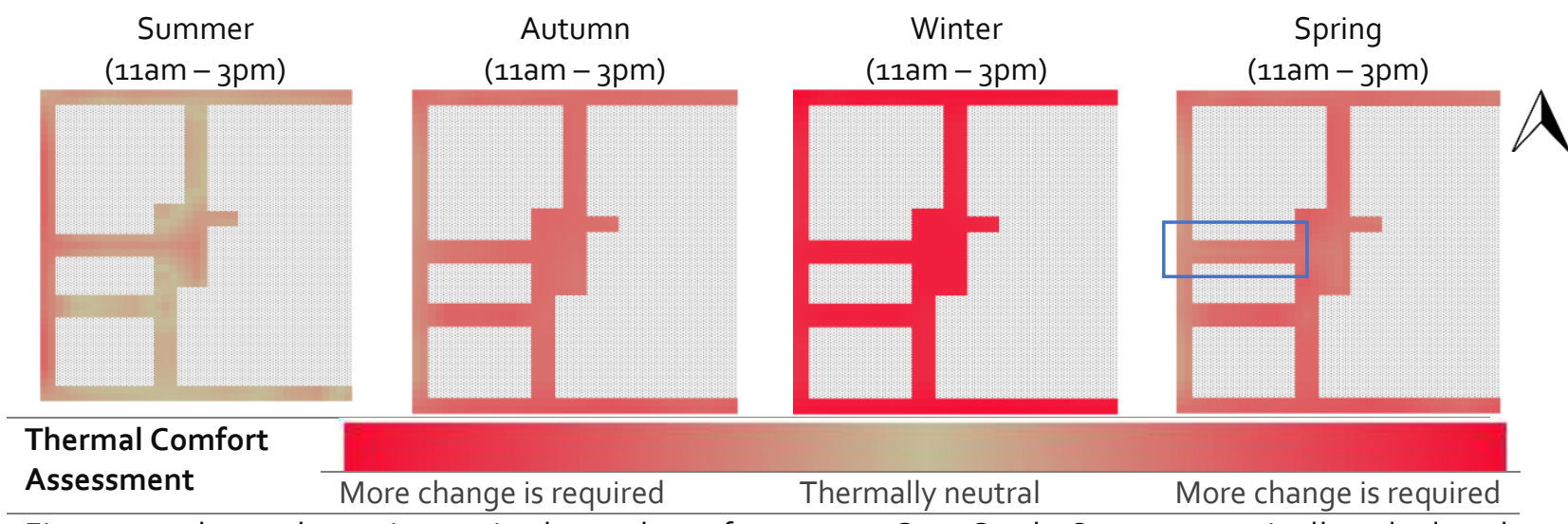

Figure 4.3 shows the variances in thermal comfort across Case Study One automatically calculated and communicated by The Comfort Tool.

Are the results of The Comfort Tool able to inform design changes?

For Case Study One, the thermal comfort assessment was completed between 11am - 3pm for each season (Figure 4.3). The results shown in Figure 4.3 show that The Comfort Tool is able to inform design changes by shading different areas of the case study red (thermal discomfort) or a neutral colour (thermally comfortable). This indicates that The Comfort Tool can capture the variances in thermal comfort across the different seasons for the period of 11am-3pm. In summer, most of the lanes and the majority of the central courtyard would be considered thermally comfortable (Figure 4.3). Therefore, people would not be required to change their behaviour to maintain their thermal comfort levels. However, The Comfort Tool also shows that along the Western footpath, Eastern area of 
the courtyard, and one of the Western lanes people would need to change their behaviour to maintain their thermal comfort levels.

These results also show that a hierarchy of importance needs to be created for each development based on the use of each area, as well as a hierarchy of importance for each season. Although the Western footpath is the least thermally comfortable area of this case study in summer, it is the most thermally comfortable area in spring and autumn. A designer or consultant would be required to decide whether it is more important to have the Western footpath less thermally comfortable in summer in exchange for it being more thermally comfortable in spring and autumn.

The Comfort Tool is able to inform which areas of the case study are thermal comfortable or uncomfortable, but it does not inform designers and consultants what should be focused on to improve the thermal comfort. The results of The Comfort Tool are vital as they illustrate the combined effect of wind, solar radiation, and ambient temperature on thermal comfort. However, for The Comfort Tool to be able to inform design changes, consultants and designers need to know what to change to improve thermal comfort. Do they need to shade from the sun, or design for less shade, reduce the wind, or increase the cooling effect of the breeze? The combinations of design solutions are endless.

To allow for the thermal comfort results to be used to inform design changes, the individual wind and solar radiation results across a case study were also incorporated into The Comfort Tool. This allows for the primary environmental factor which may be influencing thermal comfort or discomfort to be identified. 


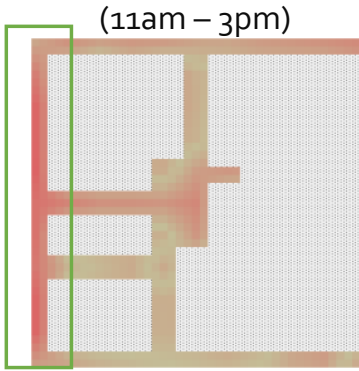

11am - 3pm

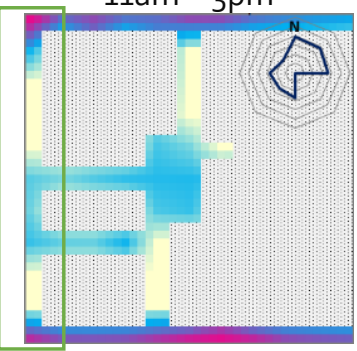

(11am - 3pm)

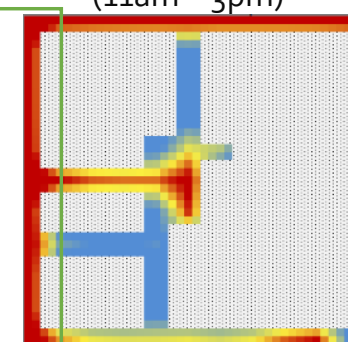

Wind Assessment

Predominant wind

direction outside of the

Low wind speeds (m/s)

High wind speeds

(greater than $5 \mathrm{~m} / \mathrm{s}$ )

\section{Solar Radiation}

Assessment

Thermal Comfort

Assessment $\quad$ More change is required Thermally neutral More change is required

The least solar radiation

The most solar radiation

Figure 4.4 shows that when the results of The Comfort Tool are next to one another (thermal comfort, wind, and solar radiation) that the environmental factor which is causing the discomfort can be more easily identified.

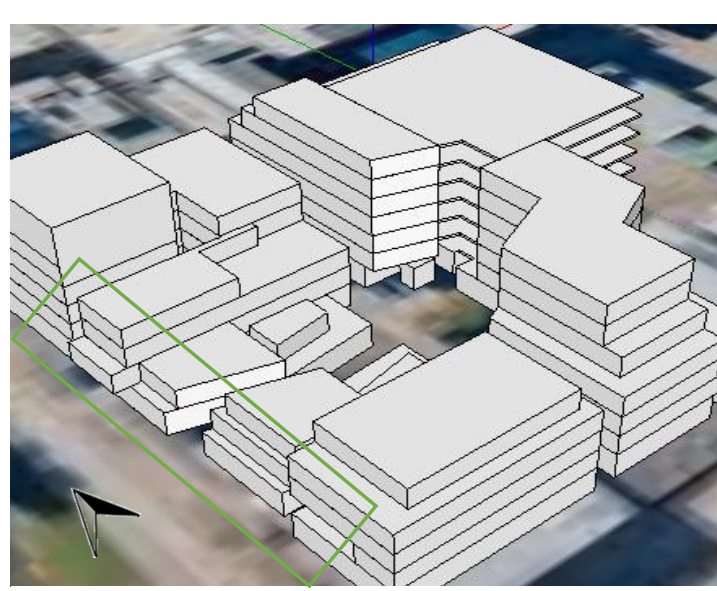

Figure 4.5 shows a view of Case Study One. If a thermal comfort assessment focuses on the Western footpath, then the design features along this Western footpath can be analysed to determine potential improvements in design to mitigate issues with thermal comfort.
When the wind, solar radiation and thermal comfort results are next to one another, along with a plan or diagram of a case study (Figure 4.5) then a deeper understanding of what is causing the thermal discomfort or comfort is gained.

For example, if a designer or consultant wanted to improve thermal comfort along the Western footpath of Case Study One, the results of the solar radiation and wind can be assessed closely along the Western footpath (green rectangle, Figure 4.4). This shows that there are high levels of solar radiation along the Western footpath. Although it is sheltered from the wind to the North and South of the Western footpath, there are high levels of wind in the central area where the lanes from the central courtyard link onto the Western footpath (green rectangle, Figure 4.4). 
The inclusion of the individual wind and solar radiation results in The Comfort Tool can show the variations in wind speed and solar radiation for each season. For example, a designer or consultant may be concerned with high wind levels along the Southern footpath next to Case Study One, and the affect that this has on comfort. These seasonal differences can provide useful design information (green rectangle, Figure 4.6).
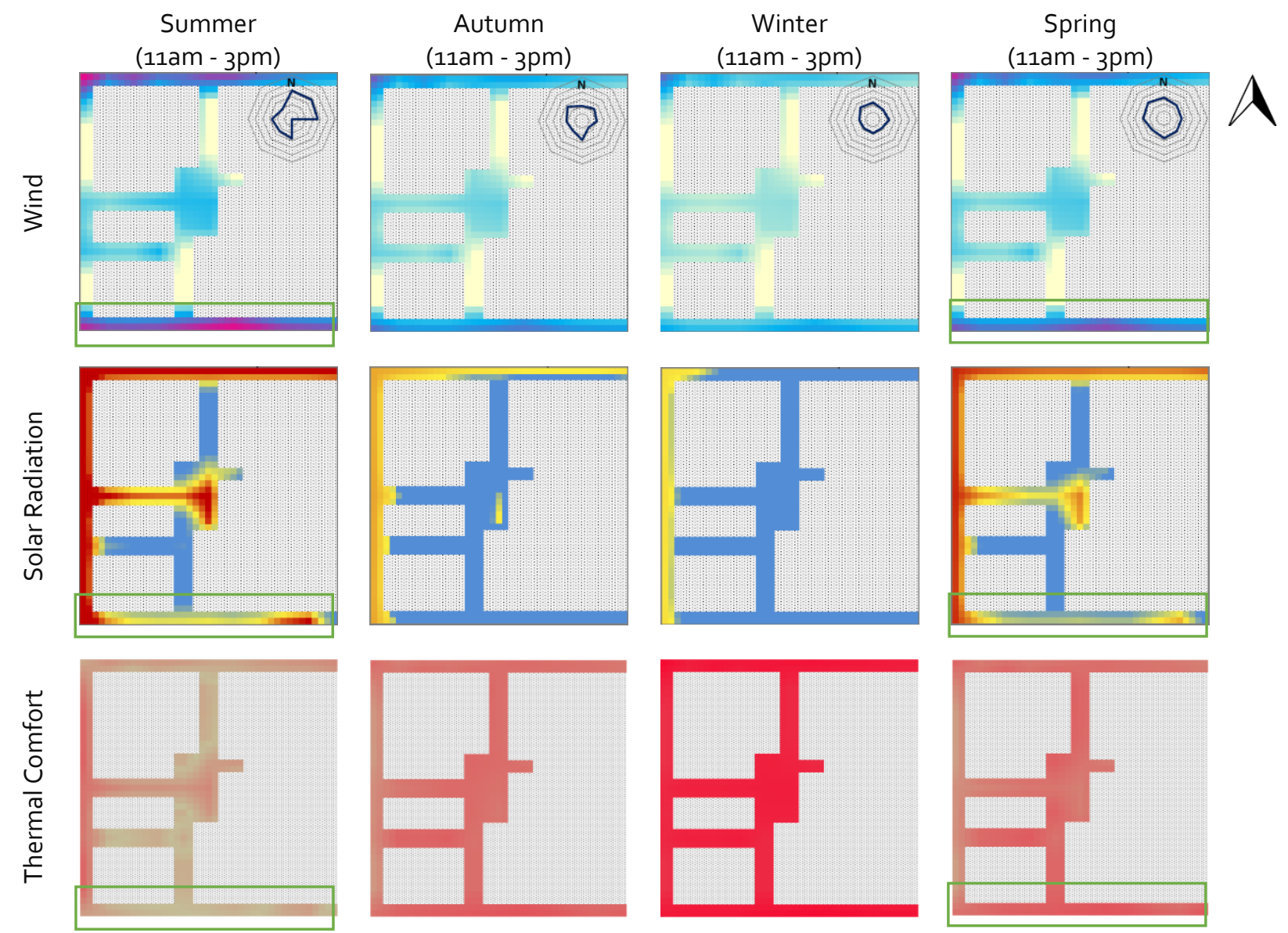

\begin{tabular}{|c|c|c|}
\hline \multicolumn{3}{|l|}{ Wind Assessment } \\
\hline $\begin{array}{l}\text { Predominant wind } \\
\text { direction outside of the } \\
\text { case study }\end{array}$ & Low wind speeds (m/s) & $\begin{array}{r}\text { High wind speeds } \\
\text { (greater than } 5 \mathrm{~m} / \mathrm{s} \text { ) }\end{array}$ \\
\hline \multicolumn{3}{|l|}{ Solar Radiation } \\
\hline Assessment & The least solar radiation & The most solar radiation \\
\hline \multirow{2}{*}{$\begin{array}{l}\text { Comfort } \\
\text { Assessment }\end{array}$} & & \\
\hline & More change is required & More change is required \\
\hline
\end{tabular}

Figure 4.6 shows how a consultant can focus on areas where there is concern. For example, there may be a concern with high wind speeds along the Southern footpath (green) then The Comfort Tool can be used to show the wind speeds, and how this effects comfort. 
The Comfort Tool shows that although the wind speeds are high along this Southern footpath in summer and spring, it is still comfortable in summer and fairly comfortable in spring (green rectangles, Figure 4.6). This may be because there is still solar radiation at pedestrian level during this assessment period.

To test if The Comfort Tool can reveal differences in comfort when design changes are made, the original design of Case Study One was altered to improve the comfort levels along the Western footpath and the Northern lane. The changes that were made were informed by the comfort results (Figure 4.6).

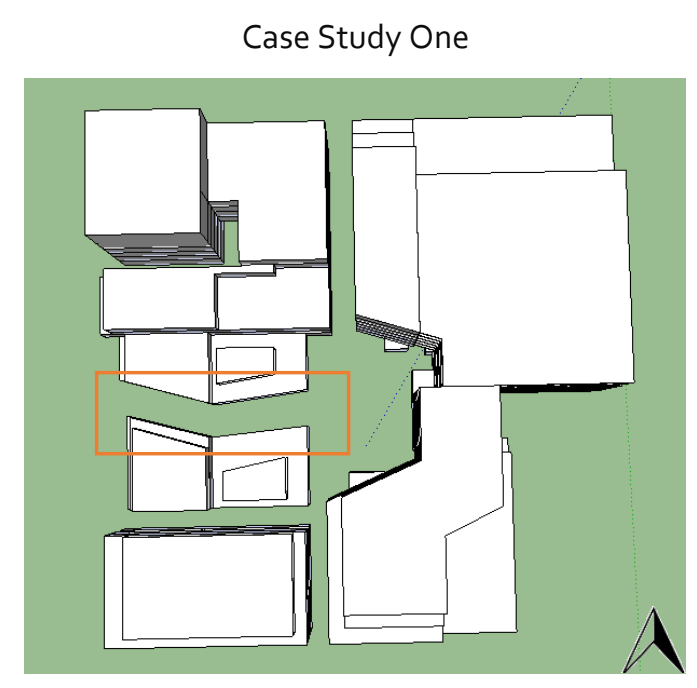

Case Study One

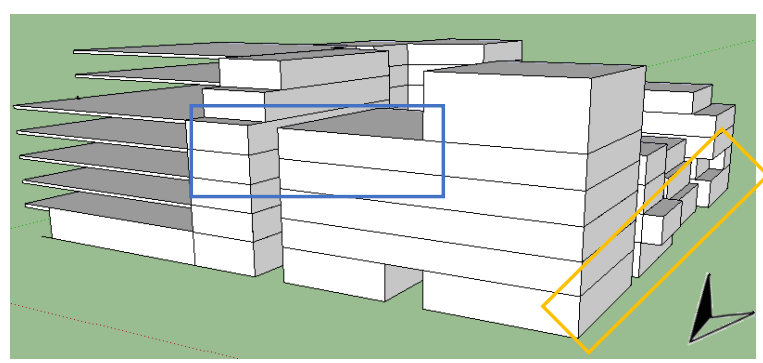

Case Study One with therm comfort improvments

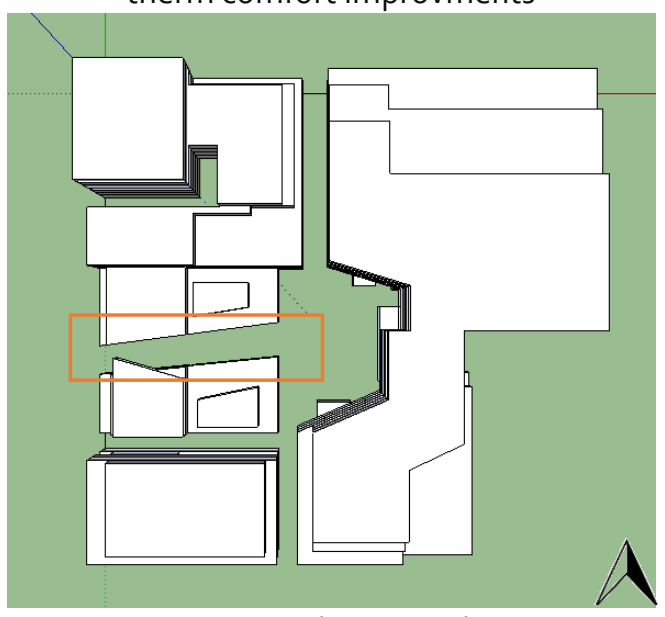

Case Study One with thermal comfort improvments

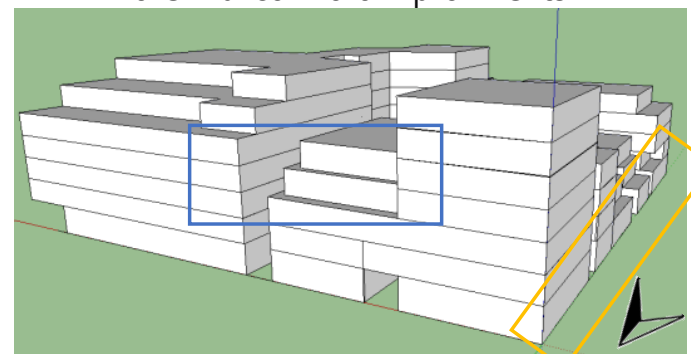

Figure 4.7 shows the design changes made to test if The Comfort Tool could inform designers how a change in design may effect a change in comfort.

1. The offsets were removed from the Western footpath to prevent wind from passing under them, and also reduce shading onto the footpath below (yellow rectangle, Figure 4.7).

2. The buildings next to the Northern lane have stepbacks at roof level to reduce the 'down wash' effect from the buildings causing the wind to flow down the buildings and into the lane (blue rectangle, Figure 4.7). 
3. Orientation of the Western lane was changed to face away from the North-westerly 'annoying wind' to face the South-west, a less common wind direction. This is to prevent the funnelling effect through the main hospitality lane into the central Courtyard (orange rectangle Figure 4.7).

\section{Comparison of Case Study One and Case Study One with Design Improvements}

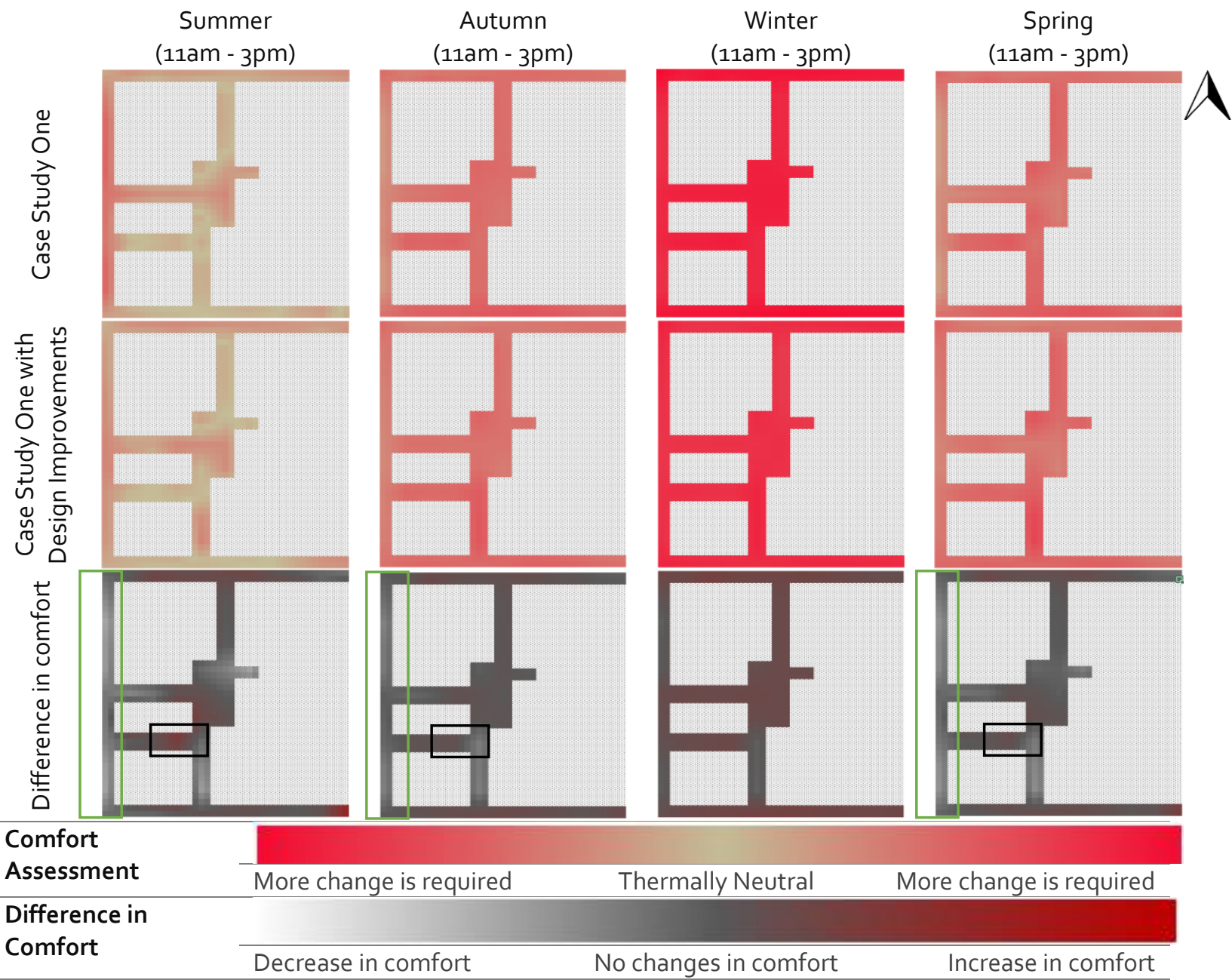

Figure 4.8 shows how changes to the original case study's built form improved comfort along the Western footpath in summer, autumn, and spring. However, the changes to the Northern lane to improve comfort resulted in little change.

Areas in Figure 4.8 which are white (green rectangle) show that changing the angle of the Western lane, and removing the offsets improved comfort along the Western footpath in summer, spring, and autumn. However, in winter there was a decrease in comfort. This shows that The Comfort Tool is able to capture the effect that design changes have on comfort. These design changes also caused an adverse effect on the comfort levels in the secondary lane (black rectangle). Therefore, a thermal comfort trade-off would need to be 
decided on between increasing comfort along the Western footpath in summer, spring, and autumn, and decreasing thermal comfort in the secondary lane in all seasons.

When a designer makes a design change to address a specific environmental factor, they can cross reference their hypothesis with the results of The Comfort Tool. As an example, the angle of the lane (orange retangle, Figure 4.7) was changed to face away from the predominent wind. It was predicted that this would decrease the wind speeds in this lane, and improve comfort. However, this only slightly decreases the wind speed shown by the white shading (green retangle, Figure 4.9).

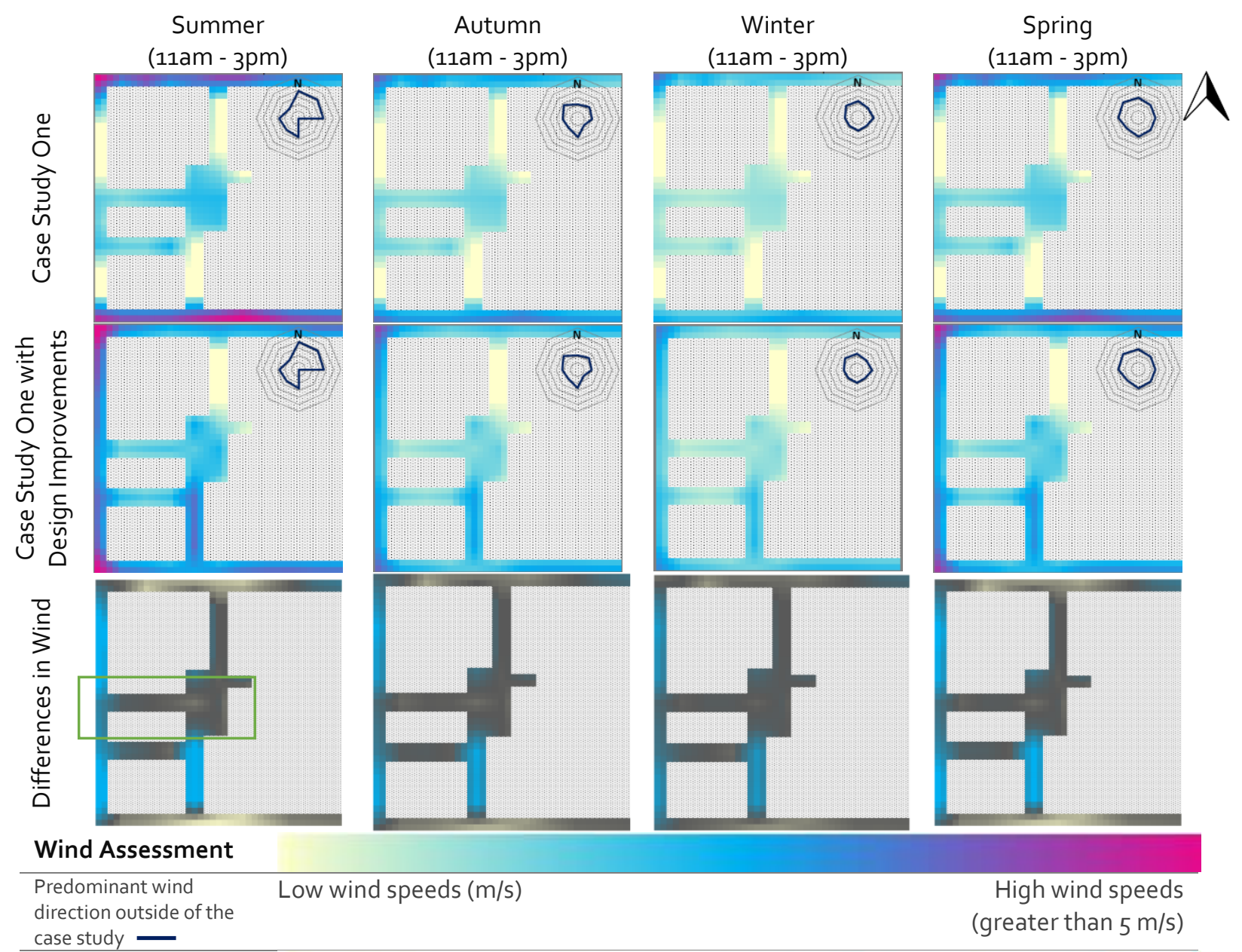

Difference in Wind

Decrease in wind speed Increase in wind speed

Figure 4.9 shows how the wind speeds decreased along the Southern and Northern footpath. However, increased in the Southern lane, as captured by The Comfort Tool. 
A designer or consultant may also be concerned with the amount of solar radiation in an area of a development. Along the Western footpath, the offsets were removed to prevent shading on the footpath below (yellow rectangle, Figure 4.7). The Comfort Tool is able to test this hypothesis, to see if making this design change would increase the solar radiation along the Western footpath. It did increase the solar radiation at one end of the Western footpath, but only slightly (black rectangle, Figure 4.10).

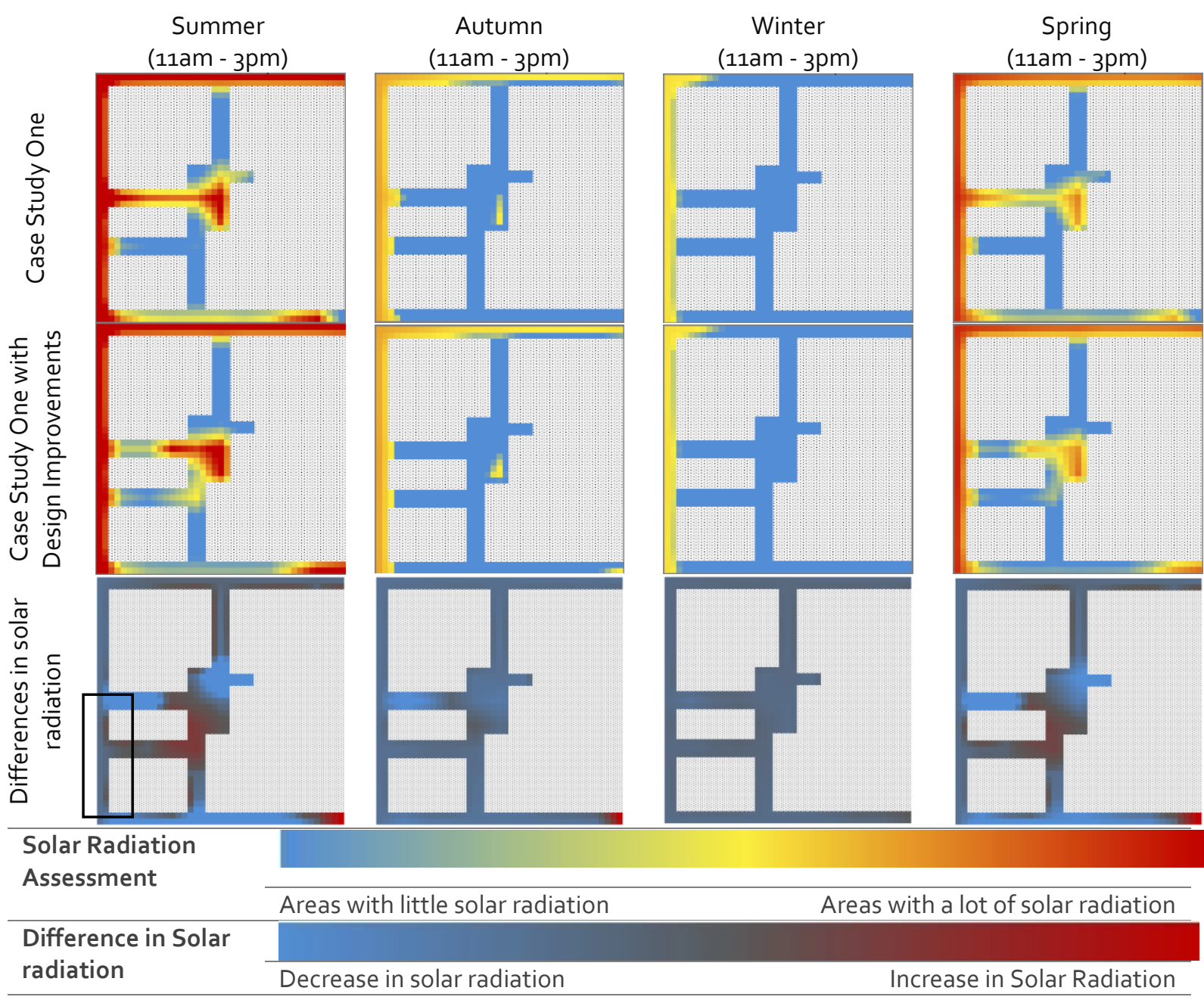

Figure 4.10 shows how The Comfort Tool can be used to test a design hypothesis, such as removing the setbacks (yellow rectangle, Figure 4.7) may increase solar radiation. The Comfort Tool shows that this had little impact on the level of solar radiation. Therefore, this change would not make a large change to comfort levels. 
4.2.2. CASE STUDY TWO

Case Study Two was selected to test if The Comfort Tool could reveal more about The Comfort Tool's ability to predict comfort for a case study which is more exposed to the wind. In contrast to Case Study One, this development faces the predominant wind (blue arrows, Figure 4.11), and has a large courtyard surrounded by buildings which are all the same height, indicated with the dotted lines. This design may cause more issues with wind.
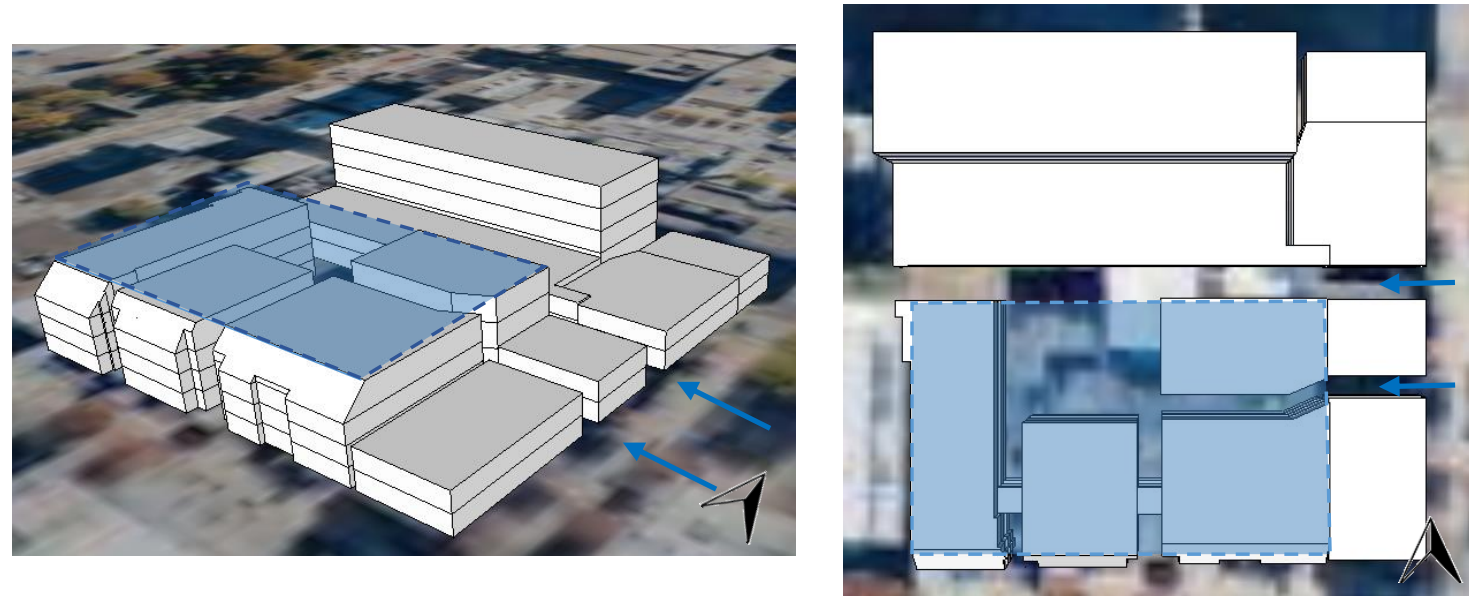

Figure 4.11 shows Case Study Two. The predominate wind direction is indicated by the blue arrows. The similar heights of the buildings may have an impact on the wind levels (blue shaded rectangle).

\section{Can comfort be automatically communicated across a development?}

For Case Study Two, the measurement points did not need to be moved to display comfort levels across the development in The Comfort Tool. It was able to show the variations in thermal comfort indicated by different areas of the development shaded in either a neutral or red colour (Figure 4.13). However, The Comfort Tool was unable to show the angled lane (blue rectangle, Figure 4.12) and displayed this as a straight lane (blue rectangle, Figure 4.13). Although The Comfort Tool is unable to show the angled lane, it is still taken into account as the wind reduction factors and solar radiation were calculated in a threedimensional model of Case Study Two with an angled lane.

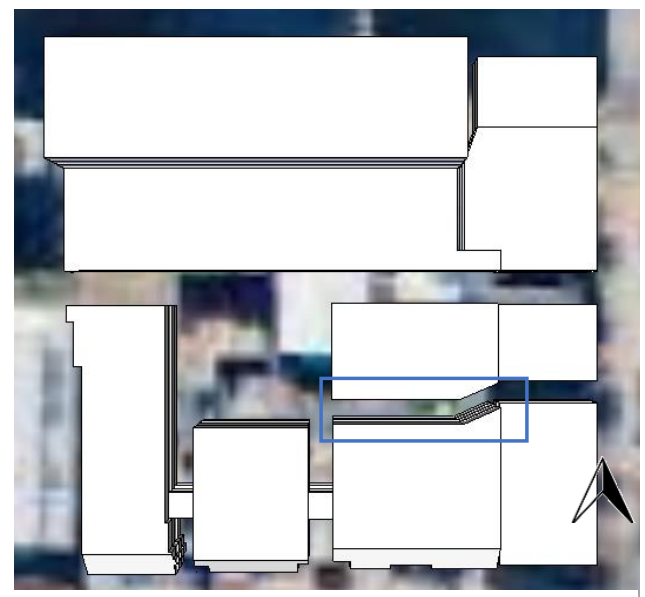

Figure 4.12 shows the angled lane (blue rectangle) which The Comfort Tool showed as a straight lane. 


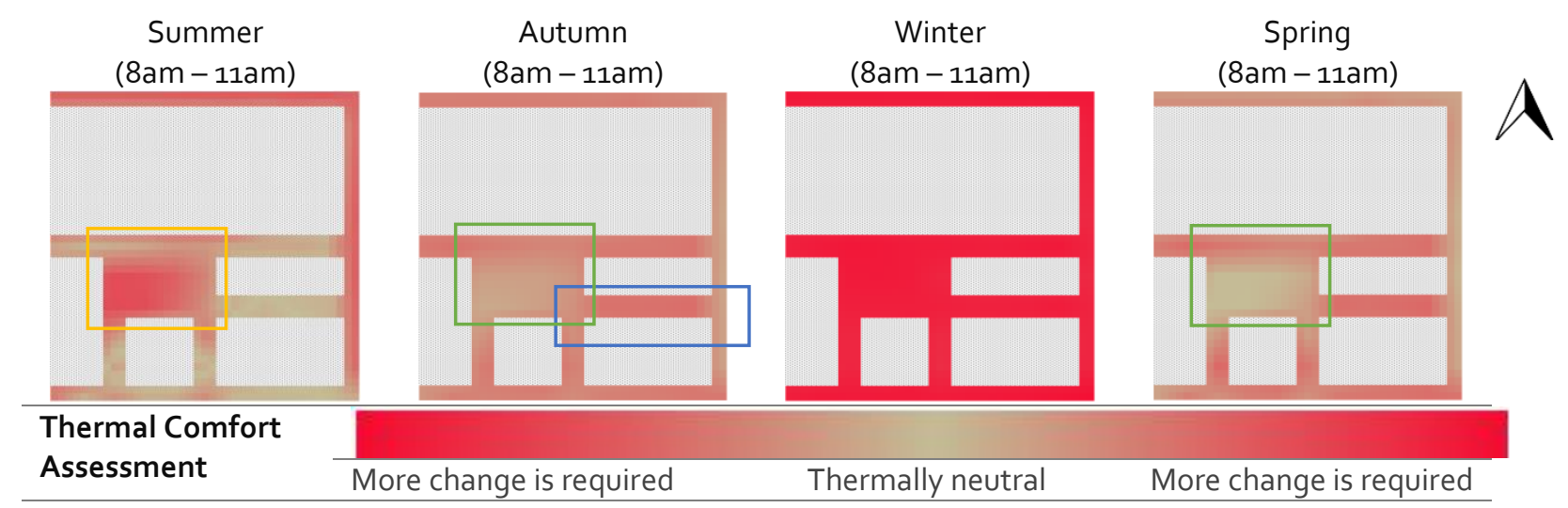

Figure 4.13 shows how The Comfort Tool can show variences in thermal comfort across a case study.

Are the results of The Comfort Tool able to inform design changes?

For Case Study Two, the thermal comfort assessment was completed between 8am-11am

for each season (Figure 4.13). This shows that The Comfort Tool is able to show variations in thermal comfort across the second case study with higher wind levels than Case Study One.

In summer, the thermal comfort assessment shows that the central courtyard is more thermally uncomfortable (yellow rectangle, Figure 4.13) than the surrounding lanes. Therefore, this indicated that people within the central courtyard would need to change their behaviour to maintain their thermal comfort. In contrast, in spring and autumn, it is the Western area of the central courtyard which is the most comfortable area (green rectangles, Figure 4.13). 
Thermal Comfort in Autumn (8am-11am)

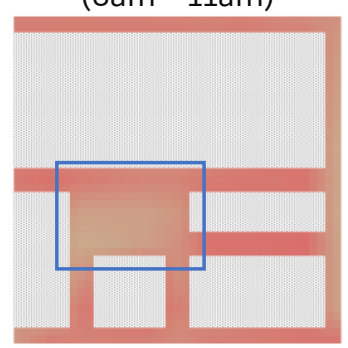

Wind in Autumn

(8am-11am)

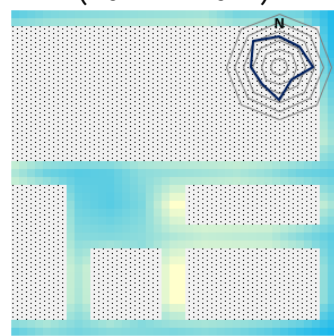

Solar Radiation in Autumn

(8am-11am)

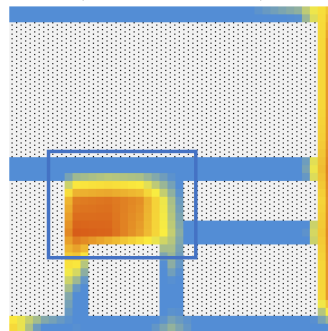

Wind Assessment

Predominant wind direction outside of the Low wind speeds (m/s)

High wind speeds

(greater than $5 \mathrm{~m} / \mathrm{s}$ )

Solar Radiation

Assessment

Thermal Comfort

Assessment

More change is required

Thermally neutral

More change is required

Figure 4.14 shows how the thermal comfort, wind, and solar radiation results can be assessed next to one another to determine which environmental factor is causing thermal comfort or discomfort. These results suggest that it is solar radiation (blue rectangle) which is causing the central courtyard in Case Study Two to be thermal comfortable.

When the thermal comfort, wind, and solar radiation results from The Comfort Tool are placed next to one another, this suggests that it is the solar radiation which is having the largest influence on the thermal discomfort in the West end of the courtyard (blue rectangle, Figure 4.14). Therefore, limiting the solar radiation in summer at the West end of the courtyard, while still allowing it in other seasons would improve thermal comfort in summer, without reducing it in the other seasons.

Comfort levels are lower along the Northern and Southern Footpaths (green rectangle, Figure 4.15). As there is excessive solar radiation, and the wind speeds are between low and medium, it is likely that it is the solar radiation which is causing the thermal discomfort along the Northern footpath. There may also be an issue with thermal discomfort in the Eastern lanes (black rectangle, Figure 4.15). They do not receive much solar radiation at pedestrian level. However, as wind levels are already low, it is likely not the wind which is causing the thermal discomfort. 


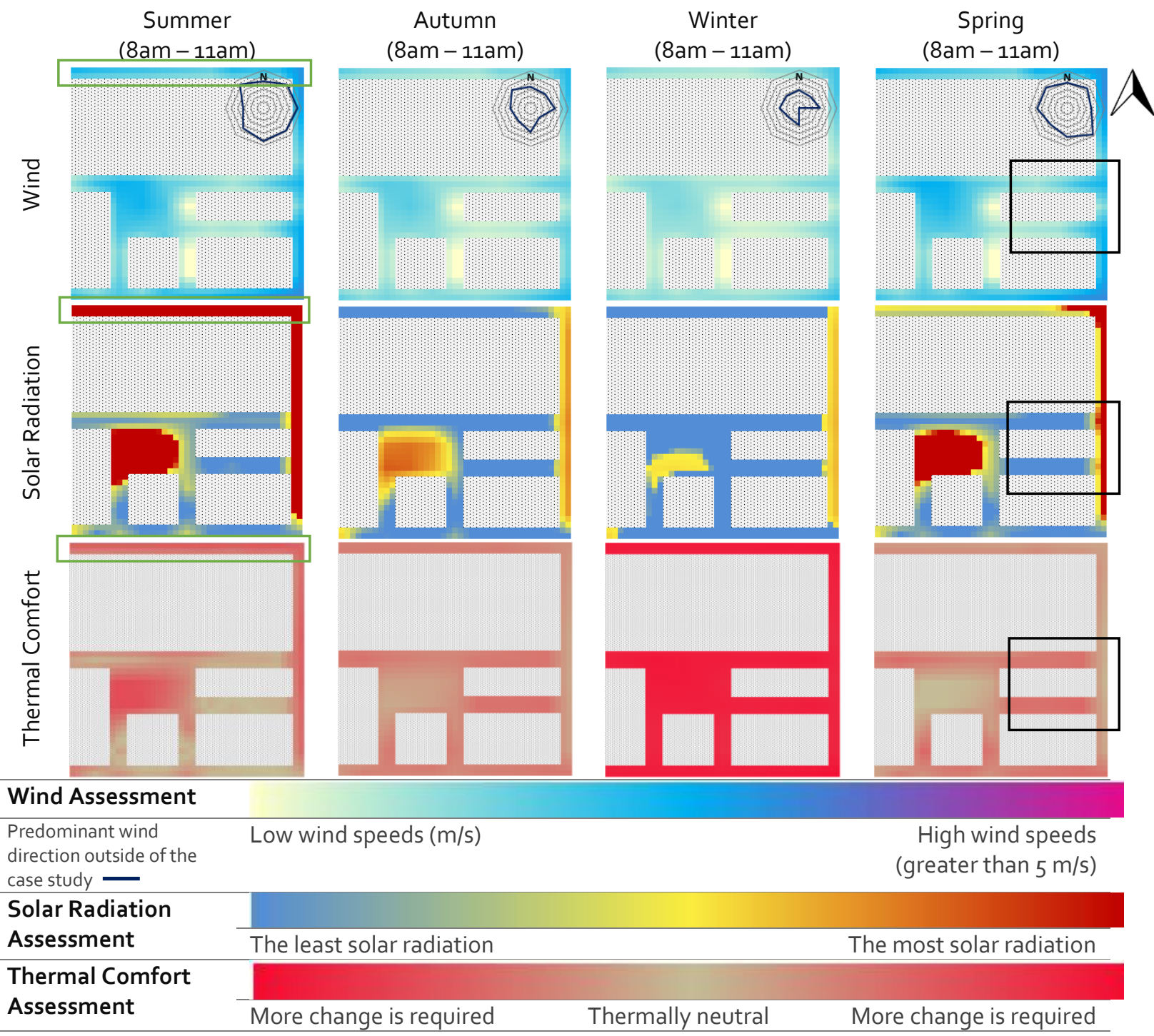

Figure 4.15 shows that when the results of The Comfort Tool are next to one another that it can be identified that it is likely not the wind, but the lack of solar radiation which is causing thermal discomfort in the Eastern lanes (black). 
A designer or consultant may want to test design changes to mitigate the issue with thermal discomfort along the Northern footpath in summer, and also reduce the wind funnelling into the Eastern facing lanes. These design changes can be tested using The Comfort Tool.

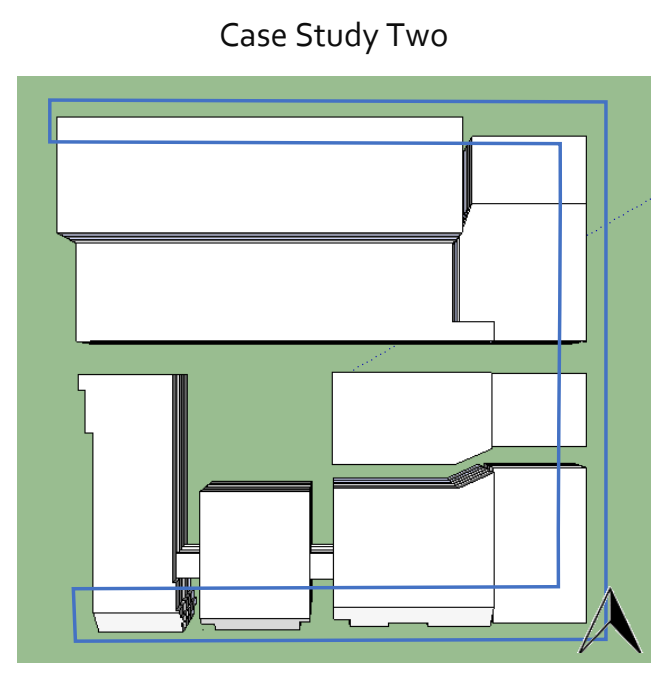

Case Study Two

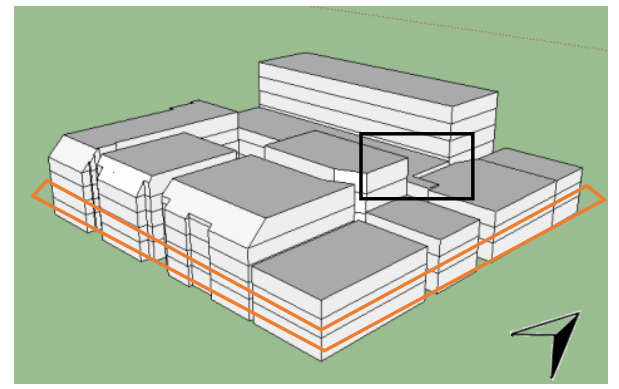

Case Study Two with thermal comfort improvments

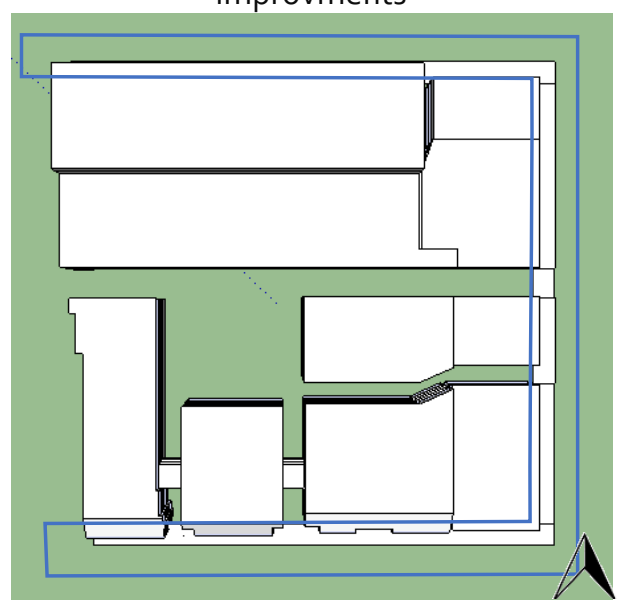

Case Study Two with thermal comfort improvements

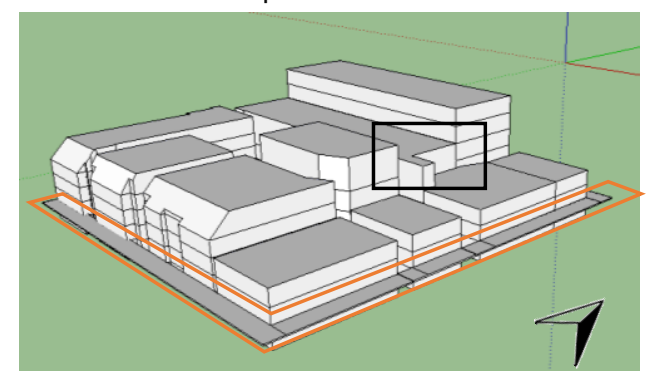

Figure 4.16 shows the design changes made to Case Study Two to test The Comfort Tool.

As a demonstration, two design changes were made to Case Study Two to limit the wind:

1. Verandas were added to the North, South, and East sides of Case Study Two, above the footpaths (Orange rectangle, Figure 4.16). This was to direct the wind away from the development, rather than allowing it to funnel into the lanes.

2. An extra storey was added to a building to block the North-easterly wind from entering the courtyard (black rectangle, Figure 4.16). 
Comparison of Case Study Two and Case Study Two with Design Improvements

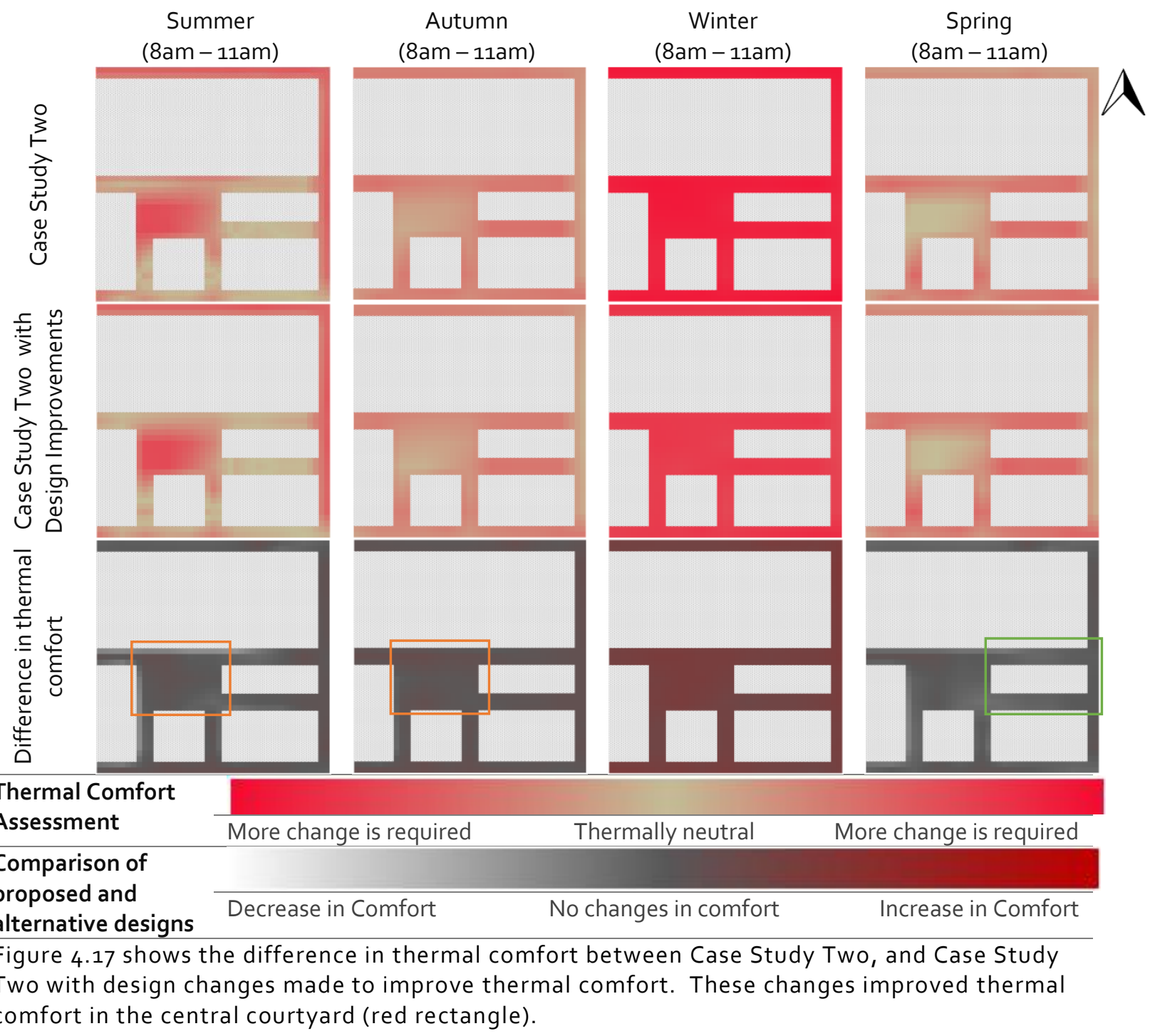

These design changes improved thermal comfort in the central courtyard in summer and autumn (orange rectangle, Figure 4.17). It had a minimal change in thermal comfort in the Eastern lanes (green rectangle, Figure 4.17). This shows the importance of using The Comfort Tool to test design decisions, as the design decisions may not always have the expected outcome. 
As these design changes were made to decrease the wind levels, The Comfort Tool was used to show the difference in wind levels between Case Study Two, and Case Study Two with thermal comfort improvements (Figure 4.18). The Comfort Tool shows that these design changes decreased wind at the North-west corner of the courtyard in summer and spring (orange rectangle). However, wind speeds increased in the Eastern lane (green rectangle).

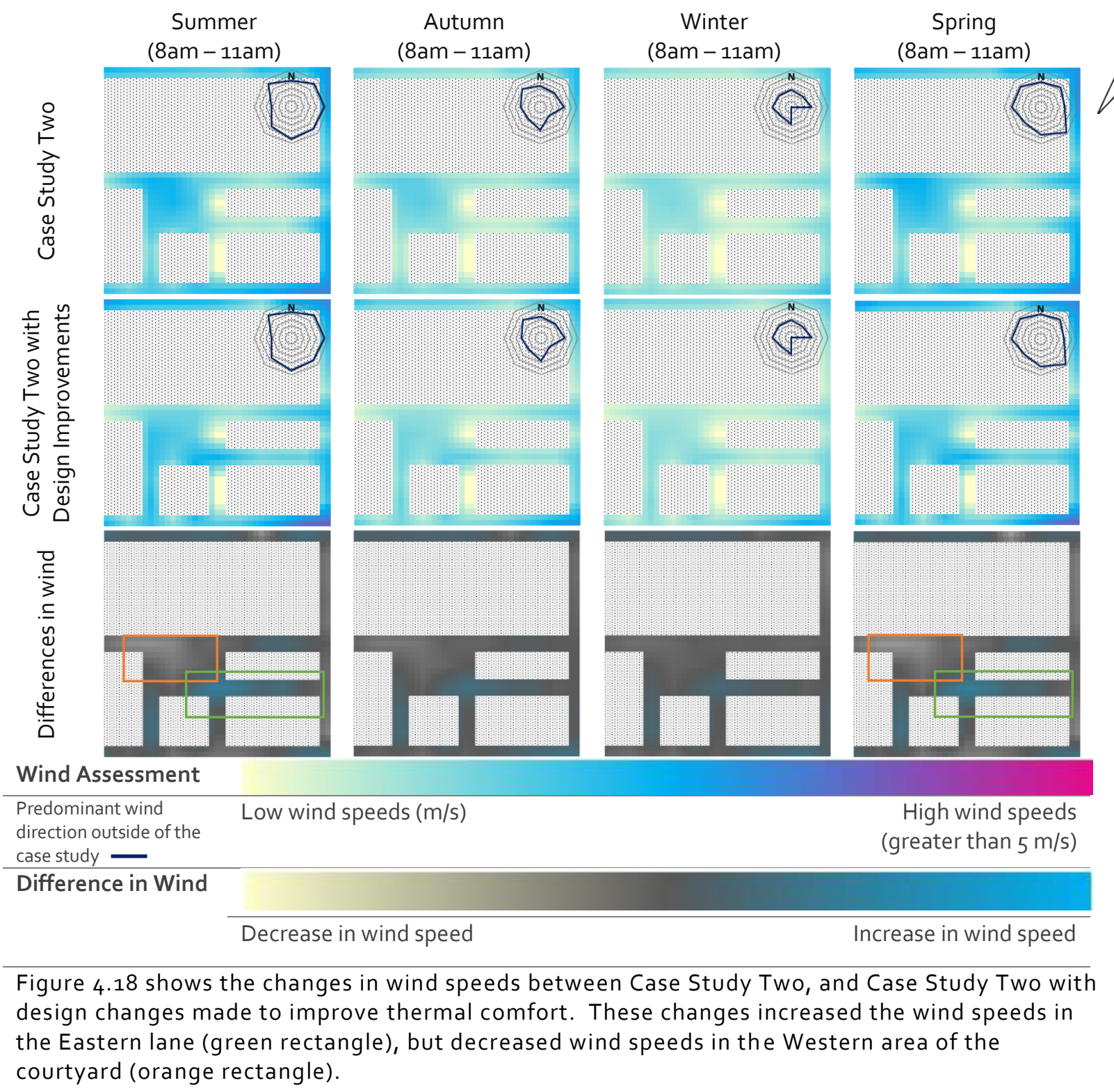


4.2.3. CASE STUDY THREE

Case Study Three was selected to determine if The Comfort Tool could communicate thermal comfort levels for evening periods when solar radiation levels are low. Therefore, design changes to improve thermal comfort would focus on the wind. Although it is a large development which covers half a city block, the lanes and courtyard within the development are narrow (yellow rectangles, Figure 4.19). These design features may cause wind to funnel into these areas within the development. As the assessment time is from 7pm until 11pm, there is potential for solar radiation to be at pedestrian level during summer.
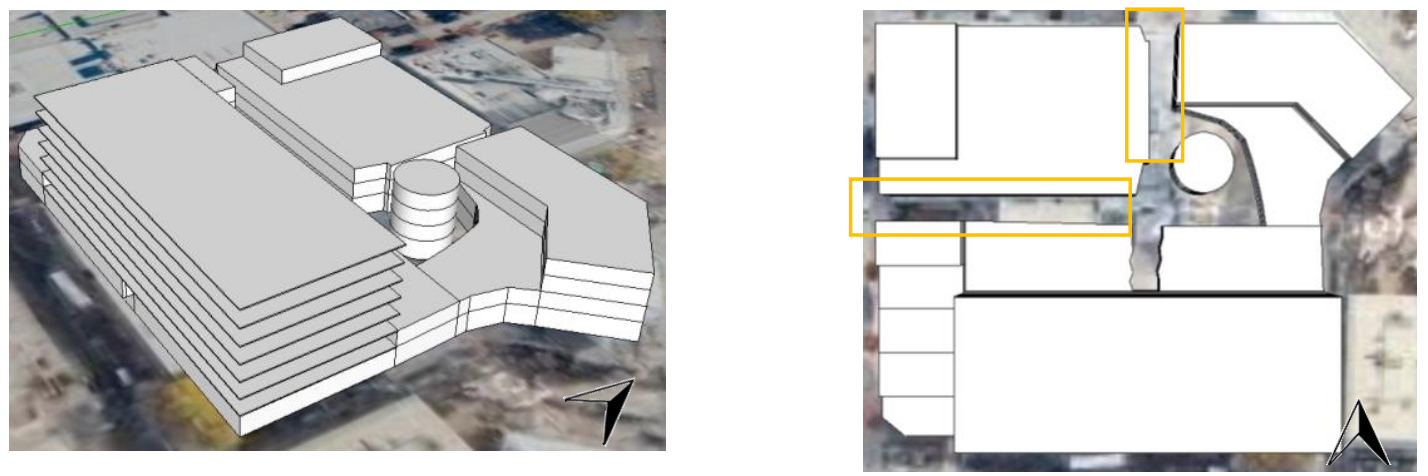

Figure 4.19 shows Case Study Three. It has narrow lanes (yellow rectangle). This case study will be tested for evening periods where there is limited solar radiation.

\section{Can thermal comfort be automatically communicated across a development?}

The process for calculating thermal comfort was automatic for this case study once the data was in The Comfort Tool. However, The Comfort Tool was not able to show the angled facades or the circular building located centrally in the courtyard (blue rectangle, Figure 4.20).

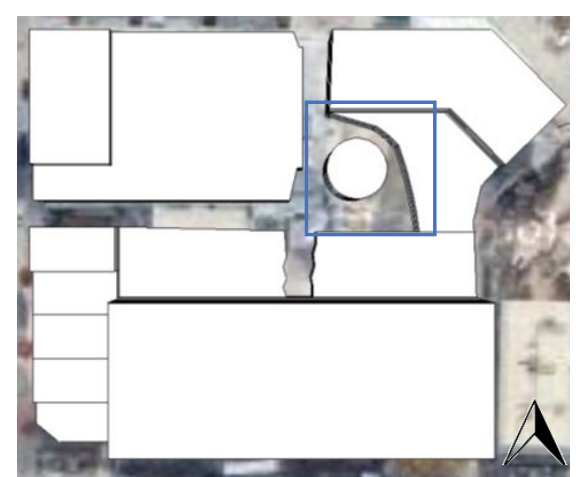

Figure 4.20 shows the circular building which The Comfort Tool showed as a square. 
The Comfort Tool is able to show variations in thermal comfort for different seasons, as shown by the neutral and red shading (Figure 4.21). However, there are no variations between thermal comfort levels in different areas of Case Study Three.

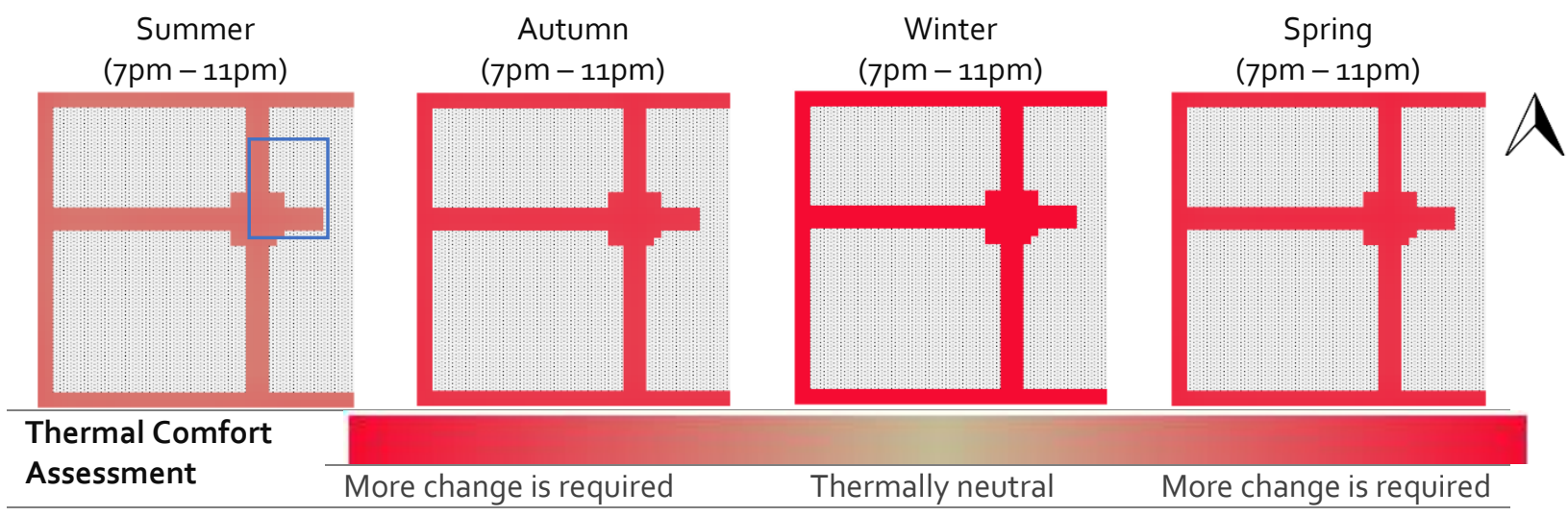

Figure 4.21 shows the where the circular building is located (blue rectangle) which The Comfort Tool showed as a straight edges. The Comfort Tool does not show variance in thermal comfort across Case Study Three when there are low solar radiation levels. However, it still shows the differences in thermal comfort between seasons.

\section{Are the results of The Comfort Tool able to inform design changes?}

The Comfort Tool is only able to show changes in thermal comfort levels between seasons, but not variations in thermal comfort across a development for one season. This is shown by the results of The Comfort Tool being shaded a solid colour across the development (Figure 4.21).

In spring, winter, and autumn, the thermal comfort results are a solid red colour. However, without the wind results, it is unknown if this is because the wind levels are uniform across the case study. 
As shown by the wind rose in the right top corner of each season's wind results, the predominant wind direction changes for each season. The predominant wind speed in summer is from the South-east direction (black rectangle, Figure 4.22). Whereas, in spring there was no wind from this direction (blue rectangle).

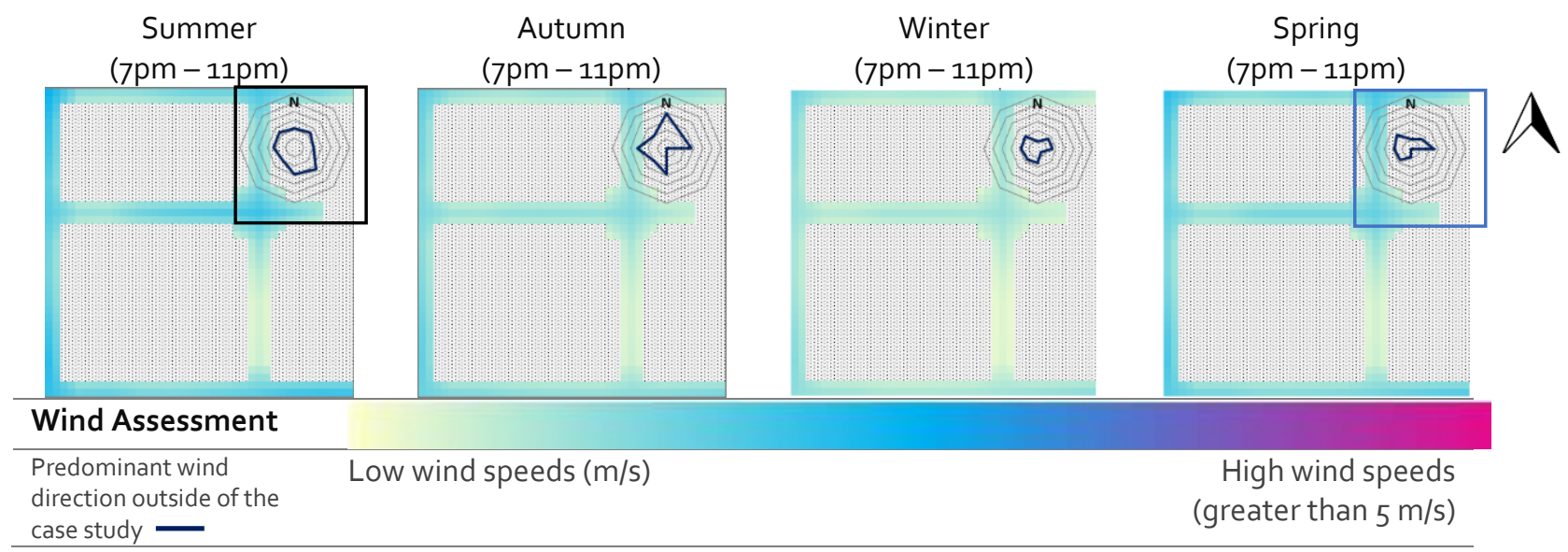

Figure 4.22 shows the wind rose included in The Comfort Tool. This allows for design changes to be made to limit the predominant wind speed for each season.

To test if The Comfort Tool could show variations in thermal comfort even when wind was the only environmental factor which could be modified to improve thermal comfort levels, design changes were made to Case Study Three (Figure 4.23). 

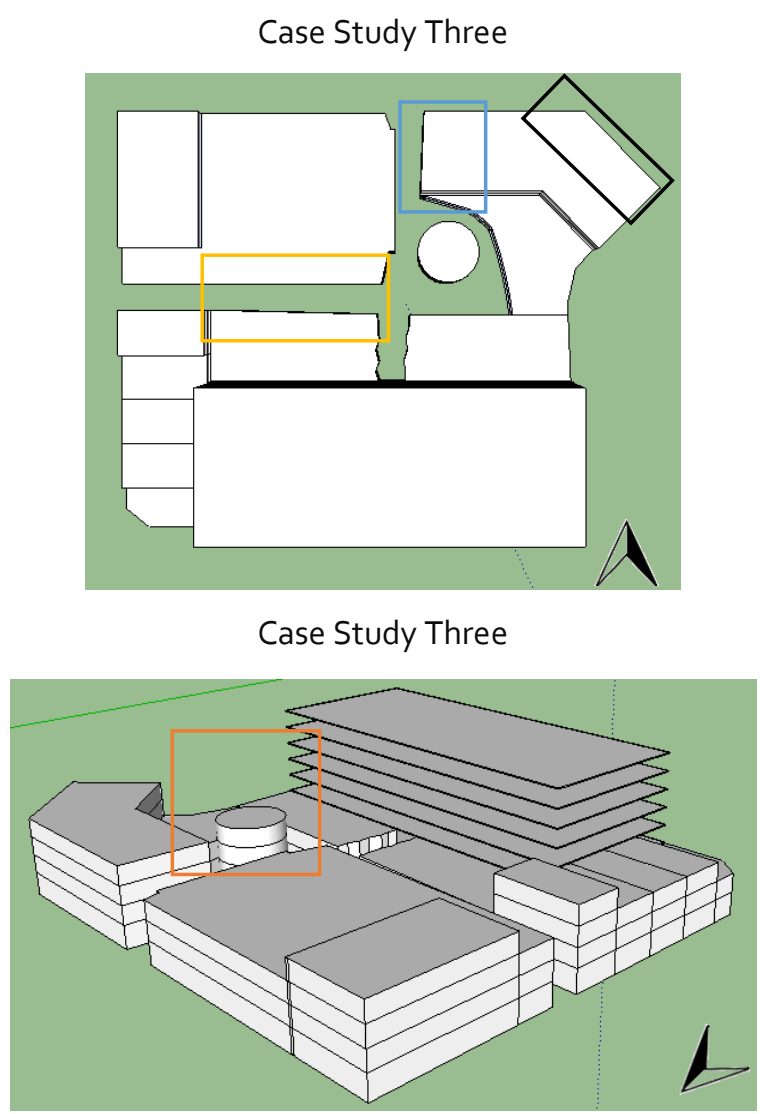

Figure 4.23 shows the design changes made to Case Study Three to improve the thermal comfort levels based on the wind results.

1. The Eastern lane was increased in width to prevent the wind funnelling down the narrow lane (yellow rectangle, Figure 4.23)

2. Stepbacks were created near the entrance to the North facing lane to deflect the North to North-westen wind from funnelling down the Northern lane (blue rectangle, Figure 4.23)

3. The height of the circular building was increased in height to encourage wind to flow around it, rather then down into the central courtyard (orange rectangle, Figure 4.23)

4. The North-east facing building had a stepback built into the roof to deflect the wind away from the roof of the building, and down into the central courtyard (black rectangle, Figure 4.23). 
Comparison of Case Study Three and Case Study Three with Design Improvements

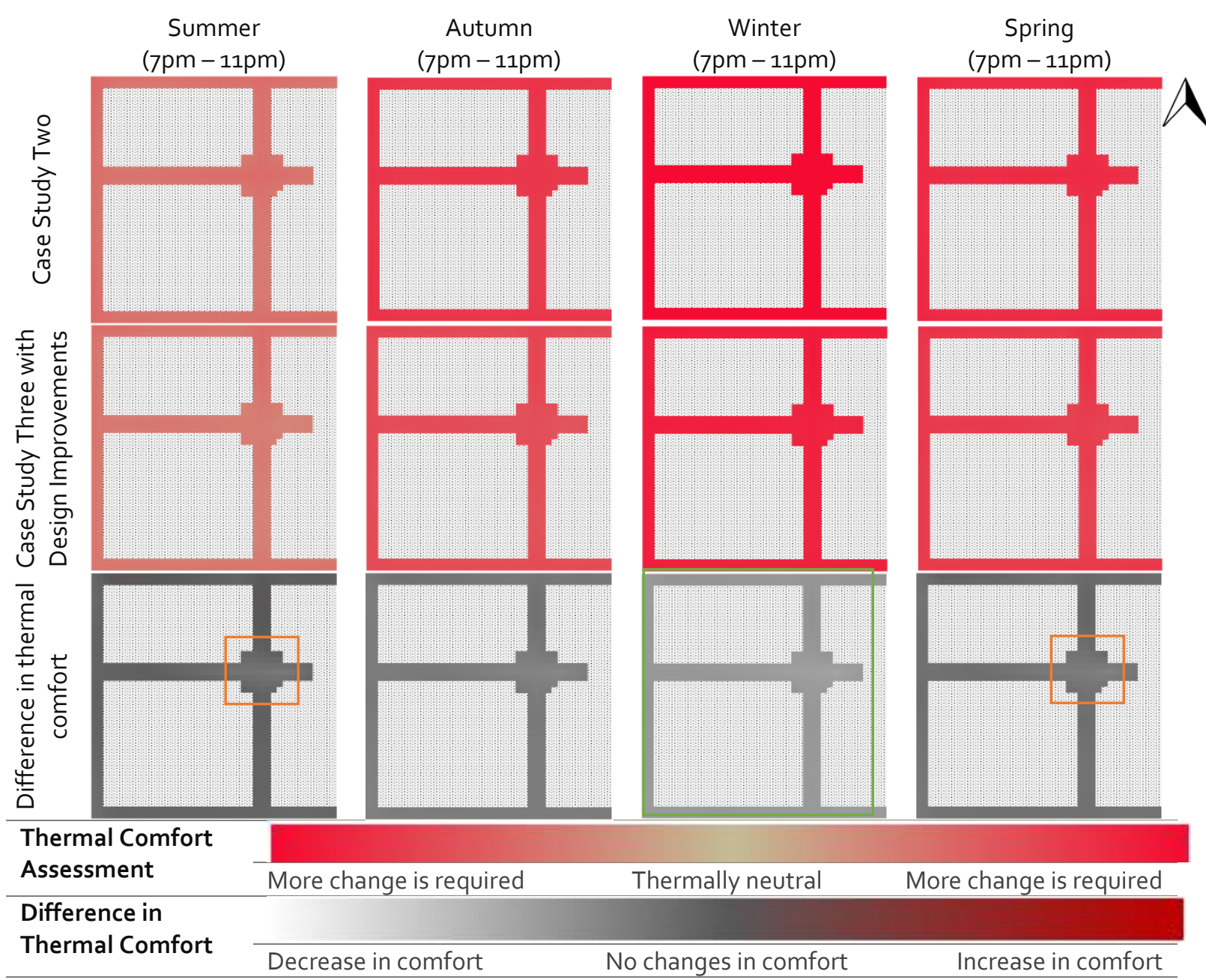

Figure 4.24 shows the differences in thermal comfort between Case Study Three and Case Study Three with design changes to improve thermal comfort. This shows that The Comfort Tool can inform design changes even though the solar radiation levels are low (orange rectangles).

These thermal comfort results show that The Comfort Tool is able to demonstraight how a change in design which focuses on only wind for the evening can show a change in thermal comfort. However, these design changes had a limited effect on thermal comfort (Orange rectangle, Figure 4.24). Therefore, for this scenario for evening periods when there is limited solar radiation, The Comfort Tool may be able to provide more insightful information when larger design changes are made. An example of this may be the building footprints, the height of the buildings, and the location of the lanes and courtyards. 
The Comfort Tool captured the reduction in wind speeds in the central courtyard (green retangle, Figure 4.25). However, these design changes also increased the wind speed along the Northern lane and footpath (black rectangle). These results would allow consultants and designers to make design changes based on a hierachy of which areas they would like to focus on reducing the wind, even if design changes increase wind speeds in another area. In Case Study Three, lowering the wind in the central courtyard may be the focus of design improvments as this is the location of a restaurant which will be used during evening periods (green rectangle). Whereas, people will only be passing through the lane and Northern footpath (black rectangle).
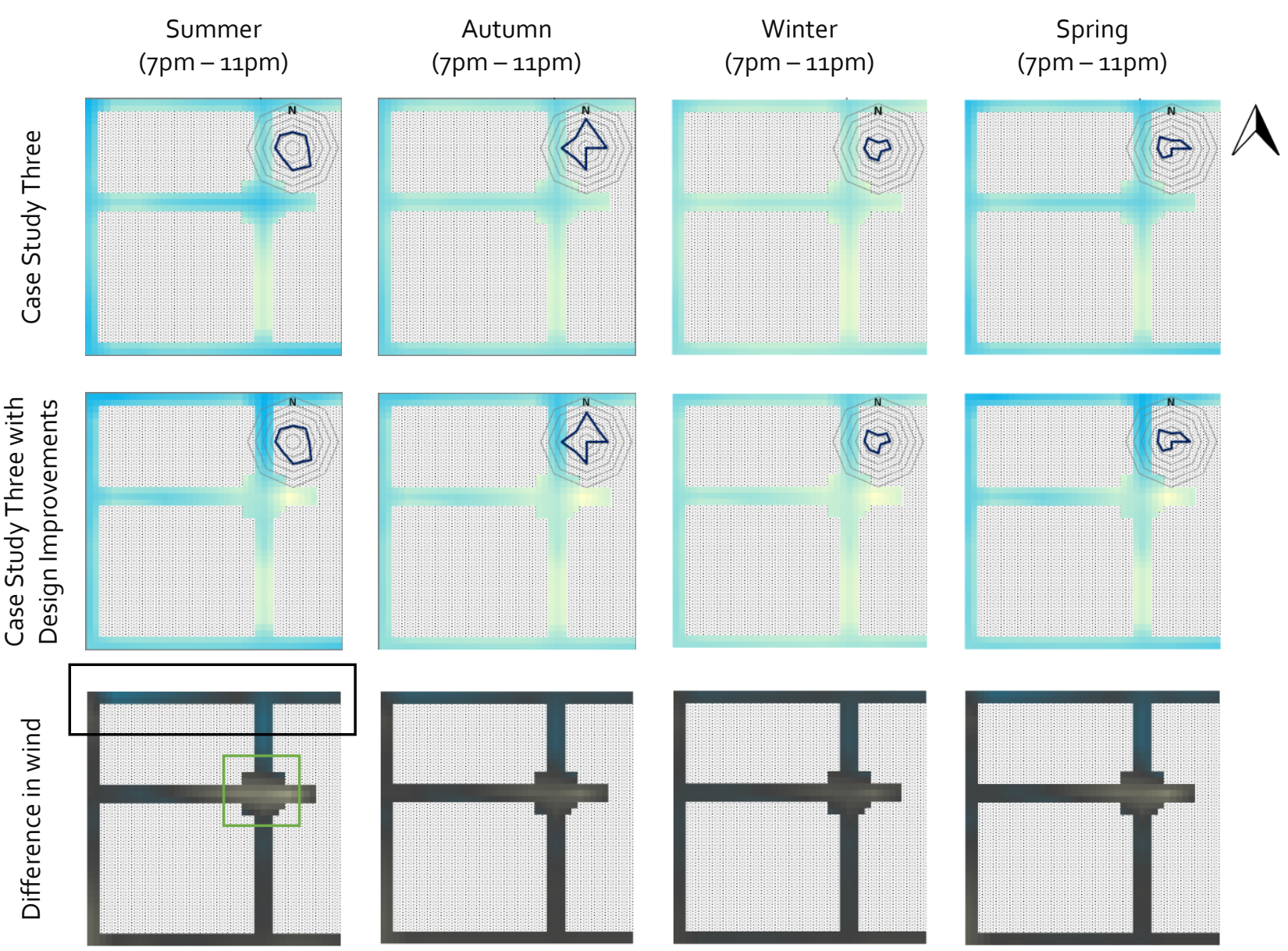

Wind Assessment

Predominant wind Low wind speeds $(\mathrm{m} / \mathrm{s})$ direction outside of the Difference in Wind

Figure 4.25 shows the design changes decreased wind in the central courtyard and increased wind along the Northern footpath and Northern lane 
4.2.4. CASE STUDY FOUR

Case Study Four was selected to test The Comfort Tool as it is a small development which faces away from the sun (Figure 4.26). There is also a six storey building situated next door (solid grey rectangle). This is in contrast to Case Study One and Two which have large central courtyards, and Case Study Three which assessed thermal comfort for the evening period when there is limited solar radiation.
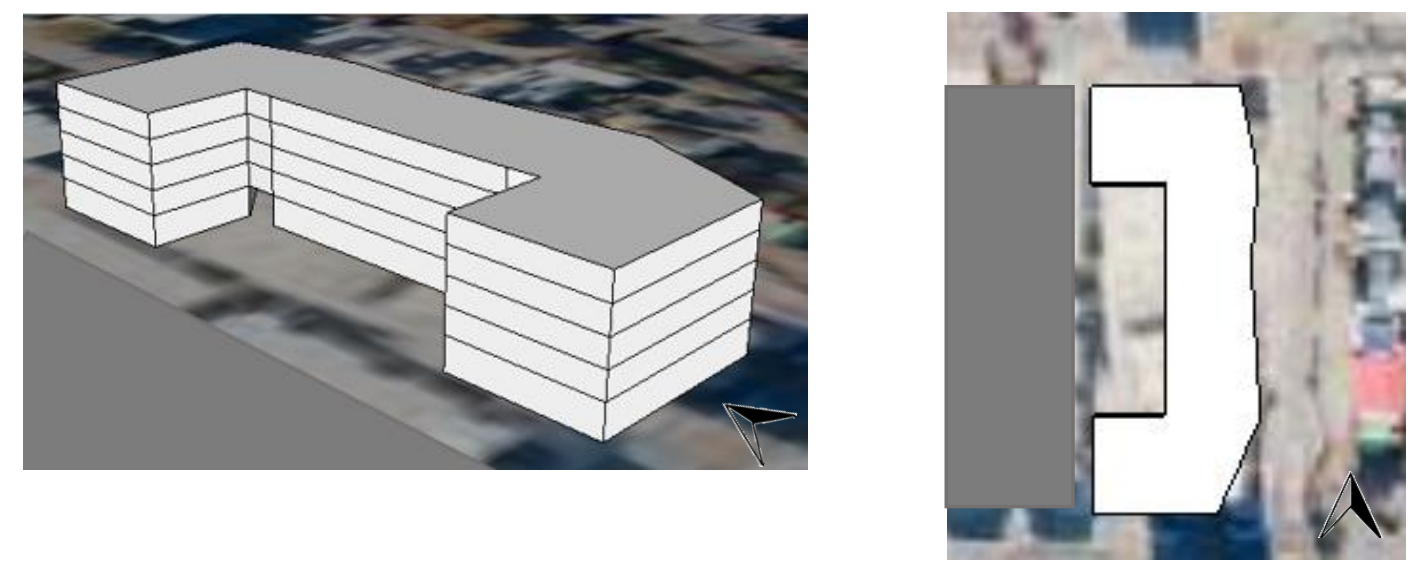

Figure 4.26 shows Case Study Four, with the neighbouring building (grey rectangle) which limits the solar radiation in the central courtyard.

Can thermal comfort be automatically communicated across a development?

Once the solar radiation and wind results were placed in The Comfort Tool, no changes were required in The Comfort Tool to produce the results for the thermal comfort assessment. The thermal comfort results show that variations in thermal comfort across Case Study Four were captured by The Comfort Tool as the

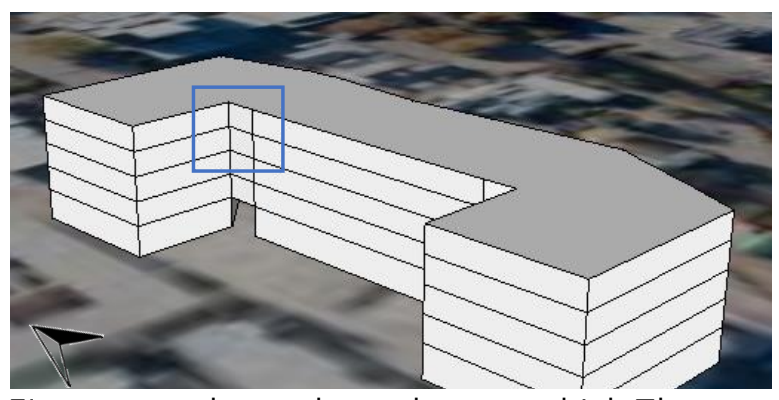

Figure 4.27 shows the underpass which The Comfort Tool did not show in the thermal comfort results.

comfort results show areas of comfort and discomfort (Figure 4.28). In winter, the results were solid red across the development, so design changes which focus on improving thermal comfort in winter could not be made based solely on these thermal comfort results. 
Case Study Four has an angled underpass, sheltered by the level above (blue rectangle, Figure 4.27). However, The Comfort Tool was unable to show this underpass (blue rectangle, Figure 4.28).

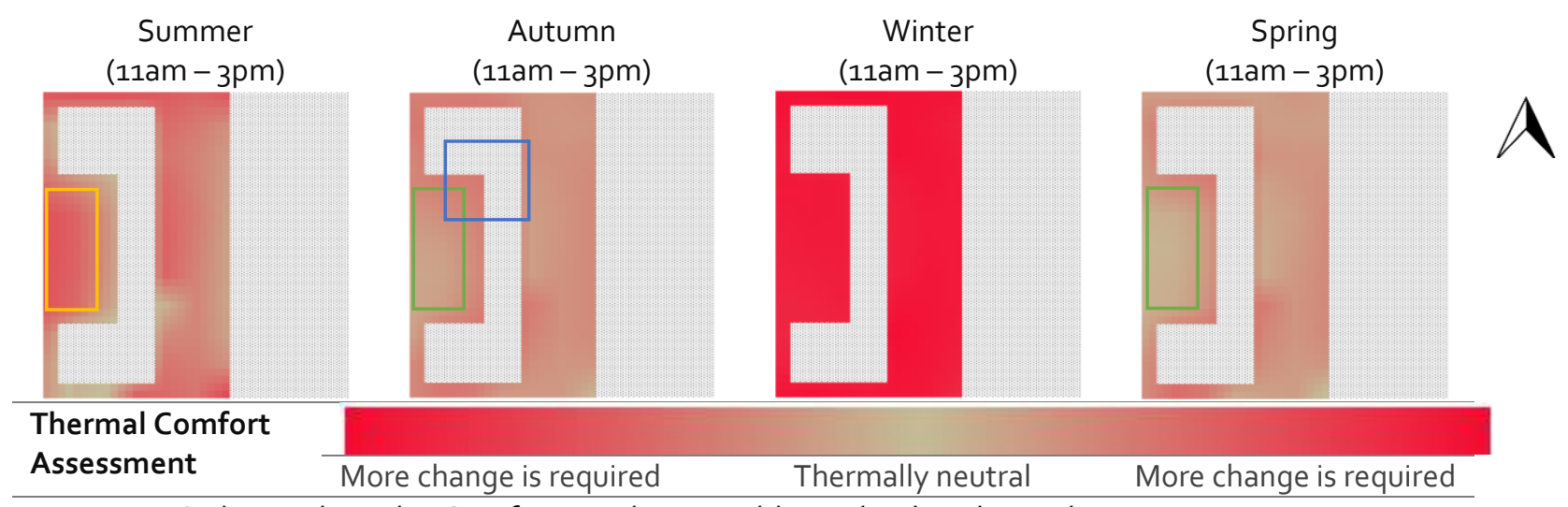

Figure 4.28 shows that The Comfort Tool is not able to display the underpass

Are the results from a comfort tool able to inform design changes?

The Comfort Tool is able to show variations in thermal comfort across Case Study Four as shown by the red and the neutral shading (Figure 4.28). In summer between 11am and 3pm, the thermal comfort levels are higher at the base of the buildings than in the middle of the courtyard (yellow rectangle, Figure 4.29). The Comfort Tool shows that in autumn and spring it is more thermally comfortable further away from the building (green rectangle, Figure 4.28). However, without the solar radiation and wind results it is difficult to identify what is causing the thermal discomfort in the central courtyard in

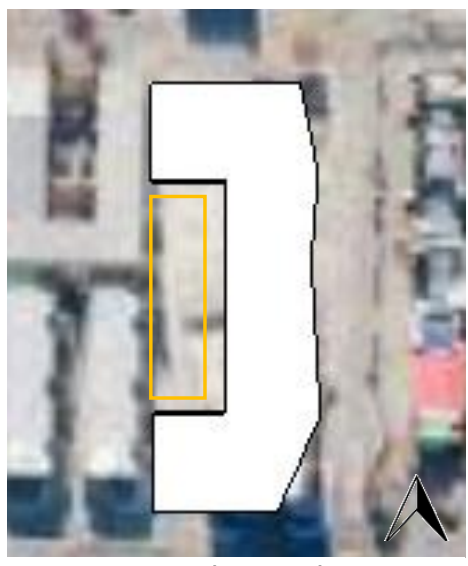

Figure 4.29 shows the central courtyard which may receive limited solar radiation in Case Study Four. summer. 

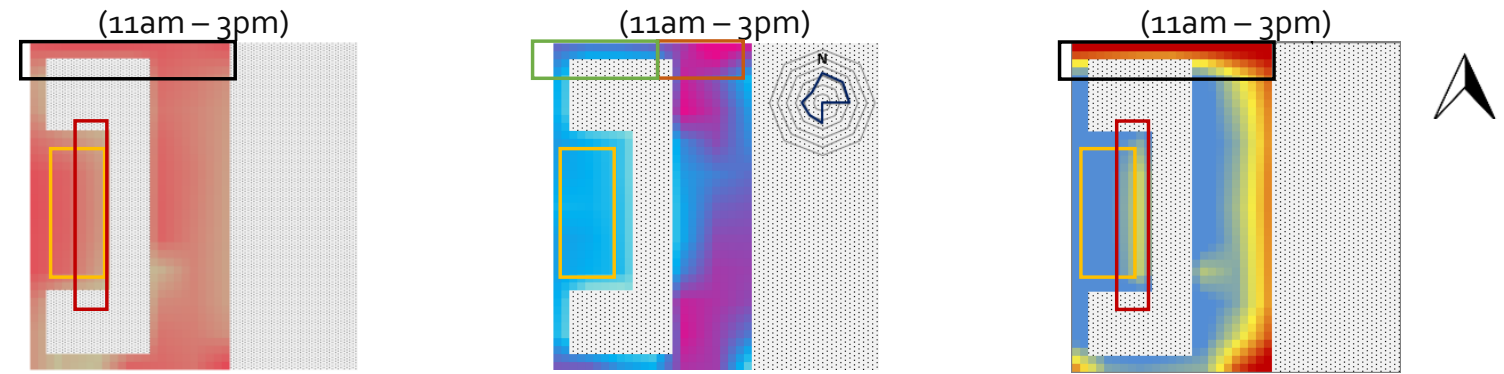

\section{Wind Assessment}

Predominant wind direction outside of the

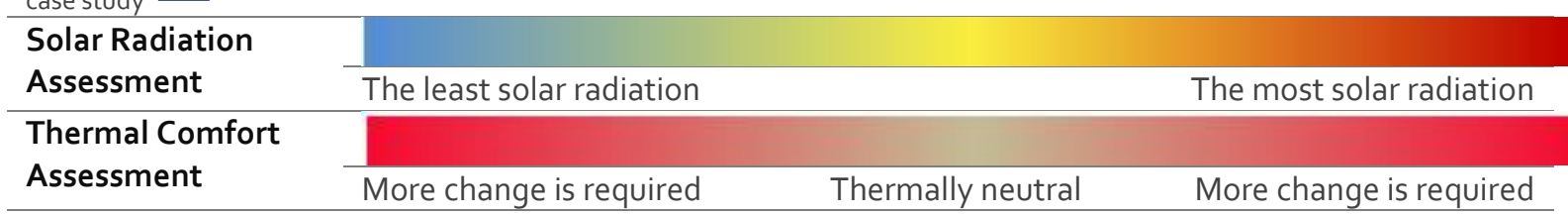

Figure 4.30 shows how The Comfort Tool can be used to identify what may be causing thermal comfort or discomfort. Solar radiation is low, and wind speeds are fairly high in the central courtyard. However, The Comfort Tool indicates that if solar radiation increased that this would increase thermal comfort (red rectangle).

The Comfort Tool is able to identify that the solar radiation levels are low in summer in the central courtyard and the wind levels are high (yellow rectangle, Figure 4.30). However, at a closer assessment, The Comfort Tool was able to show that the thermal comfort levels were neutral at the base of the building in the central courtyard where the solar radiation levels were higher (red rectangle, Figure 4.30). This suggests that although the wind levels are high in the courtyard, that only a small amount of solar radiation would improve the comfort. Therefore, by reducing the wind, the comfort levels may also increase. The design changes aimed at reducing the wind as there was not much potential for design improvements for increasing solar radiation. 


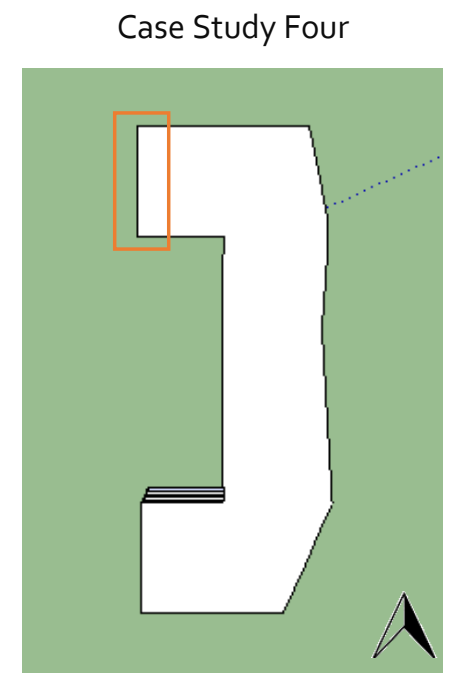

Case Study Four

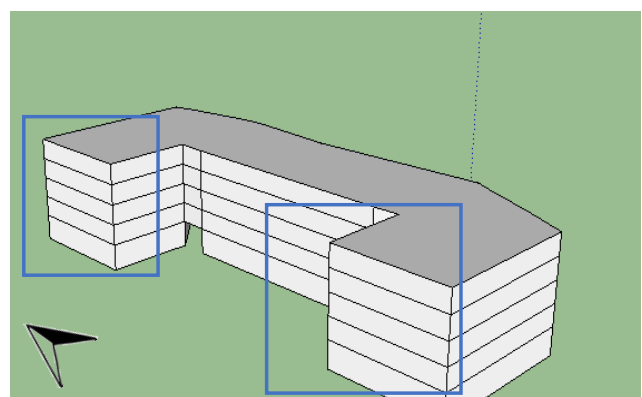

Case Study Four with thermal

comfort improvements

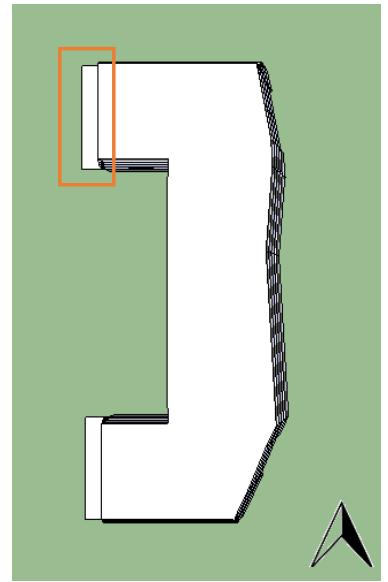

Case Study Four with thermal comfort improvements

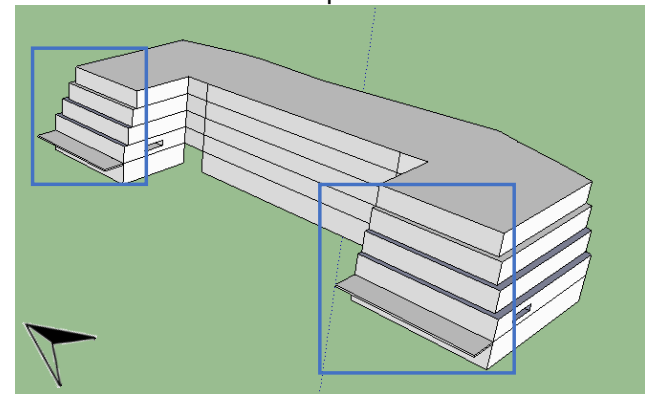

Figure 4.31 shows the design changes made to Case Study Four to improve thermal comfort.

1. Verandas were added to the two Western wings of Case Study Four to direct any Easterly or North-easterly wind which comes across the roof of Case Study Four and down into the North to South lanes away from the development (orange rectangle, Figure 4.31).

2. Stepbacks were incorperated into the West wings to encourage the wind to deflect away from Case Study Four (blue rectangle, Figure 4.31). 
Comparison of Case Study Four and Case Study Four with Design Improvements

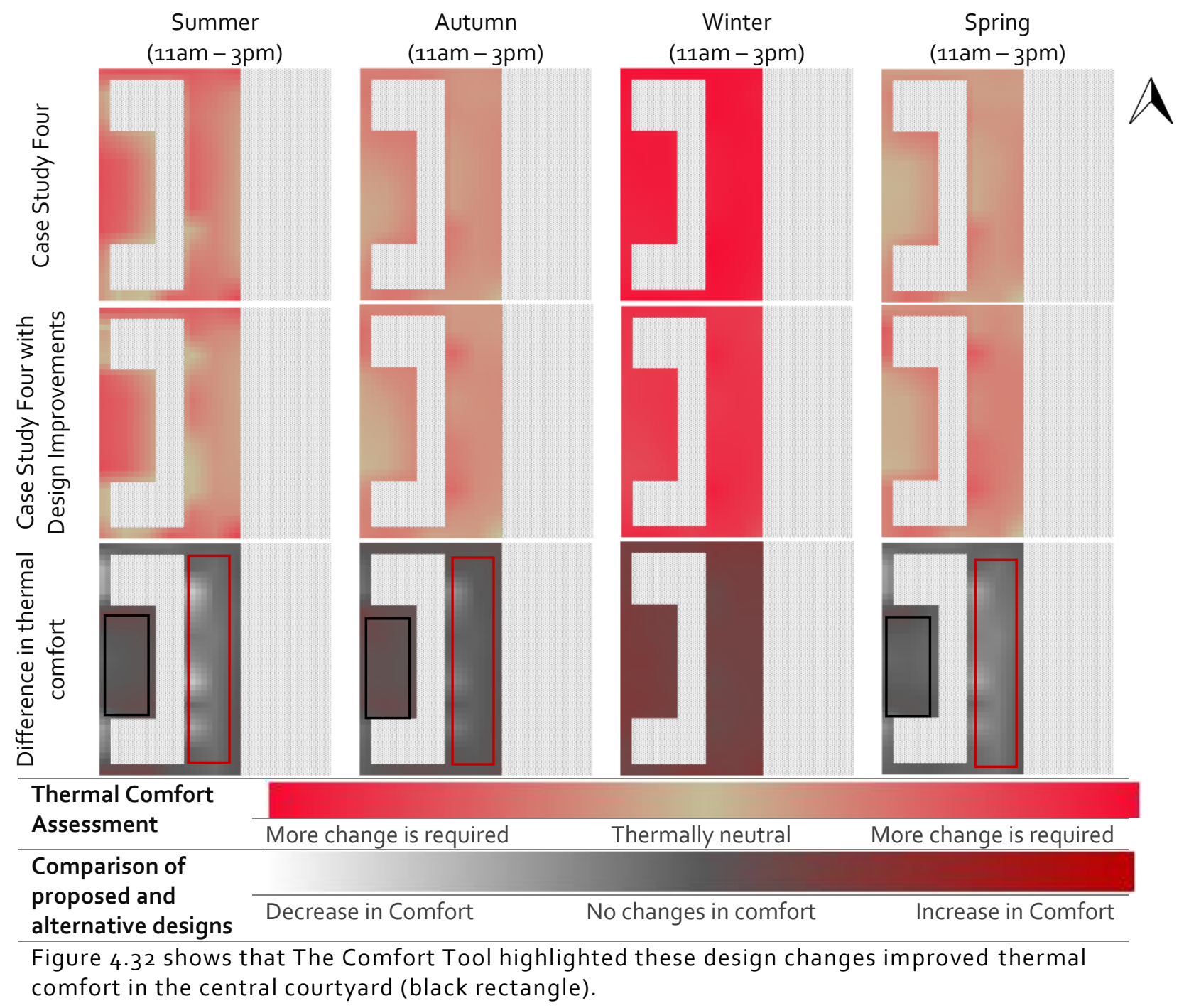

The Comfort Tool shows that these design changes improved outdoor thermal comfort across the development in summer, spring, and autumn (black rectangle, Figure 4.32). In winter, The Comfort Tool shows that there was an improvement in thermal comfort in all areas of the case study. In spring, summer, and autumn, these design changes decreased thermal comfort along the Eastern footpath (red rectangle, Figure 4.32). 


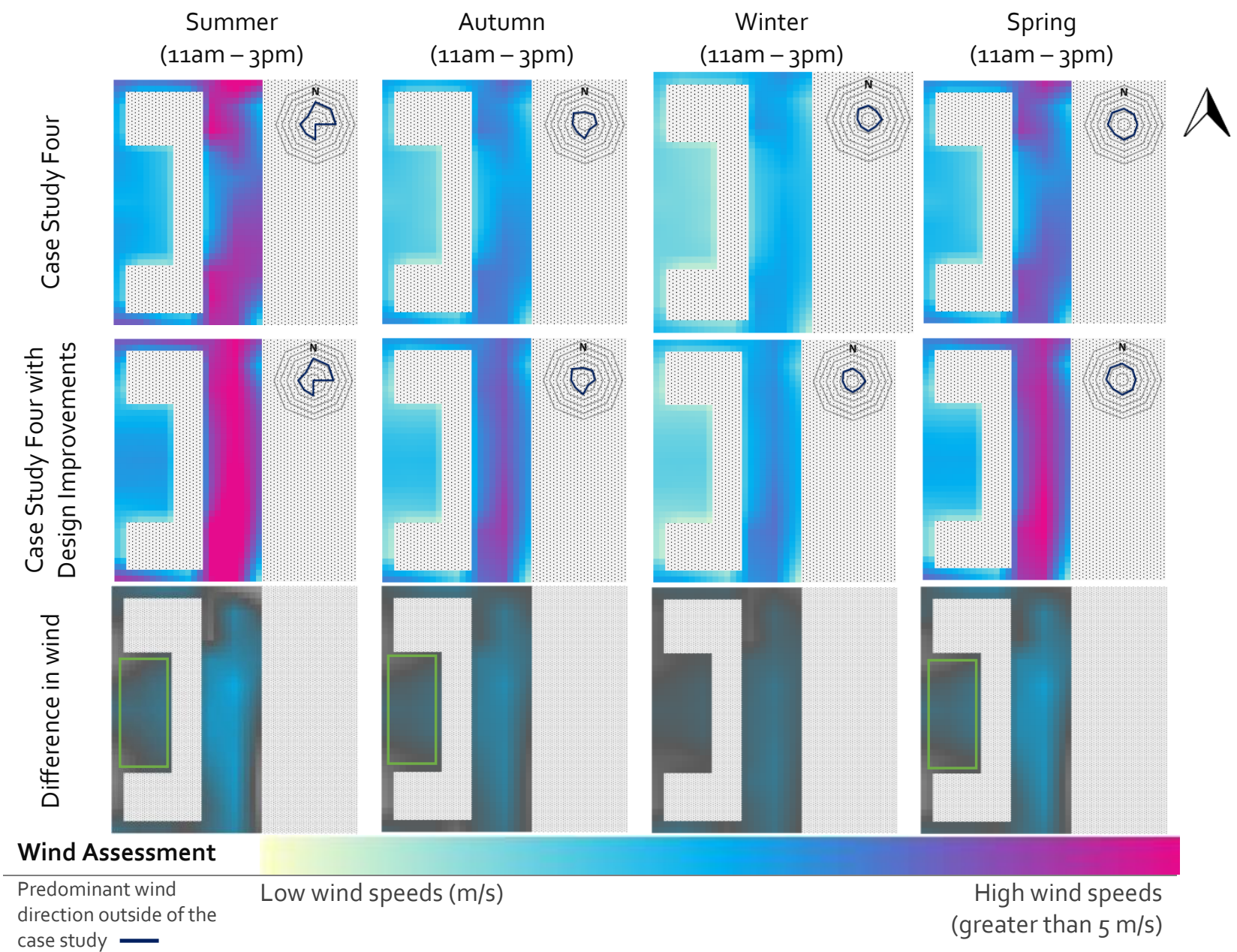

Difference in Wind

Decrease in wind speed

Increase in wind speed

Figure 4.33 shows that the wind results for Case Study four showed an increase in wind around Case Study Four. Therefore, when The Comfort Tool is used for informing deigns changes, it could show when a design change will have an adverse effect on thermal comfort, rather than improving thermal comfort.

When the wind results for Case Study Four, and Case Study Four with design changes are compared, it shows that there was an increase in wind in the central courtyard in summer, spring, and autumn (green rectangle, Figure 4.33). These design changes had improved thermal comfort in the central courtyard (black rectangle, Figure 4.32), and there was minimal change in solar radiation at pedestrian level (red rectangle, Figure 4.34), The Comfort Tool suggests that these thermal comfort improvements are due to the increased solar radiation in the central courtyard. 


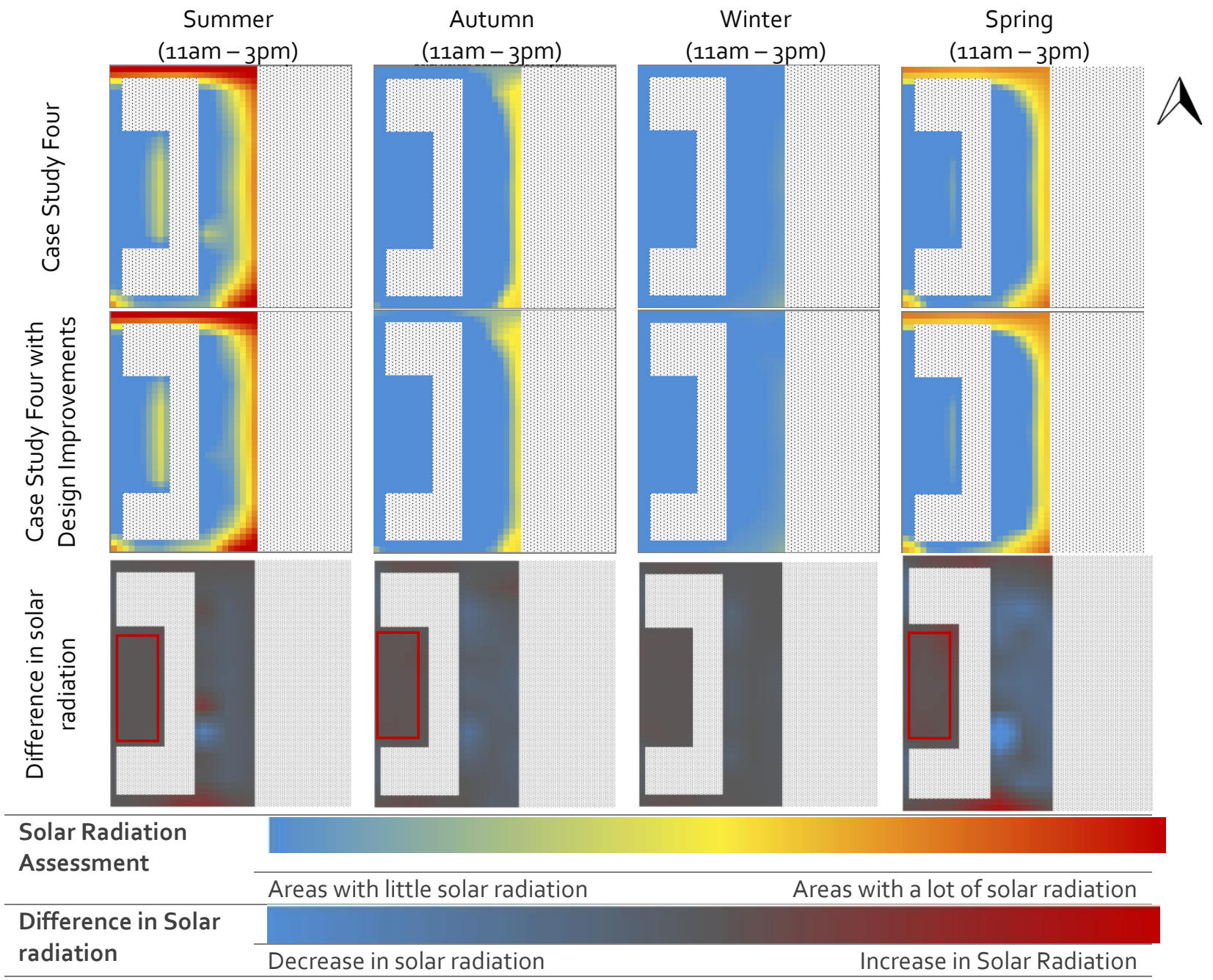

Figure 4.34 shows there was a slight increase in solar radiation from these design changes. 


\subsection{ASSUMPTIONS AND CONSIDERATIONS OF THE COMFORT TOOL}

This section covers the modelling assumptions made when modelling the case studies within the case study area, as well as the assumptions made when using the solar radiation and wind analysis computer programs.

\subsubsection{MODELLING ASSUMPTIONS AND CONSIDERATIONS}

Each case study was modelled with a neighbouring building where there was an existing building before the Canterbury Earthquakes. All surrounding buildings were modelled as twenty-eight metres in height, as this is the building height restriction defined by the Christchurch Central Recovery Plan for this area of Central Christchurch (Canterbury Earthquake Recovery Authority, 2012, p. 106). The distance between a proposed development and a neighbouring building follows the site's boundaries. It has been assumed that the new buildings cover the same footprints as the existing city blocks, and there are no lanes. This decision was made as the lane locations, widths and lengths, and orientation is unknown. The neighbouring buildings of each proposed development were modelled as they may affect the wind patterns and solar radiation in areas surrounding a case study.

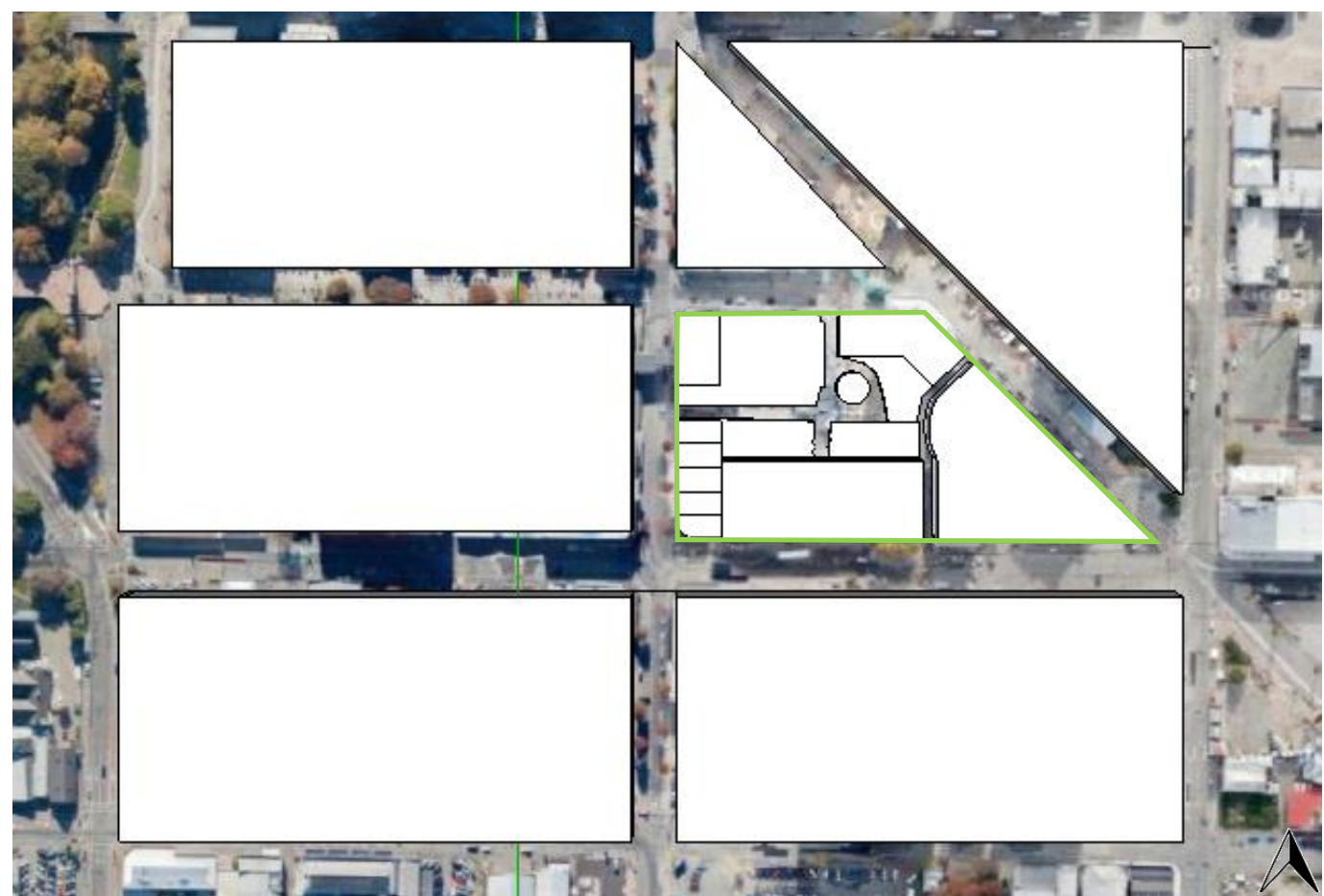

Figure 4.35 shows how the case studies were modelled in the wind analysis and solar radiation programs with twenty-eight metre high surrounding city blocks. This is Case Study Three (green box). 
The Comfort Tool's results for each case study were used as demonstrations of The Comfort Tool's ability at informing and testing design decisions. However, once the new Central Christchurch is complete, these results may be invalid due to the surrounding buildings being different than the 28 metre high buildings modelled for this thesis project. Design changes between these assumptions and what may happen in reality include buildings not being twenty-eight metres in height, having additional lanes, courtyards, changing their orientation, or having variations in built form.

The case studies were modelled without landscaping, and did not take into account the river which runs past two of the case studies, or the topography of the land.

The three-dimensional model for each case study was used for calculating the solar radiation and wind reduction factors. The three-dimensional models were modelled in SketchUp.

\section{Assumptions for UrbaWind}

It has been assumed that the case study area has a terrain-roughness of 0.35 , defined as a small density city with large open areas (Grimmond \& Oke, n.d., p. 1283). The mesh size was set to medium. This assumption was made as this is the recommended mesh coarseness recommended by UrbaWind when calculating wind reduction factors in low-rise urban areas. The wind reduction factors were calculated for eight wind directions (North, North-east, East, South-east, South, South-west, West, and North-west). This assumption was made as this calculates the primary wind speeds in Christchurch - North-east, Southwest, and North-west (Figure 4.36). 


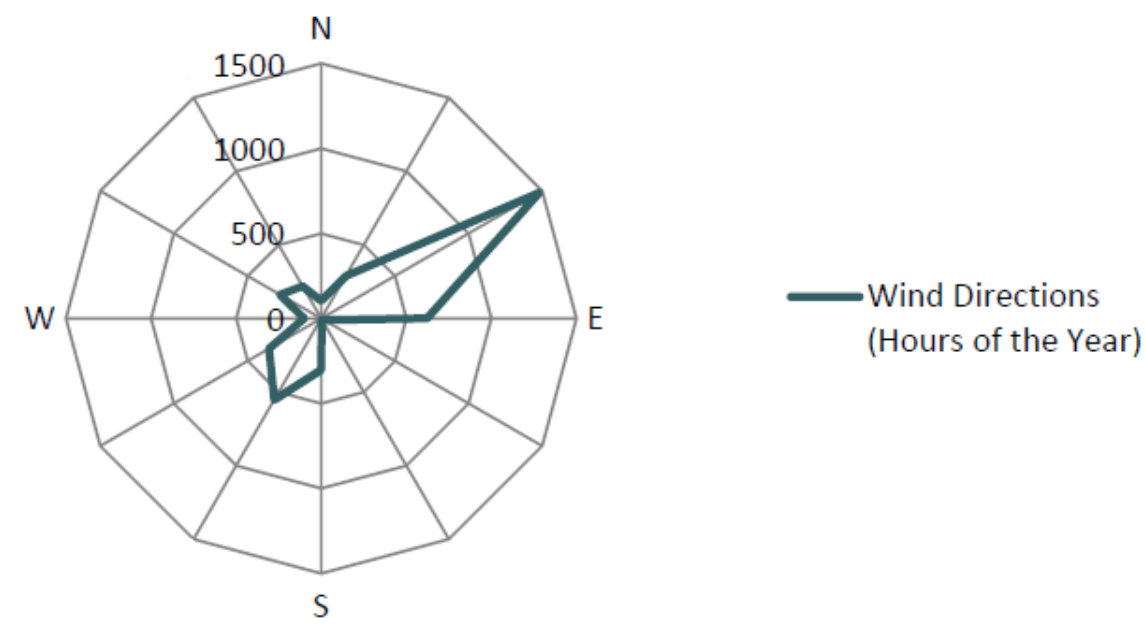

Figure 4.36 shows the predominate winds based on an TMY weather file for Christchurch ('TMY Weather Data', 2013).

The wind reduction factors were calculated at the height of 1.2 metres. This is based on the height of a person when they are seated. This was the same height as the mean wind speed was measured in the study which developed The Wellington Comfort Index (Walton et al., 2007, p. 3168).

\section{Assumptions for EnergyPlus}

Solar radiation was calculated using EnergyPlus version 8.1. It was measured at a height of 1.2 metres, as this is the average height of a person when they are seated (Walton et al., 2007, p. 3168). An EPW weather file for Christchurch was used to for the solar radiation calculations. This is representative of a typical meteorological year. Therefore, does not include unseasonable weather conditions.

\section{Assumptions for the Ambient Temperature}

The solar radiation and wind reduction factors were calculated within each case study therefore took into account the effect each built form had on solar radiation and wind patterns. However, the ambient temperature was measured at the Christchurch International Airport, rather than Central Christchurch and it is unknown how much the ambient temperature varies from Christchurch International Airport and Central Christchurch. The TMY weather file was only used to test if the ambient temperature in a TMY weather file could be used as part of The Comfort Tool. 


\section{DISCUSSION AND CONCLUSION}

This research began with the aim of developing the Process for Predicting Outdoor Thermal Comfort into a tool for use at the preliminary design stage of a development. The purpose of this thesis project was to test the hypothesis that a tool for predicting outdoor thermal comfort could be developed to inform design changes. This section responds to each of the four research questions outlined in the introduction to frame the line of investigation for this thesis project.

The research question "Are the results from a comfort tool able to inform design changes?" was used to identify if The Comfort Tool was able to communicate differences in thermal comfort across a development, allowing for the results to inform design changes. This question was able to identify whether the aim of this thesis project had been met through developing the Process for Predicting Outdoor Thermal Comfort into a tool for predicting outdoor thermal comfort at the preliminary design stage of a project. A case study research approach was selected to test The Comfort Tool. The success of The Comfort Tool was based on two criteria: "Can thermal comfort be automatically communicated across a development?" and "Are the results from a comfort tool able to inform design changes?". Four case studies were selected. These were selected on the differences in built form, and how these differences would affect solar radiation and wind levels at pedestrian level.

The results showed that The Comfort Tool could communicate variations in thermal comfort across three of the case studies for each season. The Comfort Tool also tested a case study for evening periods for each season when there was limited solar radiation. The Comfort Tool was not able to show differences in thermal comfort across Case Study Three for each season. However, variations in thermal comfort between seasons were identified. Through testing these case studies it was also revealed that The Comfort Tool needed to be able to provide sufficient extra information about the likely cause of thermal discomfort. This was important for assisting designers and consultants in identifying design changes likely to improve thermal comfort. For this reason, solar radiation and wind assessments were also added to The Comfort Tool. 
Through testing The Comfort Tool, the importance of thermal comfort trade-offs were also revealed. For example, improving thermal comfort in one area of a case study may have an adverse effect on thermal comfort in another area of the case study. Therefore, there could be a need for a hierarchy of design outcomes. This was demonstrated in Case Study One, where improving thermal comfort along the Northern footpath caused a decrease in one of the internal lanes.

The answer to the second question "Can the Process for Predicting Outdoor Thermal Comfort be developed into a tool for use at the preliminary design stage?" a set of criteria were developed to assist designers and consultants in selecting their own wind analysis programs. This was because the Process for Predicting Outdoor Thermal Comfort required specialist skills. However, the criteria outlined what would be required from a wind analysis program for use with The Comfort Tool, as well as how to test if a wind analysis program could produce accurate results based on wind tunnel test results. The criteria were tested on three wind analysis programs and were able to highlight the strengths and weaknesses of each program. These criteria would allow designers and consultants with knowledge of three-dimensional modelling and simulation to understand what is required from a wind analysis program.

The third research question "Can thermal comfort be automatically communicated across a development?" addressed the problem that the Process for Predicting Outdoor Thermal Comfort could only predict thermal comfort for a single point in a development at a time. For an assessment of a whole development, this point by point thermal comfort assessment is inadequate for the construction industry as it would be time consuming, as the process would need to be repeated hundreds of times for an assessment across a whole development. In response to this research question, the Process for Predicting Outdoor Thermal Comfort was developed into The Comfort Tool which took wind and solar radiation data for 121 measurement points across a case study, and calculated thermal comfort for each of the points, automatically displaying the thermal comfort across each case study. This was tested on four case studies and showed that thermal comfort can be communicated for different times of the day and seasons, with areas of thermal comfort and discomfort identified using The Comfort Tool. However, these four case studies with different built forms identified the problem that The Comfort Tool was unable to accurately 
represent diagonal lanes, and circular buildings. These were displayed as straight lines. This means that The Comfort Tool provides useful information at the concept stage. However, there are some limitations when displaying more complex designs such as, angled or nonrectangular floor plans.

The final research question asked "What is the applicability of The Wellington Comfort Index to cities outside of Wellington?". This question was asked as it was unknown if The Wellington Comfort Index was able to predict thermal comfort in cities outside of Wellington, or if it was only representative of Wellington. It was unknown if mean wind speed, maximum wind speed, solar radiation, and ambient temperature were the environmental factors which needed to be considered when predicting comfort in cities outside of Wellington. To understand the Wellington Comfort Index's applicability to other cities, the survey conducted in Wellington to create the Wellington Comfort Index was conducted in another city, using Christchurch as a case study. This allowed for the development of The Christchurch Comfort Index using the same methodology as was used to develop The Wellington Comfort Index. Once The Christchurch Comfort Index was developed, the environmental factors which predict comfort in each city were compared. In Christchurch, the ambient temperature and maximum wind speed were important factors when predicting thermal comfort. Mean wind speed and mean radiant temperature were not considered important when calculating people's adaption to maintain comfort in The Christchurch Comfort Index. However, as the sample size in Christchurch was less than ten percent of the sample size in Wellington, further investigation is needed. It is unknown if a larger sample size in Christchurch would have resulted in mean radiant temperature and mean wind speed also being included in The Christchurch Comfort Index.

This aim of this thesis project was to develop the Process for Predicting Outdoor Thermal Comfort into a tool for use at the preliminary design stage of a development. The motivation of this study was the rebuilding of Christchurch after the Canterbury Earthquakes. Through this thesis project, a tool has been developed which informs design changes to allow outdoor thermal comfort to be improved in the preliminary design stage. The Comfort Tool is able to assist designers and consultants working on the Christchurch rebuild in creating a new central city which has been designed with improved outdoor thermal comfort. 
pg. 147 


\section{FUTURE DEVELOPMENT OF THE COMFORT TOOL}

This thesis project has developed the Process for Predicting Outdoor Thermal Comfort into a tool. However, there are ways The Comfort Tool could be improved for use within urban planning and architecture. These improvements are discussed below. They include further testing of The Wellington Comfort Index.

\section{The Comfort Tool}

Currently the results of The Comfort Tool are in an excel spreadsheet with conditional formatting used to communicate the thermal comfort levels on two-dimensional plans. For the results to be communicated in a more dynamic way, allowing for the user or client to feel as though they are within the development, a three-dimensional virtual environment of a proposed urban development could be created (Figure 6.1). This could be developed as a 'walk-through' allowing people to walk through a space virtually which visually shows the thermal comfort levels using colours or icons. The virtual environment would be threedimensional, allowing for a feeling of being inside a propose development and understanding the comfort levels before it is even constructed.

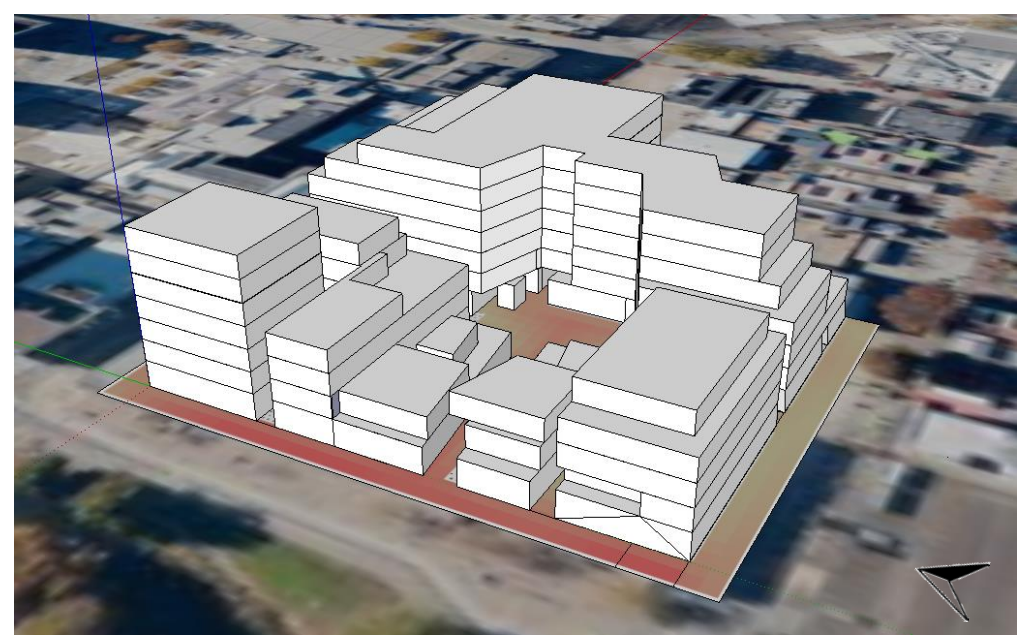

Figure 6.1 shows the virtual environment with the comfort displayed for one season underneath Case Study One as an example. 
Although The Comfort Tool can automatically calculate and display the comfort results for 121 measurements points for 8760 hours of a year, data is lost when these 8760 hours are averaged into different periods of the day for each season. Being able to look at one hour at a time through the use of a slider would allow for a much richer analysis.

Although the wind reduction factors and solar radiation modelling programs take into account how the angled lanes and circular buildings affected wind and solar radiation, The Comfort Tool is unable to show diagonal lanes or circular buildings. However, in the future the interoperation method used to communicate the data measured at 121 points across a development on a plan view could be improved to show angled lanes and circular buildings.

The Comfort Tool displayed the average wind results for approximately three-hundred hours of data for each season. If all 8760 hours of wind data had been averaged, this may have been misleading as the hours with high wind speeds may be lost when averaged with periods of low wind speeds. However, future development could include showing the difference in wind in the proposed development, and the development with design changes made to reduce wind speeds for a specific point (black dot, Figure 6.2). The wind rose indicates that the wind speeds at the specific point (black dot) have reduced in the North direction. This could be animated, so that the user of The Comfort Tool can indicate a point where they would like the wind speeds to be compared appearing on a wind rose.
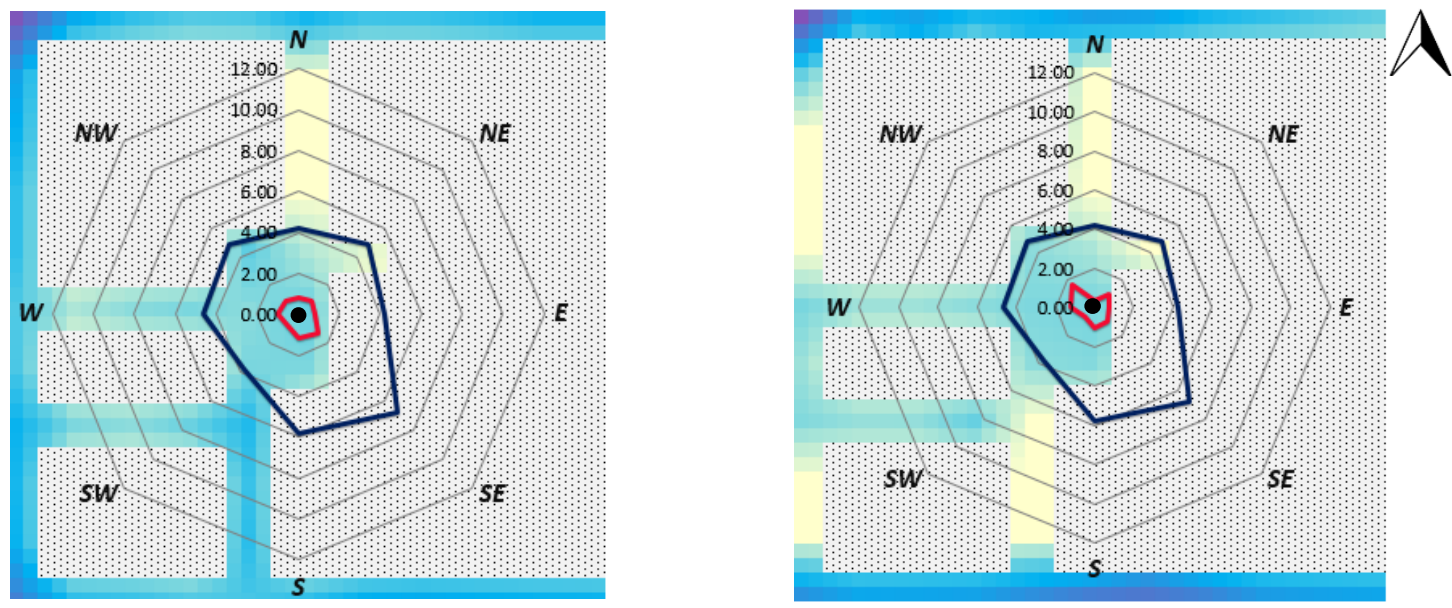

Figure 6.2 shows the difference in wind speeds for proposed development (left) and a proposed development with design changes made to improve comfort (right) for a specific point. The wind rose on the right has lower wind speeds in the North direction (pink) The predominant wind speeds outside of the development are also indicated (navy blue). 
The thermal properties of building materials within a development may influence the ambient temperature within an outdoor area. This is due to construction materials such as concrete having a greater thermal mass than materials such as glass. Materials with a greater thermal mass absorb more heat from solar radiation and release it gradually. This has not been included in The Comfort Tool. However, further development of The Comfort Tool could include constructing the three-dimensional model of a development to include the thermal properties. This may also include the roads, surrounding footpaths, lanes, and courtyards. The three-dimensional model could then calculate the effect of the thermal properties of the construction materials on ambient temperature and include this ambient temperature, rather than the ambient temperature measured at the regional weather station in The Comfort Tool.

Although The Comfort Tool was developed for assessing thermal comfort, it could be further developed to be a design tool. This could be through including design recommendations automatically generated depending on the thermal comfort results for a development. For example, if wind is a cause of thermal discomfort at a corner café, a design recommendation automatically generated could be:

1. Change the height of the buildings

2. Add a podium

3. Increase or decrease the distance between buildings

4. Change the shape of the building (square corner, versus curved corners)

5. Add a canopy or balconies

6. Add breeze-ways

7. Increase/decrease setbacks

8. Include passageways/corridors

9. Add fences, screens

10. Add vegetation

11. Turn area into an arcade

In the future, design changes could be optimised through the use of an optimisation program. Currently these programs are available for assessing energy use in buildings which cycle through a range of options such as construction types, R-values of materials, 
and glazing area and calculate the best combination of options for an energy efficient building. For outdoor thermal comfort, an example of this could be varying the height of each building within a development until the optimal combination of building heights for the most thermally comfortable outdoor area is calculated, while maintaining the net lettable area of the development.

Currently The Comfort Tool does not include the topography of the site a development is on. However, in cities which have hills or are surrounded by water, the topography may have an impact on the wind results calculated by the wind analysis program.

The wind analysis program also did not include landscaping. However, in developments which have a large amount of landscaping it is important that this is included in The Comfort Tool in the future as it may have an effect on both wind patterns and solar radiation within a development.

\section{The Wellington Comfort Index}

Through calculating The Christchurch Comfort Index, it was determined that only ambient temperature and maximum wind speed were the environmental factors which can be used to predict thermal comfort in Christchurch. However, this sample only contained thirty people, which was ten percent of the sample size used to develop The Wellington Comfort Index. For a deeper understanding, The Wellington Comfort Index should be calculated using the same methodology in cities other than Wellington with a sample size closer to what was used to develop The Wellington Comfort Index.

The Wellington Comfort Index has been tested on another city with a temperate climate. However, for a deeper understating, the same methodology for calculating The Wellington Comfort Index should be conducted in cities with a radically different climate (M Salinger, G Griffiths, 2001). This may include tropical climates where humidity affects thermal comfort more than in temperate climates. Another climate may be an arid climate where outdoor thermal comfort design is focused on humidifying the air and cooling down outdoor areas. Humidity has not been included in The Wellington Comfort Index. This is because it was found that humidity was not an important factor in outdoor thermal comfort for 
Wellington, and The Christchurch Comfort Index was calculated based on the survey questions which were important in Wellington. Christchurch and Wellington do not typically experience high levels of humidity. However, for The Wellington Comfort Index to be used in cities which have higher humidity, then the survey should be repeated and include questions from the original survey asking about humidity.

To make The Wellington Comfort Index more robust it should be recalculated for Wellington with the black globe temperature, instead of the mean radiant temperature. The Wellington Comfort Index was created using the black globe temperature as a solarimeter was unavailable, which was then converted to mean radiant temperature. However, the long term TMY weather data includes solar radiation, not black globe temperature. Therefore, it is important that The Wellington Comfort Index is recalculated with the black globe as this reduces the reliance on a two different formulae, one for calculating black globe temperature, and one for calculating mean radiant temperature which were derived from different studies (Turco et al., 2008; Walton et al., 2007). This is especially important as the calculation used for converting solar radiation and ambient temperature to black globe was based on a small dataset in Brazil. It is unknown if this formula works on a range of climates. The recalculation of The Wellington Comfort Index to include black globe temperature instead of mean radiant temperature was not included as part of this thesis project as the full dataset for Wellington was not available.

\section{Other Future Development Areas of Outdoor Thermal Comfort}

There is a link between the vitality and the increased revenue for an area (Lian Chen, Edward Ng, 2011, p. 118). However, there needs to be more research in this area to provide more evidence to support this link. This would encourage developers to invest the extra time and money to ensure that a development has mitigated any issues with outdoor thermal comfort during the design phase. 
pg. 153 


\section{REFERENCES}

2005 ASHRAE Handbook Fundamentals. (2005). Atlanta: American Society of Heating, Refrigerating and Air-Conditioning Engineers.

American Society of Heating, Refrigerating and Air-Conditioning Engineers. (1985).

ASHRAE Handbook: Fundamentals. Atlanta: American Society of Heating, Refrigerating and Air-Conditioning Engineers.

ASHRAE. (2013). ANSI/ASHRAE Standard 55-2012. ASHRAE.

ASHRAE Terminology. (2015). Retrieved from https://www.ashrae.org/resources-publications/free-resources/ashrae-terminology

Autodesk. (2015). Simulation CFD. Retrieved from

http://www.autodesk.com/education/free-software/simulation-cfd

Blocken, B., \& Carmeliet, J. (2004). Pedestrian Wind Environment around Buildings:

Literature Review and Practical Examples. Journal of Thermal Envelope and Building Science, 28(2), 107-159. http://doi.org/10.1177/1097196304044396

Blocken, B., \& Gualtieri, C. (2012). Ten iterative steps for model development and evaluation applied to Computational Fluid Dynamics for Environmental Fluid Mechanics. Environmental Modelling and Software, 33, 1-22.

Blocken, B., Janssen, W. ., \& Hooff, T. V. (2012). CFD simulation for pedestrian wind comfort and wind safety in urban areas: general decision framework and case study for the Eindhoven University campus. Environmental Modelling and Software, 30, 1534 . 
Boston Development Authority. (2006). BRA Development Review Guidelines. Retrieved from http://www.bostonredevelopmentauthority.org/getattachment/65dba1c10947-4dac-9309-23b395849bbo

Bottema, M. (1999). Towards rules of thumb for wind comfort and air quality. Atmospheric Environment, 33, 4009-4017.

Bottema, M. (2000). A method for optimisation of wind discomfort criteria. Building and Environment, 35, 1-18.

Bradburn, N. (1978). Respondent Burden (p. 40). Chicago: University of Chicago.

Brown, R. (2011). Ameliorating the effects of climate change: Modifying microclimates through design. Landscape and Urban Planning: An International Journal of Landscape Ecology, Planning and Design, 100(1), 3672-374.

Brown, R., \& Gillespie, T. (1995). Microclimate Landscape Design. New York: John Wiley and Sons.

Canterbury Earthquake Recovery Authority. (2012). Christchurch Central Recovery Plan. Canterbury Earthquake Recovery Authority.

Chapter 3: What influences the amount of solar radiation? (2014).

Cheng, V., \& Ng, E. (2006). Thermal Comfort in Urban Open Spaces for Hong Kong. Architectural Science Review, 49(3), 236-242. http://doi.org/10.3763/asre.2006.4932

Christchurch City Council. (2006a). Central City Revitalisation Strategy.

Christchurch City Council. (2006b). Project Central City: Lanes Design Guide. Christchurch City Council.

Christchurch City Council. (2011, August). Draft Central City Plan. 
Clark, H. (2012, July 30). The new-look Christchurch CBD unveiled. Retrieved g June 2014, from http://www.3news.co.nz/The-new-look-Christchurch-CBDunveiled/tabid/423/articleID/263208/Default.aspx

De Dear, R., \& Schiller Brager, G. (2001). The adaptive model of thermal comfort and energy conservation in the built environment. Int J Biometeorology, (45), 400-108.

DOE Sponsored Tools — Building Energy Simulation Test (BESTEST). (2011). Retrieved from

http://apps1.eere.energy.gov/buildings/tools_directory/doe_sponsored_bestest.cfm Donn, M., Selkowitz, S., \& Bordass, B. (2012). The building performance sketch. BUILDING RESEARCH \& INFORMATION, 4O(2), 186-208.

Eliasson, I., Knez, I., Westerberg, U., Thorsson, S., \& Lindberg, F. (2007). Climate and behaviour in a Nordic city. Landscape and Urban Planning, 82, 72-84.

Fadl, M., \& Karadelis, J. (n.d.). CFD Simulation for Wind Comfort and Safety in Urban Area: A Case Study of Coventry University Central Campus (pp. 364-374). Coventry University.

Fiala, D., Lomas, K., \& Stohrer, M. (2001). Computer prediction of human thermoregulatory and temperature responses to a wide range of environmental conditions. International Journal of Biometeorology, 45, 143-159.

Field, A. (2013). Discovering Statistics Using IBM SPSS Statistics (4th ed.). London: SAGE Publications Limited.

Flow Design Preliminary Validation Brief. (2014, July). Autodesk.

Folk, E. (2015). Accliatization: Adjusting to the Temperature. Retrieved 10 February 2015, from http://www.uihealthcare.org/health-library/acclimatization-adjusting-to-thetemperature/ 
Franke, J., Hirsch, C., Jensen, A. G., Krus, H. W., Schatzmann, M., Westbury, P. S., ...

Wright, N. G. (2004). Recommendations on the Use of CFD in Wind Engineering (p.

11). Siegen, Germany: University of Siegen.

Frizzell Agricultural Electronics. (2014). Wireless Weather Station with 7" Colour LCD Display. Frizzell Agricultural Electronics.

Frost, \& Sullivan. (2013, December 11). NZ will have 90\% smartphone and 78\% tablet ownership by 2018 [Press Release].

Gaitani, N., Mihalakakou, G., \& Santamouris, M. (2007). On the use of bioclimatic architecture principles in order to improve thermal comfort conditions in outdoor spaces. Building and Environment, 42(1), 317-324.

http://doi.org/http://dx.doi.org/10.1016/j.buildenv.2005.08.018

Gandemer, J. (1978, March). Building Research Translation Discomfort Due to Wind near Buildings Aerodynamic Concepts. U.S. Department of Energy.

Gandemer, J., \& Guyot, A. (1976). Integration du Phenomene Vent dans la Conception du Milieu Bati. Paris: CTSB.

Gates, A., Liley, B., \& Donn, M. (2011). New Zealand's New Weather Data - How Different. In Proceedings of Building Similations 2011. Sydney.

Givoni, B., Noguchi, M., Saaroni, H., Pochter, O., Yaacov, Y., Feller, N., \& Becker, S. (2003). Outdoor comfort research issues. Energy and Buildings, 35(1), 77-86. http://doi.org/10.1016/s0378-7788(02)00o82-8

Goshayeshi, D., Shahidan, M. F., Khafi, F. K., \& Ehtesham, E. (2013). A review of researches about human thermal comfort in semi-outdoor spaces. European Online Journal of Natural and Social Sciences 2013, 2(4), 516- 523. 
Grimmond, C. S. B., \& Oke, T. R. (n.d.). Aerodynamics Properties of Urban Areas Derived from Analysis of Surface Form. Journal of Applied Meteorology, 38, 1262-1292.

Groen, G., \& Wever, N. (2009). Improving potential wind for extreme wind statistics (p. 120). The Netherlands: Netherlands Royal Meteorological Institute (KNMI).

He, J., \& Song, C. (1999). Evaluation of pedestrian winds in urban area by numerical approach. Journal of Wind Engineering and Industrial Aerodynamics, 81, 295-309.

Honjo, T. (2009). Thermal Comfort in Outdoor Environment (pp. 43-47). Faculty of Horticulture, Chiba University.

Höppe, P. (2002). Different aspects of assessing indoor and outdoor thermal comfort. Energy and Buildings, 34(6), 661-665. http://doi.org/10.1016/s0378-7788(02)00017-8 Houda, S., Zemmouri, N., Hasseine, A., Athmani, R., \& Bensalem, R. (2012). A CFD Model for Simulating Urban Flows in Complex Morphological Street Network. The Online Journal of Science and Technology, 2(1), 10.

Hussin, M. (2002). Dependence of power law index on surface wind speed. Energy Conversion and Management, (43), 467-472.

Isyumov, N., \& Davenport, A. G. (1977). The Ground Level Wind Environment in Built-up Areas (pp. 403-417). Great Britain: Cambridge University Press.

Jacket, R., Walton, D., \& Cleland, B. (n.d.). Investigation of Predicted Mean Vote (PMV) outdoors (p. 10). Lower Hutt, N.Z.: Opus International Consultants.

Jamieson, Carpenter., P., \& Cenek, P. (1992). The effect of architectural detailing on pedestrian level wind speeds. Journal of Wind Engineering and Industrial Aerodynamics, 41-44, 2301-2312. 
Jendritzky, G., Maarouf, A., \& Staiger, H. (2001). Looking for a universal thermal climate index UTCI for outdoor applications. In Windsor-Conference on Thermal Standards. Windsor.

J Hoof. (2008). Forty years of Fanger's model of thermal comfort: Comfort for all? Indoor Air, (18), 182-201.

John Zacharias, Ted Stathopoulos, Hanging Wu. (2001). Microclimate and Downtown Open Space Activity. Environment and Behavior, (33), 296-315.

Kepa, B. (2010, April). Area Assessment of Pedestrian Wind Environment Using Point Wind Speed Measurements. Victoria University, Wellington.

Knez, I. (2005). Attachment and identity as related to a place and its perceived climate. Journal of Environmental Psychology, 25(2), 207-218. http://doi.org/10.1016/j.jenvp.2005.03.003

Knez, I., \& Thorsson, S. (2006). Influences of culture and environmental attitude on thermal, emotional and perceptual evaluations of a public square. International Journal of Biometeorology, 50, 258-262.

Lian Chen, Edward Ng. (2011). Outdoor thermal comfort and outdoor activities: A Review of research in the past decade. Cities, 29, 118-125.

Lykoudis, (first), \& Nikolopoulou, M. (2006). Thermal comfort in outdoor urban spaces: analysis across different European countries. Building and Environment, (41), 14551470.

Meteodyn FAQ. (2010, February 12). [Forumn]. Retrieved 16 October 2014, from http://www.cfdonline.com/Wiki/MeteoDyn_FAO\#What_do_you_mean_by_.22automatic_CFD_sof tware.22.3F 
Met Office U.K. (n.d.). Beaufort wind force scale. Retrieved from

http://www.metoffice.gov.uk/weather/marine/guide/beaufortscale.html

Mochida, A., \& Lun, I. (2008). Prediction of wind environment and thermal comfort at pedestrian level in urban area. Journal of Wind Engineering and Industrial Aerodynamics, (96), 1498-1527.

M Salinger, G Griffiths. (2001). Trends in New Zealand Daily Temperature and Rainfall Extremes. International Journal of Climatology, 21, 1437-1452.

Nikolopoulou, M., Baker, N., \& Steemers, K. (2001). Thermal Comfort in Outdoor Urban Spaces: Understanding the Human Parameter. Solar Energy, 70(3), 227-235.

Nikolopoulou, M., Baker, N., \& Steemers, K. (2001). Thermal Comfort in Outdoor Urban

Spaces: Understanding the Human Parameter. Solar Energy, 70(3), 227- 235.

Nikolopoulou, M., \& Lykoudis, S. (2007). Use of outdoor spaces and microclimate in a Mediterranean urban area. Building and Environment, 42, 3691-3707.

Nikolopoulou, M., \& Steemers, K. (2003). Thermal Comfort and Psychological Adaptation as a Guide for Designing Urban Spaces. Energy and Buildings, 35, 95-101.

NIWA. (2015a). Cliflo Help - NIWA. Retrieved 3 April 2015, from http://clifloniwa.niwa.co.nz/pls/niwp/wh.do_help?id=ls_rad

NIWA. (2015b). Station Details for Agent: 24120. Retrieved 4 April 2015, from http://cliflo.niwa.co.nz/pls/niwp/wstn.stn_details?cAgent=24120

Parsons, R. (Ed.). (1997). 1997 Fundamentals. Atlanta: American Society of Heating, Atlanta, Georgia, U.S.A.

Planning and Consents. (2013). [City Council]. Retrieved 4 April 2015, from https://ccdu.govt.nz/faq/planning-and-consents 
Reiter, S. (2010). Assessing wind comfort in urban planning. Environment and Planning B: Planning and Design, 37, 857-873.

Rofail, A. (2007). Comparison of wind environment criteria against field observations. In 12th International Conference of Wind Engineering. Sydney.

Sangkertadi, Reny Syafriny. (2012). Proposition of Regression Equations to Determine Outdoor Thermal Comfort in Tropical and Humid Environments. The Journal for Technology and Science, 23(2), 59-67.

Shimazaki, Y., Yoshida, A., Suzuki, R., Kawabata, T., Imai, D., \& Kinoshita, S. (2011).

Application of human thermal load into unsteady condition for improvement of outdoor thermal comfort. Building and Environment, 46, 1716-1724.

Spagnolo, J., \& de Dear, R. (2003). A field study of thermal comfort in outdoor and semioutdoor environments in subtropical Sydney Australia. Building and Environment, 38(5), 721-738. http://doi.org/10.1016/s0360-1323(02)00209-3

Spera, D. A., \& Richards, T. R. (1979). Modified Power Law Equations for Vertical Wind Profiles. U.S. Department of Energy.

Stoffel, T. (2005, April). 20 Years of Solar Measurements: The Solar Radiation Research Laboratory (SRRL) at NREL. NREL.

Thorsson, S., Lindqvist, M., \& Lindqvist, S. (2004). Thermal bioclimatic conditions and patterns of behaviour in an urban park in Göteborg, Sweden. International Journal of Biometeorology, 48(3), 149-156.

TMY Weather Data. (2013). Retrieved 3 April 2015, from http://apps1.eere.energy.gov/buildings/energyplus/weatherdata_about.cfm?CFID=3 149866\&CFTOKEN=cecdoef73531b751-FoD61633-9231-6EgF037492CAF2EE 51 C1\&jsessionid=FD2891F943ED0323CACo44A ${ }_{5} C_{49}$ B6F8F.eere 
Tokunaga, K., \& Shukuya, M. (2011). Human-body energy balance calculation under unsteady state conditions. Building and Environment, 46, 2220-2229.

Tominaga, Y., Mochida, A., Yoshie, R., Kataoka, H., Honjo, T., Yoshikawa, M., \& Shirasawa, T. (2008). AlJ Guidelines for Practical Applications of CFD to Pedestrian Wind Environment around Buildings. Journal of Wind Engineering and Industrial Aerodynamics, (96), 1749-1761.

Turco, S. H. N., Silva, T. G. F. da, Oliveira, G. M. de, Leitão, M. M. V. B. R., Moura, M. S. B. de, Pinheiro, C., \& Padilha, C. V. da S. (2008). Estimating black globe temperature based on meteorological data. Presented at the International Livestock Environment Symposium VIII, Iguassu Falls City, Brazil: International Commission of Agricultural Engineering (CIGR), Institut fur Landtechnik. Retrieved from http://www.cabdirect.org/abstracts/20093329506.html;jsessionid=oF388A0598F7D $\mathrm{B}_{78} \mathrm{BDC}_{3} \mathrm{~B}_{2} \mathrm{E}_{5} \mathrm{~F}_{501596}$

U.S. Department of Energy. (2011). Building Energy Software Tools Directory: UrbaWind. Retrieved from http://apps1.eere.energy.gov/buildings/tools_directory/software.cfm/ID=588/pagen ame=alpha_list_sub?print

Walton, D., Dravitzki, V., \& Donn, M. (2007). The relative influence of wind, sunlight and temperature on user comfort in urban outdoor spaces. Building and Environment, 42(9), 3166-3175. http://doi.org/10.1016/j.buildenv.2006.08.004

Wellington City Council. (2007, October). Appendix 8. Wind.

Willemsen, E., \& Wissse, J. (2007). Design for wind comfort in The Netherlands: Procedures, criteria, and open research. Journal of Wind Engineering and Industrial Aerodynamics, (95), 1541-1550. 
Wu, H., \& Kriksic, F. (2012). Designing for pedestrian comfort in response to local climate. Journal of Wind Engineering and Industrial Aerodynamics, 104-106, 397-407. http://doi.org/10.1016/j.jweia.2012.02.027

Yoshie, R., Mocjida, A., Tominaga, Y., Hataoka, H., Harimoto, K., Nozu, T., \& Shirasawa, T. (2007). Cooperative project for CFD prediction of pedestrian wind environment in the Architectural Institute of Japan. Journal of Wind Engineering and Industrial Aerodynamics, 95, 1551-1578. 


\section{APPENDICES}

These Appendices have been included to provide further evidence which supports the methodology used to develop The Comfort Tool, and The Christchurch Comfort Index. As The Comfort Tool does not specify the wind analysis program to be used as part of The Comfort Tool, there is also an appendix which contains wind tunnel test results for The Simple City Test. 


\subsection{APPENDIX ONE: THE DEVELOPMENT OF THE COMFORT TOOL}

\subsubsection{SIMPLE CITY TEST RESULTS FOR ASSESSING WIND ANALYSIS PROGRAMS FOR THEIR ACCURACY}

The results for the wind tunnel test for The Simple City have been included to allow designers and consultants to test wind analysis programs for their accuracy based on this Simple City Test. This is important before a wind analysis program is used to calculate the wind reduction factors to be used in The Comfort Tool.

Uniform Simple City $360^{\circ}$ (Northerly wind)

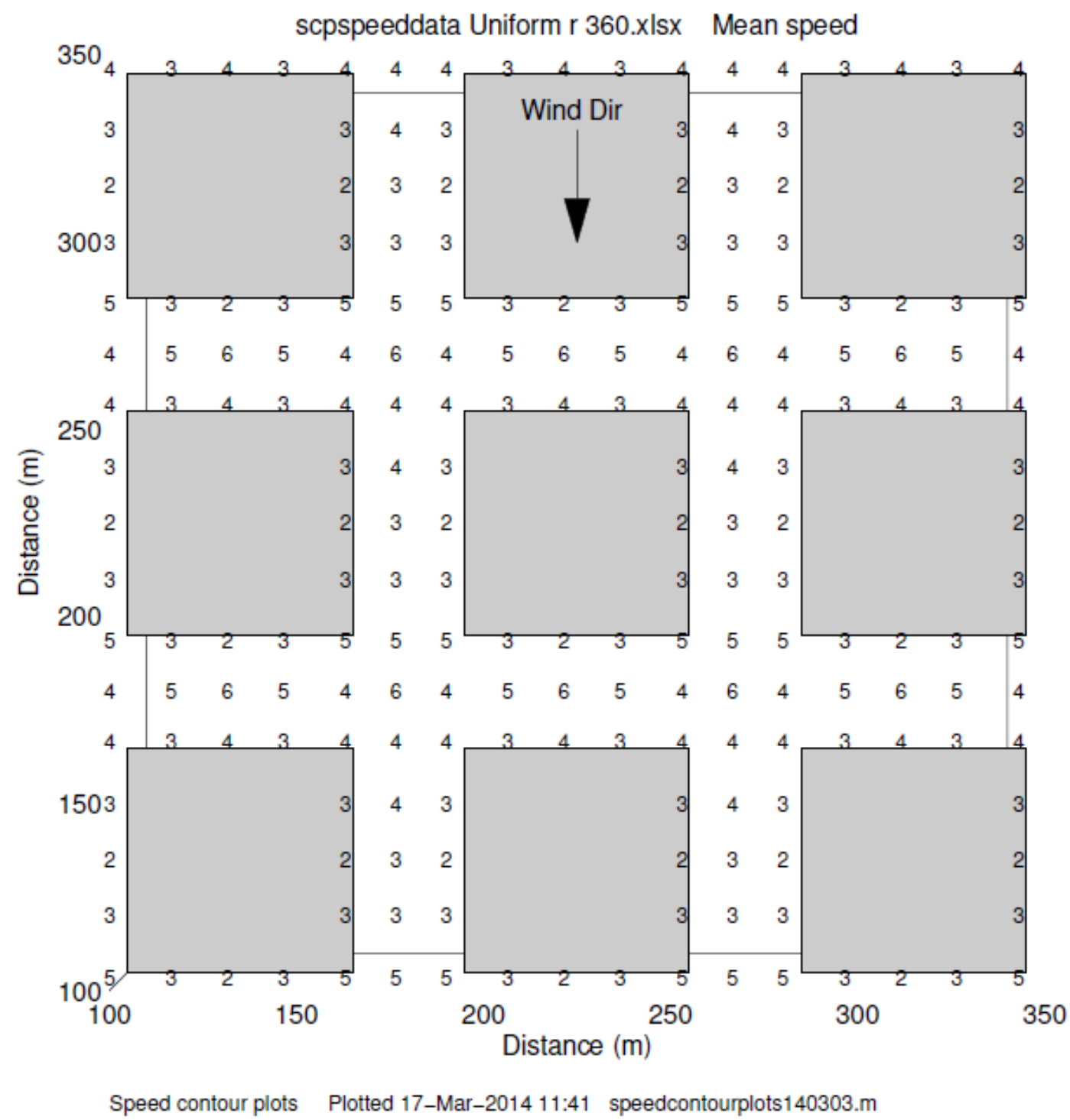


Uniform Simple City $45^{\circ}$ (North-easterly wind)

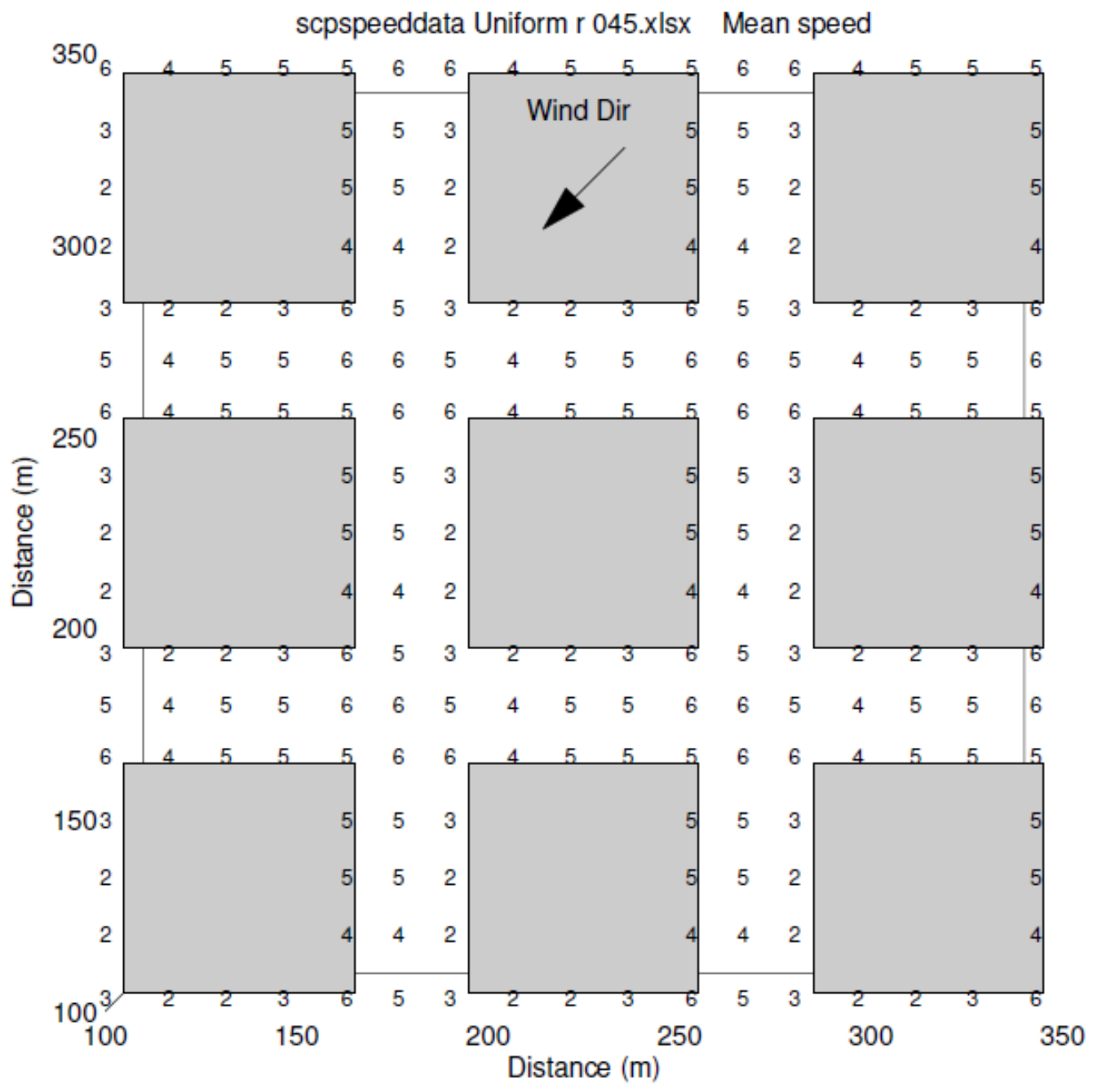

Speed contour plots Plotted 17-Mar-201411:41 speedcontourplots140303.m 
Non-uniform Simple City $360^{\circ}$ (Northerly Wind)

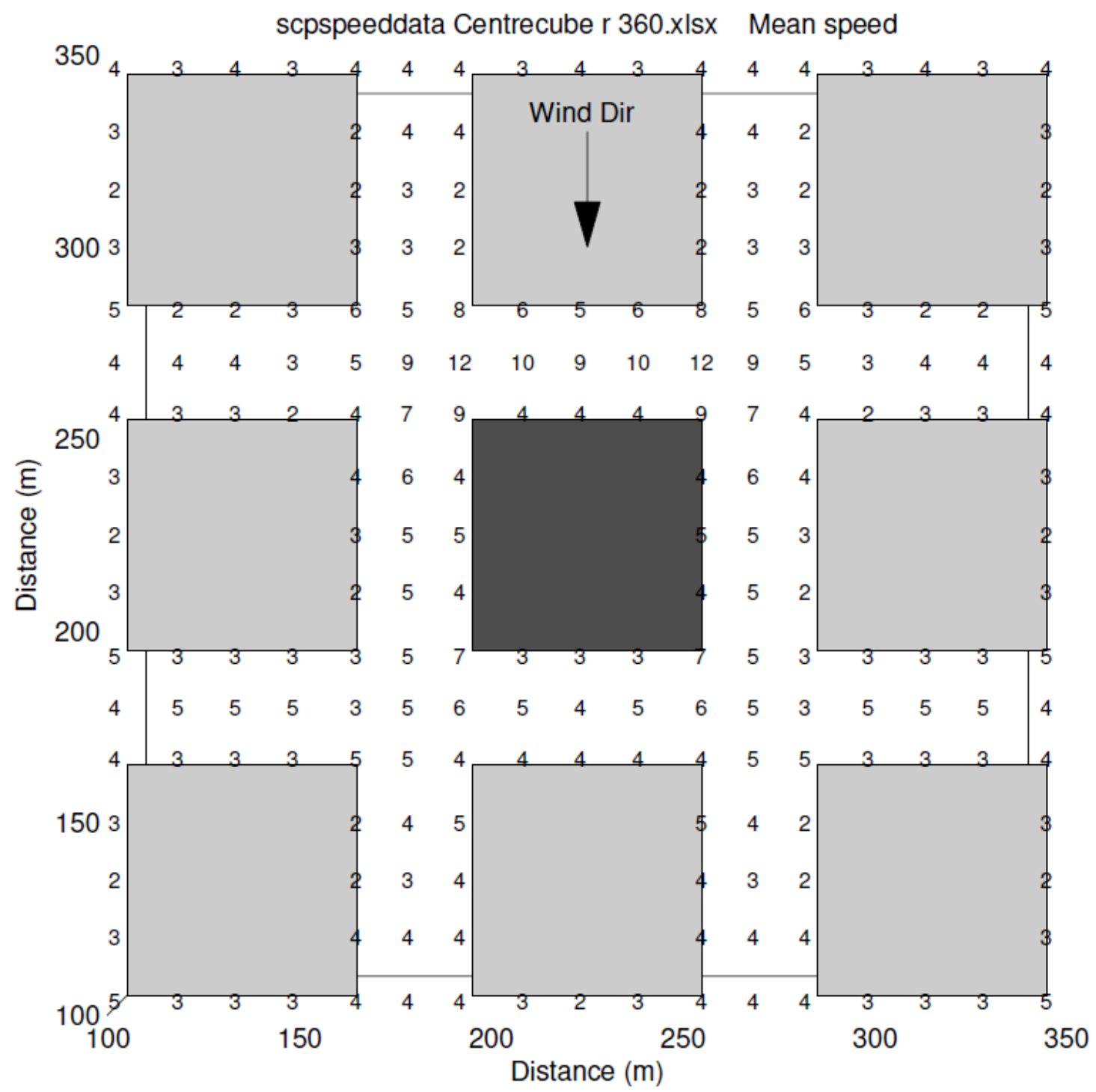

Speed contour plots Plotted 17-Mar-2014 11:41 speedcontourplots140303.m 
Non-uniform Simple City $45^{\circ}$ (North-easterly wind)

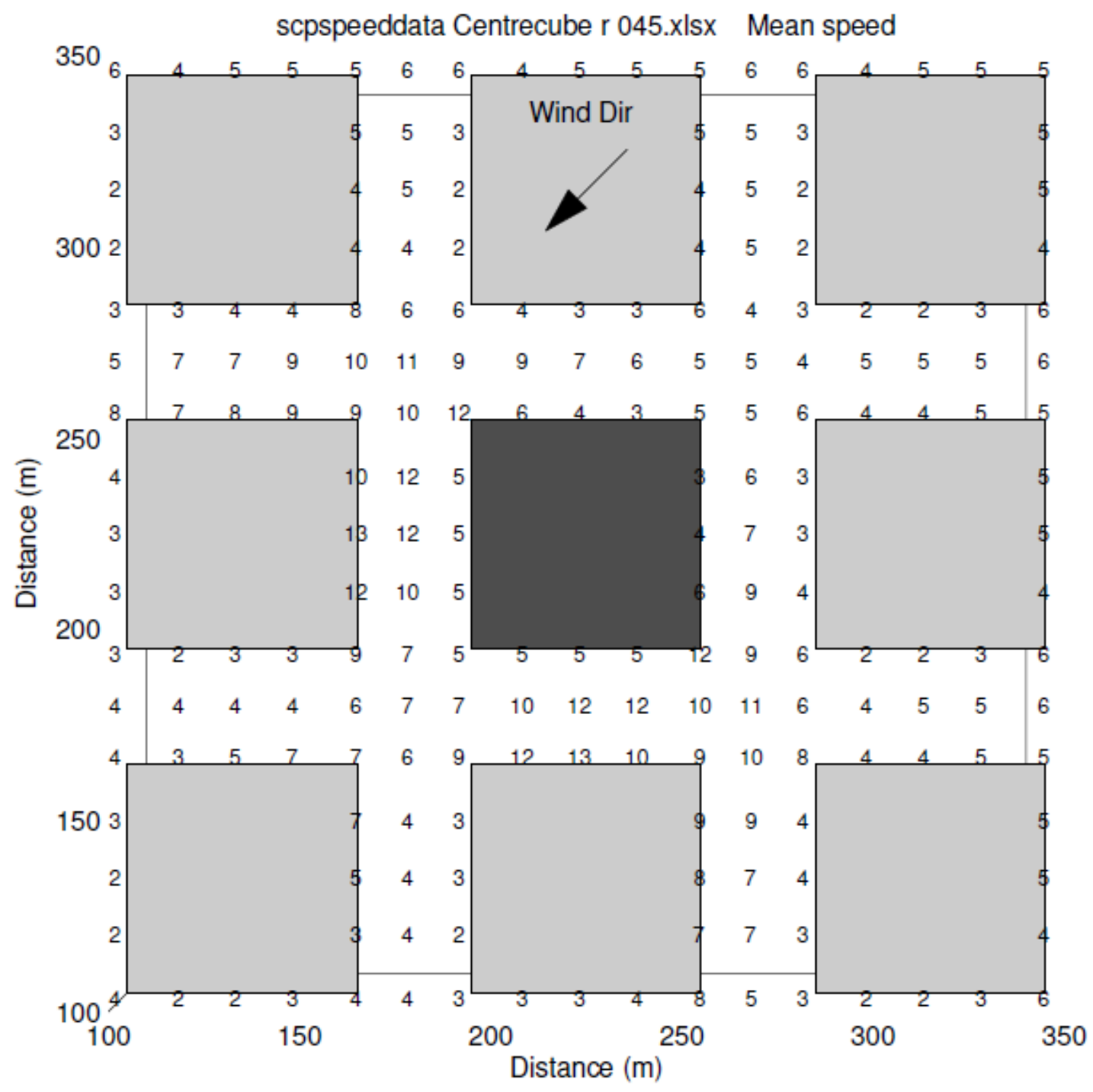

Speed contour plots Plotted 17-Mar-201411:41 speedcontourplots140303.m 
8.1.2. CALCULATING THE GUST CO-EFFICIENT

As the wind analysis programs could not calculate the gust wind speed, a gust co-efficient was calculated based on data from the case study weather station. This was conducted on ten minute data (Figure 8.2), and sixty minute data (Figure 8.1) using a linear regression analysis. The gust co-efficient was used for calculating the gust speed from the mean wind speed in the TMY weather file, as the TMY weather data is sixty minute data ('TMY Weather Data', 2013).

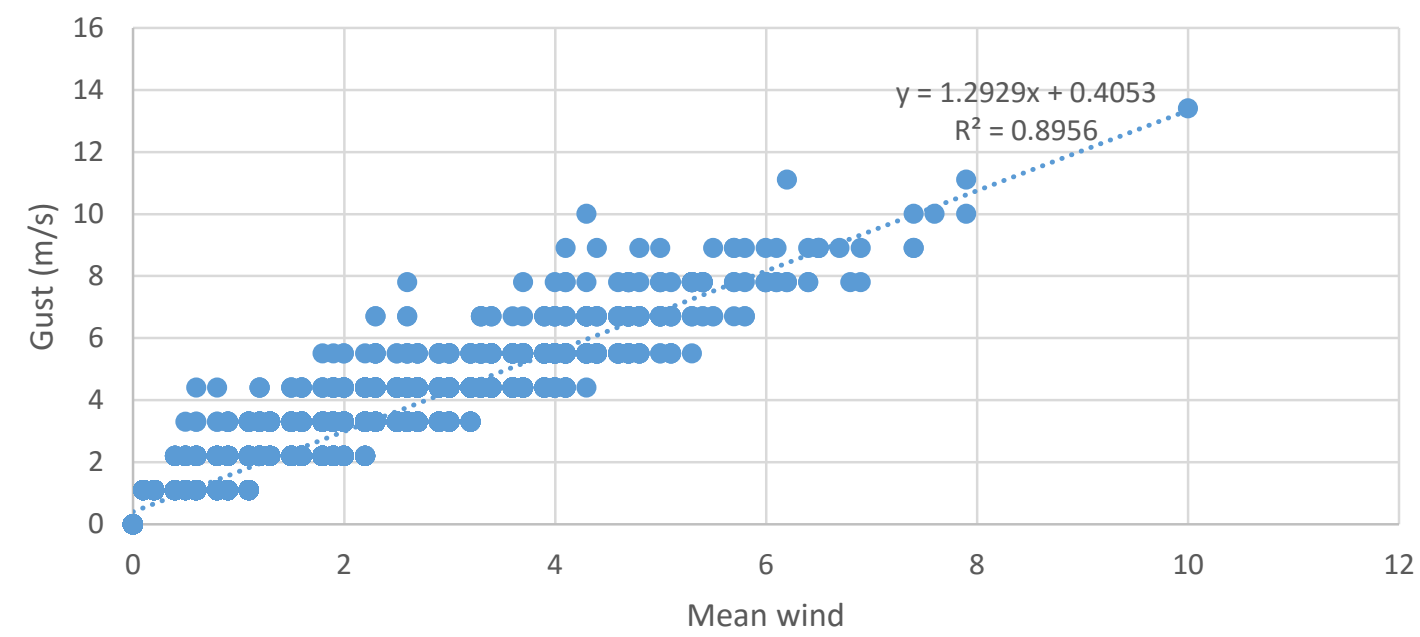

Figure 8.1 shows the linear regression analysis for calculating the gust co-efficient on ten minute data

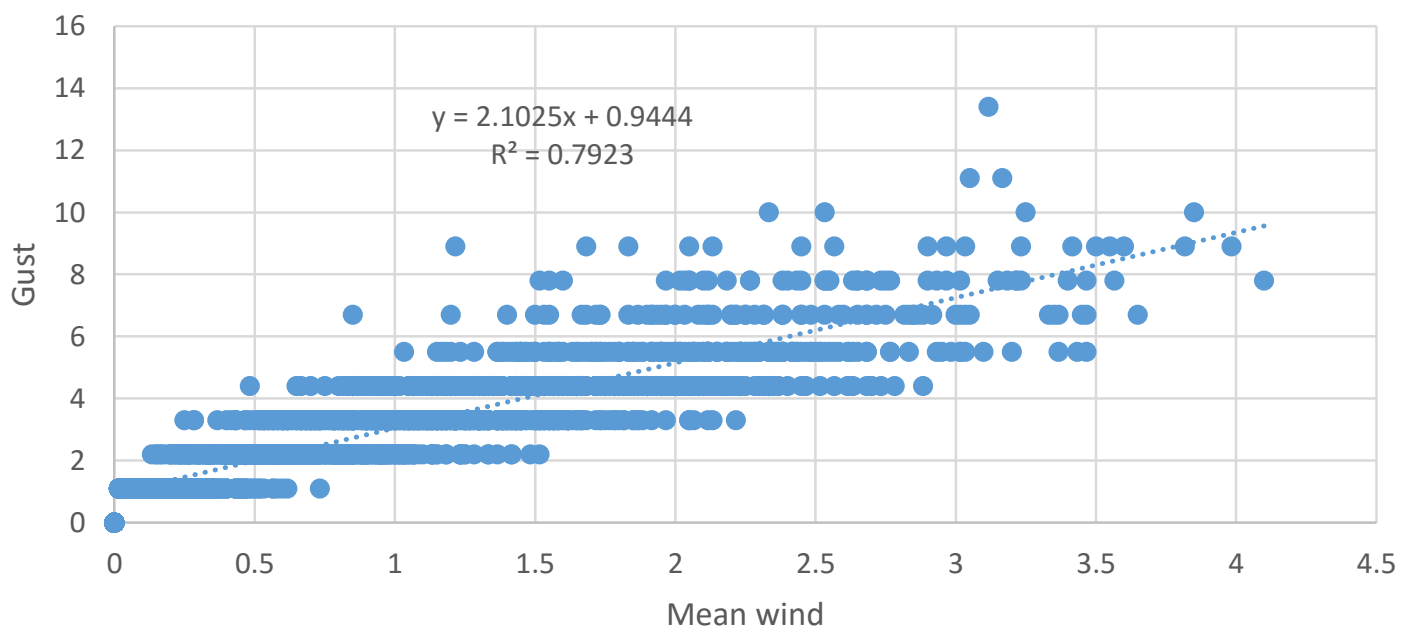

Figure 8.2 shows the Equation linear regression analysis for calculating the gust co-efficient on sixty minute data. This gust co-efficient is the co-efficient used in The Comfort Tool 
pg. 171 
8) Rate your impression of the sunlight level.

\begin{tabular}{|c|c|c|c|c|c|c|}
\hline$\underset{\substack{\text { Much too } \\
\text { dull }}}{\square}$ & $\begin{array}{c}\square \\
\text { Too dull }\end{array}$ & $\underset{\substack{\text { Slightly too } \\
\text { dull }}}{\square}$ & $\begin{array}{c}\square \\
\text { Neutral }\end{array}$ & $\underset{\substack{\text { Sllghtly too } \\
\text { bright }}}{\square}$ & $\begin{array}{c}\square \\
\text { Too bright }\end{array}$ & $\underset{\substack{\text { Much too } \\
\text { bright }}}{\square}$ \\
\hline
\end{tabular}

9) Rate your impression of the noise level.

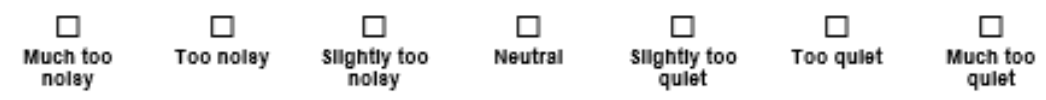

10) Rate your impression of the air humidity (The dampness of the air, not your surroundings)

\begin{tabular}{|c|c|c|c|c|c|c|}
\hline$\square \underset{\substack{\text { Much too } \\
\text { humid }}}{\square}$ & $\begin{array}{c}\square \\
\text { Too humld }\end{array}$ & $\underset{\substack{\text { Sllghtly too } \\
\text { humid }}}{\square}$ & $\square_{\text {Neutral }}^{\square}$ & $\underset{\substack{\text { Sllghtly too } \\
\text { dry }}}{\square}$ & $\underset{\text { Too dry }}{\square}$ & $\square_{\text {Much too dry }}^{\square}$ \\
\hline
\end{tabular}

11) Rate your impression of the air quality.

$\begin{array}{ccccccc}\square & \square & \square & \square & \square & \square & \square \\ \begin{array}{c}\text { Extremely } \\ \text { bad }\end{array} & \begin{array}{c}\text { Very bad } \\ \text { Bad }\end{array} & \square \text { Avage } & \text { Good } & \begin{array}{c}\text { Very good } \\ \text { Extremely }\end{array}\end{array}$

12) When exposed to the sun the heat you receive leaves you feeling?

\begin{tabular}{|c|c|c|c|c|c|}
\hline$\square_{\text {Far too hot }}^{\square}$ & ${ }_{\text {Too hot }}^{\square}$ & $\underbrace{\square}_{\substack{\text { A uttle too } \\
\text { hot }}}$ & $\underset{\text { Comfortable }}{\square}$ & $\underbrace{\square}_{\substack{\text { A Ilttle too } \\
\text { Cool }}}$ & $\begin{array}{c}\square \\
\text { Too cool }\end{array}$ \\
\hline
\end{tabular}

13) Rate how warm or cold your surroundings are (e.g. the concrete, grass etc).

\begin{tabular}{|c|c|c|c|c|c|c|}
\hline$\underset{\text { Hot }}{\square}$ & $\underset{\text { Warm }}{\square}$ & ${ }_{\substack{\text { sllghtly too } \\
\text { warm }}}^{\square}$ & $\square_{\text {Neutral }}^{\square}$ & $\underset{\substack{\text { Slightly too } \\
\text { cold }}}{\square}$ & $\underset{\text { Cool }}{\square}$ & $\underset{\text { cold }}{\square}$ \\
\hline \multicolumn{7}{|c|}{ 14) Rate your impression of the cooling effect of the wind..............? } \\
\hline & $\begin{array}{c}\square \\
\text { Far too chilly }\end{array}$ & $\begin{array}{c}\square \\
\text { Too chilly }\end{array}$ & $\begin{array}{c}\square \\
\text { A Inttle chilly }\end{array}$ & $\underset{\text { Tolerable }}{\square}$ & $\underset{\substack{\text { Not } \\
\text { noticeable }}}{\square}$ & \\
\hline \multicolumn{7}{|c|}{ 15) In exposed places, the wind is .............? } \\
\hline & $\begin{array}{c}\square \\
\text { Far too } \\
\text { gtrong }\end{array}$ & $\begin{array}{c}\square \\
\text { Too strong }\end{array}$ & $\begin{array}{c}\square \\
\begin{array}{c}\text { A ilttie too } \\
\text { strong }\end{array}\end{array}$ & $\underset{\text { Tolerable }}{\square}$ & $\underset{\substack{\text { Not } \\
\text { noticeable }}}{\square}$ & \\
\hline
\end{tabular}

16) On the scale below indicate what you usually prefer in terms of warmth (place an $X$ on the line)

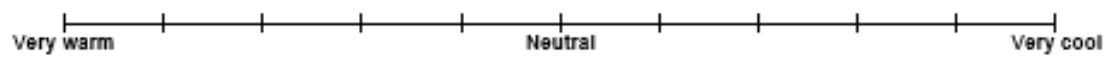

17) On the scale below indicate what you usually prefer in terms of wind (place an $X$ on the line) $\ddagger$

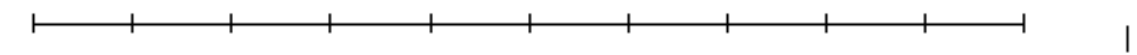


18) On the scale below indicate what you usually prefer in terms of sunshine (place an $X$ on the line)

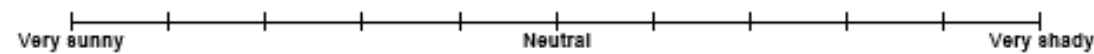

19) How good is your location compared to others in your location?

$\begin{array}{ccccc}\square & \square & \square & \square & \square \\ \text { Much Better } & \begin{array}{c}\text { slightly } \\ \text { better }\end{array} & \begin{array}{c}\text { it's about the } \\ \text { aame as } \\ \text { other apots }\end{array} & \begin{array}{c}\text { sllghtly } \\ \text { worse }\end{array} & \text { Much worse } \\ & & \end{array}$

20) Why did you choose this spot?

(Plesse select the option that influenced your choice the most)

\begin{tabular}{|c|c|c|c|}
\hline$\square$ & Empty/Avallable & $\square$ & Vlew of people \\
\hline$\square$ & Sheltered from wind & $\square$ & Away from people \\
\hline$\square$ & Shady & $\square$ & Lots of factors \\
\hline 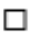 & sunny & $\square$ & Other \\
\hline ㅁ & Qulet & $\square$ & Don't really know \\
\hline
\end{tabular}

21) How likely is it that you will move to another spot if one becomes available?

$\begin{array}{ccccc}\square & \square & \square & \square & \square \\ \text { Very llkely } & \text { Llkely } & \text { Unsure } & \text { Unillkely } & \text { Very unllikely }\end{array}$

22) During your time here, your comfort in this location has

$\underset{\substack{\text { Improved } \\ \text { elgniflcantly }}}{\square} \underset{\substack{\text { Improved } \\ \text { stayed the } \\ \text { eame }}}{\square} \quad \underset{\text { Degraded }}{\square} \quad \underset{\begin{array}{c}\text { Degraded } \\ \text { algninicantly }\end{array}}{\square}$

23) How often do you come to this location?

$\begin{array}{cccccc}\square & \square & \square & \square & \square & \square \\ \text { Everyday } & \begin{array}{c}\text { Pretty much } \\ \text { every day }\end{array} & \begin{array}{c}\text { About twice a } \\ \text { week }\end{array} & \begin{array}{c}\text { About once a } \\ \text { we日k }\end{array} & \begin{array}{c}\text { Every now } \\ \text { and then }\end{array} & \text { Hardly ever }\end{array}$

24) What was your intended main use of this location (choose one option that is the most appropriate)?
$\square \quad$ Resting
$\square \quad$ Meeting someone
$\square$ No alngle activity
EatingiDrinking
$\square \quad$ Smoking
$\square$ other

25) Please rate how appropriate your clothes are for the weather conditions

$\begin{array}{lcccccc}\square & \square & \square & \square & \square & \square & \square \\ \text { Ideal } & \square \text { Good } & \text { Fine } & \text { Neutral } & \text { Not good } & \text { Bad } & \text { Really bad }\end{array}$


Please indicate whether you agree with the following statements.

26) Today the wind is annoying (e.g. because it's gusty, blows litter around, etc)

\begin{tabular}{|c|c|c|c|}
\hline$\underset{\substack{\text { strongly } \\
\text { ggre日 }}}{\square}$ & $\underset{\text { Agree }}{\square}$ & $\begin{array}{c}\square \\
\text { Neutral }\end{array}$ & $\underset{\text { Dleagree }}{\square}$ \\
\hline
\end{tabular}

27) Today is a really good day to be outdoors in this sort of area.

\begin{tabular}{|c|c|c|c|}
\hline $\begin{array}{l}\square \\
\text { strongly } \\
\text { agre日 }\end{array}$ & $\underset{\text { Agree }}{\square}$ & $\begin{array}{c}\square \\
\text { Neutral }\end{array}$ & $\underset{\text { Dlaggree }}{\square}$ \\
\hline
\end{tabular}

28) The main source of pollution is this area is from litter.

\begin{tabular}{|c|c|c|c|}
\hline$\underset{\substack{\text { strongly } \\
\text { gore日 }}}{\square}$ & $\square_{\text {Agree }}^{\square}$ & $\square_{\text {Neutral }}^{\square}$ & $\underset{\text { Dleagree }}{\square}$ \\
\hline
\end{tabular}

29) The main source of pollution in the city comes from heavy vehicles (e.g. buses and trucks).

\begin{tabular}{|c|c|c|c|}
\hline$\underset{\substack{\text { strongly } \\
\text { gore日 }}}{\square}$ & $\underset{\text { Agree }}{\square}$ & $\begin{array}{c}\square \\
\text { Neutral }\end{array}$ & $\begin{array}{c}\square \\
\text { Dlaggree }\end{array}$ \\
\hline
\end{tabular}

30) Rank the importance of things that affect your enjoyment of being outside by giving a 1 to the most important | thing through to $a 5$ for the least important.

(Give each item a score using the numbers 1,2,3,4 \& 5 but do not use the same number twice).

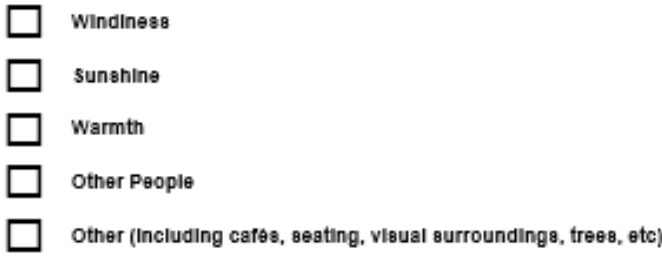


31) Please indicate your gender

$\square$ Male $\square$ female
32) Please indicate your age

$\begin{array}{ll}\square \text { Under } 16 & \square 56-65 \\ \square 16-25 & \square 66-75 \\ \square 26-35 & \square 76-85 \\ \square 36-45 & \square 86 \text { or more } \\ \square 46-55 & \end{array}$

33)

Your "Clo" Value: the value of your clothing's insulation

We are only intersated in the thermal value of the clothes. We want to know how much insulation you have on to protsct you from the environmental conditions.

Please tick next to those items you are currently wearing 


\begin{tabular}{|c|c|c|c|c|c|}
\hline Footwear/Leg wear & & value & Trousers and Coveralls & & value \\
\hline Shoes & $\square$ & 0.02 & Short shorts & $\square$ & 0.06 \\
\hline Ankle socks & $\square$ & 0.02 & Walking shorts & $\square$ & 0.08 \\
\hline Calf length socks & $\square$ & 0.03 & Knee length Shorts & $\square$ & 0.10 \\
\hline Panty hose & $\square$ & 0.02 & Thin trousers & $\square$ & 0.15 \\
\hline \multirow[t]{2}{*}{ Boots } & $\square$ & 0.10 & Thick trousers & $\square$ & 0.24 \\
\hline & & & Sweatpants & $\square$ & 0.28 \\
\hline Shirts and Tops & & & Overalls & $\square$ & 0.30 \\
\hline Sleeveless, scoop-neck & $\square$ & 0.12 & & & \\
\hline Short sleeve, dress shirt & $\square$ & 0.19 & Dresses and Skirts & & \\
\hline Long sleeve, dress shirt & $\square$ & 0.25 & Thin skirt & $\square$ & 0.14 \\
\hline Long sleeve, flannel shirt & $\square$ & 0.34 & Thick skirt & $\square$ & 0.23 \\
\hline Long Sleeve, knit shirt & $\square$ & 0.25 & Long-sleeve dress & $\square$ & 0.33 \\
\hline Short sleeve, knit shirt & $\square$ & 0.17 & Short-sleeve dress & $\square$ & 0.29 \\
\hline Long sleeve, sweat shirt & $\square$ & 0.34 & Sleeveless, scoop neck & $\square$ & 0.23 \\
\hline Coats and Jackets & & & Jerseys and Jumpers & & \\
\hline Overcoat & $\square$ & & Sleeveless vest & $\square$ & 0.13 \\
\hline Thick Jacket & $\square$ & & Long-sleeved (thin) & $\square$ & 0.25 \\
\hline Thin wind jacket & $\square$ & & Long-sleeved (thick) & $\square$ & 0.36 \\
\hline Raincoat & $\square$ & & & & \\
\hline \multirow[t]{3}{*}{ Waterproof over trousers } & $\square$ & & Suit Jackets and Vests & & \\
\hline & & & Single-breasted & $\square$ & 0.36 \\
\hline & & & Double-breasted & $\square$ & 0.42 \\
\hline Basic clothing & & & Sleeveless vest & $\square$ & 0.10 \\
\hline T-shirt/Singlet & $\square$ & 0.08 & & & \\
\hline Full slip & $\square$ & 0.16 & Miscellaneous & & \\
\hline Half slip & $\square$ & 0.14 & Sunglasses & $\square$ & \\
\hline Long underwear top & $\square$ & 0.20 & Woollen hat & $\square$ & 0.20 \\
\hline \multirow[t]{5}{*}{ Long underwear bottoms } & $\square$ & 0.15 & Scarf/shawl & $\square$ & 0.15 \\
\hline & & & Gloves & $\square$ & 0.18 \\
\hline & & & Sunhat, cap & $\square$ & 0.02 \\
\hline & & & 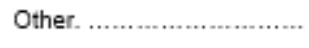 & $\square$ & \\
\hline & & & Other.... & $\square$ & \\
\hline
\end{tabular}




\subsubsection{DEMOGRAPHIC QUESTIONS INCLUDED IN THE CHRISTCHURCH SURVEY}

Below are the demographic questions which were include in the Christchurch survey. These allowed for flexibility in the data analysis if the survey responses from the survey were used for further analysis outside of this thesis project. These demographic questions would allow for the survey responses to be separated into meaningful groups, such as how males change their behaviour maintain their thermal comfort compared with females.

\begin{tabular}{l|l}
\hline 16) "Are you a visitor to New & $\begin{array}{l}\text { This question was asked to allow flexibility in the survey data } \\
\text { analysis. If there was a large sample size, it could be separated } \\
\text { into two groups: visitors and locals to provide more detail in The } \\
\text { Wellington Comfort Index's applicability to cities outside of } \\
\text { Wellington. }\end{array}$ \\
\hline $\begin{array}{ll}\text { 17) "Are you a visitor to } \\
\text { Canterbury?" }\end{array}$ & $\begin{array}{l}\text { This question was asked to allow flexibility in the survey data } \\
\text { analysis. If there was a large sample size, it could be separated } \\
\text { into two groups: visitors and locals to provide more detail in The } \\
\text { Wellington Comfort Index's applicability to cities outside of } \\
\text { Wellington. }\end{array}$ \\
\hline 18) Please indicate your gender & $\begin{array}{l}\text { This question was asked to allow flexibility in the survey data } \\
\text { analysis. If there was a large sample size, it could be separated } \\
\text { into two groups: males and females to understand the variations } \\
\text { between each sex and how they may perceive thermal comfort. }\end{array}$ \\
\hline 19) Please indicate your age & $\begin{array}{l}\text { This question was asked to allow flexibility in the survey data } \\
\text { analysis. If there was a large sample size, it could be separated } \\
\text { into age groups to understand how at different ages people } \\
\text { perceive thermal comfort differently. }\end{array}$ \\
\hline
\end{tabular}


8.2.3. TEMPERATURES DURING THE SURVEY PERIOD

This graph shows the minimum and maximum ambient temperatures for the survey period. It is important that the survey period captures a variance in weather (Walton et al., 2007, p. 3168). The survey period covered temperatures ranging from less than $0^{\circ} \mathrm{C}$ and more than $30^{\circ} \mathrm{C}$ (Figure 8.3). This is covers the range of temperatures where people are likely to be spending time outside in Christchurch.

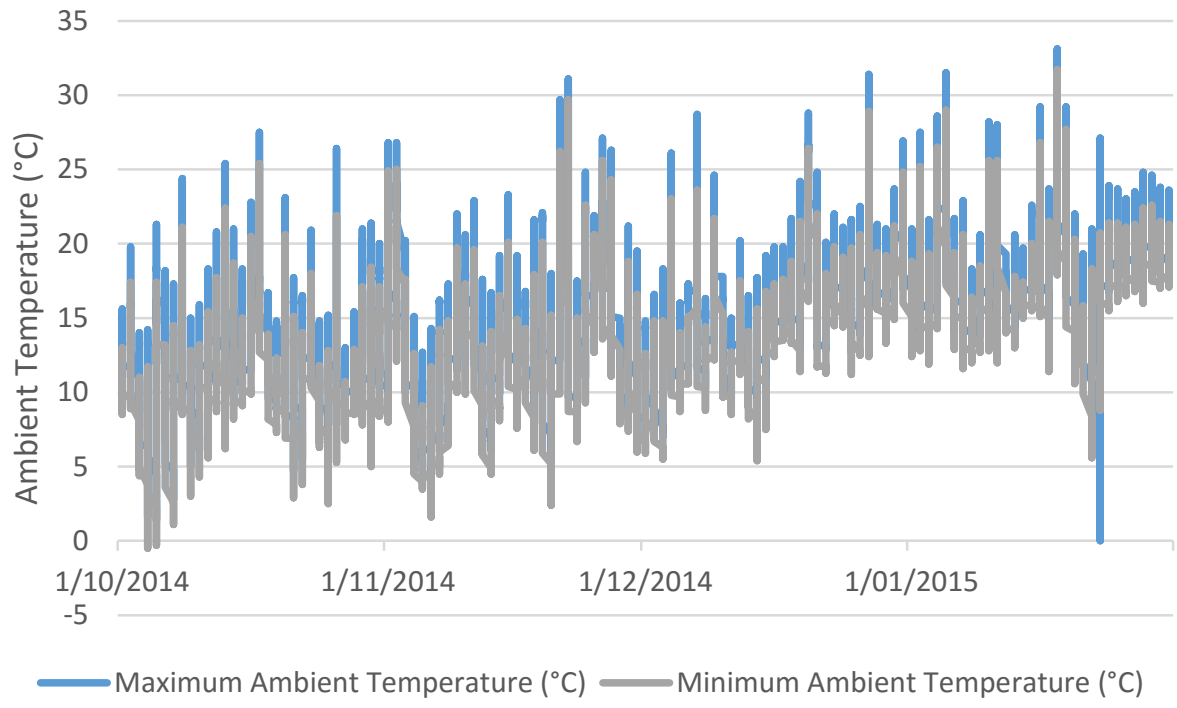

Figure 8.3 shows the minimum and maximum temperatures over the survey period (NIWA, 2015b) 
8.2.4. LIST OF EQUIPMENT, ACCURACY, AND SPECIFICATIONS

The case study weather station was a Radiance Wireless Weather Station. Its accuracy was taken into account when comparing the data between the case study weather station and the local regional weather station. The case study weather station had an accuracy of $+/$ $1 \mathrm{~m} / \mathrm{s}$ when the wind speed is less than $5 \mathrm{~m} / \mathrm{s}$, and $10 \%$ when wind speed is above $5 \mathrm{~m} / \mathrm{s}$. Ambient temperature has an accuracy of $+/-1^{\circ} \mathrm{C}$. No accuracy for the solar radiation specified. The accuracy of the wind speeds were not compared as there was no defined pattern between the wind patterns and the case study weather station and the local regional weather station.

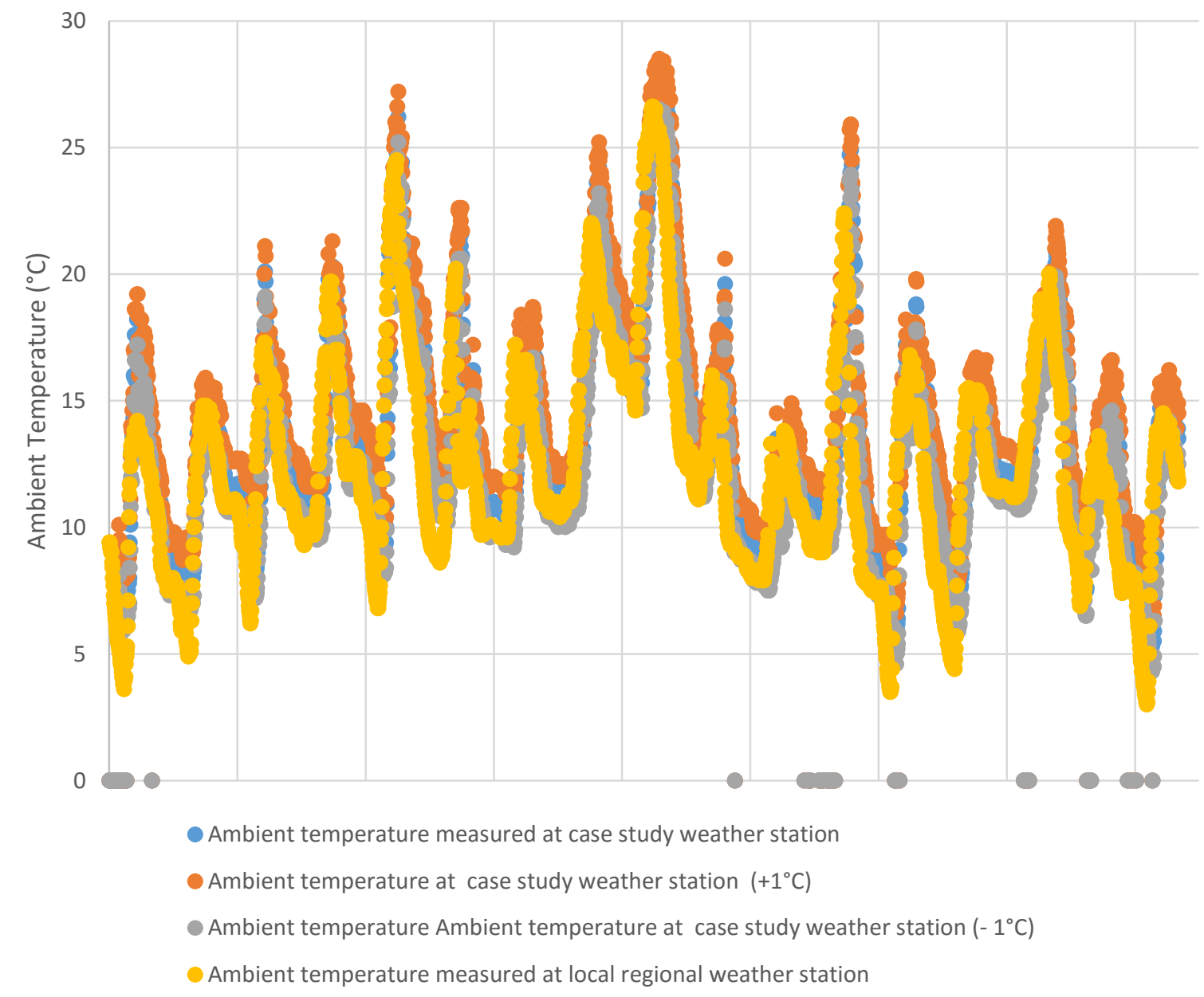

Figure 8.4 shows the ambient temperature with the accuracy considered. This shows that the location regional weather station and the case study weather station recorded similar ambient temperatures. However, the case study weather station's temperature lagged slightly. This indicated that there is more thermal mass surrounding the case study weather station which is causing the change in ambient temperature to take longer to have an effect on the measurements. 
Radiance Wireless Weather Station Information (Frizzell Agricultural Electronics, 2014):

\section{Specifications:}

- Outdoor/indoor temperature: $-40^{\circ} \mathrm{C}-60^{\circ} \mathrm{C} /-40^{\circ} \mathrm{F}-140^{\circ} \mathrm{F}$

- Outdoor/indoor humidity: $1 \%-99 \%$

- Wind speed: 0-50m/s / 0-100mph $-(\mathrm{km} / \mathrm{h}, \mathrm{knot}, \mathrm{mph}, \mathrm{bft}, \mathrm{ft} / \mathrm{s}, \mathrm{m} / \mathrm{s})$

- Wind gust: km/h, knot, mph, bft, ft/s, m/s

- Wind direction: Degrees, cardinal directions

- Wind chill: Yes $\mathrm{C}^{\circ} / \mathrm{F}^{\circ}$

- Dew point: Yes $\mathrm{C}^{\circ} / \mathrm{F}^{\circ}$

- Rain gauge: 0-9999mm, inch (Daily, weekly, monthly, yearly)

- Rain rate: $\mathrm{mm} / \mathrm{hr}$, in/hr

- Weather forecast symbols: Sunny, partly cloudy, cloudy, rainy, storm

- Barometric pressure:300-1100hPA / 8.85-32.5inHg) hpa, in $\mathrm{Hg}, \mathrm{mm} \mathrm{Hg}$ (Absolute, Relative)

- UV index: uW/cm2

- Solar radiation (lux) meter: 0-400k Lux (W/mm2, lux, fc)

- Time and date display (HH:MM:SS)

- Mounting hardware: Pole, U bolts, clamps, nuts

- Level indicator: Bubble

- Display unit dimensions $195(\mathrm{~W}) \times 138(\mathrm{H}) \times 20(\mathrm{D}) \mathrm{mm}$

Features:

- Alarm clock

- Display night switch

- Includes 38MB Built-in memory

- Records of all minimum and maximum values with time/date of recordings

- Recording interval: 1 to 240 mins (tabulated and graphic with zoom)

- Up to $100 \mathrm{~m}$ line of sight wireless transmission range

- Uses microSD Card memory (not included) for backup (can accept any capacity MicroSD card) 
Local Regional Weather Station Information (NIWA, 2015b):

\begin{tabular}{|c|c|}
\hline Parameter & Indicator \\
\hline Agent Number & 24120 \\
\hline Network Number & $\mathrm{H}_{3256 \mathrm{~F}}$ \\
\hline Name & Christchurch, Kyle St Ews \\
\hline Lat (dec deg, S of equator is neg) & -43.53074 \\
\hline Longitude (dec deg, E of Greenwich is pos e.g. NZ) & 172.60769 \\
\hline Position Precision & $\mathrm{H}$ \\
\hline \multicolumn{2}{|c|}{$\begin{array}{l}\text { Note: Position precision types are: } \\
\text { "W" = based on whole minutes, "T" = estimated to tenth minute, } \\
" G "=\text { derived from gridref, " } E "=\text { error cases derived from gridref, } \\
" H "=\text { based on GPS readings }(N Z G D 49), " D "=\text { by definition i.e. grid points. }\end{array}$} \\
\hline Height above MSL in metres & $6 \mathrm{~m}$ \\
\hline Grid Reference (NZ Metric Map Series) & M35782417 \\
\hline Start Date & $30-$ Oct-2002 \\
\hline End Date & - \\
\hline Closed Indicator (Closed = 1) & o \\
\hline Stty Station Type & C: Clitel \\
\hline Synoptic Number (World Met. Organisation Number) & - \\
\hline WRA No & 325615 \\
\hline Observing Authority & Niwa \\
\hline
\end{tabular}

Current Indicators:

Note: the following indicators show the current status for open stations.

Closed stations may show no recorded parameters.

\begin{tabular}{llll}
\hline Parameter & Indicator & Parameter & Indicator \\
\hline Rain & X & Evaporation & - \\
\hline Surface Wind Dirn & X & Surface Wind Speed & X \\
\hline Max Gust Dirn & X & Max Gust Speed & X \\
\hline Solar Radiation & X & Sunshine Hours & - \\
\hline 10cm Earth Temp & - & 20cm Earth Temp & - \\
\hline 30cm Earth Temp & - & 10ocm Earth Temp & - \\
\hline Dry Bulb Temp & X & Wet Bulb Temp & X \\
\hline Grass Min Temp & X & Weather Phenomonen & - \\
\hline Max Temp & X & Min Temp & X \\
\hline Visibility & - & Cloud Amount & - \\
\hline MSL Pressure & X & & \\
\hline Wind Run & $X$ & & 02 \\
\hline Time Offset (from UTC) & 12 & dayl_daylight_area & 0 \\
\hline
\end{tabular}




\subsubsection{ASHRAE CLO-VALUES}

The table below shows the ASHRAE clo-values for each clothing item. When the clo-value was missing for one of the items included in the Wellington survey, the value for the clothing item was used from this table (ASHRAE, 2013, p. 3).

TABLE 1

Characteristics of Garments

\begin{tabular}{|c|c|c|c|c|c|}
\hline Design Description and Fabric Type & $\begin{array}{l}\text { Garment } \\
\text { Weight } \\
(\mathrm{kg})\end{array}$ & $\begin{array}{c}\text { Body Surface } \\
\text { Area Covered } \\
(\bar{x}) \\
\end{array}$ & $\mathrm{f}_{\mathrm{cl}}$ & $\begin{array}{l}\mathrm{I}_{\mathrm{cle}} \\
\text { (clo) }\end{array}$ & $\begin{array}{l}I_{c 1} \\
(c 10) \\
\end{array}$ \\
\hline \multicolumn{6}{|l|}{ Sh1rts } \\
\hline 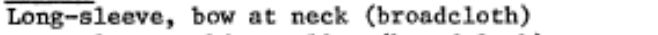 & 0.206 & 52 & 1.13 & 0.25 & 0.33 \\
\hline Long-sleeve, shirt collar (broadcloth) & 0.196 & 51 & 1.12 & 0.25 & 0.33 \\
\hline Long-sleeve, shirt collar (flannel) & 0.309 & 51 & 1.12 & 0.34 & 0.42 \\
\hline Short-sleeve, sh1rt collar (broadcloth) & 0.156 & 43 & 1.10 & 0.19 & 0.25 \\
\hline Short-sleeve, sport shirt (double knit) & 0.228 & 40 & 1.02 & 0.17 & 0.18 \\
\hline $3 / 4$ length sleeve, boat neck* (broadcloth) & 0.142 & 46 & 1.11 & 0.27 & 0.34 \\
\hline Cap sleeve, boat neck* (broadcloth) & 0.113 & 36 & 1.09 & 0.21 & 0.27 \\
\hline Sleeveless, scoop neck (broadcloth) & 0.117 & 30 & 1.08 & 0.13 & 0.18 \\
\hline Tube top (double knit) & 0.067 & 12 & 1.01 & 0.06 & 0.07 \\
\hline Long-sleeve, sweat shirt (fleece-backed knit) & 0.284 & 45 & 1.06 & 0.34 & 0.38 \\
\hline \multicolumn{6}{|l|}{ Sweaters } \\
\hline 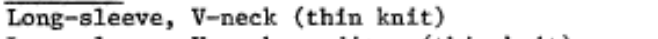 & 0.215 & 44 & 1.04 & 0.25 & 0.28 \\
\hline Long-sleeve, V-neck cardigan (thin knit) & 0.215 & 39 & 1.04 & 0.23 & 0.26 \\
\hline Short-sleeve, V-neck (thin kn1t) & 0.188 & 35 & 1.04 & 0.20 & 0.23 \\
\hline Short-sleeve, V-neck cardigan (thin knit) & 0.188 & 30 & 1.04 & 0.17 & 0.20 \\
\hline Sleeveless, V-neck (thin knit) & 0.130 & 28 & 1.03 & 0.13 & 0.15 \\
\hline Long-sleeve, round neck (thick knit) & 0.424 & 45 & 1.06 & 0.36 & 0.40 \\
\hline Long-sleeve, round neck cardigan (thick knit) & 0.424 & 39 & 1.06 & 0.31 & 0.35 \\
\hline Sleeveless, round neck (thick knit) & 0.301 & 29 & 1.04 & 0.22 & 0.25 \\
\hline Long-sleeve, turtleneck (thin knit) & 0.231 & 47 & 1.05 & 0.26 & 0.29 \\
\hline Long-sleeve, turtleneck (thick knit) & 0.459 & 47 & 1.06 & 0.37 & 0.41 \\
\hline \multicolumn{6}{|l|}{ Suit Jackets and Vests (1ined) } \\
\hline Single-breasted suit facket (denim) & 0.518 & 50 & 1.12 & 0.36 & 0.44 \\
\hline Single-breasted suit jacket (tweed) & 0.652 & 50 & 1.12 & 0.44 & 0.52 \\
\hline Double-breasted sult Jacket (denim) & 0.562 & 50 & 1.13 & 0.42 & 0.50 \\
\hline Double-breasted sult jacket (tweed) & 0.702 & 50 & 1.13 & 0.48 & 0.56 \\
\hline Work jacket (duck) & 0.885 & 55 & 1.21 & 0.39 & 0.51 \\
\hline Vest (denin) & 0.150 & 21 & 1.05 & 0.10 & 0.13 \\
\hline Vest (tweed) & 0.185 & 21 & 1.05 & 0.17 & 0.20 \\
\hline \multicolumn{6}{|l|}{ Trousers and Covera11s } \\
\hline Stra1ght, long, fitted (denim) & 0.298 & 45 & 1.09 & 0.15 & 0.21 \\
\hline Straight, long, fitted (tweed) & 0.404 & 45 & 1.09 & 0.24 & 0.30 \\
\hline Strafght, long, loose (denim) & 0.354 & 45 & 1.20 & 0.20 & 0.32 \\
\hline Straight, long, loose (tweed) & 0.459 & 45 & 1.20 & 0.28 & 0.40 \\
\hline Walking shorts(denim) & 0.195 & 25 & 1.06 & 0.08 & 0.12 \\
\hline Walk1ng shorts (tweed) & 0.251 & 25 & 1.06 & 0.17 & 0.21 \\
\hline Short shorts (denfm) & 0.164 & 18 & 1.05 & 0.06 & 0.09 \\
\hline Sweat pants (fleece-backed knit) & 0.345 & 44 & 1.10 & 0.28 & 0.34 \\
\hline Work pants (duck) & 0.832 & 46 & 1.21 & 0.24 & 0.36 \\
\hline Overalls (den1m) & 0.854 & 55 & 1.18 & 0.30 & 0.41 \\
\hline Covera1ls (gabardine) & 0.995 & 81 & 1.21 & 0.49 & 0.61 \\
\hline Insulated coveralls (multicomponent) & 1.313 & 81 & 1.23 & 0.96 & 1.09 \\
\hline \multicolumn{6}{|l|}{ Skirts } \\
\hline A-11ne, ankle length (denim) & 0.284 & 45 & 1.34 & 0.23 & 0.41 \\
\hline A-line, ankle length (tweed) & 0.378 & 45 & 1.34 & 0.28 & 0.46 \\
\hline A-11ne, 6" below knee (denim) & 0.288 & 40 & 1.25 & 0.18 & 0.32 \\
\hline A-11ne, 6" below knee (tweed) & 0.384 & 40 & 1.25 & 0.25 & 0.39 \\
\hline A-11ne, 6" above knee (denim) & 0.179 & 28 & 1.12 & 0.10 & 0.18 \\
\hline A-11ne, 6" above knee (tweed) & 0.238 & 28 & 1.12 & 0.19 & 0.27 \\
\hline A-line, knee length (denim) & 0.229 & 35 & 1.18 & 0.14 & 0.25 \\
\hline A-line, knee length (tweed) & 0.305 & 35 & 1.18 & 0.23 & 0.34 \\
\hline
\end{tabular}




\begin{tabular}{|c|c|c|c|c|c|}
\hline Design Description and Fabric Type & $\begin{array}{l}\text { Garment } \\
\text { Weight } \\
\text { (kg) }\end{array}$ & $\begin{array}{l}\text { Body Surface } \\
\text { Area Covered } \\
(\%)\end{array}$ & $\mathrm{f}_{\mathrm{cl}}$ & $\begin{array}{l}I_{\text {cle }} \\
\text { (clo) }\end{array}$ & $\begin{array}{l}\mathrm{I}_{\mathrm{c} 1} \\
\text { (clo) }\end{array}$ \\
\hline Stralght, knee length, with slit (denim) & 0.194 & 34 & 1.15 & 0.14 & 0.23 \\
\hline Straight, knee length, with slit (tweed) & 0.259 & 34 & 1.15 & 0.22 & 0.31 \\
\hline Blas flair, knee length (denim) & 0.286 & 35 & 1.22 & 0.13 & 0.26 \\
\hline Blas flair, knee length (tweed) & 0.380 & 35 & 1.22 & 0.22 & 0.35 \\
\hline Ful1 gathered, knee length (den1m) & 0.271 & 35 & 1.19 & 0.14 & 0.25 \\
\hline Ful1 gathered, knee length (tweed) & 0.359 & 35 & 1.19 & 0.22 & 0.33 \\
\hline Knife pleated, knee length (denin) & 0.410 & 35 & 1.19 & 0.16 & 0.27 \\
\hline Kn1fe pleated, knee length (tweed) & 0.539 & 35 & 1.19 & 0.26 & 0.37 \\
\hline \multicolumn{6}{|l|}{ Dresses } \\
\hline Long-8leeve, shirt collar, A-1ine (broadcloth) & 0.254 & 69 & 1.21 & 0.32 & 0.44 \\
\hline Long-sleeve, shirt collar, A-line (tweed) & 0.280 & 69 & 1.21 & 0.47 & 0.59 \\
\hline Long-sleeve, shirt collar, A-1ine, belt (broadcloth) & 0.283 & 69 & 1.18 & 0.35 & 0.46 \\
\hline Long-sleeve, sh1rt collar, A-1ine, belt (tweed) & 0.327 & 69 & 1.18 & 0.48 & 0.59 \\
\hline Short-sleeve, sh1rt collar, A-11ne, belt (broadcloth) & 0.237 & 61 & 1.15 & 0.29 & 0.38 \\
\hline Sleeveless, scoop neck, A-11ne (broadcloth) & 0.153 & 48 & 1.19 & 0.23 & 0.34 \\
\hline S1eeveless, scoop neck, A-1ine (tweed) & 0.414 & 48 & 1.19 & 0.27 & 0.38 \\
\hline \multicolumn{6}{|l|}{ Sleepwear } \\
\hline Long-sleeve, long gown (tricot) & 0.260 & 81 & 1.49 & 0.29 & 0.52 \\
\hline Long-sleeve, long gown (flanne1) & 0.435 & 81 & 1.49 & 0.46 & 0.69 \\
\hline Long-sleeve, short gown (tricot) & 0.180 & 66 & 1.25 & 0.24 & 0.38 \\
\hline Long-sleeve, short gown (flanne1) & 0.305 & 66 & 1.25 & 0.39 & 0.53 \\
\hline Short-sleeve, long gown (tricot) & 0.239 & 74 & 1.44 & 0.25 & 0.47 \\
\hline Short-sleeve, short gown (tricot) & 0.157 & 59 & 1.20 & 0.21 & 0.33 \\
\hline Sleeveless, long gown (tricot) & 0.217 & 65 & 1.42 & 0.20 & 0.41 \\
\hline Sleeveless, short gown (tricot) & 0.138 & 50 & 1.18 & 0.18 & 0.29 \\
\hline Thin strap, long gown (tricot) & 0.157 & 58 & 1.33 & 0.18 & 0.36 \\
\hline Thin strap, short gown (tricot) & 0.094 & 42 & 1.12 & 0.15 & 0.23 \\
\hline Hospital gown (print cloth) & 0.270 & 57 & 1.23 & 0.31 & 0.44 \\
\hline Long-sleeve, long pajamas (broadcloth) & 0.327 & 80 & 1.30 & 0.48 & 0.64 \\
\hline Long-sleeve, long pajamas (flannel) & 0.447 & 80 & 1.30 & 0.57 & 0.73 \\
\hline Short-sleeve, long pajamas (broadcloth) & 0.297 & 71 & 1.26 & 0.42 & 0.57 \\
\hline Long pajama trousers (broadcloth) & 0.149 & 45 & 1.20 & 0.17 & 0.29 \\
\hline Body sleeper with feet (knit fleece) & 0.599 & 86 & 1.38 & 0.72 & 0.92 \\
\hline \multicolumn{6}{|l|}{ Robes } \\
\hline Long-sleeve, wrap, long (velour) & 0.690 & 80.5 & 1.40 & 0.53 & 0.73 \\
\hline Long-sleeve, wrap, long (terrycloth) & 1.196 & 80.5 & 1.43 & 0.68 & 0.89 \\
\hline Long-sleeve, wrap, long (pile knit) & 1.535 & 80.5 & 1.47 & 1.02 & 1.25 \\
\hline Long-sleeve, wrap, short (broadcloth) & 0.298 & 68 & 1.24 & 0.41 & 0.55 \\
\hline Long-sleeve, wrap, short (velour) & 0.556 & 68 & 1.25 & 0.46 & 0.60 \\
\hline $3 / 4$ length sleeve, wrap, short (velour) & 0.514 & 63 & 1.20 & 0.43 & 0.55 \\
\hline Long-sleeve, button front, long (broadcloth) & 0.268 & 82 & 1.47 & 0.43 & 0.66 \\
\hline Long-sleeve, button front, long (velour) & 0.586 & 82 & 1.48 & 0.49 & 0.72 \\
\hline Long-sleeve, button front, short (broadcloth) & 0.260 & 69 & 1.32 & 0.40 & 0.57 \\
\hline Long-sleeve, button front, short (velour) & 0.472 & 69 & 1.33 & 0.45 & 0.63 \\
\hline Short-sleeve, button front, short (broadcloth) & 0.231 & 61 & 1.28 & 0.34 & 0.50 \\
\hline \multicolumn{6}{|l|}{ Underwear/Footwear } \\
\hline Briefs (kn1t) & 0.065 & 12 & 1.01 & 0.04 & 0.05 \\
\hline Panties (tricot) & 0.027 & 12 & 1.01 & 0.03 & 0.04 \\
\hline Bra (knft/foam) & 0.044 & 5 & 1.01 & 0.01 & 0.02 \\
\hline Half slip (tricot) & 0.065 & 32 & 1.11 & 0.14 & 0.21 \\
\hline Full slip (tricot) & 0.082 & 40 & 1.12 & 0.16 & 0.24 \\
\hline T-shirt (kn1t) & 0.105 & 32 & 1.03 & 0.08 & 0.10 \\
\hline Therma1 long underwear top (knit) & 0.200 & 49 & 1.06 & 0.20 & 0.24 \\
\hline Therma1 long underwear bottoms (knit) & 0.210 & 44 & 1.06 & 0.15 & 0.19 \\
\hline Pantyhose(knit) & 0.039 & $51 * *$ & 1.00 & 0.02 & 0.02 \\
\hline
\end{tabular}

\begin{tabular}{|c|c|c|c|c|c|}
\hline Design Description and Fabric Type & $\begin{array}{l}\text { Garment } \\
\text { We1ght } \\
(\mathrm{kg}) \\
\end{array}$ & $\begin{array}{l}\text { Body Surface } \\
\text { Area Covered } \\
(\%) \\
\end{array}$ & $\mathrm{f}_{\mathrm{cl}}$ & $\begin{array}{l}\text { I cle } \\
\text { (clo) }\end{array}$ & $\begin{array}{l}\mathrm{I}_{\mathrm{cl}} \\
\text { (clo) }\end{array}$ \\
\hline Ankle length athletic socks (knit) & 0.049 & 7 & 1.01 & 0.02 & 0.03 \\
\hline Calf length athletic socks (knit) & 0.082 & 14 & 1.01 & 0.03 & 0.04 \\
\hline Calf length dress socks (kn1t) & 0.053 & 13 & 1.01 & 0.03 & 0.04 \\
\hline Knee socks (thick knit) & 0.068 & 20 & 1.01 & 0.06 & 0.07 \\
\hline Thongs/sandals (vinyl) & 0.346 & 5 & 1.01 & 0.02 & 0.03 \\
\hline Hard-soled street shoes (viny1) & 1.006 & 7 & 1.03 & 0.02 & 0.04 \\
\hline Slippers (quilted fleece) & 0.186 & 9 & 1.04 & 0.03 & 0.06 \\
\hline Soft-soled athletic shoes (canvas) & 0.182 & 7 & 1.03 & 0.02 & 0.04 \\
\hline
\end{tabular}

* These shirts are cut fuller than the others for a loose fit.

$\star \star$ In the regression analysis, $12 \%$ BSAC was used because only the panty provided insulation. 


\subsubsection{RE-CODING OF QUESTIONS}

The questions were re-coded so the Christchurch Comfort Index could be interoperated as fifty meaning thermally comfortable and a one or one-hundred indicating thermally uncomfortable. This was to align the data with The Wellington Comfort Index. Thermally comfortable (neutral colour) and thermally uncomfortable (red colour) have been shaded to show how the scales have changed (Table 8.1).

Table 8.1 shows how the raw data from the Christchurch survey was re-coded to make the index for predicting the degree of change of behaviour required to maintain comfort could be more easily interoperated.

\begin{tabular}{|c|c|c|c|c|c|c|c|}
\hline $\begin{array}{l}\text { "Rate how } \\
\text { warm or cold } \\
\text { you feel" }\end{array}$ & $\begin{array}{l}\text { Much too } \\
\text { Warm }\end{array}$ & $\begin{array}{l}\text { Too } \\
\text { Warm }\end{array}$ & $\begin{array}{l}\text { Comfortably } \\
\text { Warm }\end{array}$ & Neutral & $\begin{array}{l}\text { Comfortab } \\
\text { ly Cool }\end{array}$ & $\begin{array}{l}\text { Too } \\
\text { Cool }\end{array}$ & $\begin{array}{l}\text { Much } \\
\text { too Cool }\end{array}$ \\
\hline $\begin{array}{l}\text { Current } \\
\text { numbers }\end{array}$ & 1 & 2 & 3 & 4 & 5 & 6 & 7 \\
\hline $\begin{array}{l}\text { Re-worked } \\
\text { numbers }\end{array}$ & 4 & 3 & 2 & 1 & 2 & 3 & 4 \\
\hline $\begin{array}{l}\text { "Rate your } \\
\text { impression of } \\
\text { the wind level" }\end{array}$ & $\begin{array}{l}\text { Much too } \\
\text { windy }\end{array}$ & $\begin{array}{l}\text { Too } \\
\text { windy }\end{array}$ & $\begin{array}{l}\text { Comfortably } \\
\text { windy }\end{array}$ & Neutral & $\begin{array}{l}\text { Slightly } \\
\text { too cool }\end{array}$ & $\begin{array}{l}\text { Too } \\
\text { still }\end{array}$ & $\begin{array}{l}\text { Much } \\
\text { too still }\end{array}$ \\
\hline $\begin{array}{l}\text { Current } \\
\text { numbers }\end{array}$ & 1 & 2 & 3 & 4 & 5 & 6 & 7 \\
\hline $\begin{array}{l}\text { Re-worked } \\
\text { numbers }\end{array}$ & 4 & 3 & 2 & 1 & 2 & 3 & 4 \\
\hline $\begin{array}{l}\text { "Rate how } \\
\text { warm or cold } \\
\text { your } \\
\text { surroundings } \\
\text { are" }\end{array}$ & Hot & Warm & $\begin{array}{l}\text { Slightly too } \\
\text { warm }\end{array}$ & Neutral & $\begin{array}{l}\text { Slightly } \\
\text { too cool }\end{array}$ & Cool & Cold \\
\hline $\begin{array}{l}\text { Current } \\
\text { numbers }\end{array}$ & 1 & 2 & 3 & 4 & 5 & 6 & 7 \\
\hline $\begin{array}{l}\text { Re-worked } \\
\text { numbers }\end{array}$ & 4 & 3 & 2 & 1 & 2 & 3 & 4 \\
\hline $\begin{array}{l}\text { "Rate your } \\
\text { impression of } \\
\text { the cool effect } \\
\text { of the wind" }\end{array}$ & $\begin{array}{l}\text { Far too } \\
\text { chilly }\end{array}$ & Too chilly & $\begin{array}{l}\text { A little too } \\
\text { chilly }\end{array}$ & Tolerable & $\begin{array}{l}\text { Not } \\
\text { noticeable }\end{array}$ & & \\
\hline $\begin{array}{l}\text { Current } \\
\text { numbers }\end{array}$ & 1 & 2 & 3 & 4 & 5 & & \\
\hline $\begin{array}{l}\text { Re-worked } \\
\text { numbers }\end{array}$ & 5 & 4 & 3 & 2 & 1 & & \\
\hline $\begin{array}{l}\text { "In exposed } \\
\text { places the wind } \\
\text { is..." }\end{array}$ & $\begin{array}{l}\text { Far too } \\
\text { strong }\end{array}$ & $\begin{array}{l}\text { Too } \\
\text { strong }\end{array}$ & $\begin{array}{l}\text { A little too } \\
\text { strong }\end{array}$ & Tolerable & $\begin{array}{l}\text { Not } \\
\text { noticeable }\end{array}$ & & \\
\hline $\begin{array}{l}\text { Current } \\
\text { numbers }\end{array}$ & 1 & 2 & 3 & 4 & 5 & & \\
\hline $\begin{array}{l}\text { Re-worked } \\
\text { numbers }\end{array}$ & 5 & 4 & 3 & 2 & 1 & & \\
\hline $\begin{array}{l}\text { "Today the } \\
\text { wind is } \\
\text { annoying" }\end{array}$ & $\begin{array}{l}\text { Strongly } \\
\text { agree }\end{array}$ & Agree & $\begin{array}{l}\text { Neither } \\
\text { agree nor } \\
\text { disagree }\end{array}$ & Disagree & $\begin{array}{l}\text { Strongly } \\
\text { disagree }\end{array}$ & & \\
\hline
\end{tabular}




\begin{tabular}{|c|c|c|c|c|c|c|c|}
\hline $\begin{array}{l}\text { Current } \\
\text { numbers }\end{array}$ & 1 & 2 & 3 & 4 & & & \\
\hline $\begin{array}{l}\text { Re-worked } \\
\text { numbers }\end{array}$ & 3 & 2 & 1 & 2 & & & \\
\hline $\begin{array}{l}\text { "Today is a } \\
\text { really good day } \\
\text { to be outside in } \\
\text { this sort of } \\
\text { location" }\end{array}$ & $\begin{array}{l}\text { Strongly } \\
\text { agree }\end{array}$ & Agree & Neutral & Disagree & $\begin{array}{l}\text { Strongly } \\
\text { disagree }\end{array}$ & & \\
\hline $\begin{array}{l}\text { Current } \\
\text { numbers }\end{array}$ & 1 & 2 & 3 & 4 & 5 & & \\
\hline $\begin{array}{l}\text { Re-worked } \\
\text { numbers }\end{array}$ & 3 & 2 & 1 & 2 & 3 & & \\
\hline $\begin{array}{l}\text { Wind speed } \\
\text { relative to the } \\
\text { central location }\end{array}$ & \multirow{2}{*}{\multicolumn{7}{|c|}{$\begin{array}{l}\text { This was not on a scale, it was the difference in wind speed between the case study } \\
\text { weather station and the local regional weather station. }\end{array}$}} \\
\hline $\begin{array}{l}\text { Current } \\
\text { numbers }\end{array}$ & & & & & & & \\
\hline Clo-value & \multirow{2}{*}{\multicolumn{7}{|c|}{ This was not on a scale, it was the sum of the clo-values each participant was wearing }} \\
\hline $\begin{array}{l}\text { Current } \\
\text { numbers }\end{array}$ & & & & & & & \\
\hline $\begin{array}{l}\text { "Seating } \\
\text { position: How } \\
\text { exposed are } \\
\text { you in relation } \\
\text { to the wind?" }\end{array}$ & Facing & $\begin{array}{l}\text { Turned } \\
\text { against }\end{array}$ & Side on & $\begin{array}{l}\text { Partially } \\
\text { sheltered }\end{array}$ & $\begin{array}{l}\text { Fully } \\
\text { sheltered }\end{array}$ & $\begin{array}{l}\text { No } \\
\text { wind/ } \\
\text { cannot } \\
\text { tell }\end{array}$ & \\
\hline $\begin{array}{l}\text { Current } \\
\text { numbers }\end{array}$ & 1 & 2 & 3 & 4 & 5 & 6 & \\
\hline $\begin{array}{l}\text { Re-worked } \\
\text { numbers }\end{array}$ & 2 & 5 & 4 & 3 & 6 & 1 & \\
\hline $\begin{array}{l}\text { "Seating } \\
\text { position: How } \\
\text { exposed are } \\
\text { you in relation } \\
\text { to the sun?" }\end{array}$ & Facing & $\begin{array}{l}\text { Turned } \\
\text { against }\end{array}$ & Side on & $\begin{array}{l}\text { Partially } \\
\text { shaded }\end{array}$ & $\begin{array}{l}\text { Fully } \\
\text { shaded }\end{array}$ & $\begin{array}{l}\text { No } \\
\text { wind/ } \\
\text { cannot } \\
\text { tell }\end{array}$ & \\
\hline $\begin{array}{l}\text { Current } \\
\text { numbers }\end{array}$ & 1 & 2 & 3 & 4 & 5 & 6 & \\
\hline $\begin{array}{l}\text { Re-worked } \\
\text { numbers }\end{array}$ & 2 & 5 & 4 & 3 & 6 & 1 & \\
\hline $\begin{array}{l}\text { Are you } \\
\text { wearing } \\
\text { sunglasses }\end{array}$ & Yes & No & & & & & \\
\hline $\begin{array}{l}\text { Current } \\
\text { numbers }\end{array}$ & 1 & 0 & & & & & \\
\hline $\begin{array}{l}\text { Re-worked } \\
\text { numbers }\end{array}$ & 1 & 0 & & & & & \\
\hline $\begin{array}{l}\text { "Approximatel } \\
\text { y how long } \\
\text { have you been } \\
\text { here?" }\end{array}$ & $0-5$ & $6-15$ & $15-30$ & $30-60$ & 60 & & \\
\hline $\begin{array}{l}\text { Current } \\
\text { numbers }\end{array}$ & 1 & 2 & 3 & 4 & & & \\
\hline $\begin{array}{l}\text { Re-worked } \\
\text { numbers }\end{array}$ & 5 & 4 & 3 & 2 & 1 & & \\
\hline $\begin{array}{l}\text { "If you had no } \\
\text { constraints on }\end{array}$ & $0-5$ & $6-15$ & $15-30$ & $30-60$ & 60 & & \\
\hline
\end{tabular}




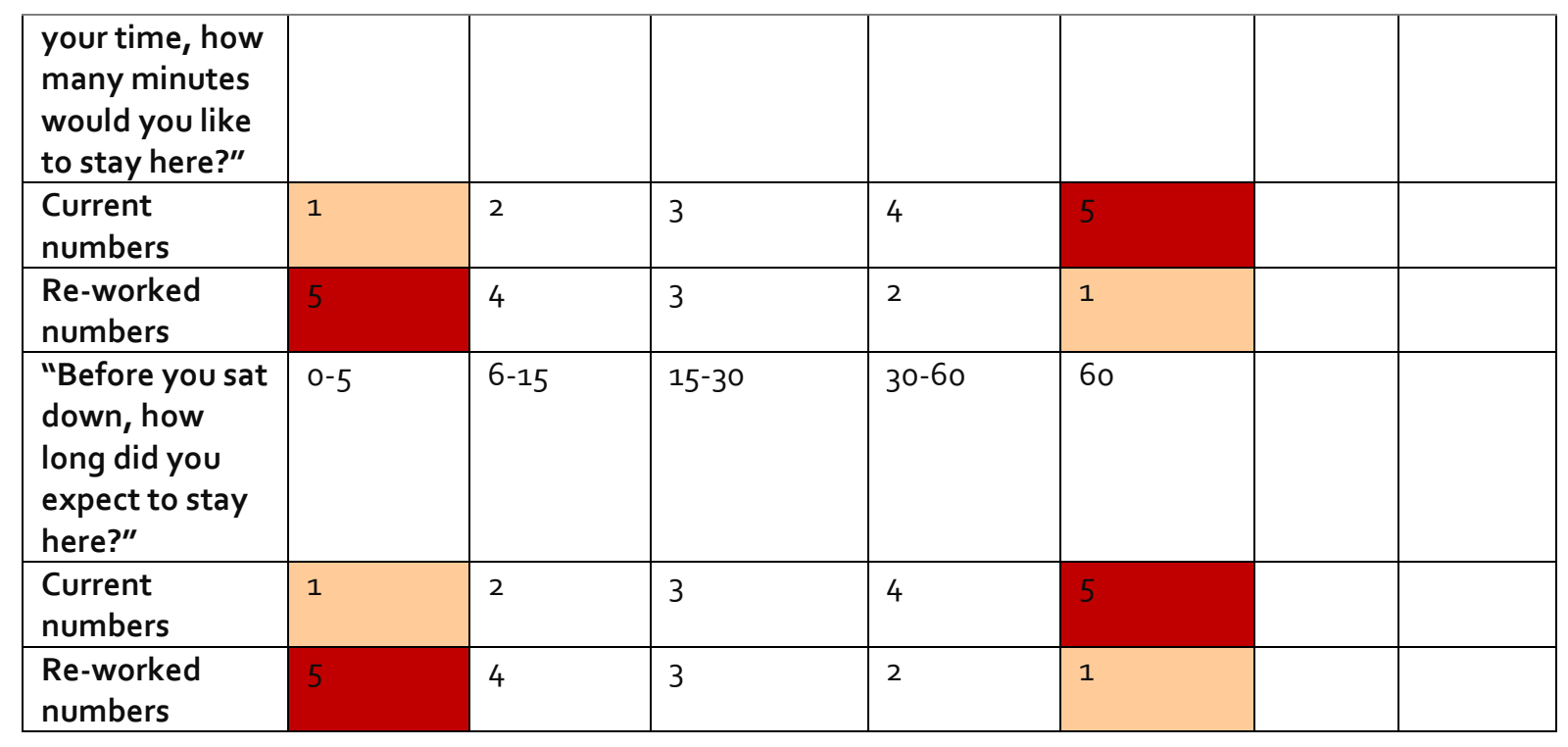


8.2.7. SURVEY RESULTS: RAW DATA OF THE CHRISTCHURCH COMFORT INDEX

The data below is the raw survey responses for each participant for each question, and how they were used to calculate the single thermal comfort score for each participant:

1. They were rearranged to have a response of 'one' meaning comfortable/not noticeable/thermally neutral, and a response of 'four' in each direction indicating (see Appendix 8.2.6 'Re-Coding of Questions' for how these were rearranged).

2. These re-coded survey responses were standardised to achieve scale uniformity

3. They were multiplied by the weighting of importance each question has within Component One (based on the principal component analysis)

4. The sum of this number (the recoded, standardised, and weighted number) was summed for each participant.

5. These thirty thermal comfort scores (representing each of the thirty survey participants) were then used as the dependent variable in the regression analysis, with the mean wind speed, maximum wind speed, mean radiant temperature, and ambient temperature as the dependent variables. The result of this is The Christchurch Comfort Index.

The environmental data highlighted in red in this raw data are the values which the case study weather station had not recorded, so the values were used from the local regional station. 
ป $\frac{3}{\mathbb{D}}$

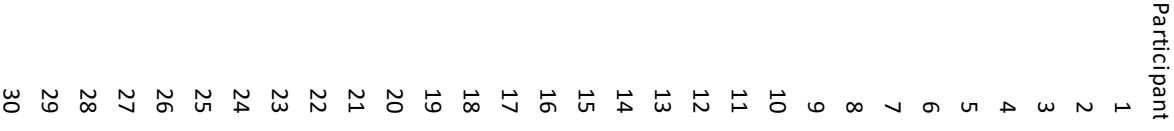
弟

嵳

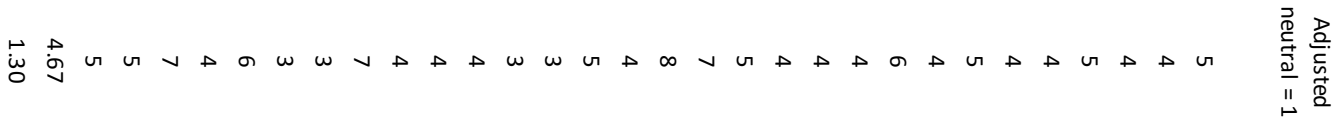

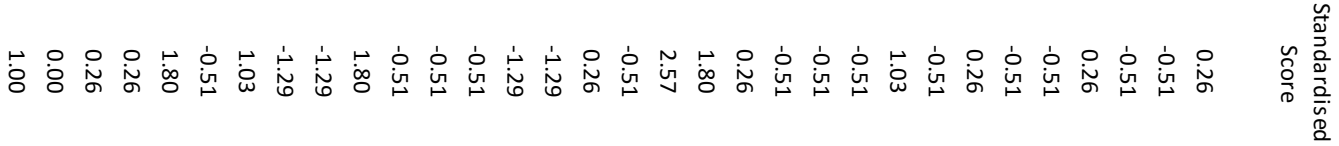

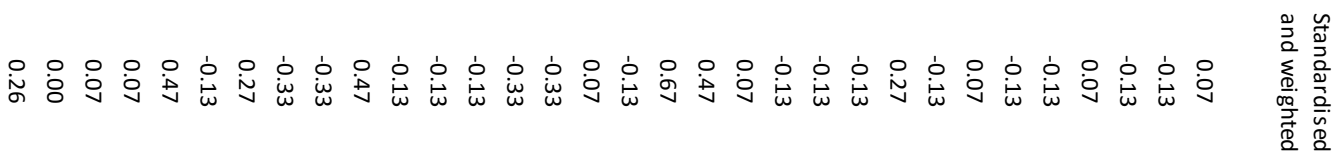

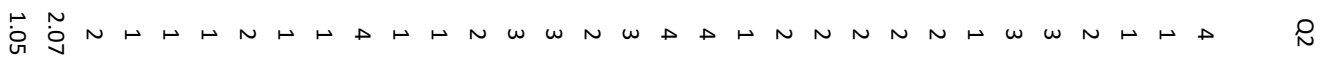

岀 岂

岕芯

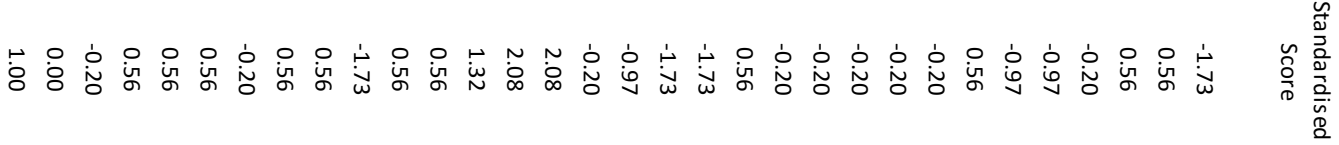

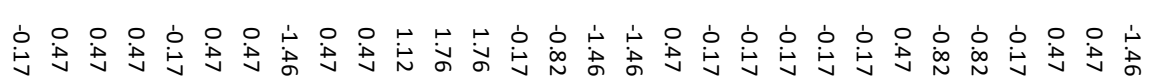

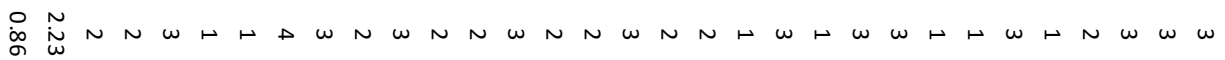
¿

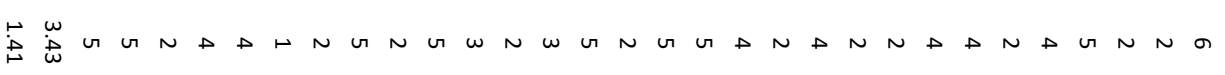

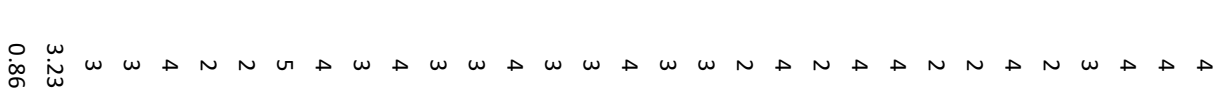

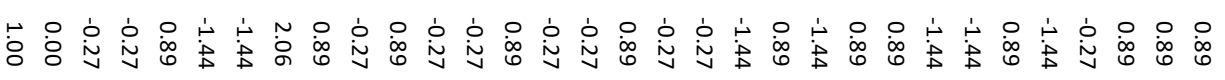

웅 
苔

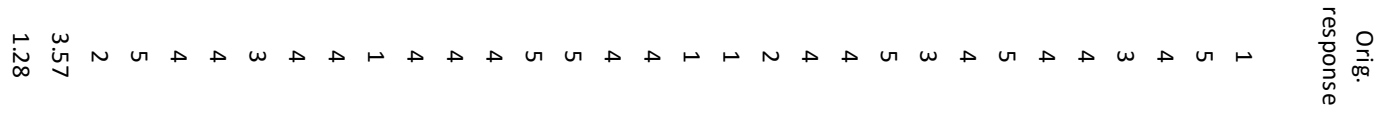

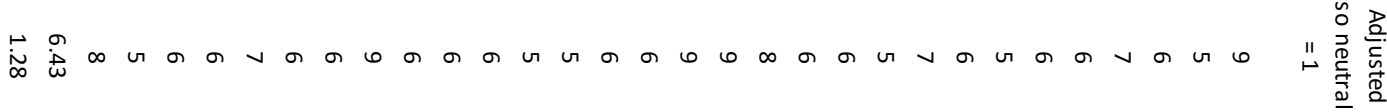

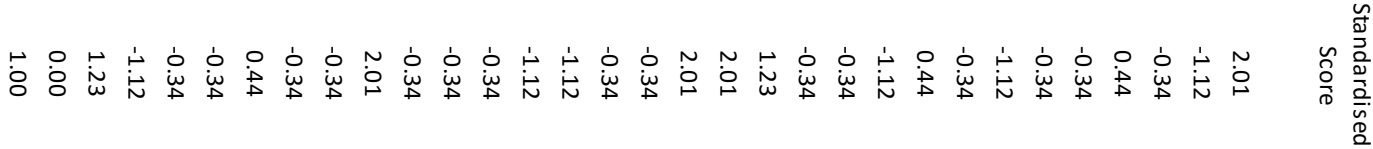

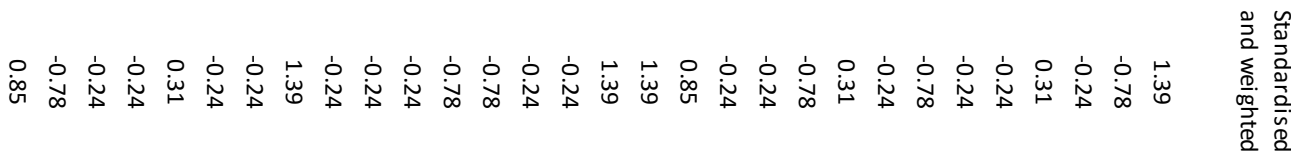

䓀

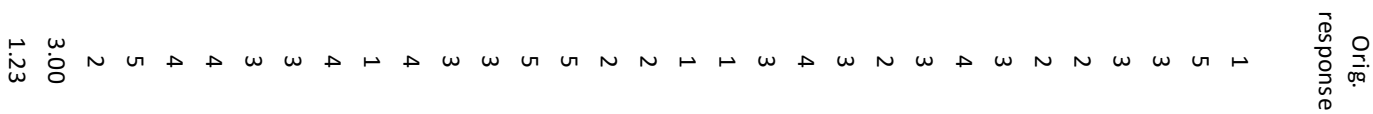

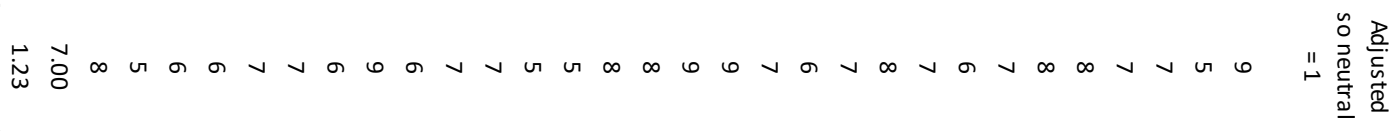

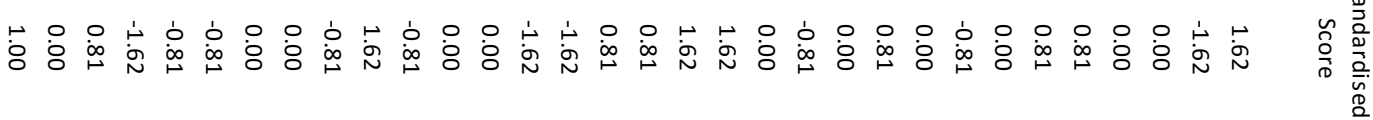

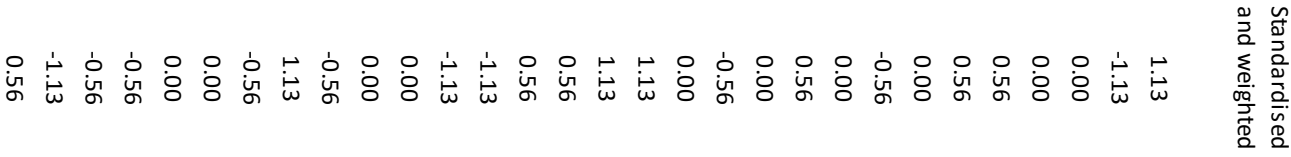

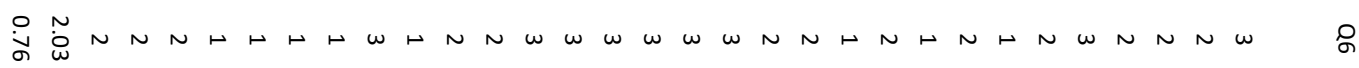

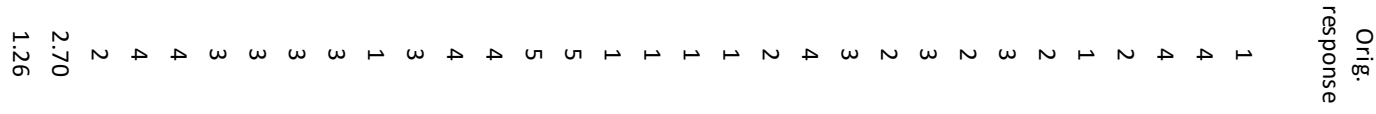

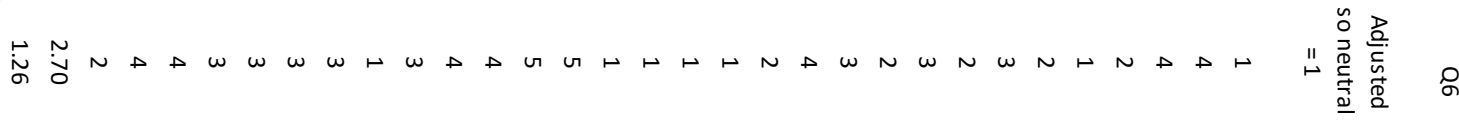

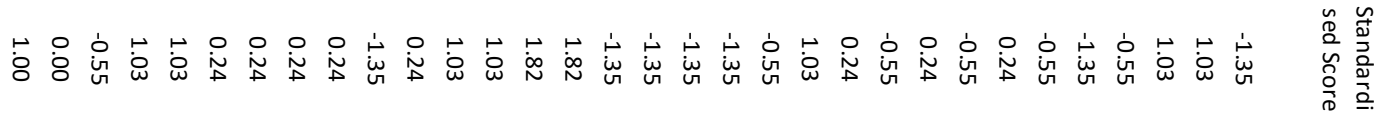

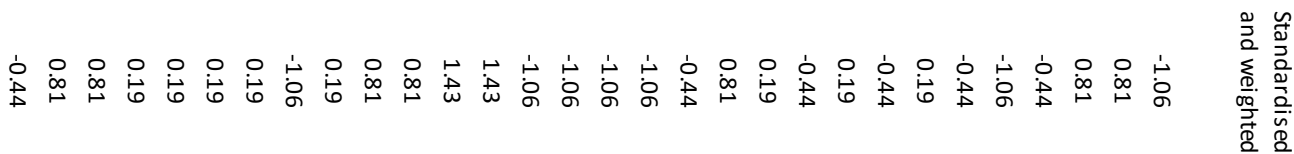


$\stackrel{\circ}{\text { ò }}$

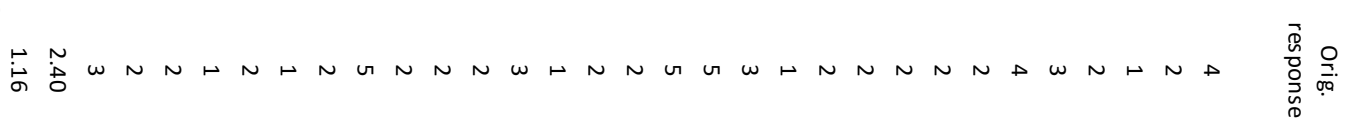

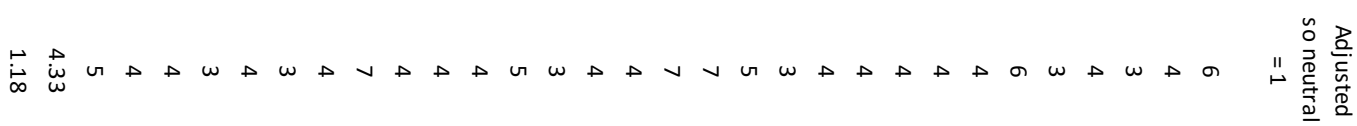

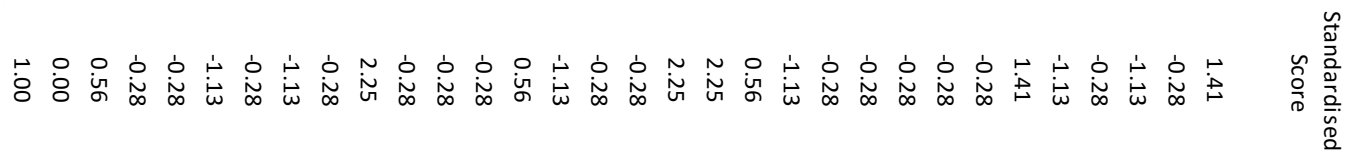

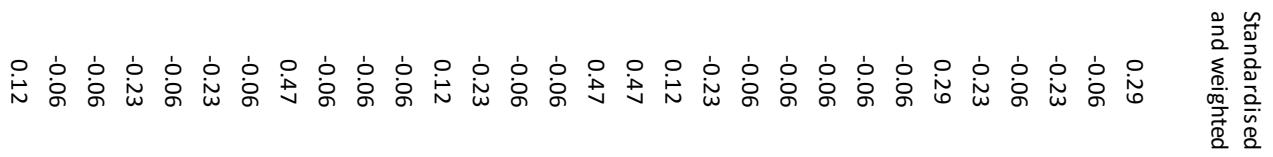

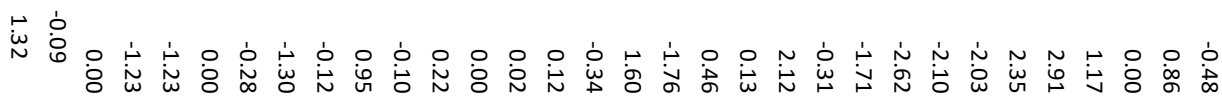

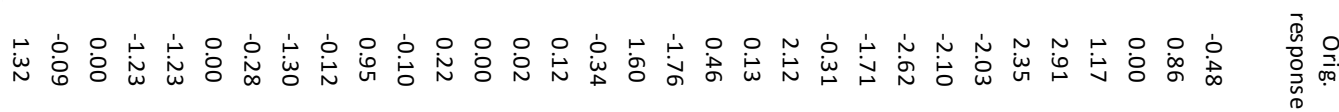

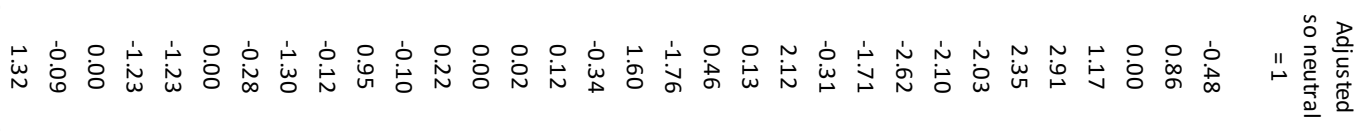

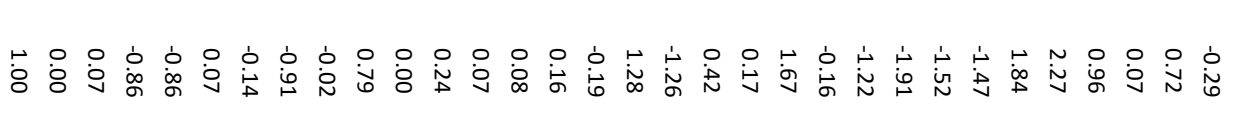

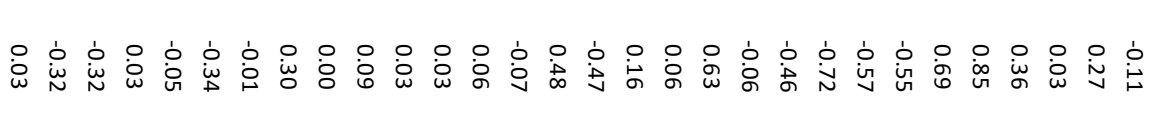

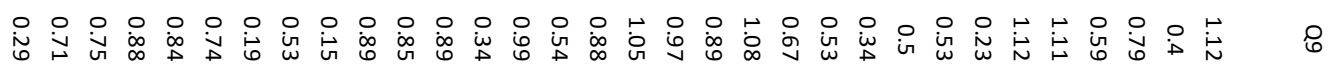

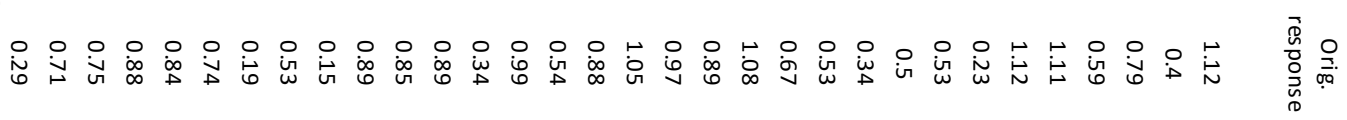

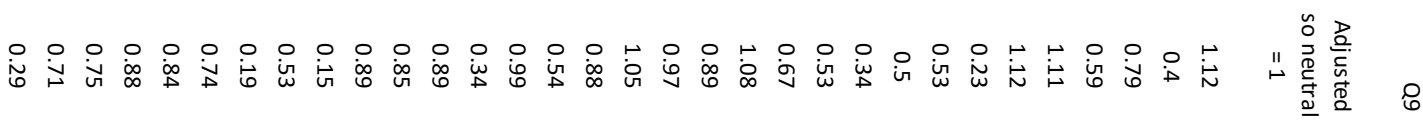

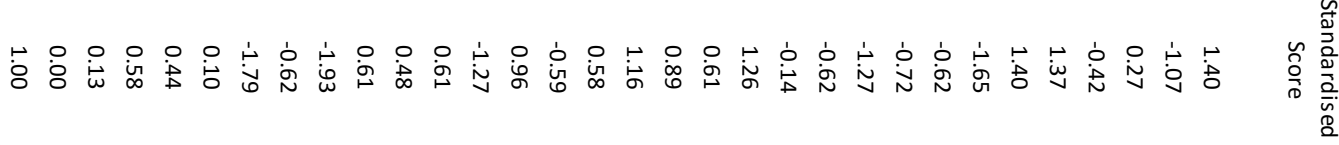

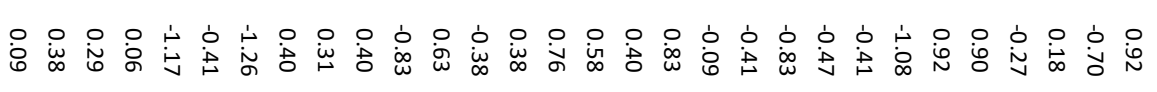

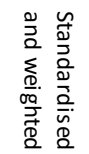




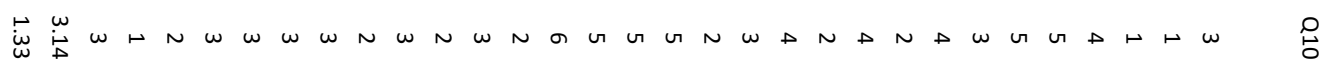

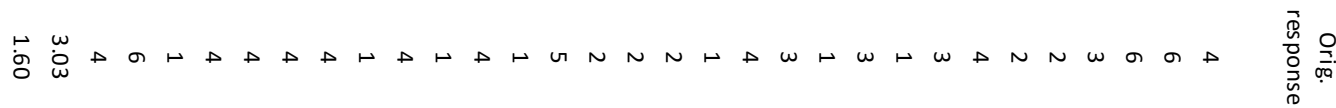

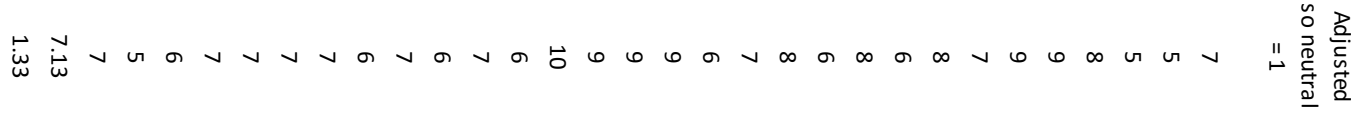

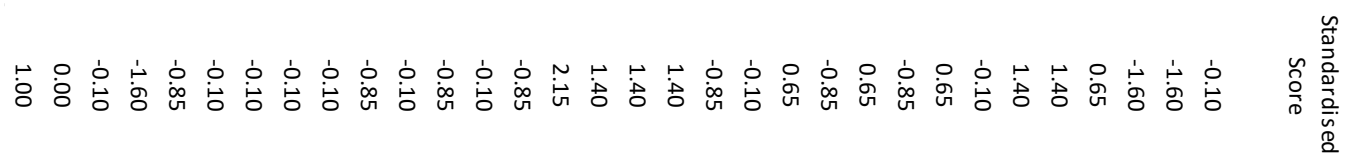

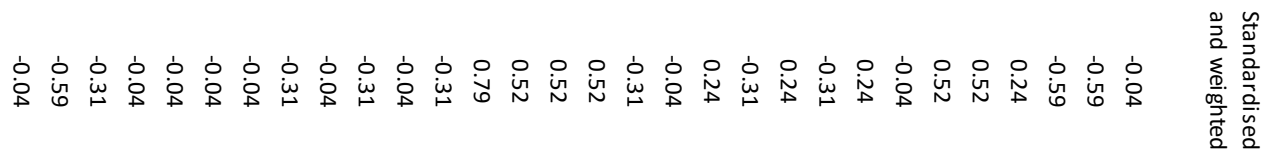

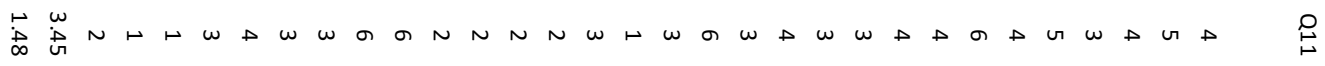

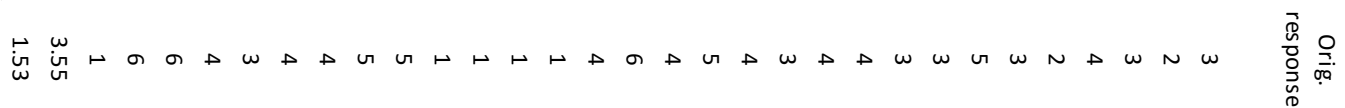

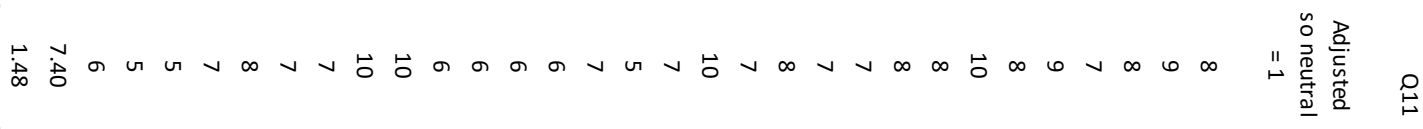

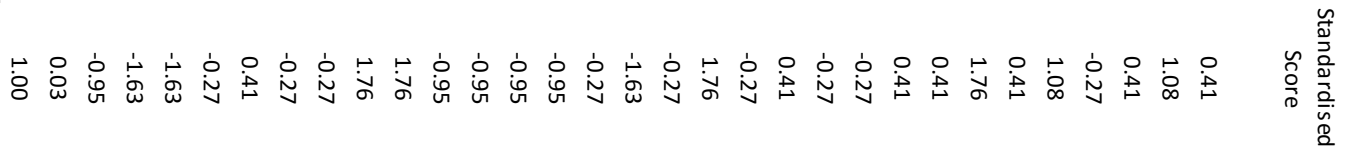

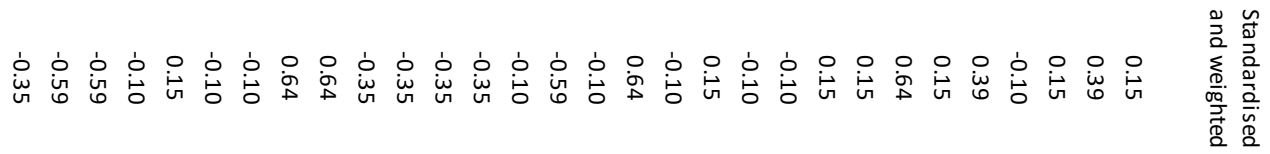

岕京H O OH

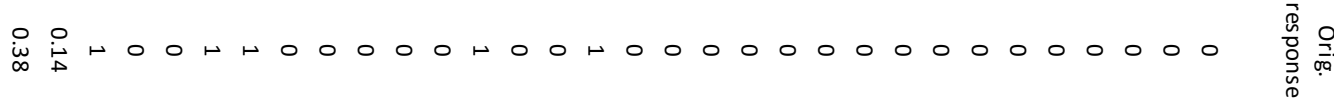

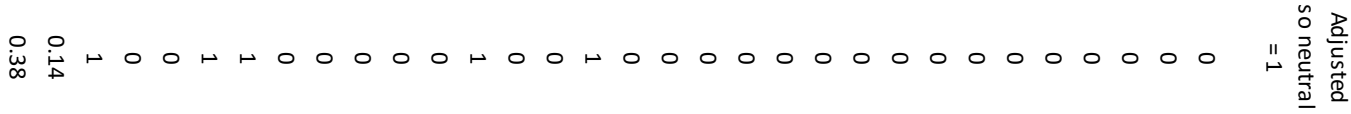

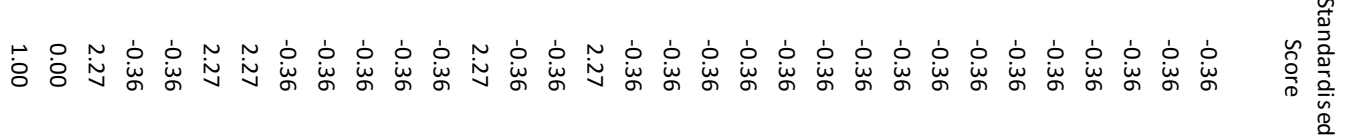

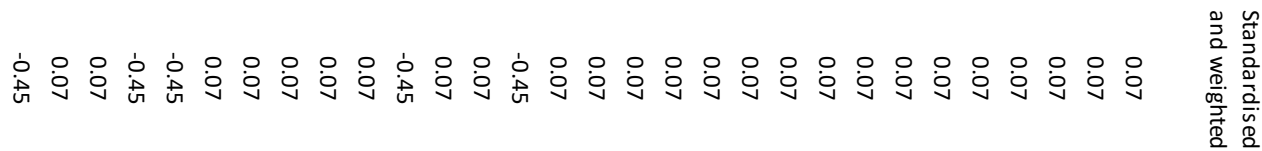




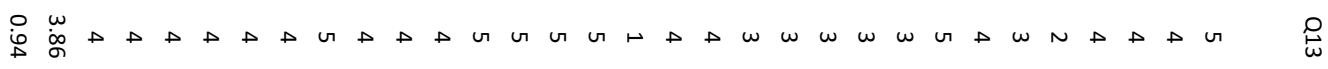

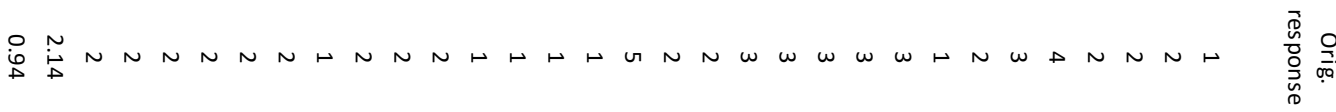

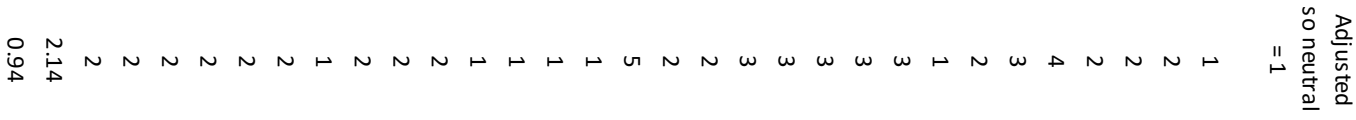

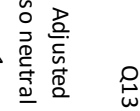

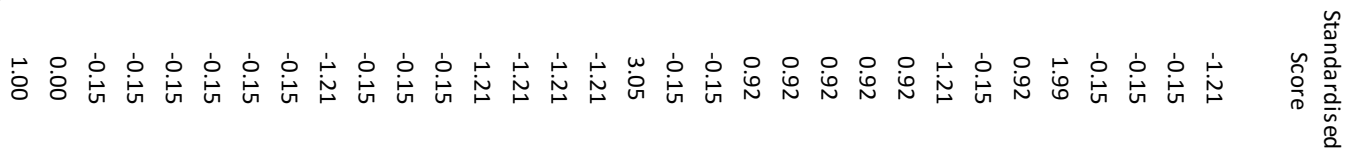

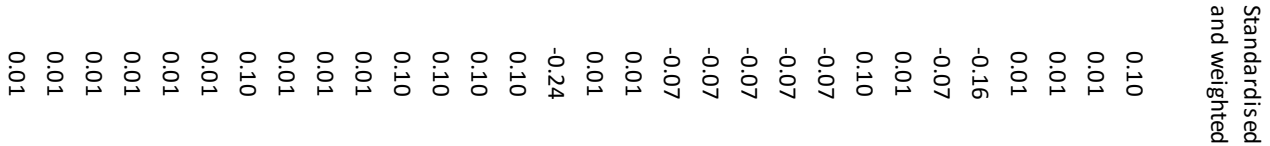

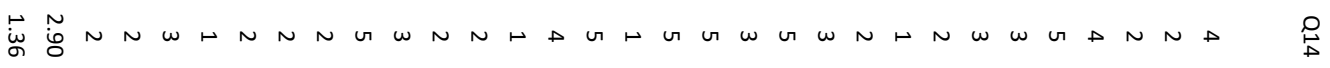

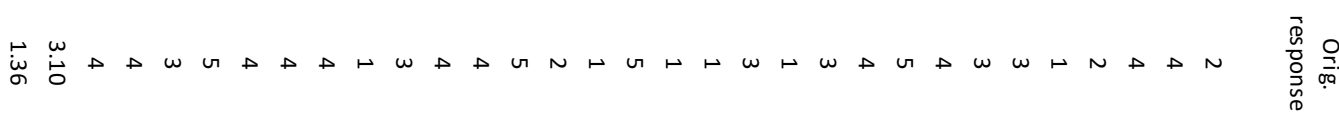

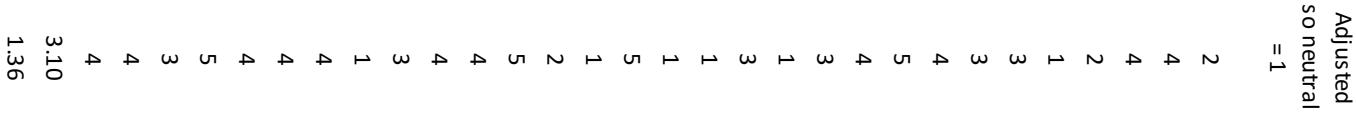

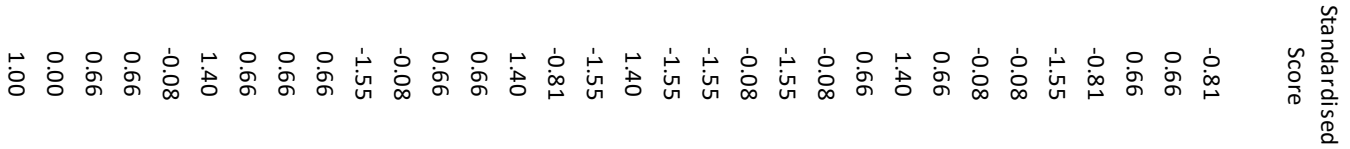

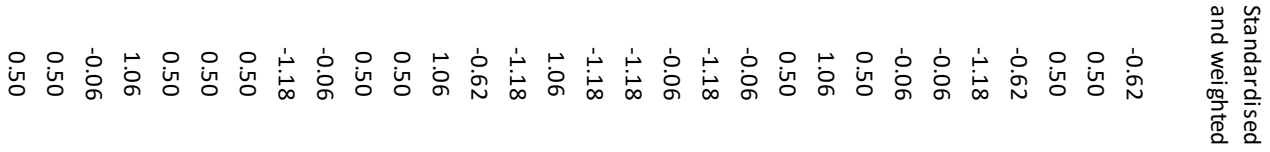

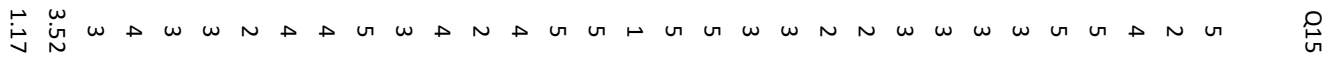

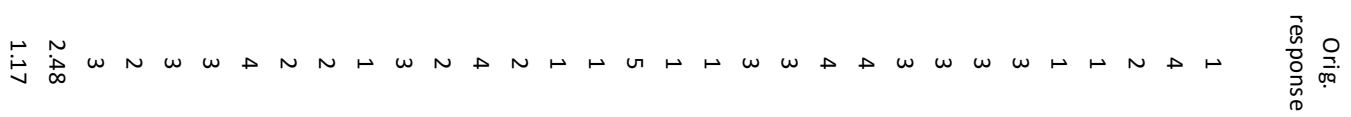

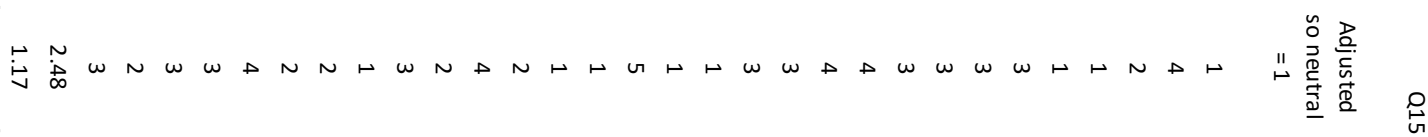

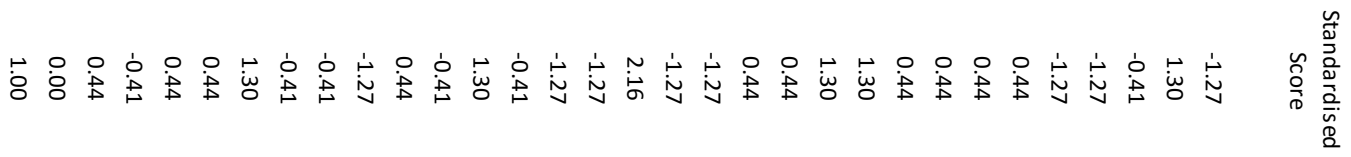

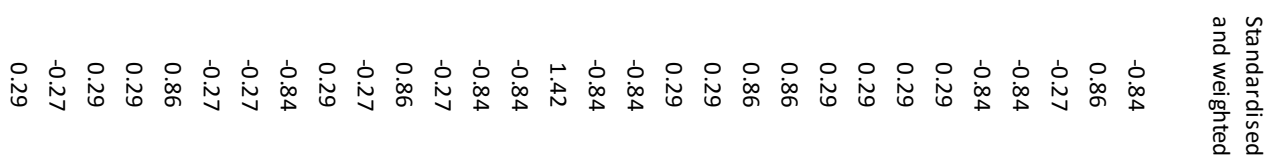




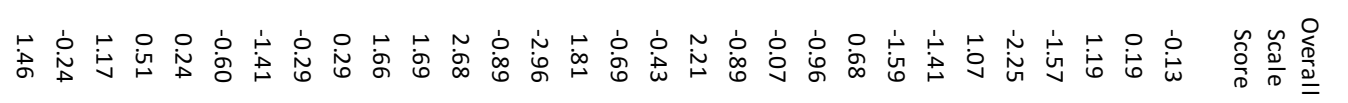

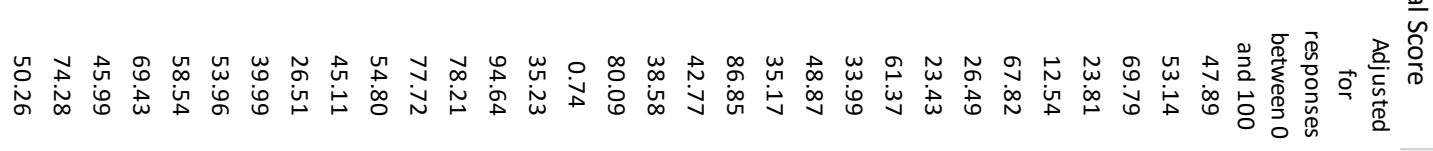

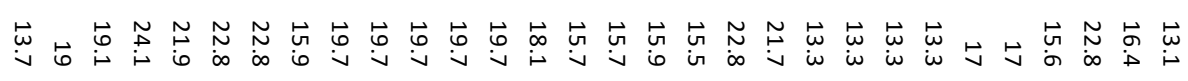

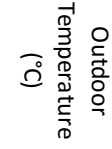

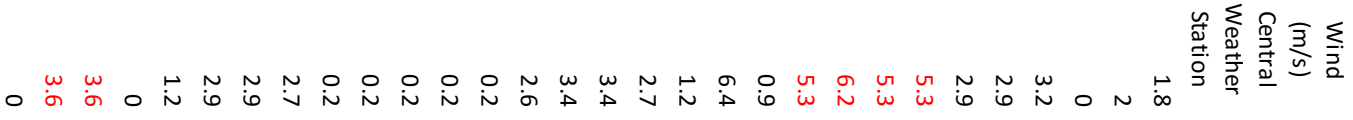

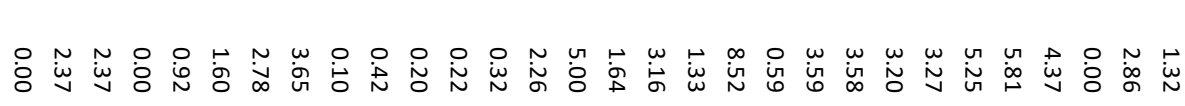
啰总

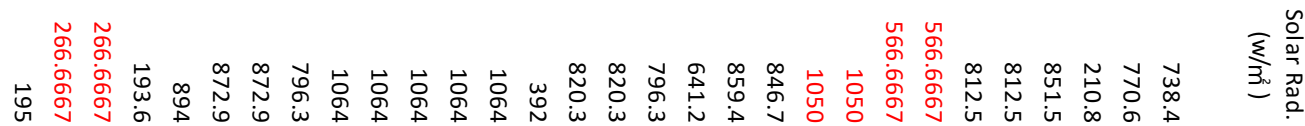

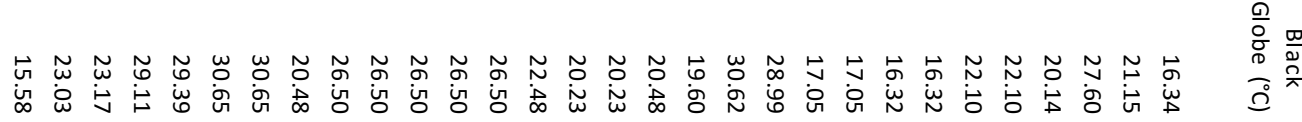

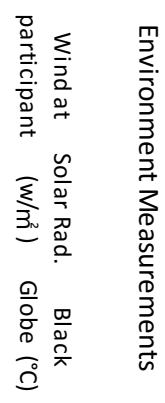

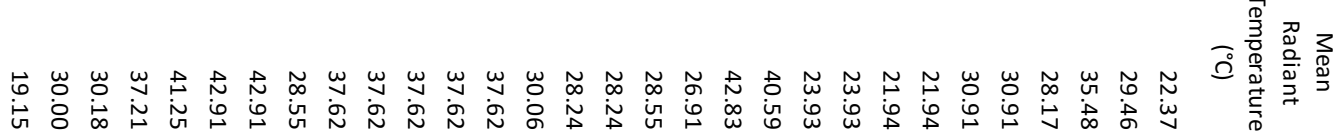

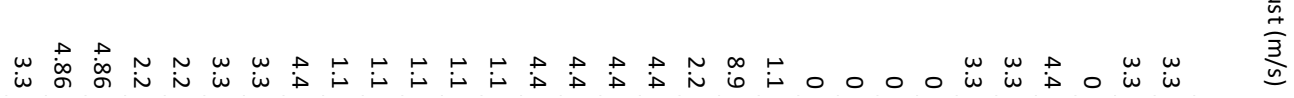


9. GLOSSARY

\section{Ambient temperature}

Black Globe Temperature

Case study weather station

Central Christchurch

Local regional weather station

Maximum gust

Mean Radiant Temperature

Mean wind speed

Relative humidity

Terrain-roughness

The Comfort Tool

The Christchurch Comfort Index

The Wellington Comfort Index

Turbulence

Regional weather station

Solar radiation
Temperature of air indicated by an ordinary thermometer shielded from solar and long wave radiation ('ASHRAE Terminology', 2015).

This is the temperature measured using a black globe thermometer.

The weather station located centrally in the case study area (Central (hristchurch).

This is defined by the four avenues which form a frame around the central area. The four avenues are Bealey, Fitzgerald, Moorhouse, and Deans Avenue).

The weather station located $2 \mathrm{~km}$ from the case study area

The maximum gust the maximum wind vector occurring during the period measurement is done (NIWA, 2015a).

The mean radiant temperature is the temperature of an exposed surface in the environment (American Society of Heating, Refrigerating and Air-Conditioning Engineers, 1985, p. 134).

This is the mean wind speed occurring within a measurement period.

Ratio of the mole fraction of water vapour to the mole fraction of water vapour saturated at the same temperature and barometric pressure ('ASHRAE Terminology', 2015).

The terrain-roughness takes into account the differences in topography between the meteorological site where the weather data was measured and the site of a proposed development (Blocken \& Carmeliet, 2004, p. 115).

The tool developed through this thesis project for predicting outdoor thermal comfort across a proposed development.

The index for predicting comfort which was developed using the same methodology as was used to develop The Wellington Comfort Index (Walton et al., 2007, p. 1368).

Walton et al,'s formula for predicting the degree people would need to change their behaviour to maintain their comfort (measures adaptivity in outdoor spaces. (Walton et al., 2007, p. 3166).

Is caused by both steady wind and wind gusts (turbulence) (Blocken \& Carmeliet, 2004, p. 110).

The weather station located at the Christchurch International Airport where the TMY weather file is measured.

The transmission of radiant energy from the sun ('ASHRAE Terminology', 2015). 


\section{Scales for Interpreting the Results of The Comfort Tool}

The Comfort Tool's results are displayed on a plan view of each case study (Figure 9.1). Areas which are considered thermally comfortable are a neutral colour. Areas shaded red indicate the greater the degree that is required to maintain thermal comfort.

\section{Thermal Comfort}

Assessment

More change is required

Thermally neutral

More change is required

Figure 9.1 shows the scale for understanding the thermal comfort results of The Comfort Tool

When a case study has changes made to improve thermal comfort, the results of these changes are able to be compared to the original design of the case study (Figure 9.2).

There is an increase in comfort of 10 thermal comfort scores between 'No changes in Comfort' and 'Increase in Comfort' and 10 thermal comfort scores between 'No changes in Comfort' and 'Decrease in Comfort'.

\section{Difference in}

Comfort

Decrease in comfort

No changes in comfort Increase in comfort

Figure 9.2 shows the scale for unstaining the difference in thermal comfort between the case study, and the case study with changes made to improve thermal comfort.

The wind levels are displayed across a plan view of each case study. Areas which are pink indicate the wind speeds are above $5 \mathrm{~m} / \mathrm{s}$ for this time of day in the season the results are displayed. Whereas, white indicates that wind speeds are low. There is a wind rose located in the top left of each wind speed graph. This indicates the predominate wind speed in an open area outside of the case study for the season and time of day being assessed (Figure 9.3).

\begin{tabular}{lr}
\hline Wind Assessment & $\begin{array}{l}\text { High wind speeds } \\
\text { (greater than } 5 \mathrm{~m} / \mathrm{s} \text { ) }\end{array}$ \\
\hline $\begin{array}{l}\text { Predominant wind } \\
\text { direction outside of the } \\
\text { case study }-\end{array}$ & Low wind speeds $(\mathrm{m} / \mathrm{s})$
\end{tabular}

Figure 9.3 shows the scale for understanding the wind assessment as part of The Comfort Tool 
When a case study has changes made to improve thermal comfort, the results of these changes on wind are able to be compared to the original wind results for each case study (Figure 9.4). There is a $2.5 \mathrm{~m} / \mathrm{s}$ increase in wind between the neutral point in the scale and the 'Increase in wind speed' and a $-2.5 \mathrm{~m} / \mathrm{s}$ decrease in wind between the neutral point in the scale and the 'Decrease in wind speed'.

\section{Difference in Wind}

Decrease in wind speed

Increase in wind speed

Figure 9.4 shows the scale for understanding the difference in wind between the case study, and the case study with changes made to improve thermal comfort.

Solar radiation levels are displayed across a plan view of each case study. Where areas a blue, this indicates that there is limited solar radiation. Whereas, areas shaded red show that there is solar radiation access at pedestrian level (Figure 9.5).

\section{Solar Radiation}

Assessment

The least solar radiation

The most solar radiation

Figure 9.5 shows the scale for understanding the solar radiation assessment as part of The Comfort Tool

When a case study has changes made to improve thermal comfort, the results of these changes on solar radiation are able to be compared to the original wind results for each case study (Figure 9.6). There is $100 \mathrm{~W} / \mathrm{m}^{2}$ between the neutral point and the 'Increase in solar radiation' and $-100 \mathrm{~W} / \mathrm{m}^{2}$ between the neutral point and the 'Decrease in solar radiation'.

\section{Difference in Solar} radiation Decrease in solar radiation Increase in Solar Radiation Figure 9.6 shows the scale for understanding the difference in solar radiation between the case study, and the case study with changes made to improve thermal comfort.

All scales are the same for each case study. 